NBER WORKING PAPER SERIES

\title{
WHO BENEFITS FROM STATE CORPORATE TAX CUTS? A LOCAL LABOR MARKETS APPROACH WITH HETEROGENEOUS FIRMS
}

\author{
Juan Carlos Suárez Serrato \\ Owen Zidar \\ Working Paper 20289 \\ http://www.nber.org/papers/w20289
NATIONAL BUREAU OF ECONOMIC RESEARCH
1050 Massachusetts Avenue \\ Cambridge, MA 02138
}

We are very grateful for guidance and support from our advisors: Alan Auerbach, Yuriy Gorodnichenko, Patrick Kline, and Emmanuel Saez. We would like to thank the Editor Luigi Pistaferri and three anonymous referees for their helpful comments. We are also indebted to David Albouy, Dominick Bartelme, Alex Bartik, Pat Bayer, Michael Boskin, Eric Budish, David Card, Jeffrey Clemens, Robert Chirinko, Rebecca Diamond, Jonathan Dingel, Pascaline Dupas, Matt Gentzkow, Gopi Goda, Marc Hafstead, Jim Hines, Caroline Hoxby, Erik Hurst, Koichiro Ito, Matt Leister, Attila Lindner, Neale Mahoney, John McClelland, David Molitor, Enrico Moretti, Pascal Noel, Matt Notowidigdo, Alexandre Poirier, Jim Poterba, Andrés RodríguezClare, Jesse Rothstein, Greg Rosston, Florian Scheuer, John Shoven, Orie Shelef, Reed Walker, Dan Wilson, Danny Yagan, Shuang Zhang, and Eric Zwick for helpful comments and suggestions. We are especially thankful to Nathan Seegert, Dan Wilson and Robert Chirinko, and Jamie Bernthal, Dana Gavrila, Katie Schumacher, Shane Spencer, and Katherine Sydor for generously providing us with tax data. Tim Anderson, Anastasia Bogdanova, Pawel Charasz, Stephen Lamb, Matt Panhans, Prab Upadrashta, John Wieselthier, and Victor Ye provided excellent research assistance. All errors remain our own. This work is supported by the Kauffman Foundation and the Kathryn and Grant Swick Faculty Research Fund at the University of Chicago Booth School of Business. We declare that we have no relevant or material financial interests that relate to the research described in this paper. The views expressed herein are those of the authors and do not necessarily reflect the views of the National Bureau of Economic Research.

NBER working papers are circulated for discussion and comment purposes. They have not been peer-reviewed or been subject to the review by the NBER Board of Directors that accompanies official NBER publications.

(C) 2014 by Juan Carlos Suárez Serrato and Owen Zidar. All rights reserved. Short sections of text, not to exceed two paragraphs, may be quoted without explicit permission provided that full credit, including $\odot$ notice, is given to the source. 
Who Benefits from State Corporate Tax Cuts? A Local Labor Markets Approach with Heterogeneous Firms

Juan Carlos Suárez Serrato and Owen Zidar

NBER Working Paper No. 20289

July 2014, Revised August 2016

JEL No. F22,F23,H2,H22,H25,H32,H71,J23,J3,R23,R30,R58

\begin{abstract}
This paper estimates the incidence of state corporate taxes on the welfare of workers, landowners, and firm owners using variation in state corporate tax rates and apportionment rules. We develop a spatial equilibrium model with imperfectly mobile firms and workers. Firm owners may earn profits and be inframarginal in their location choices due to differences in location-specific productivities. We use the reduced-form effects of tax changes to identify and estimate incidence as well as the structural parameters governing these impacts. In contrast to standard open economy models, firm owners bear roughly $40 \%$ of the incidence, while workers and landowners bear 30-35\% and 25-30\%, respectively.
\end{abstract}

\author{
Juan Carlos Suárez Serrato \\ Department of Economics \\ Duke University \\ 213 Social Sciences Building \\ Box 90097 \\ Durham, NC 27708 \\ and NBER \\ jc@jcsuarez.com \\ Owen Zidar \\ University of Chicago \\ Booth School of Business \\ 5807 South Woodlawn Avenue \\ Chicago, IL 60637 \\ and NBER \\ owen.zidar@chicagobooth.edu
}


This paper evaluates the welfare effects of corporate income tax cuts on business owners, workers, and landowners. The conventional wisdom among economists and policymakers is that corporate taxation in an open economy is unattractive on both efficiency and equity grounds: it distorts the location and scale of economic activity and falls on the shoulders of workers. ${ }^{1}$ We revisit this conventional wisdom both empirically and theoretically.

We begin by developing a spatial equilibrium model in which firm productivity and profitability can differ across locations. ${ }^{2}$ Standard models without these features have a difficult time explaining how California, with corporate tax rates of nearly 10\%, is home to one out of nine establishments in the United States, especially when neighboring Nevada has no corporate tax. Our modeling approach acknowledges that if California were to increase corporate tax rates modestly, many new and existing technology firms would continue to find Silicon Valley to be the most profitable location in the world. The presence of such inframarginal firms changes the nature of the equity and efficiency tradeoff by allowing firms (and their shareholders) to bear some of the incidence associated with corporate taxes. ${ }^{3}$

We implement this model empirically to provide a new assessment of the welfare effects of local corporate tax cuts. The welfare effects are point identified by the reduced-form impacts of changes in business taxes on four outcomes: wages, rental costs, the location decisions of establishments, and the location decisions of workers. We estimate these impacts using variation in state corporate tax rates and rules and establish their validity through a number of tests. These reduced-form impacts enable us to estimate the welfare effects of state corporate tax cuts as well as the structural parameters that rationalize these effects. The structural parameters are similar to existing estimates from the literature, to the extent these estimates exist.

We have two main results. First, we unambiguously reject the conventional view of $100 \%$ incidence on workers and $0 \%$ on firm owners based on a variety of approaches: reduced-form estimates, structural estimates, and calibrations using existing estimates from the local labor markets literature. Second, our baseline estimates place approximately $40 \%$ of the burden on firm owners, 25-30\% on landowners and 30-35\% on workers. The result that firm owners may bear the incidence of local policies starkly contrasts with existing results in the corporate tax literature (e.g., Fullerton and Metcalf (2002)) and is a novel result in the local labor markets literature (e.g., Moretti (2011)).

We establish these results in three steps. In the first part of the paper, we construct the model to allow for the possibility that firm owners, workers, and landowners can bear incidence. The incidence on these three groups depends on the equilibrium impacts on profits, real wages, and housing costs, respectively. A tax cut mechanically reduces the tax liability and the cost of capital of local establishments, attracts establishments, and increases local labor demand. This increase in labor demand leads firms to offer higher wages, encourages migration of workers, and increases the

\footnotetext{
${ }^{1}$ See for instance, Gordon and Hines (2002). Gravelle and Smetters (2006) and Arulampalam, Devereux and Maffini (2012) show how imperfect product substitution and wage bargaining, respectively, can alter this conclusion, and Desai, Foley and Hines Jr. (2007) find that labor bears the majority but not all of the burden internationally. Note that we frequently use "tax cuts" as shorthand for "tax changes" since our main specifications use keep-rates.

${ }^{2}$ While many papers have documented large and persistent productivity differences across countries (Hall and Jones, 1999), sectors (Levchenko and Zhang, 2012), businesses (Syverson, 2011), and local labor markets (Moretti, 2011), the corporate tax literature has not accounted for the role that heterogeneous productivities may have in determining equilibrium incidence. Some research on the incidence of local corporate tax cuts exists - for instance, Fuest, Peichl and Siegloch (2013) use employer-firm linked data to assess the effects of corporate taxes on wages in Germany - but to our knowledge, there are no empirical analyses that incorporate local equilibrium effects of these tax changes. Interestingly, they also find similar results for the incidence on workers in their full sample specification.

${ }^{3}$ Existing and new firms can be inframarginal due to heterogeneous productivities. This idea is conceptually distinct from the taxation of "old" capital as discussed by Auerbach (2006). See Liu and Altshuler (2013) and Cronin et al. (2013) for incidence papers that allow for imperfect competition and supernormal economic profits, respectively.
} 
cost of housing. Our model characterizes the new spatial equilibrium following a business tax cut and relates the changes in wages, rents, and profits to a few key parameters governing labor, housing, and product markets. In particular, the incidence on wages depends on the degree to which establishment location decisions respond to tax changes, an effective labor supply elasticity that is dependent on housing market conditions, and a macro labor demand elasticity that depends on location and scale decisions of establishments. Having determined the incidence on wages, the incidence on profits is straightforward; it combines the mechanical effects of lower corporate taxes and the impact of higher wages on production costs and scale decisions. Finally, we show that the equilibrium incidence formulae on worker welfare, firm profits, and landowners' rents are identified by reduced-form effects of corporate taxes as well as by structural parameters of the model.

In the second part of the paper, the empirical analysis quantifies the responsiveness of local economic activity to local business tax changes. The variation in our empirical analysis comes from changes to state corporate tax rates and apportionment rules, which are state-specific rules that govern how national profits of multi-state firms are allocated for tax purposes. ${ }^{4}$ We implement these state corporate tax system rules using matched firm-establishment data and construct a measure of the average tax rate that businesses pay in a local area. This approach not only closely approximates actual taxes paid by businesses, but it also provides multiple sources of identifying variation from changes in state tax rates, apportionment formulae, and the rate and rule changes of other states.

We find that a $1 \%$ cut in local business taxes increases the number of local establishments by 3 to $4 \%$ over a ten-year period. This estimate is unrelated to other changes in policy that would otherwise bias our results, including changes in per-capita government spending and changes in the corporate tax base such as investment tax credits. To rule out the possibility that business tax changes occur in response to abnormal economic conditions, we analyze the typical dynamics of establishment growth in the years before and after business tax cuts. We also directly control for a common measure of changes in local labor demand from Bartik (1991). Finally, we estimate the effects of external tax changes of other locations on local establishment growth and find symmetric effects of business tax changes on establishment growth. These symmetric effects corroborate the robustness of our reducedform results of business tax changes. We also provide estimates of the effects of corporate tax cuts on local population, wages, and rental costs.

In the third part of the paper, we use these reduced-form results to estimate the incidence of business tax changes. We first apply the incidence expressions that transparently map four reduced-form effects - on business and worker location, wages, and rental costs - to the welfare effects on workers, landowners, and firm owners. We then estimate the structural parameters governing incidence by minimizing the distance between the four reduced-form effects and their theoretical counterparts. We test over-identifying restrictions of the model and find that they are satisfied. The structural elasticities are precisely estimated. These elasticities help reinforce the validity of our overall estimates for two reasons. First, our estimated elasticities align with existing estimates from the literature. Second, they enable us to use estimates from Suárez Serrato and Wingender (2011) to show that our results are robust and, if anything, modestly strengthened when accounting for the welfare effects of changes in government spending that result from changes in tax revenue. Government service reductions disproportionately hurt workers and infrastructure reductions hurt both firms and workers; lower

\footnotetext{
${ }^{4}$ Previous studies have focused on the theoretical distortions that apportionment formulae have on the geographical location of capital and labor (see, e.g., McLure Jr. (1982) and Gordon and Wilson (1986)). Empirically, several studies have used variation in apportionment rules (e.g., Goolsbee and Maydew (2000)). Hines (2009) and Devereux and Loretz (2007) have analyzed how these tax distortions affect the location of economic activity internationally.
} 
infrastructure reduces productivity and thus wages. The magnitudes of these adjustments depend on the magnitude of tax revenue changes, which can be small in practice due to low tax revenue shares from corporate taxes and fiscal externalities on sales and individual income tax bases.

In the last section of the paper, we analyze the efficiency costs of state corporate income taxes and discuss the implications of our results for tax revenues and the revenue-maximizing tax rate. Although business mobility is an often-cited justification in proposals to lower states' corporate tax rates, business location distortions per se do not lead to a low revenue-maximizing rate. Based solely on the responsiveness of establishment location to tax changes, corporate tax revenue-maximizing rates would be nearly $32 \%$. This rate greatly exceeds average state corporate tax rates, which were $7 \%$ on average in 2010. However, corporate tax cuts have large fiscal externalities by distorting the location of individuals. This additional consideration implies substantially lower revenue-maximizing state corporate tax rates than $32 \%$. The revenue-maximizing tax rate also depends on state apportionment rules. By apportioning on the basis of sales activity, policymakers can decrease the importance of firms' location decisions in the determination of their tax liabilities and thus lower the distortionary effects of corporate taxes. Overall, accounting for fiscal externalities and apportionment results in revenue-maximizing rates that are close to actual statutory rates on average.

This paper contributes a new assessment of the incidence of corporate taxation. The existing corporate tax literature provides a wide range of conclusions about the corporate tax burden. In the seminal paper of this literature, Harberger (1962) finds that under reasonable parameter values, capital bears the burden of a tax in a closed economy model in which all the adjustment has to be through factor prices. However, different capital mobility assumptions can completely reverse Harberger's conclusion (Kotlikoff and Summers, 1987). Gravelle (2010) shows how conclusions from various studies hinge on their modeling assumptions, while Fullerton and Metcalf (2002) note that "few of the standard assumptions about tax incidence have been tested and confirmed." Gravelle (2011) and Clausing (2013) critically review some of the existing empirical work on corporate tax incidence. We contribute to both the theoretical and empirical corporate tax literature by developing a new theoretical approach, which can accommodate the conventional view for hypothetical values of the four reduced-form effects, and by connecting this theory directly to the data. Doing so not only allows the data to govern the relative mobility of firms and workers, but also enables us to conduct inference on the resulting incidence calculations.

This paper also contributes to the recent local labor markets literature, which has focused on the importance of linking workers and locations (Kline, 2010; Moretti, 2011; Suárez Serrato and Wingender, 2011; Diamond, 2012; Busso, Gregory and Kline, 2013; Notowidigdo, 2013; Kline and Moretti, 2013). This literature and benchmark models (Rosen, 1979; Roback, 1982; Glaeser, 2008) have representative and perfectly competitive firms with no link between firms and location. Our work links firms and locations by incorporating features popular in the trade literature (Krugman, 1979; Hopenhayn, 1992; Melitz, 2003). Developing the demand side of local labor markets is important because it allows for the possibility that firm owners can bear some of the incidence of local economic development policies or local productivity shocks - a feature that was previously absent in models of local labor markets. ${ }^{5}$ In addition, estimating labor demand functions in models of local labor

\footnotetext{
${ }^{5}$ One finding from the set of papers linking workers to locations that differentiates them from previous work is the possibility that workers may be inframarginal in their location decisions, which allows workers to bear the benefit or cost of local policies. Our paper allows firms to be inframarginal in their location decisions. In addition, the possibility that firm owners can bear incidence implies that wage and property value responses alone are not sufficient for evaluating the incidence of productivity shocks and can alter the interpretation of existing work (e.g., Greenstone and Moretti (2004)).
} 
markets has been limited by the lack of plausibly exogenous labor supply shocks that may trace the slope of the demand function. Our framework exploits firm location decisions and the empirical tradeoff firms make among productivity, corporate taxes, and factor prices to provide a novel link between firm location choices and labor demand that can be used to recover the parameters governing labor demand (and the incidence on firm profits). Finally, this paper relates to the literature on local public finance and business location literatures. ${ }^{6}$ We contribute by providing a framework to interpret existing estimates and by implementing the state corporate tax system, which provides novel variation.

We make several simplifying assumptions that may limit some of our analysis. First, we abstract from issues of endogenous agglomerations or externalities that may result from changes in corporate taxes. Second, we do not allow firms to bear the cost of rising real estate costs. This feature could be added in a model with a real estate market that integrates the residential and commercial sectors. However, given that firms' cost shares on real estate are small, this addition would likely not change our main result and would come at the cost of additional complexity. Third, our model abstracts from the entrepreneurship margin (Gentry and Hubbard, 2000; Scheuer, 2014). Abstracting from this margin is unlikely to affect our incidence calculations to the extent that the entrepreneurship margin is small. The magnitude of this margin depends on the effect of one state's tax changes on the total number of businesses in the United States. Fourth, we compare steady states that assume labor market clearing over a ten year period. Adding the possibility of unemployment during the transition period could alter some of our conclusions about incidence. ${ }^{7}$ Fifth, many of the factors in our incidence formulae are likely to be geographically heterogeneous. A more general model that accounts for differences in housing markets, sectoral compositions, and skill-group compositions as well as non-linear housing supply functions may result in a better approximation to the incidence in specific locations and in specific contexts. Sixth, while our cross-sectional approach provides substantial variation, cross-sectional estimates necessarily abstract from general equilibrium effects that may affect outcomes in all states. ${ }^{8}$ Finally, due to data limitations, we proxy for the benefit to landowners using data on housing rents.

We proceed as follows. We develop the model in Section 1, derive simple expressions for incidence in Section 2, and show how to estimate them in Section 3. Section 4 describes the data and U.S. state corporate tax apportionment rules. Sections 5 and 6 provide reduced-form and structural results, respectively. Section 7 discusses additional policy implications and Section 8 concludes.

\footnotetext{
${ }^{6}$ Important contributions include Gyourko and Tracy (1989); Bartik (1991); Haughwout and Inman (2001); Feldstein and Vaillant (1998); Carlton (1983); Duranton, Gobillon and Overman (2011); Glaeser (2012); Hines (1997); Newman (1983); Bartik (1985); Helms (1985); Papke (1987, 1991); Goolsbee and Maydew (2000); Holmes (1998); Rothenberg (2012); Rathelot and Sillard (2008); Chirinko and Wilson (2008); Devereux and Griffith (1998); Siegloch (2014); Hassett and Mathur (2015).

${ }^{7}$ More generally, we abstract from transition dynamics, which can have important incidence implications (Auerbach, 2006). Interestingly, the benefits to firm owners are likely front-loaded as the mechanical effects of tax cuts occur immediately while the increases in wages and rental costs follow a gradual adjustment as establishments relocate. However, introducing unemployment into the model makes the welfare impacts during the transition harder to sign.

${ }^{8}$ If, for example, a tax change in Rhode Island affects all wages nation-wide, our estimate would only report the differential effect on Rhode Island versus other states and would subsume the aggregate effect in the year fixed-effect. However, to the extent that a single state's taxes do not affect the national level of wages, profits, and rental costs, our estimates will provide the general equilibrium incidence.
} 


\section{A Spatial Equilibrium Model with Heterogeneous Firms}

You have to start this conversation with the philosophy that businesses have more choices than they ever have before. And if you don't believe that, you say taxes don't matter. But if you do believe that, which I do, it's one of those things, along with quality of life, quality of education, quality of infrastructure, cost of labor, it's one of those things that matter.

-Delaware Governor Jack Markell (11/3/2013)

The model characterizes the incidence on wages, rents, and profits as functions of estimable parameters governing the supply and demand sides of the housing, labor, and product markets. In particular, the main incidence results will be functions of three key objects: the effective elasticity of labor supply $\varepsilon^{L S}$, the macro elasticity of labor demand $\varepsilon^{L D}$, and the increase in labor demand following a business tax change $\frac{\partial \ln L_{c}^{D}}{\partial \ln \left(1-\tau_{c}^{b}\right)}$.

We consider a similar environment to Kline (2010) and Moretti (2011) in terms of worker location, and develop the demand side of the local labor market by characterizing the location decisions of heterogeneous firms. Specifically, we consider a small location $c$ in an open economy with many other locations. There are three types of agents: workers, establishment owners, and landowners. Units are chosen so that the total number of workers $N=1$ and establishments $E=1$, and $N_{c}$ and $E_{c}$ denote the share of workers and establishments in location $c$. The model is static and assumes no population growth or establishment entry at the national level. Workers choose their location to maximize utility, establishments choose location and scale to maximize after-tax profits, and landowners supply housing units to maximize rental profits. In terms of market structure, capital and goods markets are global and labor and housing markets are local. The equilibrium in location $c$ is characterized by $N_{c}$ households earning wage $w_{c}$ and paying housing costs $r_{c}, E_{c}$ establishments earning after-tax profits $\pi_{c}$, and a representative landowner earning rents $r_{c}$. We compare outcomes in spatial equilibrium before and after a corporate tax cut and do not model the transition between pre-tax and post-tax equilibria.

\section{$1.1 \quad$ Household Problem}

In location $c$ with amenities $A$, households maximize Cobb-Douglas utility over housing $h$ and a composite $X$ of non-housing goods $x_{j}$ while facing a wage $w$, rent $r$, and non-housing good prices $p_{j}$ :

$\max _{h, X} \ln A+\alpha \ln h+(1-\alpha) \ln X$ s.t. $r h+\int_{j \in J} p_{j} x_{j} d j=w, \quad$ where $X=\left(\int_{j \in J} x_{j}^{\frac{\varepsilon^{P D}+1}{\varepsilon^{P D}}} d j\right)^{\frac{\varepsilon^{P D}}{\varepsilon^{P D}+1}}$,

$\varepsilon^{P D}<-1$ is the product demand elasticity, and $P$ is an elasticity of substitution (CES) price index that is normalized to $1 .{ }^{9}$ Workers inelastically provide one unit of labor.

\footnotetext{
${ }^{9}$ The price index is defined as $P=\left(\int_{j \in J}\left(p_{j}\right)^{1+\varepsilon^{P D}} d j\right)^{\frac{1}{1+\varepsilon^{P D}}}=1$. Demand from each household for variety $j$, $x_{j}=(1-\alpha) w p_{j}^{\varepsilon^{P D}}$, depends on the non-housing expenditure, the price of variety $j$, and the product demand elasticity.
} 


\subsubsection{Household Location Choice}

Wages, rental costs, and amenities vary across locations. The indirect utility of household $n$ from their choice of location $c$ is then

$$
V_{n c}^{W}=a_{0}+\ln w_{c}-\alpha \ln r_{c}+\ln A_{n c},
$$

where $a_{0}$ is a constant. Households maximize their indirect utility across locations, accounting for the value of location-specific amenities $\ln A_{n c}$, which are comprised of a common location-specific term $\bar{A}_{c}$ and location-specific idiosyncratic preference $\xi_{n c}:{ }^{10}$

$$
\max _{c} \underbrace{a_{0}+\ln w_{c}-\alpha \ln r_{c}+\bar{A}_{c}}_{\equiv u_{c}}+\xi_{n c} .
$$

The presence of the household-specific-component allows for workers to be inframarginal in their location choices and, in turn, allows for workers to bear part of the incidence of local shocks (Kline and Moretti, 2013). Households will locate in location $c$ if their indirect utility there is higher than in any other location $c^{\prime}$. Assuming $\xi_{n c}^{\prime} s$ are i.i.d. type I extreme value, the share of households for whom that is true determines local population $N_{c}$ :

$$
N_{c}=P\left(V_{n c}^{W}=\max _{c^{\prime}}\left\{V_{n c^{\prime}}^{W}\right\}\right)=\frac{\exp \frac{u_{c}}{\sigma^{W}}}{\sum_{c^{\prime}} \exp \frac{u_{c^{\prime}}}{\sigma^{W}}},
$$

where $\sigma^{W}$ is the dispersion of the location-specific idiosyncratic preference $\xi_{n c}$. This equation defines the local labor supply as a function that is increasing in wages $w_{c}$, decreasing in rents $r_{c}$, and increasing in $\log$ amenities $\bar{A}_{c}$. If workers have similar tastes for cities, then $\sigma^{W}$ will be low and local labor supply will be fairly responsive to real wage and amenity changes.

\subsection{Housing Market}

Local housing demand follows from the household problem and is given by: $H_{c}^{D}=\frac{N_{c} \alpha w_{c}}{r_{c}}$. The local supply of housing, $H_{c}^{S}=G\left(r_{c} ; B_{c}^{H}\right)$, is upward-sloping in both the rental price $r_{c}$, which allows landowners to benefit from higher rental prices, and exogenous local housing productivity $B_{c}^{H}$. The marginal landowner supplies housing at cost $r_{c}=G^{-1}\left(H_{c}^{S} ; B_{c}^{H}\right)$. For tractability, we assume $G\left(r_{c} ; B_{c}^{H}\right) \equiv\left(B_{c}^{H} r_{c}\right)^{\eta_{c}}$, where the local housing supply elasticity $\eta_{c}>0$ governs the strength of the price response to changes in demand and productivity. ${ }^{11}$ The housing market clearing condition, $H_{c}^{S}=H_{c}^{D}$, determines the rents $r_{c}$ in location $c$ and is given in log-form by the following expression:

$$
\ln r_{c}=\frac{1}{1+\eta_{c}} \ln N_{c}+\frac{1}{1+\eta_{c}} \ln w_{c}-\frac{\eta_{c}}{1+\eta_{c}} B_{c}^{H}+a_{1},
$$

where $a_{1}$ is a constant. Substituting this expression into Equation 1 yields an expression for labor supply that does not depend on $r_{c}$ but that incorporates the housing market feedback into the effective labor supply. This substitution yields the first key elasticity - the effective elasticity of labor supply.

$$
\frac{\partial \ln L_{c}^{S}}{\partial \ln w_{c}}=\left(\frac{1+\eta_{c}-\alpha}{\sigma^{W}\left(1+\eta_{c}\right)+\alpha}\right) \equiv \varepsilon^{L S}
$$

\footnotetext{
${ }^{10}$ Note that location preferences and heterogenous mobility costs, which some prior work (e.g., Topel (1986)) has included, are observationally equivalent here. We assume fixed amenities for simplicity. See Diamond (2012) for an analysis with endogenous amenities and Suárez Serrato and Wingender (2011) for an analysis where government services responds to local population. We use estimates from Suárez Serrato and Wingender (2011) to quantify how our results change if government amenities are affected in Appendix Section F.

${ }^{11}$ Note that we abstract from asymmetric housing supply; Notowidigdo (2013) discusses the incidence implications of non-linear housing supply as in Glaeser and Gyourko (2005).
} 


\subsection{Establishment Problem}

The standard local labor markets and corporate tax models do not incorporate individual establishment location decisions. We add establishment location decisions for two main reasons. Firms' location decisions enable us to identify the effects of local tax changes on the prices and after-tax profits of firm owners. They also provide a micro-foundation for the local labor demand elasticity based on firms' location and scale decisions.

Establishments $j$ are monopolistically competitive and have productivity $B_{j c}$ that varies across locations. ${ }^{12}$ Establishments combine labor $l_{j c}$, capital $k_{j c}$, and a bundle of intermediate goods $M_{j c}$ to produce output $y_{j c}$ with the following technology:

$$
y_{j c}=B_{j c} l_{j c}^{\gamma} k_{j c}^{\delta} M_{j c}^{1-\gamma-\delta}
$$

where $M_{j c} \equiv\left(\int_{v \in J}\left(x_{v, j c}\right)^{\frac{\varepsilon^{P D}+1}{\varepsilon^{P D}}} d v\right)^{\frac{\varepsilon^{P D}}{\varepsilon^{P D}+1}}$ is establishment $j$ 's bundle of goods of varieties $v$. Goods of all varieties can serve as either final goods for household consumption or as intermediate inputs for establishment production. We incorporate intermediate inputs since they represent a considerable portion of gross output and are important to consider when evaluating production technology parameter values empirically. In a given location $c$, establishments maximize profits over inputs and prices $p_{j c}$ while facing a local wage $w_{c}$, national rental rates $\rho$, national prices $p_{v}$ of each variety $v$, and local business taxes $\tau_{c}^{b}$ subject to the production technology in Equation 3:

$$
\pi_{j c}=\max _{l_{j c}, k_{j c}, x_{v, j c}, p_{j c}}\left(1-\tau_{c}^{b}\right)\left(p_{j c} y_{j c}-w_{c} l_{j c}-\int_{v \in J} p_{v} x_{v, j c} d v\right)-\rho k_{j c}
$$

where the local business tax is the effective tax from locating in location $c$. An important feature of the establishment problem is the tax treatment of the returns to equity holders. Since returns to equity holders are not tax deductible, the corporate tax affects the cost of capital (Auerbach, 2002). ${ }^{13}$ After solving this establishment problem (see Appendix B.1 and Appendix B.2), we can express economic profits in terms of local taxes, factor prices, and local productivity:

$$
\pi_{j c}=\left(1-\tau_{c}^{b}\right) w_{c}^{\gamma\left(\varepsilon^{P D}+1\right)} \rho_{c}^{\delta\left(\varepsilon^{P D}+1\right)} B_{c}^{-\left(\varepsilon^{P D}+1\right)} \kappa,
$$

where the local tax rate is $\tau_{c}^{b}$, local factor prices are $w_{c}$ and $\rho_{c}=\frac{\rho}{1-\tau_{c}^{b}}$, the establishment's local productivity is $B_{c}$, and $\kappa$ is a constant term across locations.

\subsubsection{Establishment Location Choice}

When choosing location, firm owners maximize after tax profits $\pi_{j c}$. The log of establishment $j$ 's productivity $B_{j c}$ in location $c$ equals $\bar{B}_{c}+\zeta_{j c}$ where $\bar{B}_{c}$ is a common location-specific level of productivity and $\zeta_{j c}$ is an idiosyncratic establishment and location-specific term that is i.i.d. type I extreme value. Establishments may be idiosyncratically more productive for a variety of reasons, including

\footnotetext{
${ }^{12}$ To simplify exposition, we describe the case in which firms are single-plant establishments in the main text, but fully characterize the more general firm problem and its complex interaction with apportionment rules in Appendix B.

${ }^{13}$ Establishments are equity financed in the model, which we view as a reasonable characterization given non-tax costs of debt and firm optimization. See Heider and Ljungqvist (2014) for evidence on the effects of taxes on capital structure.
} 
match-quality, sensitivity to transportation costs, factor or input market requirements, sector-specific concentration, and agglomeration. ${ }^{14}$

Define an establishment $j$ 's value function $V_{j c}^{F}$ in location $c$ :

$$
V_{j c}^{F}=\underbrace{\frac{\ln \left(1-\tau_{c}^{b}\right)}{-\left(\varepsilon^{P D}+1\right)}+\bar{B}_{c}-\gamma \ln w_{c}-\delta \ln \rho_{c}+\frac{\ln \kappa_{1}}{-\left(\varepsilon^{P D}+1\right)}}_{\equiv v_{c}}+\zeta_{j c} .
$$

This value function is a positive monotonic transformation of log profits. ${ }^{15}$ Similar to the household location problem, establishments will locate in location $c$ if their value function there is higher there than in any other location $c^{\prime}$. The share of establishments for which that is true determines local establishment share $E_{c}$ :

$$
E_{c}=P\left(V_{j c}=\max _{c^{\prime}}\left\{V_{j c^{\prime}}\right\}\right)=\frac{\exp \frac{v_{c}}{\sigma^{F}}}{\sum_{c^{\prime}} \exp \frac{v_{c^{\prime}}}{\sigma^{F}}}
$$

where $\sigma^{F}$ is the dispersion of the location-specific idiosyncratic establishment productivity $\zeta_{j c}$.

\subsubsection{Local Labor Demand}

Local labor demand depends on the share of establishments that choose to locate in $c$ as well as the average employment of local firms and is given by the following expression: ${ }^{16}$

$$
\begin{aligned}
L_{c}^{D} & =E_{c} \times \mathbb{E}_{\zeta}\left[l_{j c}^{*}\left(\zeta_{j c}\right) \mid c=\underset{c^{\prime}}{\left.\operatorname{argmax}\left\{V_{j c^{\prime}}\right\}\right]}\right. \\
& =\underbrace{\left(\frac{1}{C \bar{\pi}} \exp \left(\frac{v_{c}}{\sigma^{F}}\right)\right)}_{\text {Extensive margin }} \times \underbrace{w_{c}^{\left(\gamma \varepsilon^{P D}+\gamma-1\right)} \rho_{c}^{\left(1+\varepsilon^{P D}\right) \delta} \kappa_{0}\left(e^{\bar{B}_{c}\left(-\varepsilon^{P D}-1\right)}\right) z_{c}}_{\text {Intensive margin }}
\end{aligned}
$$

where $C$ is the number of cities, $\bar{\pi} \equiv \frac{1}{C} \sum_{c^{\prime}} \exp \left(\frac{v_{c^{\prime}}}{\sigma^{F}}\right)$ is closely related to average profits in all other locations, $\kappa_{0}$ is a common term across locations, and $z_{c}$ is a term increasing in the idiosyncratic productivity draw $\zeta_{j c}$. From this equation we obtain a key object of interest for incidence - the macro elasticity of local labor demand:

$$
\frac{\partial \ln L_{c}^{D}}{\partial \ln w_{c}}=\underbrace{\gamma-1}_{\text {Substitution }}+\underbrace{\gamma \varepsilon^{P D}}_{\text {Scale }}-\underbrace{\frac{\gamma}{\sigma^{F}}}_{\text {Firm-Location }} \equiv \varepsilon^{L D},
$$

where $\gamma$ is the output elasticity of labor, $\epsilon^{P D}$ is the product demand elasticity, and $\sigma^{F}$ is the dispersion of idiosyncratic productivity. This expression is labeled the macro elasticity of labor demand because

\footnotetext{
${ }^{14}$ Allowing for endogenous agglomeration, i.e., making $B_{j c}$ a function of local population, is beyond the scope of this paper. See Kline and Moretti (2014) for a related model of agglomeration with a representative firm and Diamond (2012) for amenity-related agglomerations. We use estimates from Suárez Serrato and Wingender (2011) to quantify how our results change if government infrastructure (and thus productivity) is affected in Appendix Section F.

${ }^{15}$ The transformation divides log profits by $-\left(\varepsilon^{P D}+1\right) \geq 1$, where log profits are the non-tax shifting portion of log profits, i.e., $\ln \pi_{j c}=\ln \left(1-\tau_{i}^{A}\right)+\gamma\left(\varepsilon^{P D}+1\right) \ln w_{c}+\delta\left(\varepsilon^{P D}+1\right) \ln \rho_{c}-\left(\varepsilon^{P D}+1\right) \ln \bar{B}_{c}+\ln \kappa_{1}$, which closely approximates the exact expression for $\log$ profits as shown in Appendix B.2.2. Note that $-\left(\varepsilon^{P D}+1\right)^{-1}=\mu-1$, which is the net-markup.

${ }^{16}$ Given a large number of cities $C$, we can follow Hopenhayn (1992) and use the law of large numbers to simplify the denominator of $E_{c}$ and express the share $E_{c}=\left(\frac{\exp \frac{v_{c}}{\sigma F}}{C \bar{\pi}}\right)$ as a function of average location-specific profits in all other locations $\bar{\pi} \equiv \frac{1}{C} \sum_{c^{\prime}} \exp \left(\frac{v_{c^{\prime}}}{\sigma^{F}}\right)$.
} 
it combines the average firm's elasticity plus the effect of firm entry on labor demand. In addition, this equation also yields our last key object of interest: the effect of a business tax change on local labor demand, which is given by:

$$
\frac{\partial \ln L_{c}^{D}}{\partial \ln \left(1-\tau_{c}^{b}\right)}=\frac{\partial \ln E_{c}}{\partial \ln \left(1-\tau_{c}^{b}\right)}=\frac{1}{-\left(\varepsilon^{P D}+1\right) \sigma^{F}}=\frac{\mu-1}{\sigma^{F}},
$$

where the last equation uses the definition of the net-markup: $\mu-1$.

\section{The Incidence of Local Corporate Tax Cuts}

We characterize the incidence of corporate taxes on wages, rents, and profits and relate these effects to the welfare of workers, landowners, and firms. We focus on the welfare of local residents as the policies we study are determined by policymakers with the objective of maximizing local welfare.

\subsection{Local Incidence on Prices and Profits}

Assuming full labor force participation, i.e., $L_{c}^{S}=N_{c}$, clearing in the housing, labor, capital, and goods markets gives the following labor market equilibrium:

$$
N_{c}\left(w_{c}, r_{c} ; \bar{A}_{c}, \eta_{c}\right)=L_{c}^{D}\left(w_{c}, \bar{\pi} ; \rho_{c}, \tau_{c}^{b}, \bar{B}_{c}, z_{c}\right) .
$$

This expression implicitly defines equilibrium wages $w_{c}$. Let $\dot{w}_{c}=\frac{d \ln w_{c}}{d \ln \left(1-\tau_{c}^{b}\right)}$ and define $\dot{r}_{c}$ analogously. The effect of a local corporate tax cut on local wages and rents are given by the following expressions:

$$
\begin{gathered}
\dot{w}_{c}=\frac{\left(\frac{\partial \ln L_{c}^{D}}{\partial \ln \left(1-\tau_{c}^{b}\right)}\right)}{\varepsilon^{L S}-\varepsilon^{L D}}=\frac{\frac{(\mu-1)}{\sigma^{F}}}{\left(\frac{1+\eta_{c}-\alpha}{\sigma^{W}\left(1+\eta_{c}\right)+\alpha}\right)-\gamma\left(\varepsilon^{P D}+1-\frac{1}{\sigma^{F}}\right)+1}, \text { and } \\
\dot{r}_{c}=\left(\frac{1+\varepsilon^{L S}}{1+\eta_{c}}\right) \dot{w}_{c} . \\
\dot{\pi}_{c}=1 \underbrace{-\delta\left(\varepsilon^{P D}+1\right)}_{\text {Reducing Capital Wedge }}+\underbrace{\gamma\left(\varepsilon^{P D}+1\right) \dot{w}_{c}}_{\text {Higher Labor Costs }},
\end{gathered}
$$

where $\dot{\pi}_{c}$ is the percentage change in after-tax profits, $\delta$ is the output elasticity of capital, $\varepsilon^{P D}$ is the product demand elasticity, $\gamma$ is the output elasticity of labor, and $\dot{w}_{c}$ is the percentage change in wages following a corporate tax cut.

\subsubsection{Discussion}

The expression for wage growth in Equation 10 has an intuitive economic interpretation that translates the forces in our spatial equilibrium model to those in a basic supply and demand diagram, as in Figure 1. The numerator captures the shift in labor demand following the tax cut: $\frac{(\mu-1)}{\sigma^{F}}$. Since this shift in demand is due to establishment entry, the numerator is a function of the location decisions of establishments. Profit taxes matter more for location decisions when markups (and thus profits) are large, but matter less when productivity is more heterogeneous across locations. The denominator is the difference between an effective labor supply elasticity and a macro labor demand elasticity. The effective elasticity of labor supply $\varepsilon^{L S}=\left(\frac{1+\eta_{c}-\alpha}{\sigma^{W}\left(1+\eta_{c}\right)+\alpha}\right)$ incorporates indirect housing market impacts. 
As $\frac{\partial \varepsilon^{L S}}{\partial \eta_{c}}>0$, the effect of corporate taxes on wages will be smaller, the larger the elasticity of housing supply. A simple intuition for this is that if $\eta$ is large, workers do not need to be compensated as much to be willing to live there. As shown in Equation 9, the elasticity of labor demand depends on both location and scale decisions of firms.

In the expression for rental costs in Equation 11, the quantity $1+\varepsilon^{L S}$ captures the effects of higher wages on housing consumption through both a direct effect of higher income and an indirect effect on the location of workers. The magnitude of the rent increase depends on the elasticity of housing supply $\eta_{c}$ and the strength of the inflow of establishments through its effect on $\dot{w}_{c}$ as in Equation 10.

Equation 12 shows that establishment profits mechanically increase by one percent following a corporate tax cut of one percent. They are also affected by effects on factor prices. The middle term reflects increased profitability due to a reduction in the effective cost of capital. The last term shows that, as firms enter the local labor market, wages rise and thus compete away profits.

\subsection{Local Incidence on Welfare}

Having derived the incidence of corporate taxes on local prices and profits, we now explore how these price changes affect the welfare of workers, landowners, and firm owners. We define the welfare of workers as $\mathcal{V}^{W} \equiv \mathbb{E}\left[\max _{c}\left\{u_{c}+\xi_{n c}\right\}\right]$. Since the distribution of idiosyncratic preferences is type I extreme value, the welfare of workers can be written as:

$$
\mathcal{V}^{W}=\sigma^{W} \log \left(\sum_{c} \exp \left(\frac{u_{c}}{\sigma^{W}}\right)\right),
$$

as in McFadden (1978) and Kline and Moretti (2013). It then follows that the effect of a tax cut in location $c$ on the welfare of workers is given by:

$$
\frac{d \mathcal{V}^{W}}{d \ln \left(1-\tau_{c}^{c}\right)}=N_{c}\left(\dot{w}_{c}-\alpha \dot{r}_{c}\right)
$$

That is, the effect of a tax cut on welfare is simply a transfer to workers in location $c$ equivalent to a percentage change in the real wage given by $\left(\dot{w}_{c}-\alpha \dot{r}_{c}\right)$. One very useful aspect of this formula is that it does not depend on the effect of tax changes on the location decisions of workers in the sense that there are no $\dot{N}_{c}$ terms in this expression (Busso, Gregory and Kline, 2013). This expression assumes $\frac{d \mathcal{V}^{W}}{d \ln \left(1-\tau_{c}^{b}\right)}=\frac{d \mathcal{V}_{c}^{W}}{d \ln \left(1-\tau_{c}^{b}\right)}$, that is, tax changes in location $c$ have no effect on wages and rental costs in other locations, consistent with the perspective of a local official.

Similarly, defining the welfare of firm owners as: ${ }^{17}$

$$
\mathcal{V}^{F} \equiv \mathbb{E}\left[\max _{c}\left\{v_{c}+\zeta_{j c}\right\}\right] \times-\left(\varepsilon^{P D}+1\right)
$$

yields an analogous expression for the effect of corporate taxes on domestic firm owner welfare:

$$
\frac{d \mathcal{V}^{F}}{d \ln \left(1-\tau_{c}^{c}\right)}=E_{c} \dot{\pi}_{c} .
$$

Finally, consider the effect on landowner welfare in location $c$. Landowner welfare in each location is the difference between housing expenditures and the costs associated with supplying that level of

\footnotetext{
${ }^{17}$ The firm owner term is multiplied by $-\left(\varepsilon^{P} D+1\right)>0$ to undo the monotonic transformation in definition of the establishment value function $V_{j c}^{F}$. Firm owners and landlords are distinct from workers for conceptual clarity.
} 
housing. This difference can be expressed as follows: ${ }^{18}$

$$
\mathcal{V}^{L}=N_{c} \alpha w_{c}-\int_{0}^{N_{c} \alpha w_{c} / r_{c}} G^{-1}\left(q ; Z_{c}^{h}\right) d q=\frac{1}{1+\eta_{c}} N_{c} \alpha w_{c}
$$

and is proportional to housing expenditures. The effect of a corporate tax cut on the welfare of domestic landowners is then given by:

$$
\frac{d \mathcal{V}^{L}}{d \ln \left(1-\tau_{c}^{c}\right)}=\frac{\dot{N}_{c}+\dot{w}_{c}}{1+\eta_{c}}
$$

\section{Empirical Implementation and Identification}

This section describes how we connect the theory to the data to implement the incidence formulae from the previous section. We write the key equations of the spatial equilibrium model from Section 1 as a simultaneous equations model and show that there is an associated exact reduced-form that relates equilibrium changes in the number of households, firms, wages, and rental prices to the structural parameters of the model. We then show that the incidence formulae are identified by simple combinations of these equilibrium responses, which can also be used to recover the key structural parameters of the model.

\subsection{Exact Reduced-Form Effects of Business Tax Changes}

The simultaneous equation model is given by the log-labor supply equation (Equation 1), the logvalue of equilibrium rents (Equation 2), the log of the establishment location equation (Equation 7), and the log-labor demand equation (Equation 8). To economize on the number of parameters, we set $\eta_{c}=\eta \forall c$. Stacking these equations yields the structural form:

$$
\mathbb{A} \mathbf{Y}_{c, t}=\mathbb{B} \mathbf{Z}_{c, t}+\mathbf{e}_{c, t}
$$

where $\mathbf{Y}_{c, t}$ is a vector of the four endogenous variables (wage growth, population growth, rental cost growth, and establishment growth), $\mathbf{Z}_{c, t}=\left[\Delta \ln \left(1-\tau_{c, t}^{b}\right)\right]$ is a vector of tax shocks, $\mathbb{A}$ is a matrix that characterizes the inter-dependence among the endogenous variables, $\mathbb{B}$ is a matrix that measures the direct effects of the tax shocks on each endogenous variable, and $\mathbf{e}_{c, t}$ is a structural error term. Explicitly, these elements are given by:

$$
\mathbf{Y}_{c, t}=\left[\begin{array}{c}
\Delta \ln w_{c, t} \\
\Delta \ln N_{c, t} \\
\Delta \ln r_{c, t} \\
\Delta \ln E_{c, t}
\end{array}\right], \mathbb{A}=\left[\begin{array}{cccc}
-\frac{1}{\sigma^{W}} & 1 & \frac{\alpha}{\sigma^{W}} & 0 \\
1 & -\frac{1}{\varepsilon^{L D}} & 0 & 0 \\
-\frac{1}{1+\eta} & -\frac{1}{1+\eta} & 1 & 0 \\
\frac{\gamma}{\sigma^{F}} & 0 & 0 & 1
\end{array}\right], \mathbb{B}=\left[\begin{array}{c}
0 \\
\frac{1}{\varepsilon^{L D} \sigma^{F}\left(\varepsilon^{P D}+1\right)} \\
0 \\
\frac{1}{-\sigma^{F}\left(\varepsilon^{P D}+1\right)}
\end{array}\right]
$$

Pre-multiplying by the inverse of the matrix of structural coefficients $\mathbb{A}$ gives the reduced form:

$$
\mathbf{Y}_{c, t}=\underbrace{\mathbb{A}^{-1} \mathbb{B}}_{\equiv \boldsymbol{\beta}^{\text {Business Tax }}} \mathbf{Z}_{c, t}+\mathbb{A}^{-1} \mathbf{e}_{c, t}
$$

where $\boldsymbol{\beta}^{\text {Business Tax }}$ is a vector of reduced-form effects of business tax changes:

\footnotetext{
${ }^{18}$ Note that, in contrast to workers and firm owners, this formulation of the utility of the representative landlord assumes constant marginal utility of income. In addition, rising rents may reflect increases in wages that do not accrue directly to landowners. Direct data on land values (e.g., Albouy and Ehrlich (2012)) could improve this measurement.
} 


$$
\boldsymbol{\beta}^{\text {Business Tax }}=\left[\begin{array}{c}
\beta^{W} \\
\beta^{N} \\
\beta^{R} \\
\beta^{E}
\end{array}\right]=\left[\begin{array}{c}
\dot{w} \\
\dot{w} \varepsilon^{L S} \\
\frac{1+\varepsilon^{L S}}{1+\eta} \dot{w} \\
\frac{\mu-1}{\sigma^{F}}-\frac{\gamma}{\sigma^{F}} \dot{w}
\end{array}\right] .
$$

The expressions in the exact reduced form have insightful intuitive economic interpretations. The observed equilibrium change in wages and rents, $\beta^{W}$ and $\beta^{R}$, are given by the incidence Equations 10 and 11. The equilibrium change in employment, $\beta^{N}$, is given by the change in wage multiplied by the effective elasticity of labor supply. The change in the number of establishments, $\beta^{E}$, is determined by two forces. The first, $\frac{\mu-1}{\sigma^{F}}$, is the increase in the number of establishments that would occur if wages did not change. The second component accounts for the equilibrium change in wages. Higher wages decrease the number of establishments by $-\frac{\gamma}{\sigma^{F}} \dot{w}$.

\subsection{Identification of Parameters and Incidence Formulae}

This section shows that these four reduced-form moments, $\boldsymbol{\beta}^{\text {Business Tax }}=\left[\beta^{W}, \beta^{N}, \beta^{R}, \beta^{E}\right]^{\prime}$, are sufficient to identify the incidence on the welfare of each of our agents, up to the calibration of expenditure share $\alpha$ and output elasticity ratio $\delta / \gamma$. Table 1 reproduces the incidence formulae for the welfare of each of our agents. The direct effects of taxes on disposable income $\left(\beta^{W}-\alpha \beta^{R}\right)$ and on rents $\beta^{R}$ identify the impacts on workers and landowners, respectively. The expression for firm owners depends on the equilibrium effect on profits, which are not directly observed empirically.

Table 1 shows that the formula for the incidence on after-tax profits includes the term $\gamma\left(\varepsilon^{P D}+1\right)$. This term measures the decrease in profits from a one-percent increase in wages normalized by the firm's net-markup. Intuitively, the amount firms care about wage changes depends on how much wage changes impact their costs, which is governed $\gamma$, and how much firms have to scale back production when costs are higher, which is governed by the product demand elasticity. We identify $\gamma\left(\varepsilon^{P D}+1\right)$ by inverting the wage incidence equation. We recover the elasticity of labor supply, which is identified by the ratio of the first two rows of Equation 17 so that $\varepsilon^{L S}=\beta^{N} / \beta^{W}$. Similarly, the shift in labor demand is given by rearranging the establishment location in the last row of Equation 17:

$$
\frac{\mu-1}{\sigma^{F}}=\beta^{E}+\frac{\gamma}{\sigma^{F}} \beta^{W}
$$

This equation states that the shift in labor demand is given by the observed change in the number of establishments, $\beta^{E}$, plus the number of establishments that would have entered had wages not risen, as given by $\frac{\gamma}{\sigma^{F}} \beta^{W}$. Expressing the wage incidence formula as a function of reduced-form parameters yields:

$$
\beta^{W}=\frac{\beta^{E}+\frac{\gamma}{\sigma^{F}} \beta^{W}}{\frac{\beta^{N}}{\beta^{W}}-\underbrace{\gamma\left(\varepsilon^{P D}+1-\frac{1}{\sigma^{F}}\right)+1}_{\varepsilon^{\mathrm{LD}}}} .
$$

Solving equation 18 for $\gamma\left(\varepsilon^{P D}+1\right)$ shows that it is identified by the following combination of reducedform moments:

$$
\gamma\left(\varepsilon^{P D}+1\right)=\left(\frac{\beta^{N}-\beta^{E}}{\beta^{W}}+1\right) .
$$

The intuition behind this derivation is that, given estimates of the equilibrium change in wages, employment, and the slope of labor supply, we can decompose the elasticity of labor demand into the 
Table 1: Identification of Local Incidence on Welfare and Structural Parameters

Panel (a) Local Incidence

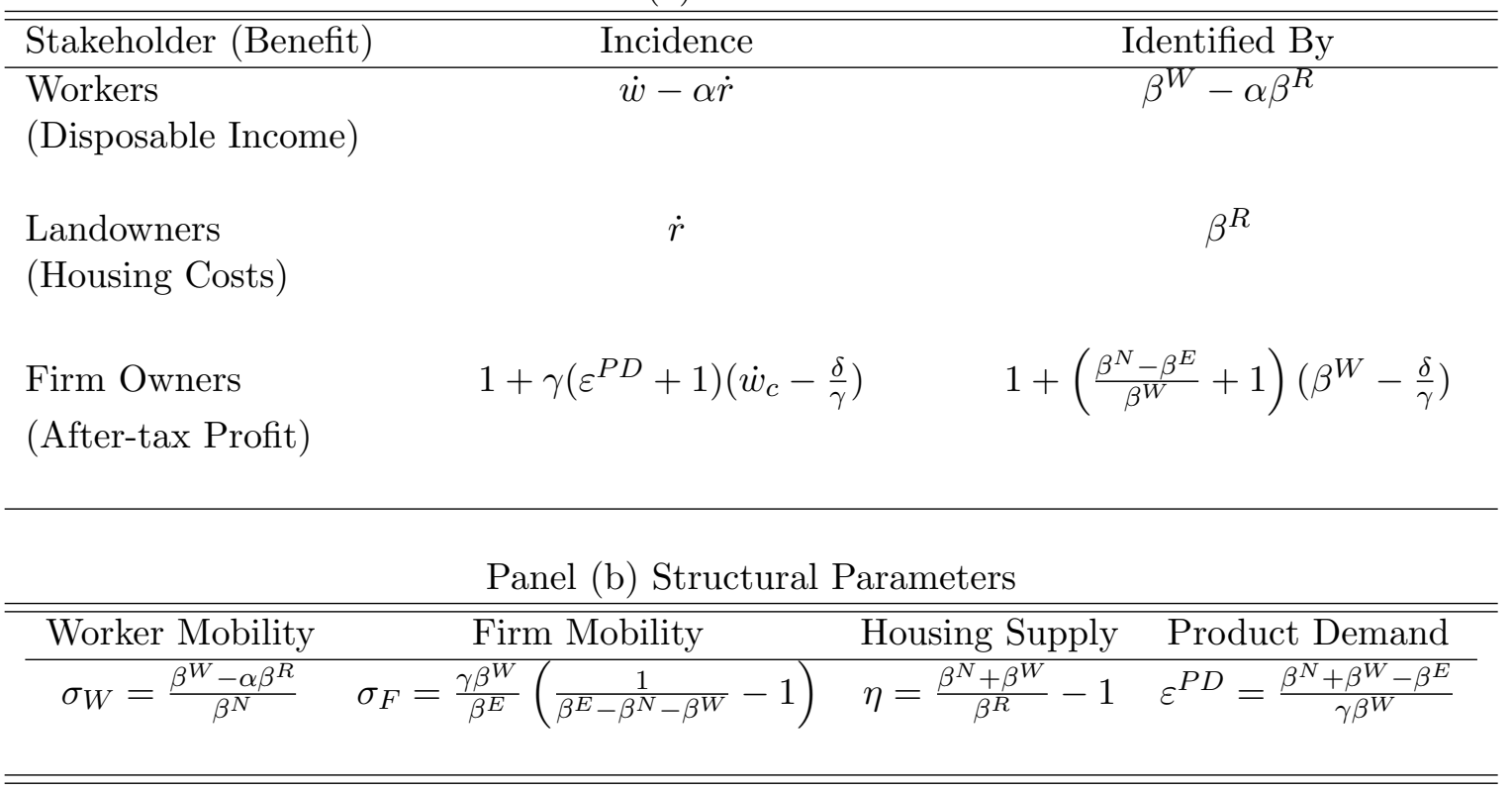

Notes: This table shows how reduced-form estimates $\boldsymbol{\beta}^{\text {Business Tax }}=\left[\beta^{W}, \beta^{N}, \beta^{R}, \beta^{E}\right]^{\prime}$ map to the incidence on welfare of workers, landowners, and firm-owners at the local level. Note that we calibrate the housing expenditure share $(\alpha)$ and the ratio of the capita to labor output elasticities $(\delta / \gamma)$.

extensive component, using the equilibrium change in establishments, and the remaining intensive margin $\gamma\left(\varepsilon^{P D}+1\right)-1$. This micro-elasticity of labor demand also reveals the effect of a wage increase on profits, which determines the incidence on firm owners.

A few remarks are worth highlighting about this identification argument. First, given $\alpha$ and $\delta / \gamma$, the welfare effects are point identified even though we cannot identify all seven model parameters with four moments. In particular, even though we cannot separately identify $\gamma$ and $\varepsilon^{P D}$, identifying the product $\gamma\left(\varepsilon^{P D}+1\right)$ is sufficient to characterize the effect of a corporate tax cut on profits. Second, we can further identify additional primitives of the model including $\sigma^{W}$ and $\eta_{c}$ by manipulating the identification of the elasticity of labor supply and the incidence on rents. Table 1 presents formulae for each of the structural parameters we estimate as functions of the four reduced-form moments and calibrated parameters $\alpha$ and $\gamma$. Third, this identification argument highlights the relationship between the model and reduced-form estimates, providing a transparent way to evaluate how sensitive our ultimate incidence estimates are to changes in the four reduced-form estimates. Finally, in some specifications we augment this model to include the effects of personal income taxes on housing supply and worker location as well as the effects of observable productivity shocks due to Bartik (1991) on the local labor market equilibrium. ${ }^{19}$ For brevity, we relegate discussion of the exact reduced-from expressions to Appendix E.5. However, note that the reduced-form identification argument above is not affected by the inclusion of additional sources of variation.

\footnotetext{
${ }^{19}$ In particular, the location decision of workers is modified by replacing $w$ with after tax income $w\left(1-\tau^{i}\right)$ and the supply of housing now becomes $H_{c}^{S}=\left(1-\tau^{i}\right)^{\chi^{H}}\left(B_{c}^{H} r_{c}\right)^{\eta_{c}}$, where the parameter $\chi^{H}$ is estimated in the cases where we estimate the system using the variation from all shocks. Note that, additionally, one could also incorporate local property taxes by including property taxes in the cost of housing in the worker location equation.
} 


\section{Data and Institutional Details of State Corporate Taxes}

We use annual county-level data from 1980-2012 for over 3,000 counties and decadal individual-level data to create a panel of outcome and tax changes for 490 county-groups. Ruggles et al. (2010) developed and named these country-groups "consistent public-use micro-data areas (PUMAs)." This level of aggregation is the smallest geographical level that can be consistently identified in Census and American Community Survey (ACS) datasets and provides several benefits (see Appendix A.1).

\subsection{Data on Economic Outcomes}

We aggregate the number of establishments in a given county to the PUMA county-groups using data from the Census Bureau's County Business Patterns (CBP). We analogously calculate population changes using Bureau of Economic Analysis (BEA) data.

Data on local wages and housing costs are available less frequently. We use individual-level data from the 1980, 1990, and 2000 U.S. censuses and the 2009 ACS to create a balanced panel of 490 county groups with indices of wages, rental costs, and housing values.

When comparing wages and housing values, it is important that our comparisons refer to workers and housing units with similar characteristics. As is standard in the literature on local labor markets, we create indices of changes in wage rates and rental rates that are adjusted to eliminate the effects of changes in the compositions of workers and housing units in any given area. We create these composition-adjusted values as follows. First, we limit our sample to the non-farm, non-institutional population of adults between the ages of 18 and 64 . Second, we partial out the observable characteristics of workers and housing units from wages and rental costs to create a constant reference group across locations and years. We do this adjustment to ensure that changes in the prices we analyze are not driven by changes in the composition of observable characteristics of workers and housing units. Additional details regarding our sample selection and the creation of composition-adjusted outcomes are available in Appendix A.2. Finally, we construct a "Bartik" local labor demand shock that we use to supplement our tax change measure and enhance the precision of labor supply parameters. ${ }^{20}$

\subsection{Tax Data}

Businesses pay two types of income taxes. C-corporations pay state corporate taxes and many other types of businesses, such as S-corporations and partnerships, pay individual income taxes. We combine these measures to calculate an average business tax rate for each local area from 1980 to 2010.

\subsubsection{State Corporate Tax Data and Institutional Details}

The tax rate we aim to obtain in this subsection is the effective average tax rate paid by establishments of C-corporations in a given location from 1980 to 2010. Firms can generate earnings from activity

\footnotetext{
${ }^{20}$ This approach weights national industry-level employment shocks by the initial industrial composition of each local area to construct a measure of local labor demand shocks:

$$
\text { Bartik }_{c, t} \equiv \sum_{\text {Ind }} \text { EmpShare }_{\text {Ind,t-10,c}} \times \Delta \operatorname{Emp}_{\text {Ind,t, US }}
$$

where EmpShare ${ }_{I n d, t-10, c}$ is the share of employment in a given industry at the start of the decade and $\Delta$ Emp $_{I n d, t, \mathrm{US}}$ is the national percentage change in employment in that industry. We calculate national employment changes as well as employment shares for each county group using micro-data from the 1980, 1990, and 2000 Censuses and the 2009 ACS. We use a consistent industry variable based on the 1990 Census that is updated to account for changes in industry definitions as well as new industries.
} 
in many states. State authorities have to determine how much activity occurred in state $s$ for every firm $i$. They often use a weighted average of payroll, property, and sales activity. The weights $\boldsymbol{\theta}_{s}$, called apportionment weights, determine the relative importance tax authorities place on these three measures of in-state activity. ${ }^{21}$ From the perspective of the firm $i$, the firm-specific "apportioned" tax rate is a weighted average of state corporate tax rates:

$$
\tau_{i}^{A}=\sum_{s} \tau_{s}^{c} \omega_{i s}
$$

where $\tau_{s}^{c}$ is the corporate tax rate in state $s$ and the firm-specific weights $\omega_{i s}$ are themselves weighted averages $\omega_{i s}=\underbrace{\left(\theta_{s}^{w} \frac{W_{i s}}{W}\right)}_{\text {payroll }}+\underbrace{\left(\theta_{s}^{\rho} \frac{R_{i s}}{R}\right)}_{\text {property }}+\underbrace{\left(\theta_{s}^{x} \frac{X_{i s}}{X}\right)}_{\text {sales }}$ of in-state activity shares. ${ }^{22}$ Equation 19 shows that the tax rate corporations pay depends on home-state and other states' tax rates and rules. We use the latter to construct an external rate $\tau_{i}^{E}$, which represents an index of the importance of changes in every other state's tax and yields variation that is likely exogenous to local economic conditions. It is defined explicitly in Appendix A.3.1.

To implement the activity shares for each firm $i$, we use the Reference USA dataset from Infogroup to compute the geographic distribution of payroll at the firm level. Due to the lack of information on the geographic distribution of property in the Reference USA dataset, we make the simplifying assumption that capital activity weights equal the payroll weights. Finally, since the apportionment of sales is destination-based, we use state GDP data for ten broad industry groups from the BEA to apportion sales to states based on their share of national GDP. ${ }^{23}$

Empirically, we use the spatial distribution of establishment-firm ownership and payroll activity in 1997, the first year in which micro establishment-firm linked data are available. We hold the spatial distribution of establishment-firm ownership and payroll activity weights constant at these initial values to avoid endogenous changes in effective tax rates. Consequently, variation in our tax measure $\tau_{i}^{A}$ comes from variation in state apportionment rules, variation in state corporate tax rules, and initial conditions, which determine the sensitivity of each firm's tax rate $\tau_{i}^{A}$ to changes in corporate rates and apportionment weights. We combine our empirical activity share measures with state corporate tax rates and apportionment rules from Book of the States, Significant Features of Fiscal Federalism and Statistical Abstracts of the United States. We then use these components to compute an average tax rate $\bar{\tau}_{c}^{A}$ for all establishments in each location and decompose it into average local "domestic" and external rates, $\bar{\tau}_{c}^{D}$ and $\bar{\tau}_{c}^{E}$.

Figure 2 shows that apart from a few states that have never taxed corporate income, most states have changed their rates at least three times since 1979. Appendix Figure A3 shows how large these rate changes have been over a 30 year period from 1980-2010. States in the South made fewer

\footnotetext{
${ }^{21}$ Goolsbee and Maydew (2000) use variation in apportionment weights on payroll activity to show that reducing the payroll weight from $33 \%$ to $25 \%$ leads to an increase in manufacturing employment of roughly one percent on average. In addition, we follow their approach of analyzing the determinants of state tax policy changes by estimating a probit of the likelihood that a state has a tax policy change based on how observable economic and tax policy conditions such as state per capita income growth, state corporate tax rates, state income tax rates, and the apportionment weights of other states relate to apportionment formula and tax rate policy changes. The results, which are discussed in Appendix A.6, are in Appendix Tables A34 and A35.

${ }^{22}$ In particular, $a_{i s}^{w} \equiv \frac{W_{i s}}{W}$ is the payroll activity share. Payroll and sales shares are defined analogously. See Appendix A.3.1 for more detail on apportionment rules.

${ }^{23}$ This assumption corresponds to the case where all goods are perfectly traded, as in our model. We use broad industry groups in order to link SIC and NAICS codes when calculating GDP by state-industry-year.
} 
changes while states in the Midwest and Rust Belt changed rates more frequently. This figure shows that changes in state corporate tax rates did not come form a particular region of the U.S. State corporate tax changes are not only frequent but they can also be sizable. Of the 1470 PUMA-decade observations in the main dataset, there are hundreds of sizable changes in both aspects of corporate tax policy over three periods of interest: 1980-1990, 1990-2000, and 2000-2010. ${ }^{24}$

States also vary in the apportionment rates that they use. Table 3 provides summary statistics of apportionment weights. Since the late 1970s, apportionment weights generally placed equal weight on payroll, property, and sales activity, setting $\theta_{s}^{w}=\theta_{s}^{\rho}=\theta_{s}^{x}=\frac{1}{3}$. For instance, $80 \%$ of states used an equal-weighting scheme in 1980. However, many states have increased their sales weights over the past few decades as shown in Figure 3. In 2010, the average sales weight is two-thirds and less than $25 \%$ of states still maintain sales apportionment weights of $33 \%$.

\subsubsection{Local Business Tax Rate}

We combine measures of state personal income tax rates from Zidar (2014) (see Appendix A.3.3 for details) and local effective corporate tax rates that account for apportionment to construct a measure of the change in average taxes that local businesses pay:

$$
\begin{aligned}
\Delta \ln \left(1-\tau^{b}\right)_{c, t, t-h} \equiv & \underbrace{f_{c, t-h}^{S C} \Delta \ln \left(1-\tau^{c}\right)_{c, t, t-h}+f_{c, t-h}^{M C} \Delta \ln \left(1-\bar{\tau}^{D}\right)_{c, t, t-h}}_{\text {Corporate }} \\
& +\underbrace{\left(1-f_{c, t-h}^{S C}-f_{c, t, t-h}^{M C}\right) \Delta \ln \left(1-\tau^{i}\right)_{c, t, t-h}}_{\text {Personal }},
\end{aligned}
$$

where $h \in\{1,10\}$ is the number of years over which the difference is measured, $f_{c, t}^{S C}$ is the fraction of local establishments that are single-state C-corporations, and $f_{c, t}^{M C}$ is the fraction of local establishments that are multi-state C-corporations. ${ }^{25}$ While this measure captures several key features of local business taxation, we made a number of simplifying assumptions in generating $\tau^{b}$ due to data limitations and feasibility. ${ }^{26}$ We discuss these assumptions and tax measurement details in Appendix A.3.4. Overall, changes in corporate tax rates, apportionment weights, and personal income tax rates generate considerable variation in effective tax rates across time and space. Table 3 provides summary statistics of a few different measures of corporate tax changes over 10 year periods. The average log change over 10 years in corporate taxes due only to statutory corporate rates $\Delta \ln \left(1-\tau^{c}\right)_{c, t, t-10}$ is near zero and varies less than measures based on business taxes that incorporate the complexities of apportionment changes. Business tax changes $\Delta \ln \left(1-\tau^{b}\right)_{c, t, t-10}$ are slightly more negative on average over a ten-year period. The minimum and maximum values are less disperse than the measure based on statuary rates since sales apportionment reduces location-specific changes in effective corporate tax rates. Overall, $76 \%$ of the variation in $\Delta \ln \left(1-\tau^{b}\right)_{c, t, t-10}$ is due to policy variation (changes in tax rates and apportionment rules).

\footnotetext{
${ }^{24}$ Specifically, Appendix Figure A6 shows a histogram of non-zero tax changes in corporate tax rates in Panel (a) and in payroll apportionment rates in Panel (b).

${ }^{25}$ These shares are from County Business Patterns and RefUSA. C-corps accounted for roughly half of employment and one-third of establishments in 2010. Yagan (2015) notes that switching between corporate types is rare empirically.

${ }^{26}$ For instance, partnerships and sole-proprietors pay taxes based on the location of the owner and not the establishment. For simplicity, we assume that owners of passthrough entities are located in the same state as the establishment. Additionally, using aggregated-average rates is not directly justified by the model, so our estimates are approximations.
} 


\subsection{Calibrated Parameters}

We calibrate two parameters when implementing the reduced-form formulae in Table 1: the ratio of the capita to labor output elasticities $(\delta / \gamma)$ and the housing expenditure share $(\alpha)$. We use .9 for the ratio of output elasticities based on data from the Bureau of Economic Analysis. BEA's 2012 data on shares of gross output by industry indicate that for private industries, compensation and intermediate inputs account for $28.5 \%$ and $45.6 \%$ respectively; the ratio $\frac{1-.285-.456}{.285} \approx .9$. Our baseline results use $\alpha=.3$, which we obtain using data from the Consumer Expenditure Survey (CEX). ${ }^{27}$

Table 2: Calibrated Parameters used in Incidence Formulae

\begin{tabular}{lcc}
\hline \hline Parameter & Values & Sources \\
\hline Parameters for Reduced-Form & Implementation & BEA \\
Ratio of Elasticities: $\gamma / \delta$ & $\{\mathbf{0 . 9 0}, 0.50,0.75\}$ & CEX, Albouy (2008), (Moretti, 2013) \\
Housing Cost Share: $\alpha$ & $\{\mathbf{0 . 3 0}, 0.50,0.65\}$ & C \\
& & \\
Additional Parameters for Structural Implementation & \\
Output Elasticity of Labor: $\gamma$ & $\{\mathbf{0 . 1 5}, 0.20,0.25\}$ & IRS, BEA, Kline and Moretti (2014) \\
Elasticity of Product & $\{\mathbf{- 2 . 5},-3.5$, & Between Head and Mayer (2013) and \\
Demand: $\varepsilon^{P D}$ & Estimated $\}$ & $\varepsilon^{L D}$ in Hamermesh (1993) \\
\hline \hline
\end{tabular}

Notes: This table shows the sources and values for calibrated parameters. Baseline values are noted in bold font.

We calibrate two additional parameters for the structural estimation: the output elasticity of labor $\gamma$ and the product demand elasticity $\varepsilon^{P D}$. We present results for calibrations for wide ranges of both parameters. We choose a baseline of $\gamma=.15$, which is close to other values used in the local labor markets literature (e.g., Kline and Moretti (2014) use $1-\alpha-\beta=1-.3-.47=.23$ in their notation) and is based on cost shares from IRS and BEA. ${ }^{28}$ For our baseline $\varepsilon^{P D}$, we use values that are slightly lower that in the macro and trade literatures (e.g., Coibion, Gorodnichenko and Wieland (2012); Arkolakis et al. (2013)) in order to obtain $\varepsilon^{L D}$ values that are closer to those used in the labor literature (Hamermesh, 1993). We also provide specifications in which we estimate $\varepsilon^{P D}$ directly.

Table 2 summarizes our choices for calibrated parameters as well as references for each parameter. Our baseline values are presented in bold and we also include alternative values that we consider in order to explore the robustness of our results. We also make other implicit calibrations from our modeling of preferences and technologies. In preferences, the income elasticity and elasticity of substitution for housing are both set to one. These assumptions result in a constant share of expenditure on housing, $\alpha$, which yields a constant elasticity of labor supply, $\varepsilon^{L S}$. In terms of technologies, the production function has constant returns to scale and unit elasticity of substitution among capital, labor, and intermediate goods. This setup affects the scale and substitution components in Equation 8 and thus the elasticity of labor demand, $\varepsilon^{L D}$.

\footnotetext{
${ }^{27}$ Similar values of this parameter are used by Notowidigdo (2013) and Suárez Serrato and Wingender (2011) and, as Moretti (2013) notes, the Bureau of Labor and Statistics uses a cost share of $32 \%$ for shelter. However, we consider larger values as well because Albouy (2008) and Moretti (2013) note that housing prices are related to non-housing "homegoods" which increases the effective cost share and Diamond (2012) also estimates a higher value of this parameter.

${ }^{28}$ The IRS SOI data are from the most recent year available (2003) and can be downloaded at http://www.irs.gov/ uac/SOI-Tax-Stats-Integrated-Business-Data. These data show that costs of goods sold are substantially larger than labor costs and that $\frac{\text { Salaries and Wages }}{\text { Salaries and Wages + COGS }}=.153$. Results based on revenue and cost shares from earlier years available are similar. BEA data on gross output for private industries show similar patterns as well.
} 


\section{$5 \quad$ Reduced-Form Results and Incidence Estimates}

We use changes in state tax rates and apportionment formulas to estimate the reduced-form effects of local business tax changes on population, the number of establishments, wages, and rents. We estimate Equation 17 for a given outcome $Y$ as the first-difference over a 10-year period:

$$
\ln Y_{c, t}-\ln Y_{c, t-10}=\beta^{Y}\left[\ln \left(1-\tau_{c, t}^{b}\right)-\ln \left(1-\tau_{c, t-10}^{b}\right)\right]+\mathbf{D}_{s, t}^{\prime} \Psi_{s, t}^{L D}+u_{c, t},
$$

where $\ln Y_{c, t}-\ln Y_{c, t-10}$ is approximately outcome growth over ten years, $\left[\ln \left(1-\tau_{c, t}^{b}\right)-\ln \left(1-\tau_{c, t-10}^{b}\right)\right]$ is the change in the net-of-business-tax-rate over ten years, and $\mathbf{D}_{s, t}$ is a vector with year dummies as well as state dummies for states in the industrial Midwest in the 1980s, and where a county-group fixed effect is absorbed in the long-difference. ${ }^{29}$ This regression measures the degree to which larger tax cuts are associated with greater economic activity. The validity of the reduced-form estimate $\beta^{Y}$ depends on the assumption that tax shocks conditional on fixed effects are uncorrelated with the residual term, i.e., $\mathbb{E}\left(u_{c, t} \mid\left[\ln \left(1-\tau_{c, t}^{b}\right)-\ln \left(1-\tau_{c, t-10}^{b}\right)\right], \mathbf{D}_{s, t}\right)=0$. This assumption would be violated by potentially confounding elements such as concomitant changes in the tax base, government spending, and productivity shocks. From a dynamic perspective, a violation would also occur if tax changes are the result of adverse local economic conditions that also determine the long-difference in a given outcome $Y$. We support this identifying assumption by showing that the main reduced-form effects of local business taxes on our outcomes are not affected by changes in a number of potential confounders and by showing that the tax changes are not related to prior economic conditions.

Table 4 provides results of long-differences specifications that account for these potential concerns for the establishment location equation. Column (1) shows that a $1 \%$ cut in business taxes causes a $4.07 \%$ increase in establishment growth increase over a ten-year period. Column (2) controls for other measures of labor demand shocks. The point estimate declines slightly, but $\chi^{2}$ tests indicate that $\hat{\beta}^{E}$ estimates are not statistically different than the estimate in Column (1). To the extent that cuts in corporate taxes are not fully self-financing, states may have to adjust other policies when they cut corporate taxes. Column (3) controls for changes in state investment tax credits and Column (4) controls for changes in per capita government spending. There is no evidence that either confounds the reduced form estimate $\hat{\beta}^{E}$. Column (5) uses variation in the external tax rates from changes in other states' tax rates and rules, $\left[\ln \left(1-\tau_{c, t}^{E}\right)-\ln \left(1-\tau_{c, t-10}^{E}\right)\right]$. This specification has three interesting results. First, the point estimate of changes in business taxes is $3.9 \%$, which is close to the estimate of $\hat{\beta}^{E}$ without controls in Column (1). Second, the point estimate from external tax changes is roughly equal and opposite to the estimates of $\hat{\beta}^{E}$. This symmetry in effects indicates that external tax shocks based on state apportionment rules have comparable effects to domestic business tax changes. $\chi^{2}$ tests show that the effects of domestic and external changes are statistically indistinguishable (in absolute value). Third, one potential concern is that firms do not appear responsive to tax changes because they expect other states to match tax cuts as might be expected in tax competition models. By holding other state changes constant, we find no evidence that expectations of future tax cuts lower establishment mobility. Column (6) controls for all of these potentially confounding elements simultaneously. The point estimate of $\beta^{E}$ is robust to including all of these controls.

Figure 4 shows that the long-difference estimate is similar to the cumulative effects of a one-percent cut in local business taxes over a ten-year period. This relationship holds even when adjusting for the years of prior economic activity as shown in Figure 4 (see Appendix E.1 for more detail). This

\footnotetext{
${ }^{29}$ Figure 2 shows more tax changes in the industrial midwest, so we include these dummies to avoid the concern that this regional variation is driving our results. Appendix Table A23 shows main results for different fixed-effects.
} 
evidence, based on annual changes in establishment growth and business taxes, suggests that (1) business tax cuts tend to increase establishment growth over a five-to-ten-year period and (2) business tax changes do not occur in response to abnormally good or bad local economic conditions. These dynamic patterns establishing the validity of local business tax variation also hold for population (see Appendix Figure A8). ${ }^{30}$ For brevity, the ten-year results for the other three outcomes - population, wages, and rental cost - are only shown for the first two specifications in Panel B; the full tables with all six specifications are provided in Appendix Tables A6, A7, and A8. Non-parametric graphs showing the relationship between outcome changes and business tax changes over a 10 year period are shown for each outcome in Appendix Figures A10, A11, A12, and A13, respectively.

\section{$5.1 \quad$ Incidence Estimates}

Having established the validity of these reduced-form estimates, we can now implement the incidence formulae in Table 1; the estimates for incidence and shares of incidence are presented in Table 5.

Column (1) shows results using the baseline reduced-form specification, Equation 21. Panel A shows that a $1 \%$ cut in business taxes increases real wages by $1.1 \%$ over a ten-year period. Rental costs and profits also increase. In contrast to the conventional view that $100 \%$ of the burden of corporate taxation falls on workers in an open economy, the estimated share of the burden for workers is only $28 \%$ as shown in Panel B. This estimate is precise enough to reject the conventional view on its own. Firm owners bear $42 \%$ of the incidence and landowners bear $30 \%$. The landowner estimate is less precise, perhaps reflecting in part regional housing supply heterogeneity. Column (2) shows that workers bear a slightly smaller share of incidence when $\alpha=.65$. Firm owner shares increase when $\delta / \gamma=.5$. Columns (4) and (5) show that these incidence results are robust to controlling for Bartik labor demand shocks and personal income tax changes. Firm owners bear roughly 40 to $45 \%$ of the incidence of state corporate taxes in each of these specifications. Formal conventional view tests, which evaluate the joint hypothesis that the share of incidence for workers equals $100 \%$ and the share for firm owners equals $0 \%$, are unambiguously rejected across all specifications. ${ }^{31}$

We use the relation between reduced-form estimates and incidence expressions in Table 1 to establish the robustness of these results. First, we explore the role of additional control variables. We show that our results are robust to including a wide-variety of controls: many dimensions of the state tax base and rules (Appendix Table A19) as well as state political controls, changes in other state tax rates and rules (including sales tax rates, income tax rates, and whether the state has gross receipt taxes), and changes in fiscal and economic conditions in Appendix Table A20. Second, we explore how different sources of variation affect our results. Column (6) of Table 5 and Appendix Table A21 show that using statutory state corporate tax rates in Equation 21 (instead of business tax rates $\tau^{b}$ ) results in similar and significant estimates, indicating that our measure of business tax rates is not crucial for the results. ${ }^{32}$ Moreover, using estimates from other sources of variation, such as the absolute value of the external tax change estimate from Table 4 Column (5), delivers similar incidence results to those in Tables 5, A20, and A21. Third, we consider alternate ways to account for changes in local

\footnotetext{
${ }^{30}$ Wage and rental cost data are only available every ten years, so making comparable graphs is not possible.

${ }^{31}$ One advantage of our reduced-form incidence formulae is that they combine the information in the four point estimates and their covariances. Thus, while individual coefficients might not be statistically different from zero, the combination of parameters in our formulae can yield estimates of incidence shares that are statistically significant.

${ }^{32}$ Since not all firms are C-corportions, using variation from this rate results in lower "intent-to-treat" reduced-form effects. However, we still recover the firm's valuation of increasing wages, i.e., $\gamma\left(\varepsilon^{P D}+1\right)$, since this number is a ratio of our reduced-form coefficients and the "intent-to-treat" aspect effectively cancels out.
} 
prices in Appendix G. Accounting for these impacts yields similar estimates to our baseline incidence estimates. ${ }^{33}$ Fourth, we explore the ability of incidence expressions in Table 1 to accommodate the possibility that firm owners do not bear incidence based on conjectured reduced-form impacts that would be consistent with this view. ${ }^{34}$ Thus, our approach does not necessarily imply that firm owners will get a large share of incidence.

Although we do not have access to direct measures of firm profits, ${ }^{35}$ evidence from the best measures available align with the firm owner estimates. Figure A9 shows that state gross operating surplus (GOS), revenue less labor compensation and taxes on production and imports, increases following business tax cuts with very little pre-trend. This result provides direct evidence that payments to firm owners are increasing following business tax cuts. We make two adjustments to GOS to make it correspond more closely to $\pi$. First, we calculate GOS per establishment. Second, we account for the consumption of fixed capital, which is $44 \%$ of GOS on average during the sample period of 1980 to 2010 (NIPA Table 1.14). Table A10 shows the effect of a one percent cut in business tax cuts on gross operating surplus per establishment ranges from 3.5 to $4.2 \%$ over a ten year period. Multiplying these effects by (1-.44) yields an estimated increase of 1.96 to $2.35 \%$ in net operating surplus per establishment over a ten year period. Sales tax revenue per establishment also provides a supplementary measure of profit growth. ${ }^{36}$ Table A11 shows that this measure increases between 2.15 to $2.27 \%$. Both of these estimates are close to the firm owner estimates in Panel A of Table 5.

Panel B of Table 1 shows that the reduced-form effects have implications not only for incidence, but also for structural parameters. Table A16 presents the implied values of these parameters based on a set of specifications used to construct Table 5 and calibrated values of $\alpha$ and $\gamma$. The implied structural parameters are not precisely estimated and, while the signs of parameters $\sigma_{F}$ and $\varepsilon^{P D}$ do not match predictions from our theory, we cannot reject these restrictions at the $5 \%$ level.

We follow two strategies to increase the precision of our structural estimates and to alleviate concerns that our main result is not reliant on these issues. First, we further calibrate the parameter $\varepsilon^{P D}$ and show that, conditional on values of $\alpha, \gamma$ and $\varepsilon^{P D}$, all other parameters have the signs predicted by theory. This calibration generates the following testable restriction: $\beta^{E}=\beta^{N}-\left(\gamma\left(\varepsilon^{P D}+1\right)-1\right) \beta^{W}$, which constrains the micro-elasticity of demand. Table A16 shows that the data do not reject this restriction. Second, we use additional sources of variation to increase the precision of our estimates. The following section augments our reduced-form model to include personal taxes and a productivity shock due to Bartik (1991). The details of the exact reduced-forms with all three shocks are presented in Appendix E.5.

\footnotetext{
${ }^{33}$ In addition, unlike the local labor market responses to some types of shocks (e.g., import competition shocks in Autor, Dorn and Hanson (2013), who find larger effects on employment than on population), in our context we observe very similar employment and population responses to business tax changes over a ten-year period (see Appendix Tables A6 and A9), which suggests that abstracting from the employment/non-employment margin over a ten-year period does not materially change the welfare calculations or incidence estimates. We present reduced-form incidence estimates using employment in Appendix Table A18.

${ }^{34}$ For instance, if the estimates for $\beta^{N}, \beta^{R}, \beta^{W}, \beta^{E}$ were $1.35,1.41,1.74$, and 4.88 , then firm owners would get $5 \%$ of the incidence. We interpret this example as a set of plausible, counterfactual parameter estimates that show that these expressions do not mechanically deliver the result that firm owners bear a substantial share of incidence.

${ }^{35}$ Ideally, we could have firm-level profit data that can be aggregated to the local labor market level.

${ }^{36}$ In the model with fixed markups, profits and sales are proportional. Equation 27 shows $p_{i j c} y_{i j c}=\mu y_{i j c} c_{i j c} \Rightarrow$ $\pi_{i j c}^{p}=p_{i j c} y_{i j c}-y_{i j c} c_{i j c}=p_{i j c} y_{i j c}\left(1-\frac{1}{\mu}\right)=\frac{p_{i j c} y_{i j c}}{-\varepsilon^{P D}}$, i.e., pre-tax profits are sales divided by $-\varepsilon^{P D}$.
} 


\section{Structural Estimation}

We estimate the model parameters and structural elasticities that rationalize the treatment effects from the previous two sections. We use a classical minimum distance (CMD) estimator (see, e.g., Chamberlain (1984)) to find the parameters that best match the moments $\mathbf{m}(\boldsymbol{\theta})=\boldsymbol{\beta}^{\text {Business Tax }}$ to the reduced form effects $\hat{\boldsymbol{\beta}}$ :

$$
\hat{\boldsymbol{\theta}}=\arg \min _{\boldsymbol{\theta} \in \boldsymbol{\Theta}}[\hat{\boldsymbol{\beta}}-\mathbf{m}(\boldsymbol{\theta})]^{\prime} \hat{\mathbf{V}}^{-1}[\hat{\boldsymbol{\beta}}-\mathbf{m}(\boldsymbol{\theta})],
$$

where $\hat{\mathbf{V}}$ is the inverse variance of the OLS estimate, and $\mathbf{m}(\boldsymbol{\theta})$ is the moment predicted by our model. ${ }^{37}$ We initially use only variation from tax changes, which provides the four moments from Equation 17, and then supplement this approach with four additional moments from a Bartik local labor demand shock $\boldsymbol{\beta}^{\text {Bartik }}$ and four moments from personal income tax changes $\boldsymbol{\beta}^{\text {Personal Tax }}$, increasing the precision of our estimates. The supplemental variation from these shocks provides over-identifying restrictions that enable us to test the goodness-of-fit and assess model predictions. ${ }^{38}$ Taking a more structured approach allows for more flexibility to match the data and likely results in more accurate estimates of both incidence and model parameters. Ultimately, however, the estimates in the next section shows that the structural incidence results are similar to the reduced-form incidence results in Table 5.

Table A32 shows that we match the moments well and that adding supplemental variation improves fit. Our model does not reject the test of over-identifying restrictions or the restriction that $\beta^{E}=\beta^{N}-\left(\gamma\left(\varepsilon^{P D}+1\right)-1\right) \beta^{W}$ imposed by our calibration of $\varepsilon^{P D}$ in any of the specifications. Note that these restrictions are identical in the model that only relies on the moments from business taxes and thus have identical p-values.

Table 6 shows parameter estimates from using only business tax shocks (panel B) and using all three shocks (panel A and C). Panel A and B show results for different calibrated values of the output elasticity of labor $\gamma$ and the product demand elasticity $\varepsilon^{P D}$ and panel $\mathrm{C}$ estimates $\varepsilon^{P D}$ directly. Our baseline specification Column (1) using all shocks yields an estimate for the productivity dispersion $\hat{\sigma}^{F}=0.28(S E=0.14){ }^{39}$ The estimate for preference dispersion $\hat{\sigma}^{W}=0.83(S E=0.28)$ is larger. The elasticity of housing supply, which is likely heterogenous across local areas, is $\hat{\eta}=0.51(S E=1.4)$ is statistically insignificant. Columns (2)-(7) show the effects of different calibrated values of $\gamma, \alpha$, and $\varepsilon^{P D}$. Recall that, by calibrating both $\gamma$ and $\varepsilon^{P D}$, we place a restriction among our reduced-form estimates. We test this restriction and find that it is not rejected by the data (p-values range from .39 to .51). The results using only business tax variation are less precise, especially for the housing supply elasticity. Panel $\mathrm{C}$ shows that using all shocks and estimating $\varepsilon^{P D}$ produces similar dispersion parameters and a reasonable but imprecise estimate of the product demand elasticity of roughly -4.7 .

\subsection{Parameter-based Incidence Estimates and Structural Elasticities}

The corresponding incidence results are provided in Table 7. Incidence estimates based on estimated parameter values are similar to those in Table 5. Figure 5 plots these results and shows that our

\footnotetext{
${ }^{37}$ The parameters are the dispersion of productivity $\sigma^{F}$ and preferences $\sigma^{W}$, the elasticity of substitution across varieties $\varepsilon^{P D}$, the elasticity of housing supply $\eta$, the housing expenditure share $\alpha$, and the output elasticity of labor $\gamma$.

${ }^{38}$ See Appendix E.5.4 for more detail on goodness-of-fit and over-identification tests. Appendix E shows that alternative approaches yield similar parameter estimates.

${ }^{39}$ The estimates in Panel B and C are similar to those in Appendix Figure A17. Note that this estimate depends on technological assumptions mentioned in Section 4.3 and on the values of $\gamma$ and $\varepsilon^{P D}$ through: $\sigma_{F}=\frac{1}{\beta^{E}}\left(\frac{-1}{\varepsilon^{P D}+1}-\gamma \beta^{W}\right)$.
} 
baseline values of $\gamma=0.15, \varepsilon^{P D}=-2.5$, and $\alpha=0.30$ give a conservative share of the incidence to firm owners. Panel (a) shows that using calibrations with more elastic product demand elasticities, while holding the output elasticity of labor constant at $\gamma=0.15$, does not change the result that the share to firm owners is roughly 40 to $50 \%$. Increasing the calibrated output elasticity of labor generally increases the share accruing to firm owners. Panel (b) shows that varying $\alpha$ also does not change the result that the share to firm owners is roughly 40 to $50 \%$. Table 7 shows that for our baseline parameters,firm owners bear $36.5 \%$ and landowners bear $41 \%$, leaving workers with substantially less than $100 \%$ of the burden. Note that the share to land owners varies between 20 to $40 \%$ across specifications, reflecting imprecise housing supply elasticity estimates. ${ }^{40}$

The effective labor supply and labor demand curves are key determinants of the incidence. The bottom of Table 7 shows the estimated supply and demand elasticities corresponding to the three CMD estimators. The supply elasticities are slightly less than one in most specifications, but range between .75 and 4.2, which is similar to ranges found in the literature (e.g., Bartik (1991); Notowidigdo (2013); Albouy and Stuart (2013)). They are somewhat less precise due to imprecision in housing supply elasticity parameters. When the housing supply is large, house prices do not get bid up quickly and discourage people from moving, resulting in larger effective labor supply elasticities. However, even in the specifications with larger housing supply elasticities, incidence results are comparable to other specifications. In particular, Column (4), which has $\hat{\varepsilon}^{L S}=4.2$, shows that firm owners bear $45 \%$, workers bear $29 \%$ and landowners bear the rest.

On the demand side, elasticity estimates are more precise and range between -1.7 and -3 . The first two CMD estimators in Columns (1) and (2) show micro elasticities of labor demand of -1.2 and macro elasticities of roughly -2 . While there are few estimates of the average slope of local labor demand, perhaps as a consequence of common assumptions of a representative firm (Card, 2011) and its implied infinite labor demand elasticity (Kline, 2010), our estimates are consistent with values cited in the literature. In particular, based on estimates from Hamermesh (1993), Kline and Moretti (2014) use a macro elasticity of local labor demand of -1.5. Column (5), which is estimates rather than calibrates $\varepsilon^{P D}$, illustrates the link between scale effects and the labor demand elasticity. Since our estimate of $\varepsilon^{P D}$ is not precise, imprecision in the scale effects cause imprecise estimates of $\hat{\varepsilon}^{L D}=-2.9(S E=6.7)$. Importantly, the incidence results with more elastic labor demand do not imply a small share of the burden on firm owners; the parameters consistent with a highly elastic labor demand curve also imply large shifts in labor demand.

Overall, these results in Table 7 show that workers do not bear $100 \%$ of state corporate taxes. Landowners often bear some of the increase in wages, which many empirical analyses of corporate tax incidence attribute as gains to workers. The incidence on firm owners in Columns (1) through (4) as well as for a wide variety of reasonable calibration values is statistically significant and economically important. The bottom line of these results is that firm owners bear a substantial burden of the incidence of U.S. state corporate taxes.

\footnotetext{
${ }^{40}$ We consider limiting cases where one actor bears all of the incidence in Appendix C.3. Workers bear 0\% of the incidence when $\sigma_{W}=0$ and landowners bear $0 \%$ of the incidence when $\eta \rightarrow \infty$. By contrast, firm owners may receive $0 \%$ of the incidence even when $\sigma_{F}>0$. In addition, note that landowner and worker versions of Figure 5 are Appendix Figures A18 and A19, respectively. Finally, Figure A20 shows the firm owner figure using employment-based estimates rather than population-based estimates (i.e., using the estimates in Table A9 instead of A6). The results are similar.
} 


\subsection{Discussion of Additional Considerations}

It is important to note that we document average effects, but there is likely heterogeneity in the effects of corporate tax cuts across regions. ${ }^{41}$ For instance, housing markets vary considerably, which affects the incidence of local corporate tax cuts. Our results should be interpreted as national averages, but location-specific considerations can alter local incidence and optimal local corporate tax policy.

The close relationship between the number of establishments and local population is notable. Future work analyzing the role that co-location of firms and entrepreneurs is worth pursuing.

Our baseline approach did not account for the effects of business tax cuts on tax revenue and government spending. In Appendix F, we provide a detailed, quantitative assessment of incidence that accounts for changes in government spending. We adjust the model to allow workers and firms to benefit from government spending and use estimates from Suárez Serrato and Wingender (2011) to quantify how much incorporating these effects changes our incidence results. We evaluate three cases for how government spending declines: cutting services only, infrastructure only, or both in proportion to state finance spending. Since governments spend more on services than they do on infrastructure, workers' government amenities decline disproportionately more. Accounting for these worker impacts increases the share of benefits firm owners enjoy overall. In the infrastructure-only case, spending cuts hurt firm owners, but they also hurt workers because lower infrastructure reduces productivity and negative productivity shocks hurt workers. Consequently, accounting for government spending changes reinforces the conclusion that firm owners enjoy a substantial portion of the benefit of business tax cuts. Finally, changes in our main results due to this consideration are limited because the revenue effects of a business tax cut (and resulting spending declines) can be limited due to low revenue shares from state corporate taxes as well as fiscal externalities from impacts on larger sales and personal income tax bases. ${ }^{42}$

\section{Tax Revenue and Policy Implications}

Since the magnitude of these revenue effects is important, we analyze expected changes in tax revenue following a state corporate tax cut and characterize the revenue-maximizing tax rate. Firm mobility is an often-cited justification in proposals to lower states' corporate tax rates. In this section, we explore whether firm mobility is a compelling reason to lower or eliminate state corporate taxes. Additionally, we consider how interactions with other state tax revenues, such as personal income taxes, and with features of apportionment rules affect this conclusion.

Consider first the effect of a corporate tax cut solely on the corporate tax income revenues of a given state. In Appendix D, we show that the corporate-tax-revenue-maximizing corporate tax rate

\footnotetext{
${ }^{41}$ For example, places like Houston, Texas, which have real estate markets that can accommodate large inflows of people without large housing costs increases, have more elastic effective labor supply curves $\varepsilon^{L S}$. Housing supply curves may also differ across location as the housing expenditure share $\alpha$ varies across location. Corporate tax cuts in these places will tend to result in more adjustment in population than in prices. Consequently, location decision distortions, and thus efficiency costs, are likely to be larger in these areas. This statement applies in the absence of other market failures affecting these areas. In terms of equity, lower adjustment in prices means less incidence on workers. Lower adjustments in prices, however, benefit firm owners since labor costs will not increase by as much as they would in places like San Francisco, California, where housing markets are less elastic. Based on this reasoning, the efficiency and equity consequences of corporate tax cuts will be bigger in places like Houston. In locations like San Francisco, the efficiency costs are likely less stark and corporate tax cuts will result in more non-firm incidence on landowners.

${ }^{42}$ Additionally, in terms of externalities, our model abstracts from wage multiplier effects (Tolley, 1974). Furthermore, due to income taxes, workers receive only a portion of the benefit of higher wages. Abstracting from this consideration implicitly assumes that income taxes provide benefits that are valued at cost in terms of government service provision.
} 
equals the following expression.

$$
\tau_{c}^{*}=\frac{1}{\dot{\bar{\pi}}_{c}+\dot{E}_{c}}\left(1-t_{f e d}\right)
$$

This expression shows that the revenue-maximizing corporate tax rate is inversely related to the effects of corporate tax changes on average establishment profitability and on establishment mobility. Recall that $\dot{\bar{\pi}}_{c}$ denotes average percentage change in after-tax profit, $\dot{E}_{c}$ is the percentage change in establishments in location $c$, and $t_{f e d}$ is the federal corporate tax rate. Based on our estimates of average national parameters, we find that establishment mobility on its own does not justify a low maximal tax rate. In particular, using estimates from Table 7, Column (1), we calculate the maximal tax rate and report the results in Table 8 for selected states. This rate is roughly $32 \%$, substantially above current state corporate tax rates. ${ }^{43}$

However, this calculation does not account for fiscal externalities on other aspects of local public finance that are quantitatively important. For instance, one can show that the total state tax revenue maximizing corporate rate equals the following expression:

$$
\tau_{c}^{* *}=\frac{1}{\dot{\bar{\pi}}_{c}+\dot{E}_{c}+\left(\text { revshare }_{c}^{\text {pers }} / \text { revshare }_{c}^{C}\right)\left(\dot{w}_{c}+\dot{N}_{c}\right)}\left(1-t_{f e d}\right),
$$

where revshare ${ }_{c}^{\text {pers }} /$ revshare $_{c}^{C}$ is the relative share of personal tax revenues and corporate tax revenues. This additional term in the denominator reflects revenue externalities from reduced personal income and sales tax revenue due to worker mobility. Since state personal income and state sales tax revenue comprise a larger share of total tax revenue for almost all states, including this extra term in the denominator lowers the revenue-maximizing corporate tax rate all else equal (e.g., the amenity and productivity effects of government spending). We present these revenue shares for a few selected states in Table 8 and provide these statistics for all states in Appendix D. In California, for example, the personal to corporate revenue share in 2010 was $9.2 \%$. Based on national averages of the percentage change in wages $\dot{\hat{w}}_{c}$ and the percentage change in population $\dot{\hat{N}}_{c}$, the revenue-maximizing rate absent fiscal externalities $\tau_{C A}^{*}=32.0 \%$ exceed the revenue-maximizing rate with fiscal externalities $\tau_{C A}^{* *}=$ $3.7 \%$ by a factor of 9 . This difference in revenue-maximizing rates is smaller in states that raise a relatively smaller share of their revenue from personal income and sales taxes.

In addition to fiscal externalities, there are also important and interesting complexities in determining the revenue-maximizing rate due to apportionment. The relevant rate that incorporates apportionment is $\frac{\tau_{c}^{* *}}{1-\theta_{s}^{x}}$. This rate scales up $\tau_{c}^{* *}$ since only a portion of state corporate taxes, namely the payroll and property components, distort location decisions. Since sales apportionment is destination-based, it does not distort location decisions (absent trade costs) and allows for higher revenue-maximizing tax rates. Reducing the location dependence of corporate taxes increases the revenue-maximizing rate since it alleviates the costs of fiscal externalities mentioned above. We present calculations of $\frac{\tau_{c}^{* *}}{1-\theta_{s}^{x}}$ for a few selected states in the last Column of Table 8. A comparison of New Mexico and Arizona illustrates the importance of apportionment considerations. As shown in Table 8, New Mexico's statutory corporate tax rate $\tau_{N M}^{c}$ was $7.6 \%$ in 2010 and Arizona's rate $\tau_{A Z}^{c}$ was $7.0 \%$. New Mexico used an

\footnotetext{
${ }^{43}$ Note that this measure varies slightly across states due to differences in state size. A corporate tax cut in large states like California affects more local areas simultaneously, which slightly diminishes the effect of a tax cut to an extent that depends on the state's establishment share (as shown in Appendix D). We adjust our estimates of the percent change in local establishments $\dot{E}_{c}$ by state to account for this simultaneous impact based on state size. The first corporate-revenue-maximizing tax rate, $\tau_{s}^{*}=\frac{1}{\dot{E}_{s}+\dot{\pi}_{c}}\left(1-t_{f e d}\right)$, is a function of this state-size-adjusted establishment response $\dot{E}_{s}$ and the estimate of national average change in profits $\dot{\pi}_{c}$ from Table 7, Column (1).
} 
equal-weighted apportionment formula with $\theta_{N M}^{w}=\theta_{N M}^{\rho}=\theta_{N M}^{x}=33 \%$ in 2010. Arizona, however, put much more weight on sales as $\theta_{A Z}^{x}=80 \%$. As a result, New Mexico's revenue-maximizing rate was roughly four times smaller than that of Arizona despite only a 0.6 percentage point difference in

their statutory corporate rates. In particular, $\frac{\tau_{N M}^{* *}}{1-\theta_{N M}^{x}}=2.1 \%$ and $\frac{\tau_{A Z}^{* *}}{1-\theta_{A Z}^{x}}=8.3 \%$. Perhaps for this reason, we have seen more states shift more weight towards the sales factor $\theta_{s}^{x}$ as shown in Figure 3. Overall, other tax factors, including apportionment formulae and differences in the reliance on other sources of tax revenue, account for the large geographic variation in the total revenue-maximizing state corporate tax rates that range from $0.7 \%$ to $36.1 \%$.

\section{Conclusion}

This paper evaluates the welfare effects of cutting corporate income taxes on business owners, workers, and landowners. This question is important for three reasons. First, the conventional view among many economists and policy makers - that workers fully bear the incidence of corporate taxes in an open economy - is based on fairly abstract arguments and less than fully convincing evidence. Second, evaluating the welfare effect of corporate taxes also highlights efficiency consequences of corporate taxation and has direct implications for revenue-maximizing rates. Third, the welfare impacts of corporate tax cuts closely relate to the welfare impacts of a broad class of local economic development policies that aim to entice businesses to locate in their jurisdictions.

We estimate the incidence of corporate taxes in four steps. First, we develop a local labor markets framework with heterogeneously productive and monopolistically competitive firms. This framework not only enables us to characterize the incidence on workers, firms, and landowners in terms of a few parameters, but it can also be used to answer other important questions, such as the welfare impacts of business location subsidies for individual companies, optimal local tax policy, and the incidence of technological change. Second, we use state corporate tax apportionment rules and matched establishment-firm data to construct a new measure of the effective tax rate that businesses pay at the local level. Third, we relate changes in these effective rates to local outcomes and show that a $1 \%$ cut in business taxes increases establishment growth by 3 to $4 \%$ over a ten-year period. Fourth, and most importantly, we combine these three components - a new framework, a new measure of business taxes, and new reduced form effects of business taxes - to estimate the incidence of corporate taxes on firm owners, workers, and landowners.

Three types of evidence support the validity of our incidence estimates. First, we show that our reduced-form incidence estimates are robust to controlling for trends economic conditions, local labor demand shocks, government spending changes, and a wide variety of other tax policy changes. Second, estimates using external business tax changes from other states imply similar incidence estimates. Third, the structural elasticities that rationalize our estimates are similar to those in the literature.

We unambiguously reject the view that workers bear $100 \%$ of the incidence of state corporate tax cuts and find that firm owners bear a substantial portion of the incidence. The intuition for this result is that non-tax considerations, namely heterogeneous productivity, can limit the mobility of businesses. If a business is especially productive in a given location, small changes in taxes won't have large enough impacts on profitability to make changing locations attractive. For instance, technology firms may still find it optimal to locate in Silicon Valley, even if corporate tax rates were increased modestly. Consequently, firm owners bear a substantial portion of the incidence of corporate tax changes, a result that starkly contrasts with the conventional wisdom. 


\section{References}

Albouy, David. 2008. "Are Big Cities Bad Places to Live? Estimating Quality of Life across Metropolitan Areas." National Bureau of Economic Research Working Paper 14472.

Albouy, David, and Bryan Stuart. 2013. "Urban Population and Amenities." University of Michigan Working Paper.

Albouy, David, and Gabriel Ehrlich. 2012. "Metropolitan Land Values and Housing Productivity." National Bureau of Economic Research Working Paper 18110.

Arkolakis, Costas, Natalia Ramondo, Andrés Rodríguez-Clare, and Stephen Yeaple. 2013. "Innovation and Production in the Global Economy." National Bureau of Economic Research Working Paper 18972.

Arulampalam, Wiji, Michael P. Devereux, and Giorgia Maffini. 2012. "The direct incidence of corporate income tax on wages." European Economic Review, 56(6): 1038 - 1054.

Auerbach, Alan J. 2002. "Taxation and Corporate Financial Policy." In Handbook of Public Economics. Vol. 3.1 ed., , ed. Alan J. Auerbach and Martin Feldstein, Chapter 19. Elsevier.

Auerbach, Alan J. 2006. "Who Bears the Corporate Tax? A Review of What We Know." In Tax Policy and the Economy. Vol. 20, , ed. James Poterba, 1-40. The MIT Press.

Autor, David H., David Dorn, and Gordon H. Hanson. 2013. "The China Syndrome: Local Labor Market Effects of Import Competition in the United States." American Economic Review, 103(6): 2121-68.

Bartik, Timothy J. 1985. "Business Location Decisions in the United States: Estimates of the Effects of Unionization, Taxes, and Other Characteristics of States." Journal of Business Es Economic Statistics, 3(1): 14-22.

Bartik, Timothy J. 1991. Who Benefits from State and Local Economic Development Policies? W.E. Upjohn Institute for Employment Research.

Basker, Emek. 2005. "Selling a Cheaper Mousetrap: Wal-Mart's Effect on Retail Prices." Journal of Urban Economics, 58(2): 203-29.

Basu, Susanto. 1995. "Intermediate Goods and Business Cycles: Implications for Productivity and Welfare." The American Economic Review, 85(3): pp. 512-531.

Beraja, Martin, Erik Hurst, and Juan Ospina. 2016. "The Aggregate Implications of Regional Business Cycles." National Bureau of Economic Research Working Paper 21956.

Bernthal, Jamie, Dana Gavrila, Katie Schumacher, Shane Spencer, and Katherine Sydor. 2012. "Single Sales-Factor Corporate Income Tax Apportionment: Evaluating the Impact in Wisconsin." The Wisconsin Department of Revenue.

Bradford, David F. 1978. "Factor Prices May Be Constant But Factor Returns Are Not." Economics Letters, 1(3): 199-203.

Busso, Matias, Jesse Gregory, and Patrick Kline. 2013. "Assessing the Incidence and Efficiency of a Prominent Place Based Policy." American Economic Review, 103(2): 897-947.

Card, David. 2011. "The Return of the Firm to Labor Economics." U.C. Berkeley.

Carlton, Dennis W. 1983. "The Location and Employment Choices of New Firms." The Review of Economics and Statistics, 75(3).

CCH. 1980-2010. State Tax Handbook 1980-2010. CCH Incorporated State Tax Handbook, Toolkit Media Group.

Chamberlain, Gary. 1984. "Chapter 22 Panel data." In . Vol. 2 of Handbook of Econometrics, 1247 - 1318. Elsevier. 
Chirinko, Robert S., and Daniel J. Wilson. 2008. "State Investment Tax Incentives: A Zero-Sum Game?" Journal of Public Economics, 92(12).

Clausing, Kimberly. 2013. "Who Pays The Corporate Tax In A Global Economy?" National Tax Journal, 66(1): 151-84.

Coibion, Olivier, Yuriy Gorodnichenko, and Johannes Wieland. 2012. "The Optimal Inflation Rate in New Keynesian Models: Should Central Banks Raise Their Inflation Targets in Light of the Zero Lower Bound?" The Review of Economic Studies, 79(4): 1371-1406.

Cronin, Julie Anne, Emily Y. Lin, Laura Power, and Michael Cooper. 2013. "Distributing The Corporate Income Tax: Revised U.S. Treasury Methodology." National Tax Journal, 66(1): 239-62.

CSG. 1976-2011. Book of the States. Council of State Governments.

Cullen, Zoe, and Juan Carlos Suárez Serrato. 2014. "State Corporate Taxes, Firm Mobility, and Innovation Productivity: Evidence from US patent data." Stanford University and Duke University Working Paper.

Desai, Mihir A., C. Fritz Foley, and James R. Hines Jr. 2007. "Labor and Capital Shares of the Corporate Tax Burden: International Evidence." Who Pays the Corporate Tax in an Open Economy?

Devereux, Michael P., and Rachel Griffith. 1998. "Taxes and the location of production: evidence from a panel of US multinationals." Journal of Public Economics, 68(3): 335 - 367.

Devereux, Michael P, and Simon Loretz. 2007. "The Effects of EU Formula Apportionment on Corporate Tax Revenues." Oxford University Centre for Business Taxation working paper.

Diamond, Rebecca. 2012. "The Determinants and Welfare Implications of US Workers' Diverging Location Choices by Skill: 1980-2000." Harvard University Job Market Paper.

Duranton, Gilles, Laurent Gobillon, and Henry G. Overman. 2011. "Assessing the Effects of Local Taxation using Microgeographic Data." The Economic Journal, 121(555): 1017-1046.

Fajgelbaum, Pablo D., Eduardo Morales, Juan Carlos Suárez Serrato, and Owen M. Zidar. 2015. "State Taxes and Spatial Misallocation." National Bureau of Economic Research Working Paper 21760.

Feldstein, Martin, and Marian Vaillant. 1998. "Can State Taxes Redistribute Income?" Journal of Public Economics, 68(3): 369-396.

Fuest, Clemens, Andreas Peichl, and Sebastian Siegloch. 2013. "Do Higher Corporate Taxes Reduce Wages? Micro Evidence from Germany." Institute for the Study of Labor Discussion Paper.

Fullerton, Don, and Gilbert E. Metcalf. 2002. "Tax Incidence." In Handbook of Public Economics. Vol. 4, , ed. Alan J. Auerbach and Martin Feldstein, Chapter 26. Elsevier.

Gentry, William M., and R. Glenn Hubbard. 2000. "Tax Policy and Entrepreneurial Entry." American Economic Review, 90(2): 283-287.

Glaeser, Edward L. 2008. Cities, Agglomeration, and Spatial Equilibrium. Oxford University Press.

Glaeser, Edward L. 2012. "Urban Public Finance." National Bureau of Economic Research Working Paper 18244.

Glaeser, Edward L., and Joseph Gyourko. 2005. "Urban Decline and Durable Housing." Journal of Political Economy, 113(2): pp. 345-000.

Goolsbee, Austan, and Edward L. Maydew. 2000. "Coveting thy neighbor's manufacturing: the dilemma of state income apportionment." Journal of Public Economics, 75(1): 125 - 143.

Gordon, Roger H., and James R. Hines. 2002. "International taxation." In Handbook of Public Economics. Vol. 4, , ed. Alan J. Auerbach and Martin Feldstein, 1935 - 1995. Elsevier. 
Gordon, Roger H., and John Douglas Wilson. 1986. "An Examination of Multijurisdictional Corporate Income Taxation under Formula Apportionment." Econometrica, 54(6): 1357-73.

Gravelle, Jane, and Kent Smetters. 2006. "Does the Open Economy Assumption Really Mean That Labor Bears the Burden of a Capital Income Tax?" The B.E. Journal of Economic Analysis \&6 Policy, 6(1): 1-44.

Gravelle, Jennifer. 2011. "Corporate Tax Incidence: Corporate Tax Incidence: A Review of Empirical Estimates and Analysis." Congressional Budget Office.

Gravelle, Jennifer C. 2010. "Corporate Tax Incidence: Review of General Equilibrium Estimates and Analysis." Congressional Budget Office Working Paper 2010-03.

Greenstone, Michael, and Enrico Moretti. 2004. "Bidding for Industrial Plants: Does Winning a 'Million Dollar Plant' Increase Welfare?" MIT Department of Economics Working Paper 04-39.

Gyourko, Joseph, and Joseph Tracy. 1989. "The Importance of Local Fiscal Conditions in Analyzing Local Labor Markets." Journal of Political Economy, 97(5): 1208-31.

Hall, Robert E., and Charles I. Jones. 1999. "Why do Some Countries Produce So Much More Output Per Worker than Others?" The Quarterly Journal of Economics, 114(1): 83-116.

Hamermesh, Daniel. 1993. Labor Demand. Princeton University Press.

Harberger, Arnold C. 1962. "The Incidence of the Corporation Income Tax." Journal of Political Economy, 70(3): pp. 215-240.

Hassett, Kevin A., and Aparna Mathur. 2015. "A spatial model of corporate tax incidence." Applied Economics, 47(13): 1350-1365.

Haughwout, Andrew F., and Robert P. Inman. 2001. "Fiscal policies in open cities with firms and households." Regional Science and Urban Economics, 31(2-3): 147 - 180.

Head, K., and T. Mayer. 2013. "Gravity Equations: Workhorse,Toolkit, and Cookbook." Handbook of International Economics Vol. 4.

Heider, Florian, and Alexander Ljungqvist. 2014. "As Certain as Debt and Taxes: Estimating the Tax Sensitivity of Leverage from Exogenous State Tax Changes." Journal of Financial Economics.

Helms, L. Jay. 1985. "The Effect of State and Local Taxes on Economic Growth: A Time SeriesCross Section Approach." The Review of Economics and Statistics, 67(4): pp. 574-582.

Hendren, Nathaniel. 2015. "The Policy Elasticity." Tax Policy and the Economy, Volume 30. University of Chicago Press.

Hines, James. 2009. "Income Misattribution under Formula Apportionment." NBER working paper 15185.

Hines, James R. 1997. "Altered States: Taxes and the Location of Foreign Direct Investment in America." National Bureau of Economic Research Working Paper 4397.

Holmes, Thomas J. 1998. "The Effect of State Policies on the Location of Manufacturing: Evidence from State Borders." Journal of Political Economy, 106(4): pp. 667-705.

Hopenhayn, Hugo A. 1992. "Entry, Exit, and Firm Dynamics in Long Run Equilibrium." Econometrica, 60(5): pp. 1127-1150.

Kline, Patrick. 2010. "Place Based Policies, Heterogeneity, and Agglomeration." American Economic Review, 100(2): 383-87.

Kline, Patrick, and Enrico Moretti. 2013. "People, Places, and Public Policy: Some Simple Welfare Economics of Local Economic Development Programs." U.C. Berkeley Working Paper. 
Kline, Patrick, and Enrico Moretti. 2014. "Local Economic Development, Agglomeration Economies and the Big Push: 100 Years of Evidence from the Tennessee Valley Authority." Quarterly Journal of Economics.

Kotlikoff, Laurence J., and Lawrence H. Summers. 1987. "Tax Incidence." In Handbook of Public Economics. Vol. 2, , ed. Alan J. Auerbach and Martin Feldstein, Chapter 16. Elsevier.

Krugman, Paul R. 1979. "Increasing returns, monopolistic competition, and international trade." Journal of International Economics, 9(4): 469 - 479.

Levchenko, Andrei A., and Jing Zhang. 2012. "Ricardian Productivity Differences and the Gains from Trade." Research Seminar in International Economics, University of Michigan Working Papers 633.

Liu, Li, and Rosanne Altshuler. 2013. "Measuring the Burden of the Corporate Income Tax Under Imperfect Competition." National Tax Journal, 66(1): 215-238.

McFadden, Daniel. 1978. "Modeling the Choice of Residential Location." In Spatial Interaction Theory and Planning Models. , ed. Karlqvist, Lundqvist, Snickars and Weibull. Amsterdam: North Holland.

McLure Jr., Charles E. 1977. "State Corporate Income Tax: Lambs in Wolves' Clothing?" Office of Tax Analysis Paper 25.

McLure Jr., Charles E. 1982. "The Elusive Incidence of the Corporate Income Tax: The State Case." National Bureau of Economic Research Working Paper 616.

Melitz, Marc J. 2003. "The Impact of Trade on Intra-Industry Reallocations and Aggregate Industry Productivity." Econometrica, 71(6): pp. 1695-1725.

Mian, Atif, and Amir Sufi. 2016. "What Explains the 2007-2009 Drop in Employment?" Econometrica.

Moretti, Enrico. 2010. "Local Multipliers." American Economic Review, 100(2): 373-77.

Moretti, Enrico. 2011. "Local Labor Markets." In Handbook of Labor Economics. Vol. 4, , ed. O. Ashenfelter and D. Card, Chapter 14, 1237-1313. Elsevier.

Moretti, Enrico. 2013. "Real Wage Inequality." American Economic Journal: Applied Economics, $5(1): 65-103$.

Newman, Robert J. 1983. "Industry Migration and Growth in the South." The Review of Economics and Statistics, 65(1): pp. 76-86.

Notowidigdo, Matthew J. 2013. "The Incidence of Local Labor Demand Shocks." University of Chicago Booth School of Business.

Papke, Leslie E. 1987. "Subnational Taxation and Capital Mobility: Estimates of Tax-Price Elasticities." National Tax Journal, 40(2).

Papke, Leslie E. 1991. "Interstate Business Tax Differentials and New Firm Location: Evidence from Panel Data." Journal of Public Economics, 45(1): 47 - 68.

Rathelot, Roland, and Patrick Sillard. 2008. "The Importance of Local Corporate Taxes in Business Location Decisions: Evidence from French Micro Data." The Economic Journal, 118.

Roback, Jennifer. 1982. "Wages, Rents, and the Quality of Life." Journal of Political Economy, 90(6): 1257-78.

Rosen, Sherwin. 1979. "Wage-Based Indexes of Urban Quality of Life." In Current Issues in Urban Economics., ed. Mahlon R. Straszheim Peter M. Mieszkowski. Johns Hopkins University Press.

Rothenberg, Alexander D. 2012. "Transport Infrastructure and Firm Location Choice in Equilibrium: Evidence from Indonesia's Highways." The RAND Corporation Working Paper. 
Ruggles, Steven, et al. 2010. "Integrated Public Use Microdata Series: Version 5.0." Minneapolis: University of Minnesota [Machine-readable database].

Saez, Emmanuel, and Stefanie Stantcheva. 2013. "Generalized Social Marginal Welfare Weights for Optimal Tax Theory." National Bureau of Economic Research Working Paper 18835.

Scheuer, Florian. 2014. "Entrepreneurial Taxation with Endogenous Entry." American Economic Journal: Economic Policy, 6(2): 126-63.

Seegert, Nathan. 2012. "Optimal Taxation with Volatility: A Theoretical and Empirical Decomposition." University of Michigan Job Market Paper.

Siegloch, Sebastian. 2014. "Employment Effects of Local Business Taxes." Annual Conference 2014 (Hamburg): Evidence-based Economic Policy.

Suárez Serrato, Juan Carlos, and Philippe Wingender. 2011. "Estimating the Incidence of Government Spending." U.C. Berkeley and International Monetary Fund Working Paper.

Syverson, Chad. 2011. "What Determines Productivity?" Journal of Economic Literature, 49(2): 326-65.

Tolley, George S. 1974. "The welfare economics of city bigness." Journal of Urban Economics, 1(3): $324-345$.

Topel, Robert H. 1986. "Local Labor Markets." Journal of Political Economy, 94(3): S111-43.

Train, Kenneth. 2009. Discrete Choice Methods with Simulation. . 2 ed., Cambridge University Press.

Wilson, Daniel J. 2009. "Beggar Thy Neighbor? The In-State, Out-of-State, and Aggregate Effects of R\&D Tax Credits." Review of Economics and Statistics, 91(2): 431-436.

Yagan, Danny. 2015. "Capital Tax Reform and the Real Economy: The Effects of the 2003 Dividend Tax Cut." National Bureau of Economic Research Working Paper 21003.

Zidar, Owen M. 2014. "Tax Cuts for Whom? Heterogeneous Effects of Income Tax Changes on Growth and Employment." University of Chicago Booth School of Business. 
Table 3: Summary Statistics

\begin{tabular}{|c|c|c|c|c|c|}
\hline Variable & Mean & S.D. & Min & Max & $\mathrm{N}$ \\
\hline \multicolumn{6}{|l|}{ Annual Outcome Data from BEA and CBP } \\
\hline Year & 1995 & 8.9 & 1980 & 2010 & 15190 \\
\hline Log Population: $\ln N_{c, t}$ & 13.8 & 1.1 & 10.9 & 16.1 & 15190 \\
\hline Log Employment: $\ln L_{c, t}$ & 13.2 & 1.2 & 9.4 & 15.6 & 15190 \\
\hline Log Establishments: $\ln E_{c, t}$ & 10.0 & 1.2 & 6.5 & 12.4 & 15190 \\
\hline \multicolumn{6}{|c|}{ Annual Data on Apportionment Rules and Corporate, Personal, and Business Tax Rates } \\
\hline \multicolumn{6}{|c|}{ State Corporate Tax Apportionment Parameters } \\
\hline Payroll Apportionment Weight: $\theta_{s, t}^{w}$ & 22.7 & 11.6 & 0.0 & 33.3 & 15190 \\
\hline Property Apportionment Weight: $\theta_{s, t}^{\rho}$ & 22.8 & 11.6 & 0.0 & 33.3 & 15190 \\
\hline Sales Apportionment Weight: $\theta_{s, t}^{x}$ & 54.5 & 23.2 & 25 & 100 & 15190 \\
\hline \multicolumn{6}{|l|}{ Corporate Income } \\
\hline Rate: $\tau_{s, t}^{c}$ & 6.6 & 3.0 & 0.0 & 12.3 & 15190 \\
\hline$\%$ Change in Net-of-Rate: $\Delta \ln \left(1-\tau^{c}\right)_{s, t, t-1}$ & -0.01 & 0.4 & -5.4 & 3.8 & 15190 \\
\hline \multicolumn{6}{|l|}{ Personal Income } \\
\hline Effective Rate: $\tau_{s, t}^{i}$ & 2.6 & 1.7 & 0.0 & 7.4 & 15190 \\
\hline$\%$ Change in Net-of-Rate: $\Delta \ln \left(1-\tau^{i}\right)_{s, t, t-1}$ & 0.03 & 0.2 & -3.3 & 2.5 & 15190 \\
\hline \multicolumn{6}{|l|}{ Business Income } \\
\hline Rate: $\tau_{c, t}^{b}$ & 3.1 & 1.1 & 0.3 & 5.4 & 15190 \\
\hline \% Change in Net-of-Rate: $\Delta \ln \left(1-\tau^{b}\right)_{c, t, t-1}$ & -0.01 & 0.2 & -1.8 & 1.2 & 15190 \\
\hline \multicolumn{6}{|l|}{ Decadal Data } \\
\hline Year & 2000 & 8.2 & 1990 & 2010 & 1470 \\
\hline$\%$ Change in Population: $\Delta \ln N_{c, t, t-10}$ & 11.2 & 10.4 & -16.6 & 76.1 & 1470 \\
\hline$\%$ Change in Establishments: $\Delta \ln E_{c, t, t-10}$ & 15.2 & 16.5 & -23 & 126.2 & 1470 \\
\hline$\%$ Change in Adjusted Wages: $\Delta \ln w_{c, t, t-10}$ & -2.8 & 7.2 & -31.2 & 14.9 & 1470 \\
\hline$\%$ Change in Adjusted Rents: $\Delta \ln r_{c, t, t-10}$ & 8.5 & 12.0 & -41.4 & 43.4 & 1470 \\
\hline$\%$ Change in Net-of-Corp.-Rate: $\Delta \ln \left(1-\tau^{c}\right)_{s, t, t-10}$ & -0.1 & 1.1 & -5.4 & 4.5 & 1470 \\
\hline$\%$ Change in Net-of-Pers.-Rate: $\Delta \ln \left(1-\tau^{i}\right)_{s, t, t-10}$ & -1.3 & 1.1 & -5.3 & 1.3 & 1470 \\
\hline$\%$ Change in Net-of-Bus.-Rate: $\Delta \ln \left(1-\tau^{b}\right)_{c, t, t-10}$ & -0.8 & 0.6 & -2.8 & 1.3 & 1470 \\
\hline$\%$ Change in Gov. Expend./Capita: $\Delta \ln G_{c, t, t-10}$ & 0.0 & 0.6 & -13.3 & 11.6 & 1470 \\
\hline Bartik Shock: Bartik $c, t, t-10$ & 7.8 & 4.8 & -15.2 & 26.0 & 1470 \\
\hline
\end{tabular}

Sources: BEA, CBP, Zidar (2014), Suárez Serrato and Wingender (2011). Corporate tax sources in Section 4. 
Table 4: Effects of Business Tax Cuts on Local Economic Activity over 10 Years

\begin{tabular}{|c|c|c|c|c|c|c|}
\hline A. Establishment Growth & $(1)$ & $(2)$ & $(3)$ & $(4)$ & $(5)$ & $(6)$ \\
\hline$\Delta \ln$ Net-of-Business-Tax Rate & $\begin{array}{l}4.07^{* *} \\
(1.82)\end{array}$ & $\begin{array}{l}3.35^{* *} \\
(1.43)\end{array}$ & $\begin{array}{l}4.06^{* *} \\
(1.83)\end{array}$ & $\begin{array}{l}4.14^{* *} \\
(1.80)\end{array}$ & $\begin{array}{l}3.91^{* *} \\
(1.78)\end{array}$ & $\begin{array}{c}3.24^{* *} \\
(1.41)\end{array}$ \\
\hline Bartik & & $\begin{array}{c}0.59^{* * *} \\
(0.19)\end{array}$ & & & & $\begin{array}{c}0.57^{* * *} \\
(0.18)\end{array}$ \\
\hline$\Delta \ln$ Gov Expend/Capita & & & $\begin{array}{l}-0.01 \\
(0.01)\end{array}$ & & & $\begin{array}{c}-0.01 \\
(0.01)\end{array}$ \\
\hline$\Delta$ State ITC & & & & $\begin{array}{l}-0.46 \\
(0.32)\end{array}$ & & $\begin{array}{l}-0.17 \\
(0.30)\end{array}$ \\
\hline Change in Other States' Taxes & & & & & $\begin{array}{c}-4.66^{* * *} \\
(1.60)\end{array}$ & $\begin{array}{c}-4.18^{* * *} \\
(1.43)\end{array}$ \\
\hline Observations & 1,470 & 1,470 & 1,470 & 1,470 & 1,470 & 1,470 \\
\hline R-squared & 0.472 & 0.491 & 0.472 & 0.475 & 0.481 & 0.500 \\
\hline \multirow[t]{2}{*}{ B: Other Outcomes } & \multicolumn{2}{|c|}{ Population Growth } & \multicolumn{2}{|c|}{ Wage Growth } & \multicolumn{2}{|c|}{ Rental Cost Growth } \\
\hline & $(1)$ & $(2)$ & $(1)$ & $(2)$ & $(1)$ & $(2)$ \\
\hline$\Delta \ln$ Net-of-Business-Tax Rate & $\begin{array}{l}4.28^{* *} \\
(1.65)\end{array}$ & $\begin{array}{c}3.74^{* *} \\
(1.48)\end{array}$ & $\begin{array}{c}1.45 \\
(0.94)\end{array}$ & $\begin{array}{c}0.78 \\
(0.82)\end{array}$ & $\begin{array}{c}1.17 \\
(1.44)\end{array}$ & $\begin{array}{c}0.32 \\
(1.37)\end{array}$ \\
\hline Bartik & & $\begin{array}{c}0.44^{* *} \\
(0.19)\end{array}$ & & $\begin{array}{c}0.56^{* * *} \\
(0.08)\end{array}$ & & $\begin{array}{c}0.70^{* *} \\
(0.27)\end{array}$ \\
\hline Observations & 1,470 & 1,470 & 1,470 & 1,470 & 1,470 & 1,470 \\
\hline R-squared & 0.085 & 0.113 & 0.402 & 0.490 & 0.139 & 0.189 \\
\hline
\end{tabular}

Notes: This table shows the effects of local business tax changes over ten years on local establishment growth in panel A and on population growth, wage growth, and rental cost growth in panel B. The data are decade changes from 19801990, 1990-2000, and 2000-2010 for 490 county-groups. See Section 4 for data sources. In panel A, Col (2)-(6) show that the effect of business taxes is robust to controlling for Bartik shocks in Col (2), per capita government spending changes in $\mathrm{Col}(3)$, state investment tax credit changes in Col (4), external tax shocks due to changes in tax rules of other states in Col (5), and all of these controls in Col (6). $\chi^{2}$ tests indicate that the coefficients in Col (1) and Col (2) are not statistically different. Similarly, the negative effect from tax cuts in other states is not statistically different than the positive effect of tax cuts. Panel B provides the results for Col (1) and (2) for three other outcomes. $\chi^{2}$ tests also indicate that the coefficients in Col (1) and Col (2) are not statistically different for each of the outcomes. The full tables similar to panel A for the other three outcomes - population, wages, and rental cost - are provided in Appendix Tables A6, A7, and A8. Non-parametric graphs showing mean outcome changes by business tax change bins are shown for each outcome in Appendix Figures A10, A11, A12, and A13, respectively. All regressions use population as weights and include year fixed effects and dummies for states in the industrial midwest in the 1980s. Table A30 and A31 show results with controls for tax rates and changes an tax rates, respectively, for each of the four reduced-form outcomes. Standard errors clustered by state are in parentheses and ${ }^{* * *} \mathrm{p}<0.01,{ }^{* *} \mathrm{p}<0.05,{ }^{*} \mathrm{p}<0.1$. 
Table 5: Estimates of Economic Incidence Using Reduced-Form Effects

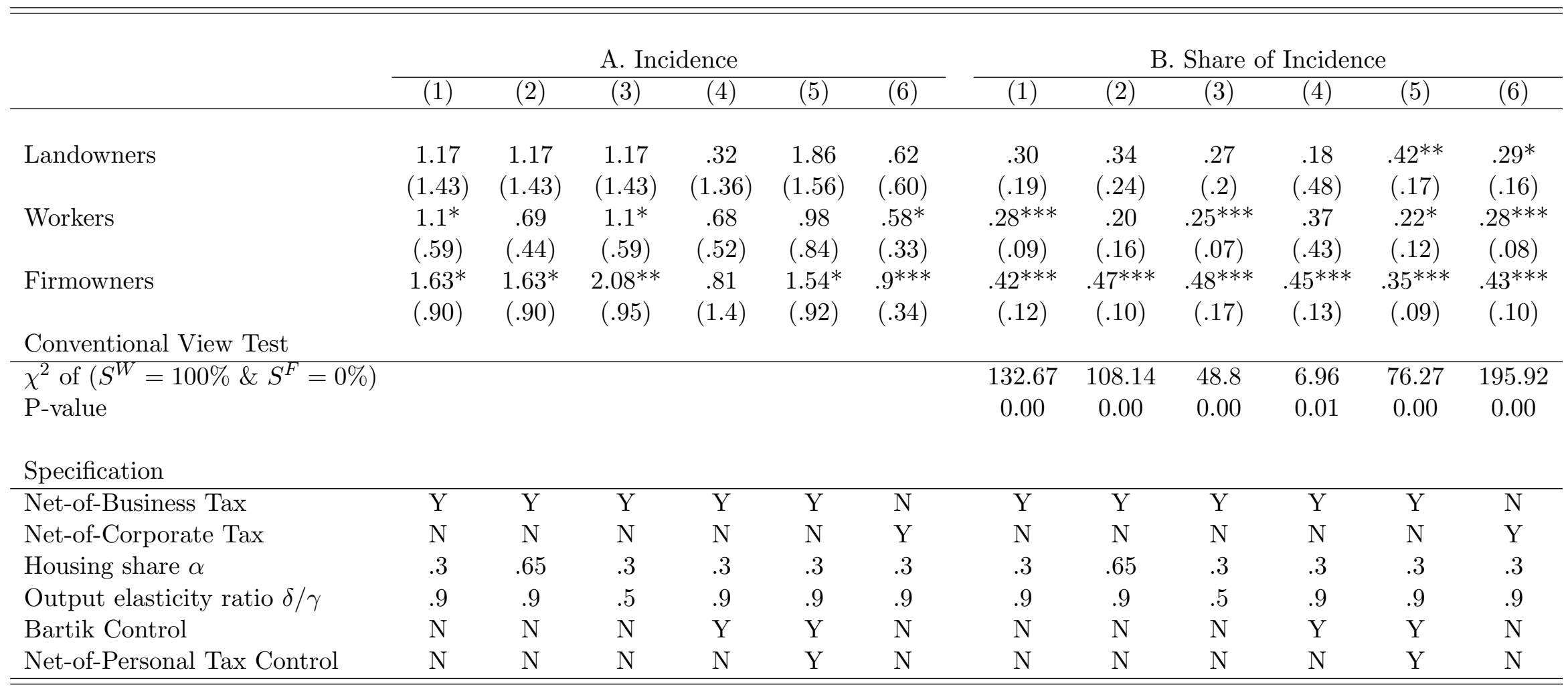

Notes: This table shows the estimates of the economic incidence expressions from Table 1. The data are decade changes from 1980-1990, 1990-2000, and 2000-2010 for 490 county-groups. See Section 4 for data sources. Results were produced by implementing Equation 21 using the specification in Column (1) of Table 4 unless otherwise specified. Columns (2) and (3) use the same specification as Column (1) but with different calibrated values of the expenditure share on housing $\alpha$ and the ratio of output elasticities $\delta / \gamma$. Column (4) controls for Bartik shocks. Column (5) controls for Bartik shocks as well as growth in the net-of-personal tax rate, i.e., $\Delta \ln \left(1-\tau_{c}^{i}\right)$. Column (6) uses the net-of-statutory-corporate tax keep rate, i.e., $\Delta \ln \left(1-\tau_{c}^{c}\right)$ rather than the business keep rate, i.e., $\Delta \ln \left(1-\tau_{c}^{b}\right)$, which is used in Columns (1)-(5). Appendix Table A19 includes many supplemental tax base controls and Appendix Table A20 includes results with additional controls for state political, economic, and fiscal policy conditions. More results using statutory state corporate tax rates are in Appendix Table A21. The conventional view test evaluates the joint hypothesis that the share of incidence for workers equals $100 \%$ and the share for firm owners equals $0 \%$. Note that Columns (4) and (5) use Bartik and net-of-personal taxes as controls but does not use the point estimates for incidence share inference beyond that purpose; Table 7 provides results that use these estimates to discipline our estimates of structural elasticities and resulting incidence share estimates and conventional view tests. Regressions use population as weights and include year fixed effects and dummies for states in the industrial midwest in the 1980s. See Section 4.3 for details on calibration values. Standard errors clustered by state are in parentheses and ${ }^{* * *} \mathrm{p}<0.01,{ }^{* *} \mathrm{p}<0.05,{ }^{*} \mathrm{p}<0.1$. 
Table 6: Minimum Distance Estimates of Structural Parameters

\begin{tabular}{|c|c|c|c|c|c|c|c|}
\hline \multirow[b]{2}{*}{ Calibrated Parameters } & \multicolumn{4}{|c|}{ A. All Shocks } & \multirow[b]{2}{*}{$(5)$} & \multirow[b]{2}{*}{$(6)$} & \multirow[b]{2}{*}{$(7)$} \\
\hline & $(1)$ & $(2)$ & $(3)$ & $(4)$ & & & \\
\hline Output Elasticity $\gamma$ & 0.150 & 0.150 & 0.150 & 0.200 & 0.250 & 0.150 & 0.250 \\
\hline Housing Share $\alpha$ & 0.300 & 0.500 & 0.650 & 0.300 & 0.300 & 0.300 & 0.500 \\
\hline Elasticity of Product & -2.500 & -2.500 & -2.500 & -2.500 & -2.500 & -4.000 & -4.000 \\
\hline \multicolumn{8}{|l|}{ Demand $\varepsilon^{P D}$} \\
\hline \multicolumn{8}{|l|}{ Estimated Parameters } \\
\hline Idiosyncratic Location & $0.277^{* *}$ & $0.271^{* *}$ & $0.233^{* *}$ & $0.321^{*}$ & 0.304 & 0.149 & 0.136 \\
\hline Productivity Disperion $\sigma^{F}$ & $(0.138)$ & $(0.120)$ & $(0.092)$ & $(0.186)$ & $(0.186)$ & $(0.096)$ & $(0.093)$ \\
\hline Idiosyncratic Location & $0.829^{* * *}$ & $0.686^{* * *}$ & $0.621^{* * *}$ & $0.845^{* * *}$ & $0.843^{* * *}$ & $0.839^{* * *}$ & $0.649^{* *}$ \\
\hline Preference Dispersion $\sigma^{W}$ & $(0.282)$ & $(0.260)$ & $(0.230)$ & $(0.294)$ & $(0.295)$ & $(0.294)$ & $(0.253)$ \\
\hline Elasticity of Housing & 0.513 & 2.185 & 1.157 & 1.600 & 0.707 & 1.995 & 2.812 \\
\hline Supply $\eta$ & $(1.417)$ & $(6.206)$ & $(2.661)$ & $(5.065)$ & $(2.301)$ & $(7.320)$ & $(13.688)$ \\
\hline \multirow[t]{2}{*}{ Overid Test (p-value) } & 0.458 & 0.390 & 0.393 & 0.385 & 0.444 & 0.390 & 0.507 \\
\hline & \multicolumn{4}{|c|}{ B. Business Tax Shock } & \multicolumn{3}{|c|}{ C. All Shocks, Estimated $\varepsilon^{P D}$} \\
\hline Calibrated Parameters & $(1)$ & $(2)$ & $(3)$ & $(4)$ & $(5)$ & $(6)$ & $(7)$ \\
\hline Output Elasticity $\gamma$ & 0.150 & 0.150 & 0.250 & 0.150 & 0.150 & 0.150 & 0.250 \\
\hline Housing Share $\alpha$ & 0.300 & 0.650 & 0.300 & 0.300 & 0.300 & 0.650 & 0.300 \\
\hline Elasticity of Product & -2.500 & -2.500 & -2.500 & -4.000 & & imated $\mathrm{Be}$ & \\
\hline Demand $\varepsilon^{P D}$ & & & & & & & \\
\hline \multicolumn{8}{|l|}{ Estimated Parameters } \\
\hline Idiosyncratic Location & $0.119^{*}$ & $0.117^{*}$ & 0.106 & 0.048 & 0.109 & 0.105 & 0.138 \\
\hline Productivity Dispersion $\sigma^{F}$ & $(0.065)$ & $(0.064)$ & $(0.075)$ & $(0.039)$ & $(0.392)$ & $(0.194)$ & $(0.411)$ \\
\hline Idiosyncratic Location & 0.188 & 0.128 & 0.171 & 0.170 & $0.892^{* * *}$ & $0.571^{* *}$ & $0.753^{* * *}$ \\
\hline Preference Dispersion $\sigma^{W}$ & $(0.184)$ & $(0.147)$ & $(0.176)$ & $(0.175)$ & $(0.337)$ & $(0.234)$ & $(0.245)$ \\
\hline Elasticity of Housing & 6.367 & 5.724 & 7.328 & 6.424 & 1.925 & 1.783 & 3.056 \\
\hline Supply $\eta$ & $(15.899)$ & $(13.090)$ & $(20.574)$ & $(16.136)$ & $(8.085)$ & $(6.503)$ & $(25.617)$ \\
\hline Elasticity of Product & & & & & -4.704 & -4.439 & -4.986 \\
\hline Demand $\varepsilon^{P D}$ & & & & & $(11.945)$ & $(6.471)$ & $(12.190)$ \\
\hline Overid Test (p-value) & 0.117 & 0.117 & 0.098 & 0.088 & 0.251 & 0.334 & 0.290 \\
\hline
\end{tabular}

Notes: This table shows the estimated parameters of our model. The data are decade changes from 1980-1990, 19902000, and 2000-2010 for 490 county-groups. See Section 4 for data sources. Panel A presents estimates from models with business tax, personal tax, and Bartik shocks relying on 12 moments to estimate 3 parameters for a variety of assumed values of $\alpha, \gamma$ and $\varepsilon^{P D}$. Panel $\mathrm{B}$ uses only the business tax shock relying on 4 moments to estimate 3 parameters for a variety of assumed values of $\alpha, \gamma$ and $\varepsilon^{P D}$. Panel $\mathrm{C}$ presents estimates from "all shocks" models to estimate 4 parameters, including $\varepsilon^{P D}$, for various calibrated values of $\gamma$ and $\alpha$. See Section 6 for more details on estimation. Regressions use initial population as weights and include 3 year fixed effects and dummies for states in the industrial midwest in the 1980s. Standard errors clustered by state are in parentheses and ${ }^{* * *} \mathrm{p}<0.01,{ }^{* *} \mathrm{p}<0.05,{ }^{*} \mathrm{p}<0.1$. 
Table 7: Estimates of Economic Incidence Using Estimated Structural Parameters

\begin{tabular}{|c|c|c|c|c|c|c|c|c|c|c|}
\hline \multirow[b]{2}{*}{ Calibrated Paramete } & \multicolumn{5}{|c|}{ Incidence } & \multicolumn{5}{|c|}{ Shares of Incidence } \\
\hline & ters & $\begin{array}{c}(2) \\
\text { All Shocks }\end{array}$ & $(3)$ & $\begin{array}{c}(4) \\
\text { Business } \\
\text { Tax }\end{array}$ & $\begin{array}{c}(5) \\
\text { All Shocks } \\
\text { Estimated } \varepsilon^{P D}\end{array}$ & $(1)$ & $\begin{array}{c}(2) \\
\text { All Shocks }\end{array}$ & $(3)$ & $\begin{array}{c}(4) \\
\text { Business } \\
\text { Tax }\end{array}$ & $\begin{array}{c}(5) \\
\text { All Shocks } \\
\text { Estimated } \varepsilon^{P D}\end{array}$ \\
\hline Output Elasticity $\gamma$ & 0.150 & 0.150 & 0.150 & 0.150 & 0.150 & 0.150 & 0.150 & 0.150 & 0.150 & 0.150 \\
\hline Housing Share $\alpha$ & 0.300 & 0.650 & 0.300 & 0.300 & 0.300 & 0.300 & 0.650 & 0.300 & 0.300 & 0.300 \\
\hline $\begin{array}{l}\text { Elasticity of Product } \\
\text { Demand } \varepsilon^{P D}\end{array}$ & -2.500 & -2.500 & -4.000 & -2.500 & $\begin{array}{c}-4.704 \\
(11.945)\end{array}$ & -2.500 & -2.500 & -4.000 & -2.500 & $\begin{array}{c}-4.704 \\
(11.945)\end{array}$ \\
\hline \multicolumn{11}{|c|}{ Estimated Incidence } \\
\hline Wages $\dot{w}$ & $\begin{array}{c}0.944^{* *} \\
(0.408)\end{array}$ & $\begin{array}{l}1.088^{* *} \\
(0.457)\end{array}$ & $\begin{array}{l}0.655^{*} \\
(0.348)\end{array}$ & $\begin{array}{c}0.839 \\
(0.847)\end{array}$ & $\begin{array}{c}0.646 \\
(1.028)\end{array}$ & & & & & \\
\hline Landowners $\dot{r}$ & $\begin{array}{c}1.111 \\
(1.119)\end{array}$ & $\begin{array}{c}0.886 \\
(1.052)\end{array}$ & $\begin{array}{c}0.428 \\
(1.079)\end{array}$ & $\begin{array}{c}0.591 \\
(1.373)\end{array}$ & $\begin{array}{c}0.420 \\
(1.517)\end{array}$ & $\begin{array}{c}0.410 \\
(0.263)\end{array}$ & $\begin{array}{c}0.376 \\
(0.339)\end{array}$ & $\begin{array}{c}0.207 \\
(0.434)\end{array}$ & $\begin{array}{c}0.261 \\
(0.430)\end{array}$ & $\begin{array}{c}0.202 \\
(0.621)\end{array}$ \\
\hline Workers $\dot{w}-\alpha \dot{r}$ & $\begin{array}{c}0.611^{* *} \\
(0.293)\end{array}$ & $\begin{array}{c}0.512 \\
(0.355)\end{array}$ & $\begin{array}{l}0.527^{*} \\
(0.269)\end{array}$ & $\begin{array}{c}0.662 \\
(0.517)\end{array}$ & $\begin{array}{c}0.520 \\
(0.703)\end{array}$ & $\begin{array}{l}0.225^{*} \\
(0.134)\end{array}$ & $\begin{array}{c}0.217 \\
(0.197)\end{array}$ & $\begin{array}{c}0.255 \\
(0.185)\end{array}$ & $\begin{array}{c}0.292^{* *} \\
(0.142)\end{array}$ & $\begin{array}{c}0.250 \\
(0.290)\end{array}$ \\
\hline Firm Owners $\dot{\pi}$ & $\begin{array}{c}0.990 * * * \\
(0.092)\end{array}$ & $\begin{array}{c}0.958^{* * *} \\
(0.103)\end{array}$ & $\begin{array}{c}1.110^{* * *} \\
(0.157)\end{array}$ & $\begin{array}{c}1.014^{* * *} \\
(0.191)\end{array}$ & $\begin{array}{l}1.141 \\
(1.012)\end{array}$ & $\begin{array}{c}0.365^{* *} \\
(0.168)\end{array}$ & $\begin{array}{c}0.407^{* *} \\
(0.164)\end{array}$ & $\begin{array}{l}0.537^{*} \\
(0.297)\end{array}$ & $\begin{array}{c}0.447 \\
(0.392)\end{array}$ & $\begin{array}{c}0.548 \\
(0.734)\end{array}$ \\
\hline Test of Standard View & (p-value) & & & & & 0.000 & 0.000 & 0.000 & 0.000 & 0.026 \\
\hline $\begin{array}{l}\text { Elasticity of Labor } \\
\text { Supply } \varepsilon^{L S}\end{array}$ & $\begin{array}{c}0.780 * * \\
(0.386)\end{array}$ & $\begin{array}{c}0.757 \\
(0.729)\end{array}$ & $\begin{array}{c}0.958 \\
(0.588)\end{array}$ & $\begin{array}{c}4.188 \\
(4.795)\end{array}$ & $\begin{array}{c}0.902 \\
(0.645)\end{array}$ & & & & & \\
\hline $\begin{array}{l}\text { Elasticity of Labor } \\
\text { Demand } \varepsilon^{L D}\end{array}$ & $\begin{array}{c}-1.766^{* * *} \\
(0.269)\end{array}$ & $\begin{array}{c}-1.867^{* * *} \\
(0.252)\end{array}$ & $\begin{array}{c}-2.457^{* * *} \\
(0.646)\end{array}$ & $\begin{array}{c}-2.485^{* * *} \\
(0.692)\end{array}$ & $\begin{array}{l}-2.933 \\
(6.731)\end{array}$ & & & & & \\
\hline
\end{tabular}

NotEs: This table shows structural estimates of economic incidence from our model. The Incidence panel shows the estimates of tax changes from our three minimum distance specifications: using all shocks, only business taxes, and all shocks with estimated $\varepsilon^{P D}$, respectively. See Table 6 for details about the estimation of the related structural models. The Shares of Incidence panel presents the shares of total economic gains to each agent that correspond to each specification. The conventional view test evaluates the joint hypothesis that the share of incidence for workers equals $100 \%$ and the share for firm owners equals $0 \%$. Panel (b) presents the associated structural elasticities. Standard errors clustered by state are in parentheses and ${ }^{* * *} \mathrm{p}<0.01,{ }^{* *} \mathrm{p}<0.05,{ }^{*} \mathrm{p}<0.1$. 
Table 8: Revenue-Maximizing Corporate Tax Rates for Selected States

\begin{tabular}{|c|c|c|c|c|c|c|c|}
\hline \multirow[b]{2}{*}{ State } & \multirow{2}{*}{$\begin{array}{l}\text { Establishment } \\
\text { Share } E_{s}\end{array}$} & \multirow{2}{*}{$\begin{array}{l}\text { Revenue Ratio } \\
\operatorname{rev}_{s}^{\text {pers }} / \mathrm{rev}_{s}^{C}\end{array}$} & \multirow{2}{*}{$\begin{array}{l}\text { Sales Apport. } \\
\text { Weight } \theta_{s}^{x}\end{array}$} & \multirow{2}{*}{$\begin{array}{c}\text { Corporate } \\
\text { Tax Rate } \tau_{s}\end{array}$} & \multicolumn{3}{|c|}{ Revenue Max. Corp. Rate } \\
\hline & & & & & $\tau_{s}^{*}$ & $\tau_{s}^{* *}$ & $\tau_{s}^{* *} /\left(1-\theta_{s}^{x}\right)$ \\
\hline Kansas & 1.0 & 16.0 & 33 & 7.1 & 30.6 & 2.2 & 3.4 \\
\hline New Mexico & 0.6 & 26.1 & 33 & 7.6 & 32.0 & 1.4 & 2.1 \\
\hline California & 11.7 & 9.2 & 50 & 8.8 & 32.0 & 3.7 & 7.4 \\
\hline Virginia & 1.5 & 18.4 & 50 & 6.0 & 30.1 & 2.0 & 3.9 \\
\hline Arizona & 1.8 & 22.1 & 80 & 7.0 & 30.0 & 1.7 & 8.3 \\
\hline Indiana & 2.0 & 20.7 & 90 & 8.5 & 32.9 & 1.8 & 17.7 \\
\hline Texas & 7.2 & & 100 & 0.0 & 30.3 & & \\
\hline U.S. State Average & 2.0 & 21.7 & 66.1 & 6.7 & 31.9 & 2.8 & 7.1 \\
\hline U.S. State Median & 1.4 & 17.1 & 50.0 & 7.1 & 31.5 & 2.1 & 4.4 \\
\hline U.S. State Min & 0.3 & 0.4 & 33.3 & 0.0 & 28.6 & 0.3 & 0.7 \\
\hline U.S. State Max & 11.7 & 141.5 & 100.0 & 12.0 & 36.8 & 24.1 & 36.1 \\
\hline
\end{tabular}

Notes: This table shows the corporate tax revenue-maximizing corporate tax rate $\tau_{s}^{*}$ and the total tax revenuemaximizing corporate tax rate $\tau_{s}^{* *}$, which accounts for fiscal externalities on personal income sources, for a few selected states (see Appendix Table A36 for the full list of states). These calculations are based on 2010 data and average national parameter estimates and do not incorporate heterogeneous housing markets. We use three state statistics to calculate state revenue-maximizing rates discussed in Section 7 and presented in the last columns of the table. These three statistics are the state's share of establishments, the state's ratio of revenue that comes from personal income, i.e. sales and personal income taxes, to their state corporate tax revenue, and their sales apportionment weight. The second column shows each state's share of national establishments in 2010. A corporate tax cut in large states like California affects more local areas simultaneously, which slightly diminishes the effect of a tax cut to an extent that depends on the state's establishment share (as shown in Appendix D). We adjust our estimates of the percent change in local establishments $\dot{E}_{c}$ by state to account for this simultaneous impact based on state size. The first corporate revenuemaximizing tax rate, $\tau_{s}^{*}=\frac{1}{\dot{E}_{s}+\dot{\pi}_{c}}\left(1-t_{f e d}\right)$, is a function of this state-size adjusted establishment response $\dot{E}_{s}$, the estimate of national average change in pre-tax profits $\dot{\pi}_{c}$ from Table 7 , panel (a), column (3), and the federal corporate tax rate $t_{f e d}$. This rate is much higher than $\tau_{s}^{* *}$ which accounts for fiscal externalities. The size of fiscal externalities from corporate tax changes vary based on the importance of other revenue sources. We measure the state-specific importance of population dependent revenue sources $\operatorname{rev}_{s}^{\text {pers }} / \mathrm{rev}_{s}^{C}$ with the ratio of (1) total state tax revenue from sales and personal income taxes to (2) total state revenue from corporate income taxes. The product of this state-specific revenue share term and national average responsiveness of wages and population is added to the denominator following the formula presented in Section 7 and Appendix D. These rates are much lower on average. However, in models without trade costs, location distortions result from payroll and property apportionment but not from sales apportionment. The right-most column divides the total state tax revenue-maximizing state corporate tax rate $\tau_{s}^{* *}$ by the apportionment factors that distort establishment location, i.e. $\left(1-\theta_{s}^{s}\right)$. Since sales is destination based, it does not distort location decisions (absent trade costs) and allows for higher revenue-maximizing tax rates. See Section 7 and Appendix D for more details. Sources: U.S. Census Annual Survey of Governments and the other sources listed in Section 4. 
Figure 1: The Impact of a Corporate Tax Cut on Workers and Firm Owners

I. Effects on Each Local Establishment
A. Before Tax Cut
B. A Corporate Tax Cut Has 3 Effects
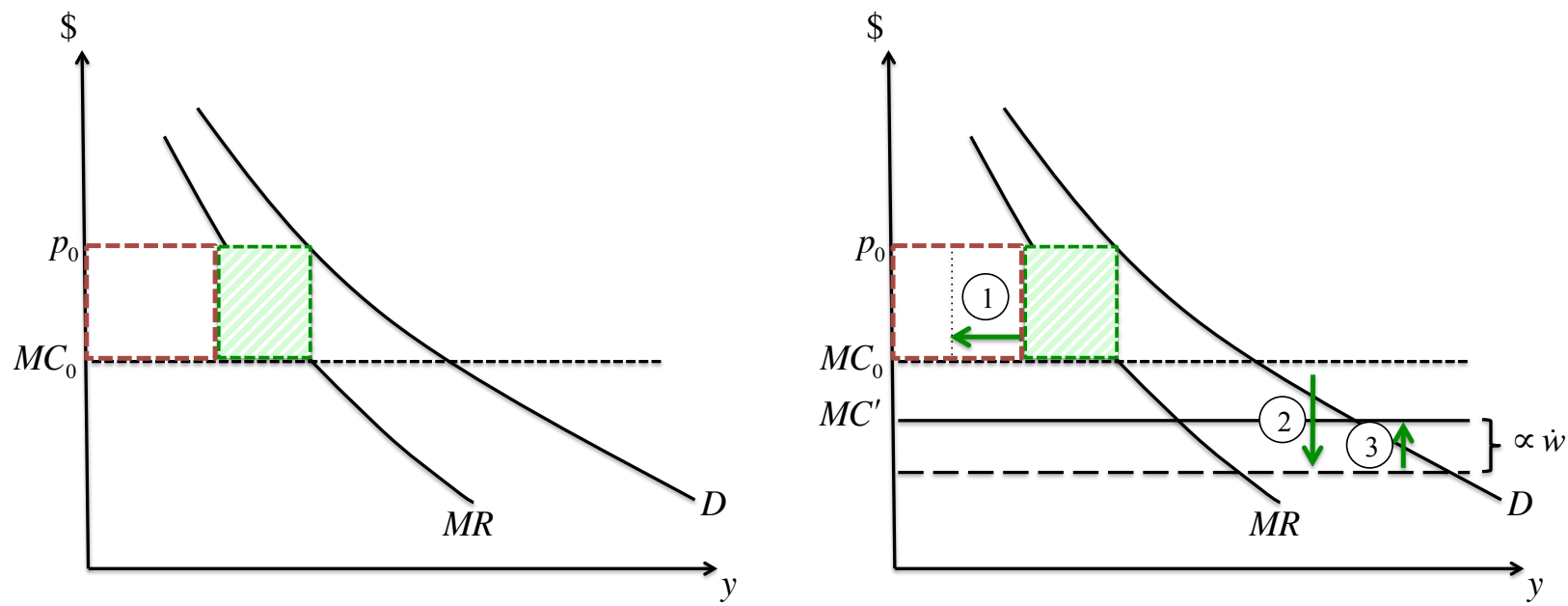

II. Equilibrium Effects on Local Wages and After-Tax Profits

C. Wage Increase $\dot{w}$ Determined in Labor Market

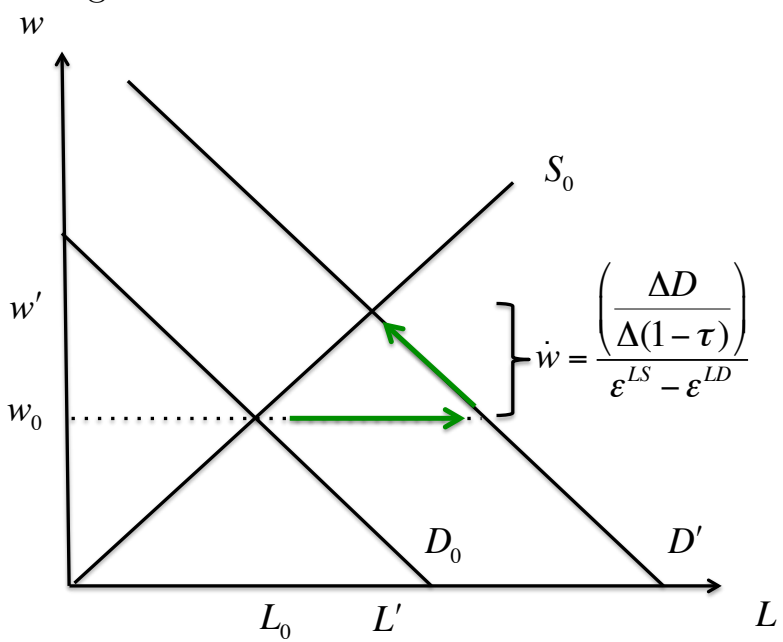

D. Net Effect on After-Tax Profits

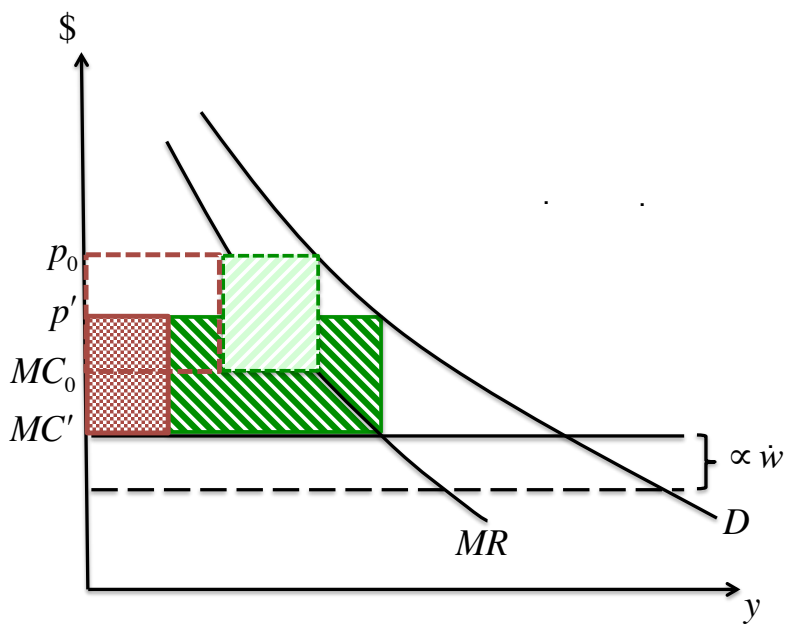

Notes: A. Monopolistically competitive establishments earn profits, which are divided into taxes and after-tax profits. B. Cutting corporate taxes has three effects on local establishments: a corporate tax cut reduces the establishment's (1) tax liability and (2) capital wedge mechanically. (3) Establishments enter the local area and bid up wages by $\dot{w}$ percent. C. Wage increases are determined in the local labor market as workers move in, house prices increase, each establishment hires fewer workers, and some marginal establishments leave. D. The cumulative percentage increase on profits $\dot{\pi}$ depends on the magnitude of wage increases. We derive the change in local labor demand, $\varepsilon^{L S}$, and $\varepsilon^{L D}$ from microfoundations and express them in terms of a few estimable parameters in Section 1. Empirical estimates of these parameters, which govern the three effects above are provided in Tables 6 and A33 and discussed in Section 6. Note that these effects are enumerated to help provide intuition, but the formal model does not include dynamics. The model shows how the spatial equilibrium changes when states cut corporate taxes. 
Figure 2: State Corporate Tax Rates

A. Number of Corporate Tax Changes by State since 1979

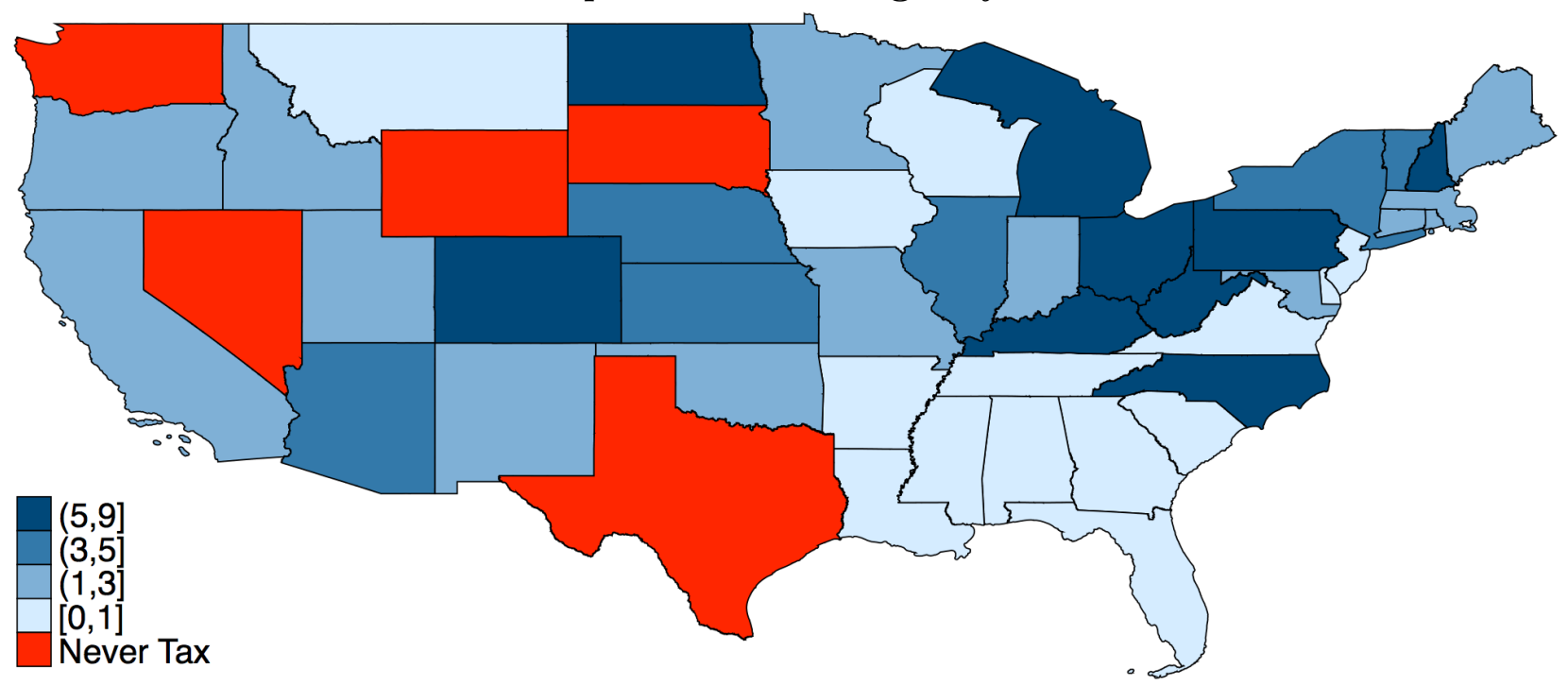

B. Corporate Tax Rates by State in 2012

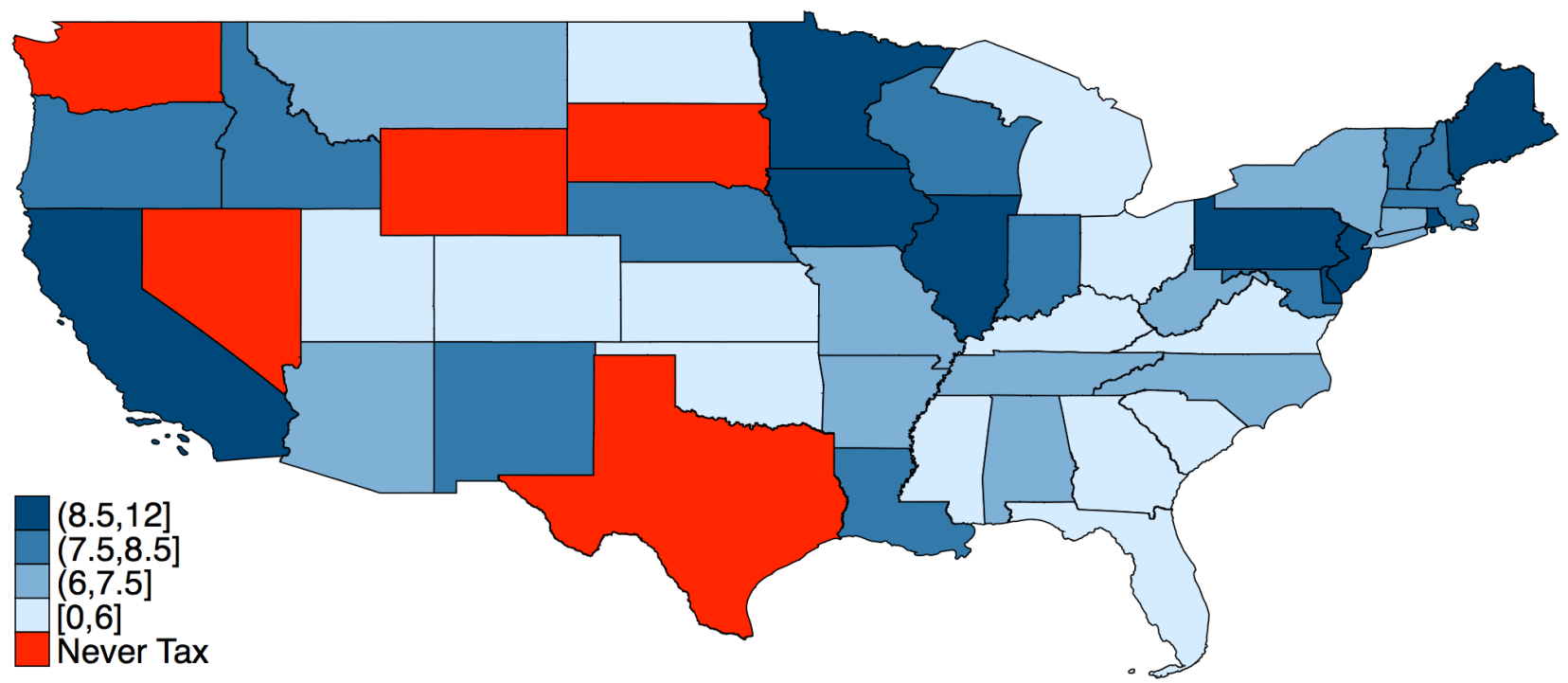

Notes: These figures show statistics on state statutory corporate tax rates across states. See Appendix Figures A2, A3, A4, and A5 for similar figures on state corporate tax apportionment rates, 30 year changes in corporate rates and apportionment rules, state establishment and population shares, and 30 year changes in establishment and population shares, respectively. 
Figure 3: Histogram of Sales Apportionment Weights by Decade

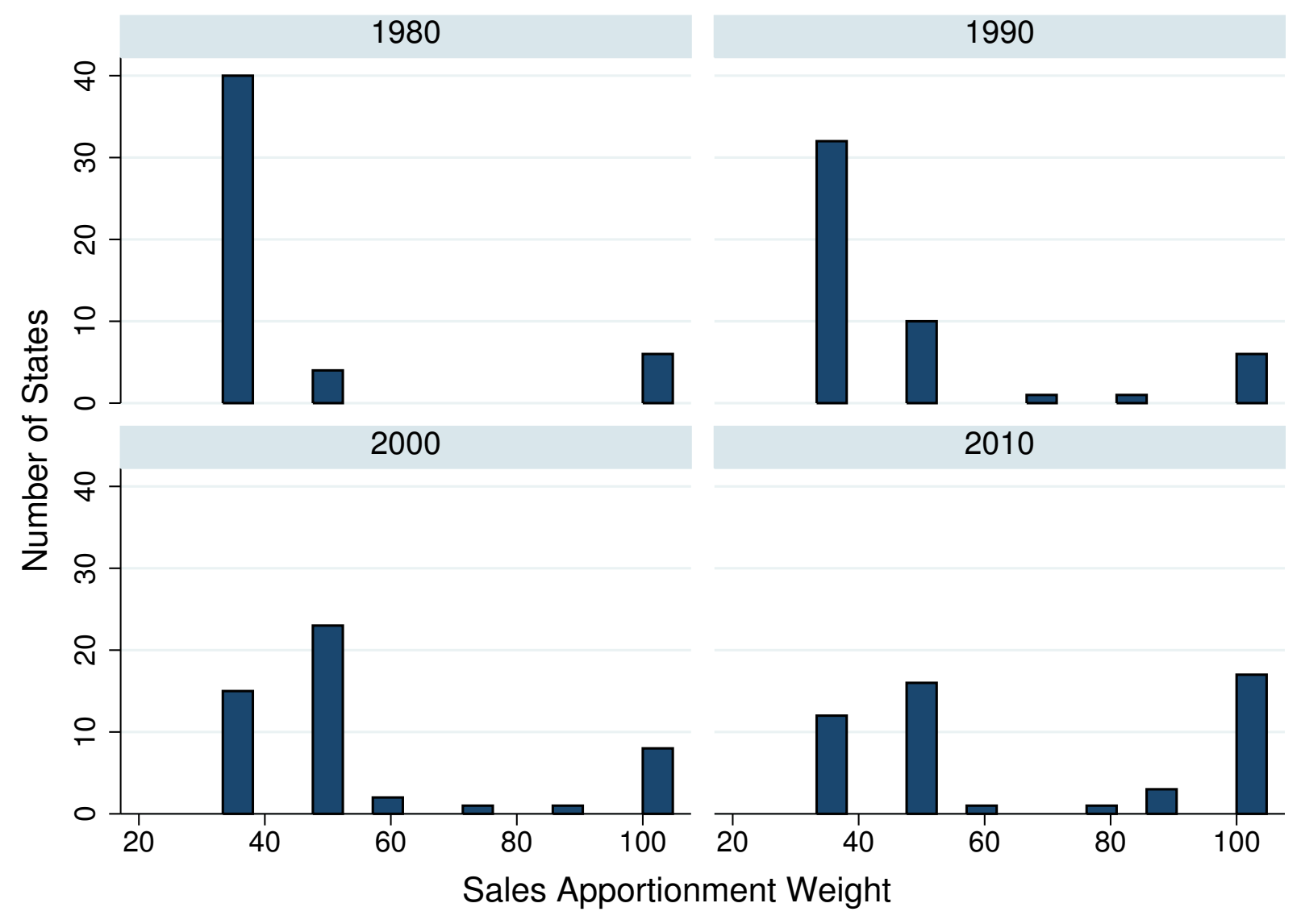

Notes: This figure shows a histogram of the weight on sales activity that states use to apportion the national profits of multi-state firms for tax purposes. Many states have increased their sales apportionment weights in recent decades. Forty states used a one-third weight in 1980. As of 2010, more states put half or full $100 \%$ weight on sales activity than the number that still uses the traditional one-third weight. See Section 4.2.1 for a description of state corporate tax apportionment rules. 
Figure 4: Cumulative Effects of Business Tax Cuts on Establishment Growth

\section{A. Cumulative Annual Effects without leads}

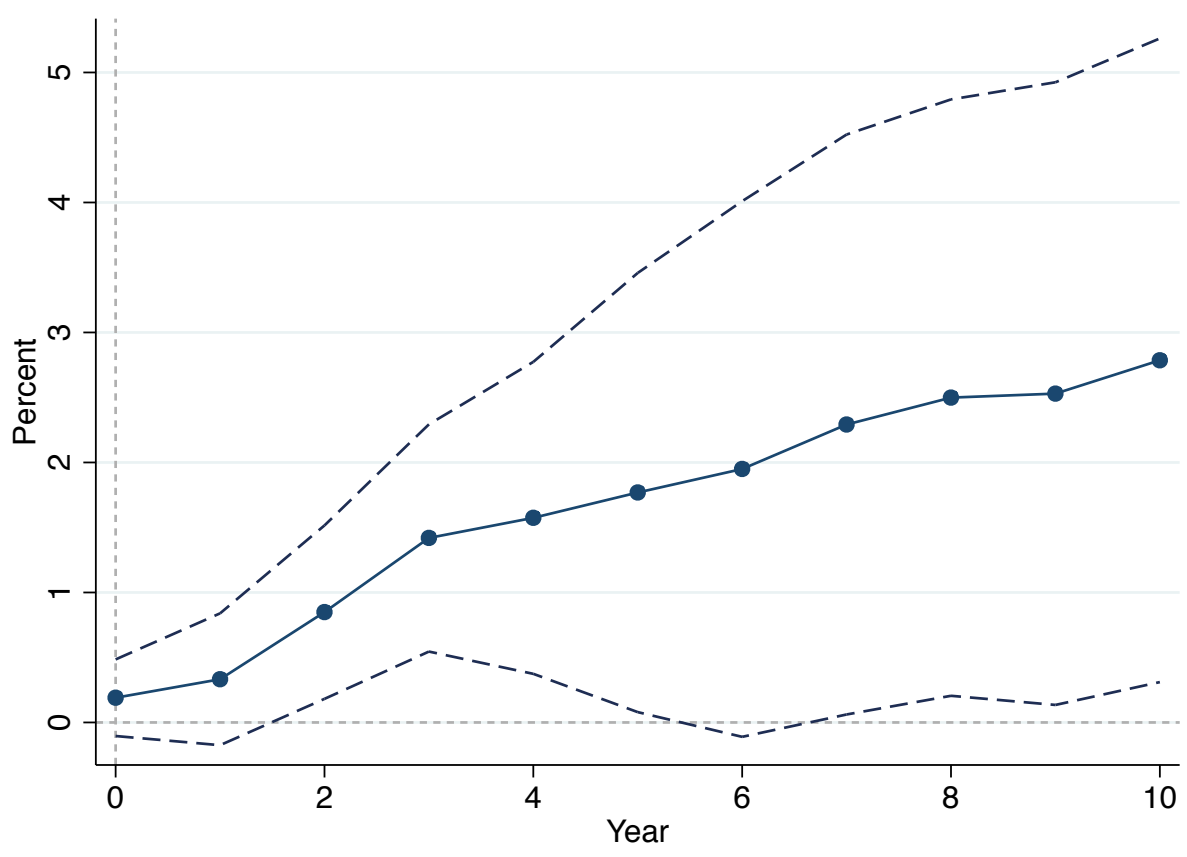

B. Cumulative Annual Effects with leads

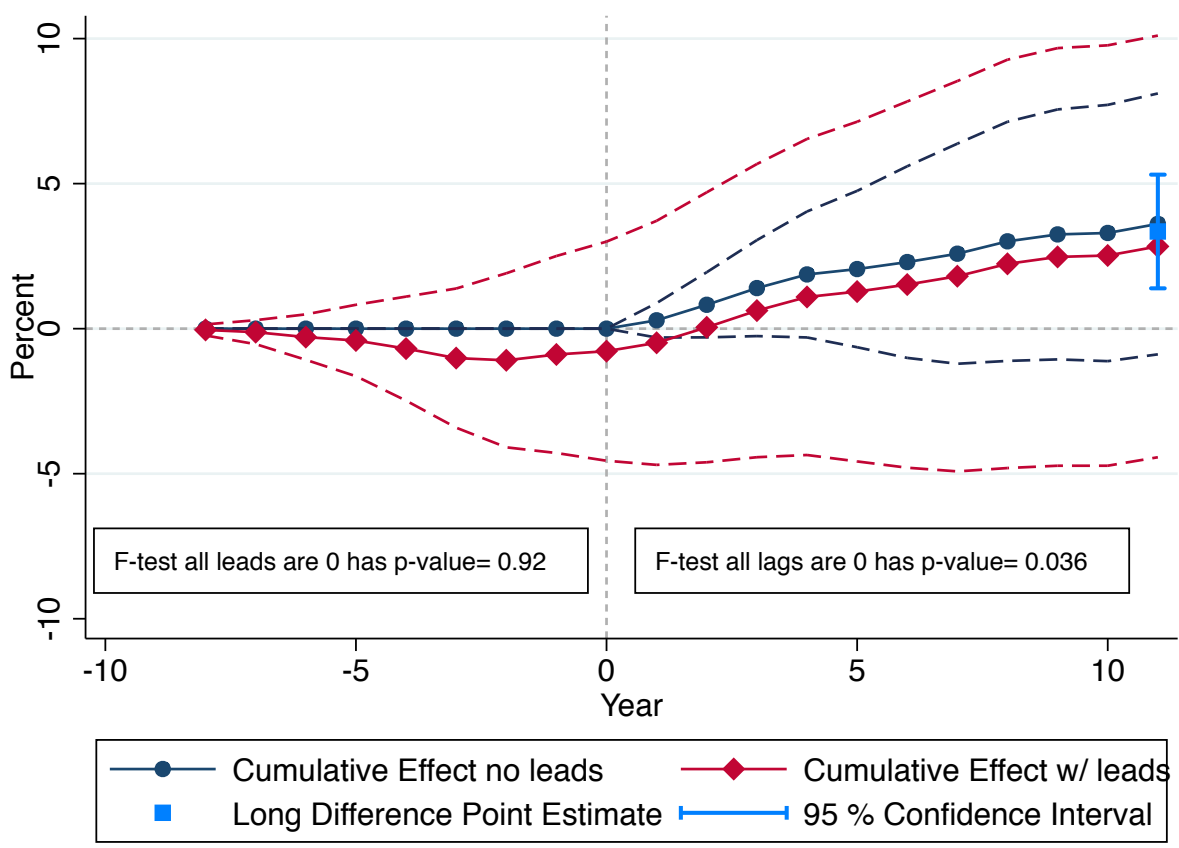

Notes: This figure shows the cumulative annual effects of local business tax cuts on local establishment growth over different time horizons. Panel A plots the sum of the point estimates in Col (4) of Table A5 and 90\% confidence interval for each time horizon. Panel B plots the sum of the point estimates in Col (7) of Table A5 and 90\% confidence interval for each time horizon starting with the greatest lead. In addition, it reports the p-values for the F-test that all leads and lags are jointly equal to zero, which is also reported in Col 7 of Table A5. The square shows the point estimate and $95 \%$ confidence interval for the long-run effect of a one percent businesses tax cut on establishment growth, which corresponds to the estimate reported in Col (4) of Table 4.40 See Section 4 for data sources and Section 5 for estimation details. 
Figure 5: Robustness of Economic Incidence

Panel (a)

Firm Owner's Share of Incidence for $\alpha=0.3$ and Calibrated Values of $\gamma$ and $\varepsilon^{P D}$

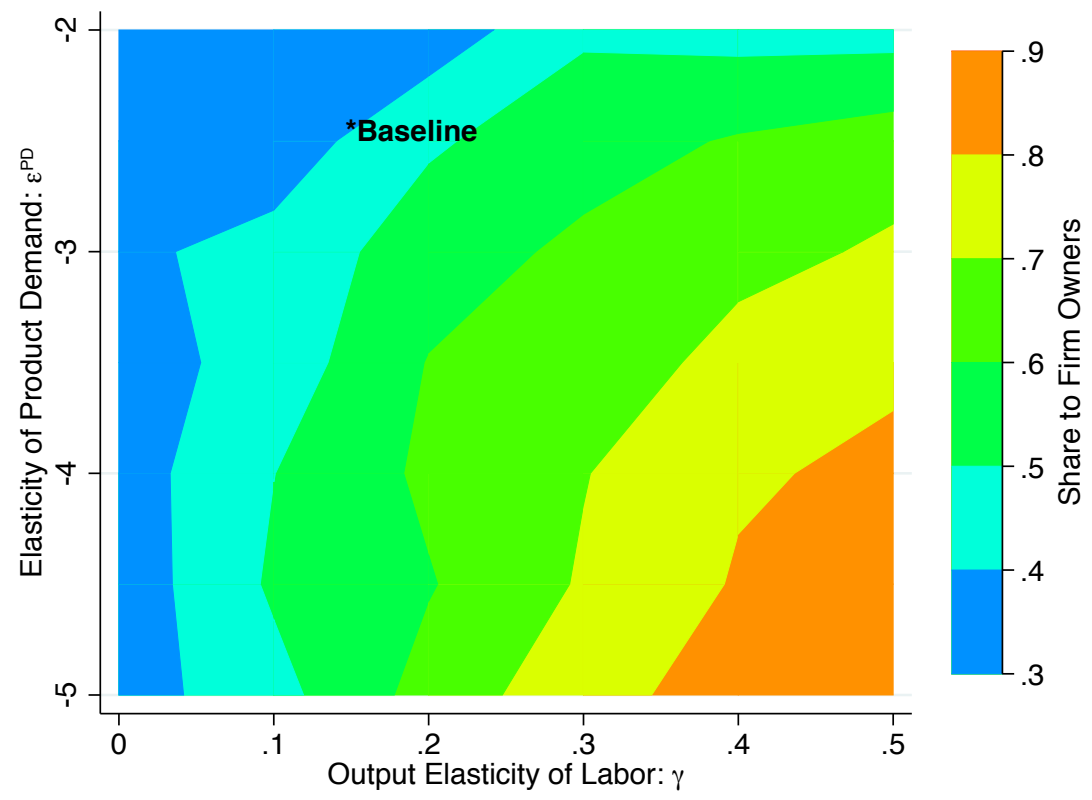

Panel (b)

Firm Owner's Share of Incidence for $\gamma=.15$ and Calibrated Values of $\alpha$ and $\varepsilon^{P D}$

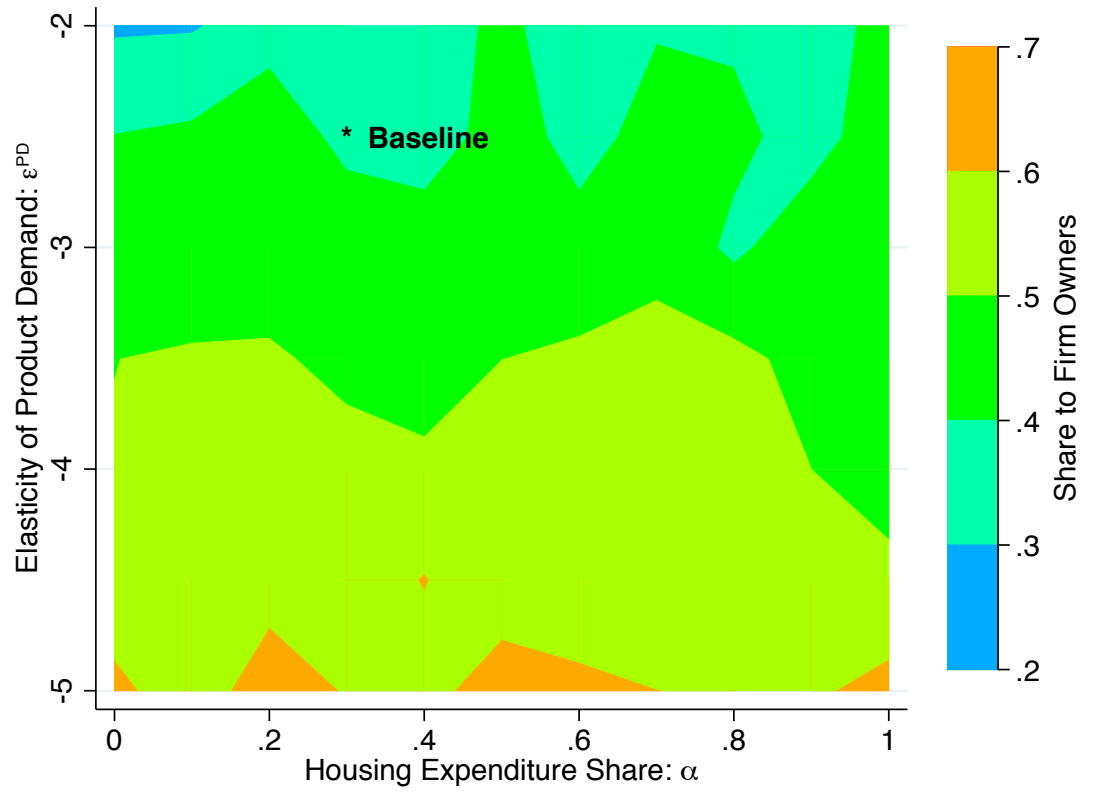

NotEs: This figure shows that our baseline empirical result - that firm owners bear a substantial share of incidence - is robust to using a wide range of calibrated parameter values. The figures plot firm owner incidence shares for a variety of parameter values and illustrates that our baseline parameters values of $\gamma=0.15, \varepsilon^{P D}=-2.5$, and $\alpha=.3$ give a conservative share of the incidence to firm owners. Using calibrations with more elastic product demand elasticities, while holding constant $\gamma=0.15$ in Panel A (or while holding constant $\alpha=.3$ in Panel B), does not change the result that the share to firm owners ranges between 35 and 40\%. Increasing the calibrated $\gamma$ in Panel A (or $\alpha$ in Panel B) generally increases the share accruing to firm owners. Overall, larger product demand elasticities $\varepsilon^{P D}$, housing expenditure shares $\alpha$, and/or larger output elasticities of labor $\gamma$ result in larger burdens on firm owners. See Section 6 for more detail. 


\section{Appendices for Online Publication}

This appendix contains several sections. Section A discusses tax measurement, supplemental data sources, and the variation in tax rates. Section B provides a characterization of the establishment problem under apportionment and several derivations of expressions in the main text. Section $\mathrm{C}$ discusses the effects of a local corporate tax change on the welfare of agents in other locations and on efficiency. Section D derives revenue-maximizing corporate tax rate expressions in the main text. Section E contains a detailed description of estimates underlying Figure 4 in the main section, a discussion of several supplemental robustness tables for key tables in the main text, a step-by-step guide through our estimation approach, an alternative equation-by-equation discussion of estimation that provides more intuition for the estimating equations relative to the system approach in the main text, and details on the structural estimation with all shocks. Section F and G provide more detail on our robustness exercises that account for the welfare effects of changes in government spending and local prices, respectively.

\section{A Data}

This section describes advantages of local areas called PUMAs in Section A.1, the derivation of composition-adjusted outcomes in Section A.2 and the tax data used in Section A.3. In particular, we provide institutional detail on apportionment and how that informed how we constructed tax rates that account for apportionment in Section A.3.1, the sources for corporate tax parameters in the main text in Section A.3.2, the source and methodological overview for our personal income tax rate data in Section A.3.3, a discussion of the limitations of our tax change measure in Section A.3.4, data on local prices in Section A.4, and data sources for variables that only appear in appendix tables in Section A.5. Finally, section A.6 describes variation in tax rates.

\section{A.1 Advantages of Using PUMAs}

There are several advantages of using "consistent public-use micro-data areas (PUMAs)." First, this geographical definition depends on county boundaries that are geographically consistent since 1980. This fact allows us to generate data series at a yearly frequency using data for individual counties. Moreover, it allows us to use micro-data from the U.S. census to create wage, rental cost, and home value indexes for geographically consistent areas across censuses. Second, the level of aggregation does not straddle state lines, in contrast to other definitions of local economies. This feature is beneficial since some of the policies we analyze, namely changes in statutory corporate tax rates, vary at the state level. Since local areas vary in industrial composition, apportionment rules create within state variation in the taxes businesses pay. To our knowledge, this paper is the first to use apportionment rules to compute the average tax rates businesses pay across different locations in the United States. Finally, this level of aggregation enables us to maximize statistical power and to exploit and measure variation in prices in local labor and housing markets, which vary considerably within states.

\section{A.2 Composition-Adjusted Outcomes}

This appendix describes in detail the construction of the skill-specific, county group outcomes using micro-data from the IPUMS samples of the 1980, 1990, and 2000 Censuses and the 2009 American Community Survey (Ruggles et al. (2010)). The data created using this process was first used in Suárez Serrato and Wingender (2011) and this data appendix is a reproduction of an identical appendix in that paper. Our sample is restricted to adults between the ages of 18 and 64 who are not 
institutionalized and that are not in the farm sector. We define an individual as skilled if they have a college degree. ${ }^{44}$

A number of observations in the data have imputed values. We remove these values from the following variables: employment status, weeks worked, hours worked, earnings, income, employment status, rent, home value, number of rooms, number of bedrooms, and building age. Top-coded values for earnings, total income, rents, and home values are multiplied by 1.5. Since the 2009 ACS does not include a variable with continuous weeks worked, we recode the binned variable for 2009 with the middle of each bin's range.

Our measure of individual wages is computed by dividing earnings income by the estimate of total hours worked in a year, given by multiplying of average hours worked and average weeks worked. Aggregate levels of income, earnings, employment, and population at the county group level are computed using person survey weights. Average values of log-wages are also computed using person survey weights while log-rents and log-housing values are computed using housing unit survey weights and restricting to the head of the household to avoid double-counting. We create composition-adjusted values of mean wages, rents, and housing values in order to adjust for changes in the characteristics of the population of a given county group. First, we de-mean the outcomes and the personal and household characteristics relative to the whole sample to create a constant reference group across states and years. We then estimate the coefficients of the following linear regression model:

$$
\dot{y}_{c t s i}=\dot{X}_{c t s i} \Gamma^{s, \tau}+\nu_{c}+\mu_{c, \tau}+\varepsilon_{c t s i},
$$

where $\dot{y}_{c t s i}$ is observations $i$ 's de-meaned $\log$-price in county group $c$, year $t$ and state group $s$. $\dot{X}_{c t s i}$ is observations $i$ 's de-meaned characteristics, $\nu_{c}$ is a county group fixed effect, and $\mu_{c, \tau}$ is a county group-year fixed effect. Allowing $\Gamma^{s, \tau}$ to vary by state and year allows for heterogeneous impacts of individual characteristics on outcomes.

We run this regression, for every state group and for years $\tau=1990,2000$, and $2010 .{ }^{45}$ For each regression we include observations for years $t=\tau, \tau-10$ so that the county group-year fixed effect corresponds to the average change in the price of interest for the reference population. Our analysis of adjusted prices uses the set of fixed effects $\left\{\mu_{c, t}\right\}$ as outcome variables.

The regressions on wage outcomes use individual survey weights, while the regressions on housing outcomes use housing survey weights and restrict to the head of the household. The wage regressions include the following covariates: a quartic in age and dummies for hispanic, black, other race, female, married, veteran, currently in school, some college, college graduate, and graduate degree status. The housing regressions included the following covariates: a quadratic in number of rooms, a quadratic in the number of bedrooms, an interaction between number of rooms and number of bedroom, a dummy for building age (every ten years), interactions of the number of room with building age dummies, and interactions of the number of bedrooms with building age dummies.

\footnotetext{
${ }^{44}$ For the 1980 Census there is no college degree code. We code those with less than 4 years of college education as not having a college degree. This corresponds to detailed education codes less than 100 .

${ }^{45}$ As a technical note, before every regression was computed, an algorithm checked that no variables would be automatically excluded by the software program in order to avoid problems with cross-equation comparisons.
} 


\section{A.3 Tax Data}

\section{A.3.1 Apportionment Details}

The tax liability for unitary businesses ${ }^{46}$ in state $s$ of firm $i$ is comprised of three parts: taxes due on apportioned national profit based on sales activity, payroll activity, and property activity in state $s$ :

$$
\text { State Tax Liability }{ }_{i s}=\underbrace{\left(\tau_{s}^{c} \theta_{s}^{x} a_{i s}^{x}\right) \Pi_{i}^{p}}_{\text {Tax from Sales Activity }}+\underbrace{\left(\tau_{s}^{c} \theta_{s}^{w} a_{i s}^{w}\right) \Pi_{i}^{p}}_{\text {Tax from Payroll Activity }}+\underbrace{\left(\tau_{s}^{c} \theta_{s}^{\rho} a_{i s}^{\rho}\right) \Pi_{i}^{p}}_{\text {Tax from Property Activity }},
$$

where $\tau_{s}^{c}$ is the corporate tax rate in state $s, 0 \leq \theta_{s}^{x} \leq 1$ is the sales apportionment weight in state $s, a_{i s}^{x} \equiv \frac{S_{i s}}{S_{i}}$ is the share of the firm's total sales activity that occurs in state $s$, and $\Pi^{p}$ is total pretax profits for the entire firm across all of its establishments in the United States. Payroll and property activity in state $s$ are defined similarly and the weights sum to one for each state, i.e., $\theta_{s}^{x}+\theta_{s}^{p}+\theta_{s}^{\rho}=1 \forall s$. Summing tax liabilities across states results in the following firm-specific "apportioned" tax rate:

$$
\tau_{i}^{A}=\sum_{s}\left(\left(\tau_{s}^{c} \theta_{s}^{x} a_{i s}^{x}\right)+\left(\tau_{s}^{c} \theta_{s}^{w} a_{i s}^{w}\right)+\left(\tau_{s}^{c} \theta_{s}^{\rho} a_{i s}^{\rho}\right)\right)
$$

where $\tau_{i}^{A}$ is the firm-specific tax rate for all of it's establishments across the U.S. This expression shows that the effective tax rate of a given establishment depends on (1) apportionment weights $\theta_{s}$ in every state, (2) the corporate rate $\tau_{s}^{c}$ in every state, and (3) the distribution of its payroll, property, and sales activity across states: $a_{i s}^{w}, a_{i s}^{\rho}$ and $a_{i s}^{x}$, respectively, for all $s$. Finally, note that while the activity weights of payroll and capital are source-based (i.e. where goods are produced), the activity weights of revenue are destination-based (i.e., where goods are consumed). This distinction has important efficiency implications, which we discuss in Section 7.

To ensure that a decrease in tax rates can be interpreted as an in increase in the attractiveness of any given location, we decompose $\tau_{i}^{A}$ into three components: one that depends on own-state "domestic" tax rates and rules, an "external" component that depends on the statutory rates and rules in other states, and a sales component.

$$
\underbrace{\tau_{i}^{A}}_{\text {Apportioned Rate }}=\underbrace{\left(\tau_{s}^{c} \theta_{s}^{w} a_{i s}^{w}\right)+\left(\tau_{s}^{c} \theta_{s}^{\rho} a_{i s}^{\rho}\right)}_{\text {Domestic Component }}+\underbrace{\sum_{s^{\prime} \neq s}\left(\tau_{s^{\prime}}^{c} \theta_{s^{\prime}}^{w} a_{i s^{\prime}}^{w}\right)+\left(\tau_{s^{\prime}}^{c} \theta_{s^{\prime}}^{\rho} a_{i s^{\prime}}^{\rho}\right)}_{\text {External Component }}+\underbrace{\sum_{s}\left(\tau_{s}^{c} \theta_{s}^{x} a_{i s}^{x}\right)}_{\text {Sales Component }}
$$

We then define the domestic tax rate that excludes the external component of tax changes, i.e., $\tau_{i}^{D} \equiv$ $\left(\tau_{s}^{c} \theta_{s}^{w} a_{i s}^{w}\right)+\left(\tau_{s}^{c} \theta_{s}^{\rho} a_{i s}^{\rho}\right)+\sum_{s}\left(\tau_{s}^{c} \theta_{s}^{x} a_{i s}^{x}\right)$, and the external rate as the difference between the apportionment rate and the domestic rate: $\tau_{i}^{E} \equiv \tau_{i}^{A}-\tau_{i}^{D}$.

\section{A.3.2 Additional Tax Rate and Tax Base Data Sources}

In addition to the sources listed in the main text, we also rely on tax rate data collected by the authors of the following papers: Seegert (2012), Bernthal et al. (2012), Chirinko and Wilson (2008), and Wilson (2009). In particular, Seegert (2012) generously shared data on corporate tax rates and Bernthal et al. (2012) provided data on apportionment formulae. In both cases we cross-checked our newly digitized data with those used by these authors. Chirinko and Wilson (2008) provided us with data on investment tax credits to analyze the concomitance of changes in corporate tax rates and the

\footnotetext{
${ }^{46}$ Unitary businesses are businesses with close connections between units in separate states. See Appendix Section A.3.4 for more detail.
} 
corporate tax base. Wilson (2009) shared panel data on R\&D tax tax credits.

In terms of tax base rules, we primarily use data from CCH (1980-2010). However, for combined reporting and throwback rules are based on the panel provided by Bernthal et al. (2012). ${ }^{47}$ Information regarding the federal deductibility of state corporate income taxes across states and years in the analysis period were gathered from the corporate income tax tables of the CSG (1976-2011), published biennially until 2002, and published annually thereafter. We enumerate the specific tax base variables we consider in subsection E.4.1 of Appendix Section E.4.

\section{A.3.3 Personal Income Tax Rate Data}

To calculate state personal income tax changes, we use the NBER Tax Simulator TAXSIM, which calculates individual tax liabilities for every annual tax schedule and stores a large sample of actual tax returns. Similar to Zidar (2014), we construct a measure of synthetic tax changes by comparing each individual's income tax liabilities in the year preceding a tax change to what their tax liabilities would have been if the new tax schedule had been applied, while holding other tax-relevant factors such as income and deductions constant. For example, suppose there was a state tax change in 1993. This measure subtracts how much a taxpayer paid in 1992 from how much she would have paid in 1992 if the 1993 tax schedule had been in place. We then use these measures to calculate effective state personal income tax changes. This process has the benefit that it mechanically ignores the effects of taxes on economic behavior, which might be related to unobservable factors driving our outcomes of interest. Before using these data in our empirical work in Section 5, we first crosscheck these simulated changes with actual statutory changes to top and bottom marginal rates for each state to ensure that the variation we observe is actually driven by statutory changes. Note that when calculating tax liabilities, TAXSIM takes into account each individual's deductions and credits and their specific implications for state personal income tax liabilities. See Zidar (2014) for more detail on the construction of this measure of income tax changes.

\section{A.3.4 Tax Data Limitations}

While our measure of local business tax changes $\Delta \ln \left(1-\tau^{b}\right)_{c, t, t-h}$ captures several important features of business taxation, the measure has a number of limitations.

First, we assume that multi-state corporations are all unitary businesses, which has implications for how profit is apportioned across states. Unitary businesses are businesses with close connections between units in separate states. If an orange grove in Florida and steel plant in Pennslyvania were owned by the same firm, these businesses would be considered separate and profits would be taxed separately in practice. Our approach of treating this firm as a unitary business would incorrectly apportion profits of the combined entity rather than keeping the establishments separate. We view our treatment as a reasonable but imperfect approximation. We provide incidence estimates in Appendix Table A21 that use only variation in statutory corporate taxes, which, in the case of the orange grove and steel plant, would be the correct and separate rates. We find that the results with our measure of business taxes and with statutory corporate tax rates are similar.

Second, an important limitation relates to our inability to assign personal tax rate of non C-corps to the residence of owners, which could be different than the state in which the firm operates. For instance, if investors from Florida own all of the non C-corps in New York, we will mistakenly use the

\footnotetext{
${ }^{47}$ We did not verify every state-year observation on throwback and combined reporting rules. We believe that the throwback series is fairly accurate, but some spot-checking revealed that approximately $15 \%$ of the combined reporting entries before 1993 may be inconsistently classified. Given the wide-variety of robustness checks and the consistency of our results, we do not expect this to have a material impact on our findings but wanted to flag for other researchers the potential accuracy issues for this series on combined reporting from Bernthal et al. (2012), especially in years before 1993.
} 
personal tax rate in New York rather than Florida for these firms. Properly measuring the ownership structure of individual firms is not possible with our data. To the extent that firm ownership shares among states are fairly stable, specifications with state fixed effects, which are in Appendix Table A23, can partially address this concern.

Third, our ability to measure the tax base is imperfect. While we account for state investment tax credits (see Appendix Section E.3), the presence of gross receipt taxes (see Appendix Section E.4), and several specific state tax base rules (enumerated in Appendix subsection E.4.1): state throwback and combined reporting rules, state research and development tax credits, state loss carry-back and carry-forward rules, state franchise taxes, state rules governing whether or not federal corporate taxes are deductible, state choices of whether or not they follow the federal income tax base and federal accelerated depreciation rules, state depreciation rules, state bonus depreciation adoption, there are other ways that state tax bases differ that we do not capture. For example, there are possible interactions due to limited loss offset, other deductions, and other credits that we are not able to capture. Importantly, we can not directly measure firm profits. Instead, we scale up costs based on wage changes under the assumption that firms markup prices over costs. The product demand elasticity $\varepsilon^{P D}$ governs the magnitude of this markup. ${ }^{48}$ We can not measure wages at the establishment level, so we use local measures of wages (as described above in Appendix Section A.2). The level of analysis in the paper - PUMA-decade - reflects the importance of our wage measure and how we are able to measure it.

Fourth, while the establishment-firm data represents a step forward in terms of empirically implementing state apportionment, the available data are imperfect. We are able to link establishments and firms and construct payroll activity shares, but comparable data on property is not available. We assume that firms' factor cost shares are the same across locations, i.e., if $60 \%$ of their labor costs are in New York, then New York will also have $60 \%$ of their property costs. Different establishments have different factor cost shares in practice. We view our approach as an imperfect but reasonable approximation. In addition, we are not able to measure the destination of all sales for every firm. Since the apportionment of sales is destination-based, we use state GDP data for ten broad industry groups from the BEA to apportion sales to states based on their share of national GDP.

Fifth, we do not incorporate local property taxes. Since rates, rules, and institutional details differ materially across local areas within states and over-time, correctly measuring local property taxes for every county in the U.S. represents a herculean data construction exercise that is beyond the scope of this paper. Specifications that control for government spending per capita, which should indirectly measure local finance pressures (via financing inflows from state-to-local governments), yield similar results to the main incidence findings of the paper.

We present several pieces of evidence to address these measurement concerns. Results with state fixed effects, variation exclusively from changes in statutory state corporate taxes, and controls for tax base differences all yield very similar results. In addition, estimates using external variation from tax changes in other states imply similar incidence results. Finally, the structural parameters that rationalize the effects we estimate align with existing estimates from the local labor markets literature. If measurement error were a substantial problem, it is unlikely we would find results that are not only consistent across several specifications, but also in line with other estimates from the literature that use completely different sources of variation for estimation. ${ }^{49}$ It is possible but unlikely that our estimates would be materially different with better data.

\footnotetext{
${ }^{48}$ We also provide results for a range of $\varepsilon^{P D}$ values, e.g., Figure 5, and estimate it directly in Appendix Section E.5.

${ }^{49}$ See the discussion in section 6.1 of Bartik (1991); Notowidigdo (2013); Albouy and Stuart (2013) regarding supplyside parameters and Hamermesh (1993); Kline and Moretti (2014) regarding demand-side parameters.
} 


\section{A.4 Local Price Data}

\section{A.4.1 Local Price Data from ACCRA}

We measure local prices using data purchased from the American Chamber of Commerce Researchers Association (ACCRA). These data report survey measures of price levels for a number of categories of spending in several cities and the quarterly reports of inter-city price indices go back to 1980 and continue to the present. ${ }^{50}$ Previous researchers using these data include Basker (2005), Moretti (2013), and Albouy (2008). Basker (2005) describes this data in detail.

We took the following steps to generate a price index at the PUMA-level (a geographic unit which is defined in section A.1) from these data:

1. The first step in processing the raw data from ACCRA is digitization. The data for years 1980-1989 were available in PDF form, and had to be hand coded. For each metro area in the ACCRA reports, three indices were recorded: the composite index, which is the index derived from all items in the survey, as well as the indices for grocery items and miscellaneous goods and services.

2. The second step was to create yearly values for these prices. We took the mean price within a city-year-category pair, where missing quarterly values were dropped.

3. The third steps was to use the city-level information to generate a price-index that is similar to our level of geography. The ACCRA data are coded at the city level but we found problems in the assignment of cities to either CBSA or MSA codes. Instead, for each metro area, we identified the primary county assigned these three indices to that county. In order to assign the price index to the relevant surrounding counties, we used a crosswalk between counties and commuting zones to assign the price index to all counties in the same commuting zone as the primary county. ${ }^{51}$ Finally, we assigned counties to PUMAs using our county-to-puma crosswalk, and each puma's price index was calculated by averaging the price indices of all included counties that had an assigned price index.

4. The final step in generating the price index is dealing with missing values. The data generated in the previous step has a wide geographical range but there are some missing values. In order to generate a balanced panel dataset with the widest-possible geographic coverage, we estimated a linear model of PUMA-level prices changes on state-level prices changes and used predicted values of this regression to fill gaps in the data. Some of the PUMAs had a significant number of imputed observation. We exclude these cities from our analysis by restricting to areas with a low number of imputed values. This procedure generated a panel data of 400 PUMAs where only $5 \%$ of the data were imputed.

\section{A.4.2 Local Price Data from BLS}

We construct a supplemental measure of local prices using price indices corresponding to "All Urban Consumers" (CPI-U) that are calculated by the Bureau of Labor Statistics (BLS) for several major metropolitan areas. Price data stretches from 1984 through 2014, with 2014 prices rebased as an index value of 100 in all CMSAs.

\footnotetext{
${ }^{50}$ Note that although the ACRRA index does measure some local prices for services (e.g., haircuts, doctor's visit, dry cleaning), local prices for services may not fully reflected in the price index, which is based on the prices of specific consumption goods (e.g., the price of one dozen large grade A eggs, a gallon of gasoline, a man's barber shop haircut with no styling, a 100 tablet bottle of aspirin, the cost of adult teeth cleaning at the dentist, etc).

${ }^{51}$ This crosswalk can be found on David Dorn's website: http://www.ddorn.net/data.htm. For robustness, we also did the same based on definitions of MSA's using the county-to-MSA crosswalk available from the http://www.dol.gov/owcp/regs/feeschedule/fee/fs04ctst.xls and found very similar results.
} 
For states where only one associated CMSA is measured, the state price index is identical to the corresponding urban CPI. Arizona and the Phoenix metropolitan area are one such example. In total, 27 CMSAs are measured. Note that several states lack any associated urban CMSA as measured by the BLS, and are therefore excluded from the final panel (Alabama, Arkansas, Idaho, Iowa, Louisiana, Mississippi, Montana, Nebraska, Nevada, New Mexico, North Carolina, North Dakota, Oklahoma, Rhode Island, South Carolina, South Dakota, Tennessee, Utah, Vermont, and Wyoming). In instances in which a state is associated with multiple CMSAs with a price index-Indiana for example, is mapped to both Cincinnati and Chicago - we construct a state-year panel collapsing the CMSA level data to the state year level average prices. The underlying price index for each CMSA can be downloaded here: http://www.bls.gov/cpi/cpiovrvw.htm.

\section{A.5 Other Data Sources for Appendix Tables}

In addition to the sources referenced in the notes of Table 5, we also use a few other data sources for control variables for Appendix Table A20, Appendix Table A21, Appendix Table A22, and Appendix Table A23. Data on the political party of state governors and sales tax rates were hand-collected from annual editions of the Book of the States. Corporate tax revenue measures are from the U.S. Census Bureau's Government Division: Database on Historical State Tax Collections.

State level gross receipts taxes are developed strictly from information provided in the CSG (19762011), in notes corresponding to corporate income tax tables and descriptions of recent legislative changes to rates. Other media reporting, including descriptions of tax systems by state government websites, were not considered. When rates included thresholds of graduation, the highest reported rate was used. Gross receipts taxes levied by states on particular industries - Connecticut and New York enacted such a tax on oil companies in 1980, for example - are not included. When states employ corporate income taxes with a gross receipts component, only the gross receipts tax is considered. Additional taxes, such as Kentucky's Limited Liability Entity Tax - in which the lesser of 0.095\% of an entity's gross receipts or $0.75 \%$ of its gross profits are taxed - as well as allowances for small business to pay a gross receipts tax in replacement of the standard corporate income tax (most recently in Idaho and Montana), are also excluded. Finally, taxes must be based on gross receipts to be considered in the Appendix specifications that control for gross receipts taxes. Franchise taxes or income taxes that use gross receipts as a threshold marker for graduation levels are not included.

We use establishment level data from the National Establishment Time Series dataset to perform additional robustness checks in Tables A15 and A17. In particular, we use these data to compute the fraction of establishments that belong to single-state firms at the PUMA-decade level. We then combine these data with the County Business Patterns establishment counts in order to analyze the effects of business taxes on single-state firms. Specifically, we use the NETS data to obtain the fraction of establishments that belong to single-state firms at the PUMA-decade level for the years 1990, 2000, and 2010 and multiply the establishment counts from the County Business Patterns by this fraction. We use this product to create new changes in the number of establishments across decades and use this variable as the dependent variable in Tables A15 and A17. This analysis alleviates concerns of endogeneity of apportionment formulas.

\section{A.6 Variation in Tax Rates}

This subsection briefly describes variation in tax rates. There are a substantial number of changes to both statutory corporate tax rates and apportionment factors that impact local areas across the United States. Panel (a) of Figure A6 shows the histogram of ten-year changes in the statutory state corporate rate and panel (b) shows a similar figure for ten-year changes in payroll apportionment weights. Of the 1470 PUMA-decade observations in the main dataset, there are hundreds of sizable 
changes in both aspects of corporate tax policy over three periods of interest: 1980-1990, 1990-2000, and 2000-2010.

In terms of the describing the determinants of state tax policy changes, we follow the approach that Goolsbee and Maydew (2000) use to address endogeneity concerns in section 4.2 of their paper. ${ }^{52}$ We find similar results. Specifically, we find that tax competition with other states is the main factor that is related to the decision to change these state tax policies. Neither economic factors nor other state tax policies are significant for any of the policy probits. For example, for the policy probit for which the dependent variable is an indicator that equals one if payroll apportionment weights are changed, only the average payroll apportionment weights of other states are significant at the $5 \%$ level. None of the economic factors or other tax rates are significant. See Appendix Tables A34 and A35 for the policy probit results for payroll apportionment and statutory corporate tax changes, respectively.

\section{B Model Details}

This section characterizes the establishment problem under apportionment in Section B.1 and derives the expression for profits, local labor demand, and incidence in Sections B.2, B.3, and B.4, respectively.

\section{B.1 Establishment Problem with Apportionment}

In a given location $c$, establishments maximize profits over inputs and prices $p_{i j c}$ while facing a local wage $w_{c}$, national rental rates $\rho$, national prices $p_{v}$ of each variety $v$, local corporate taxes $\tau_{s}^{c}$, and local apportionment weights $\theta_{s}$ subject to the production technology in Equation 3:

$$
\pi_{i j c}=\max _{l_{i j c}, k_{i j k}, x_{v, i j c}, p_{i j c}}\left(1-\tau_{i}^{A}\right)\left(p_{i j c} y_{i j c}-w_{c} l_{i j c}-\int_{v \in J} p_{v} x_{v, i j c} d v\right)-\rho k_{i j c}-\left(\tau_{i}^{A}-\tau_{i / j}^{A}\right) \Pi_{i / j}^{p},
$$

where $\tau_{i}^{A}=\left(\sum_{s^{\prime}}\left(\left(\tau_{s^{\prime}}^{c} \theta_{s^{\prime}}^{x} a_{i s^{\prime}}^{x}\right)+\left(\tau_{s^{\prime}}^{c} \theta_{s^{\prime}}^{w} a_{i s^{\prime}}^{w}\right)+\left(\tau_{s^{\prime}}^{c} \theta_{s^{\prime}}^{\rho} a_{i s^{\prime}}^{\rho}\right)\right)\right)$ is the effective "apportioned" corporate tax rate with activity weights for sales $a_{i s}^{x}$, payroll $a_{i s}^{w}$, and property $a_{i s}^{\rho}$ and $a_{i s}^{w} \equiv \frac{w_{c} l_{i j c}}{W_{i}}$ is the local share of national payroll, $W_{i}$, for firm $i .{ }^{53}$ Sales and property activity weights are defined similarly. ${ }^{54}$ In addition, $\tau_{i / j}^{A}$ and $\Pi_{i / j}^{p}$ are the effective apportioned corporate tax rate and pre-tax profit respectively for firm $i$ without any production from establishment $j$.

State tax laws, which apportion firm profits based on firm activity to determine tax liabilities, have two important effects on establishments. First, the effective apportioned corporate tax rate $\tau^{A}$ of an establishment operating in location $c$ can be quite different than $\tau_{c}^{c}$, the statutory state corporate rate, due to apportionment and activity weights. Second, increasing production at a given establishment affects the firm's tax liability by the product of the change in the firm's effective apportioned tax

\footnotetext{
${ }^{52}$ Specifically, we run policy probits where the dependent variables are an indicator that equals one if a given state tax policy changes. For apportionment weights, the indicator equals one if the apportionment weight is different from the year before. For state corporate tax rates, the indicator equals one if the tax rate change exceeds 0.5 percentage points. For each, the explanatory variables are the current and lagged mean of the dependent variable in other states, other state tax policies that are not the dependent variable, and lagged levels of state per capita income growth and national unemployment rates. This specification follows that of Goolsbee and Maydew (2000) for payroll apportionment and extends it to include more recent data and a new outcome: state corporate tax rates.

${ }^{53}$ Given the typical structure of state corporate tax schedules, one can think of $\tau_{i}^{A}$ as both the marginal and average tax rate of establishments owned by firm $i$.

${ }^{54}$ For apportionment purposes, property is measured as the sum of land and capital expenditures.
} 
rate (due to establishment production) and the firm's pretax profits: $\left(\tau_{i}^{A}-\tau_{i / j}^{A}\right) \Pi_{i / j}^{p}$. Thus, including this additional term incorporates the ultimate effects on firm $i$ 's profitability due to the location and production decisions at establishment $j$.

One can show that demand takes the following form: ${ }^{55}$

$$
y_{i j c}=I\left(\frac{p_{i j c}}{P}\right)^{\varepsilon^{P D}},
$$

where $I$ is the sum of national real income not spent on housing and intermediate good demand from establishments, and $P$ is the price level, which was normalized to 1 in the prior section.Using this demand expression to substitute for price gives the following expression for establishment $j$ 's economic profits.

$$
\pi_{i j c}=\left(1-\tau_{i}^{A}\right)\left(y_{i j c}^{\frac{1}{\mu}} I^{\left(\frac{1}{\varepsilon^{P D}}\right)}-w_{c} l_{i j c}-\int_{v \in J} p_{v} x_{v, i j c} d v\right)-\rho k_{i j c}-\left(\tau_{i}^{A}-\tau_{i / j}^{A}\right) \Pi_{i / j}^{p},
$$

where the markup $\mu \equiv\left[\frac{1}{\varepsilon^{P D}}+1\right]^{-1}$ is constant due to CES demand.

Firms maximize this establishment profit function and set the optimal choices of labor, capital, and intermediate inputs. These, in turn, determine the scale in production in each establishment. However, as first noted McLure Jr. (1977), the effective tax rate faced by a given firm is affected by changes in the geographical distribution of payroll and capital. ${ }^{56}$ Thus, when firms optimize this profit function, they take this effect into consideration, thus creating a wedge between the marginal product of factors and their respective marginal costs. These wedges are evident in the firm's first-order conditions for labor and capital: 57

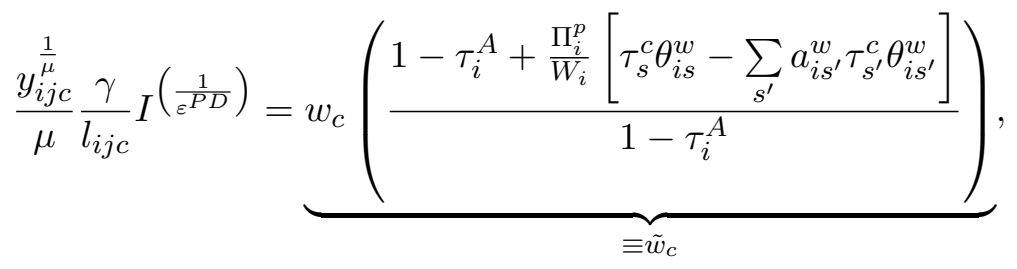

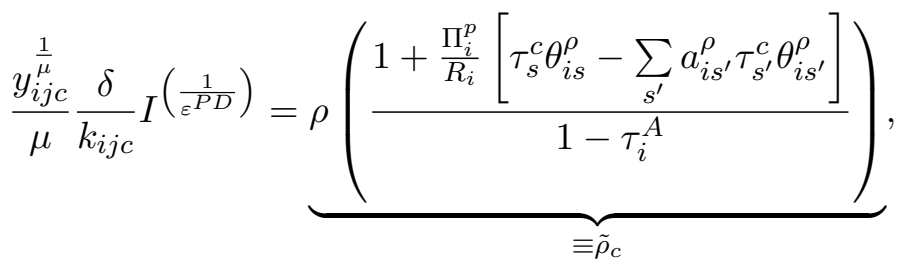

We denote the effective wage and capital rental rates $\tilde{w}_{c}$ and $\tilde{\rho}_{c}$ respectively. Note that capital owners supply capital perfectly elastically at the national rate, so local capital wedges result in lower levels of local capital. ${ }^{58}$ These conditions and the input demand for the bundle of intermediate goods yield

\footnotetext{
${ }^{55}$ See the appendix of Basu (1995) for a derivation where $I$ is analogous to the sum of intermediate goods and final goods in Equation (A6) of his paper.

${ }^{56}$ McLure Jr. (1977) assumed that the corporate rate of all other states was zero, so the term in brackets simplifies to a simpler factor wedge, e.g., $\tau_{s}^{c} \theta_{i s}^{w}\left(1-a_{i s}^{w}\right)$.

${ }^{57}$ Note the following auxiliary derivative $\frac{\partial \tau_{i}^{A}}{\partial l_{i j c}}=\frac{\tau_{s}^{c} \theta_{i s}^{w}}{W_{i}} w_{c}-\sum_{s^{\prime}} \frac{\tau_{s^{\prime}}^{c} \theta_{i s^{\prime}}^{w} W_{i s^{\prime}}}{W_{i}^{2}} w_{c}=\frac{w_{c}}{W_{i}}\left[\tau_{s}^{c} \theta_{i s}^{w}-\sum_{s^{\prime}} a_{i s^{\prime}}^{w} \tau_{s^{\prime}}^{c} \theta_{i s^{\prime}}^{w}\right]$ where the second equality exploits the assumption that all of a firm's activity in a given state is done by one establishment.

${ }^{58}$ Given the setup of the establishment problem, we effectively abstract from consequences of state corporate tax
} 
an expression for firm revenues and costs that takes the form: ${ }^{59}$

$$
y_{i j c}^{\frac{1}{\mu}} I^{\left(\frac{1}{\varepsilon^{P D}}\right)}=y_{i j c} \mu \underbrace{\frac{1}{B_{i j c}}\left[\tilde{w}^{\gamma} \tilde{\rho}^{\delta} \gamma^{-\gamma} \delta^{-\delta}(1-\gamma-\delta)^{-(1-\gamma-\delta)}\right]}_{\equiv c_{i j c}},
$$

This equation shows that revenues are a markup $\mu$ over costs, i.e., $p_{i j c} y_{i j c}=\mu y_{i j c} c_{i j c}$, indicating that prices are a markup over marginal costs $c_{i j c}$.

\section{B.2 Deriving the Profit Expression}

Taking a ratio of the first order conditions (Equation 25 and 26) and the analogous expression for the intermediate good bundle yields an expression for the capital to labor and intermediate goods to labor ratios:

$$
\frac{k_{i j c}}{l_{i j c}}=\frac{\tilde{w}_{c}}{\tilde{\rho}_{c}} \frac{\delta}{\gamma} \quad \frac{M_{i j c}}{l_{i j c}}=\frac{\tilde{w}_{c}}{1} \frac{1-\gamma-\delta}{\gamma}
$$

Plugging these expressions into the production function yields expressions for input demand:

$$
\begin{aligned}
y_{i j c}=B_{i j c} l_{i j c}^{\gamma} k_{i j c}^{\delta}\left(\frac{\tilde{w}_{c}}{1} \frac{1-\gamma-\delta}{\gamma} l_{i j c}\right)^{1-\gamma-\delta} & \Rightarrow l_{i j c}=\frac{y_{i j c}}{B_{i j c}}\left[\tilde{w}_{c}^{\gamma-1}\left(\tilde{\rho}_{c}\right)^{\delta} \gamma^{1-\gamma} \delta^{-\delta}(1-\gamma-\delta)^{-(1-\gamma-\delta)}\right] \\
& \Rightarrow k_{i j c}=\frac{y_{i j c}}{B_{i j c}}\left[\tilde{w}_{c}^{\gamma}\left(\tilde{\rho}_{c}\right)^{\delta-1} \gamma^{-\gamma} \delta^{1-\delta}(1-\gamma-\delta)^{-(1-\gamma-\delta)}\right] \\
& \Rightarrow M_{i j c}=\frac{y_{i j c}}{B_{i j c}}\left[\tilde{w}^{\gamma}\left(\tilde{\rho}_{c}\right)^{\delta} \gamma^{-\gamma} \delta^{-\delta}(1-\gamma-\delta)^{(\gamma+\delta)}\right]
\end{aligned}
$$

Substituting the expression for labor into Equation 25 and rearranging terms yields the markup expression in Equation 27. With these expressions for establishment factor demand, we can now derive the expression for profits in Equation 5.

\section{B.2.1 Profits}

We begin with the following expression for profits in terms of factors:

$$
\pi_{i j c}=\left(1-\tau_{i}^{A}\right)\left(p_{i j c} y_{i j c}-w_{c} l_{i j c}-\int_{v \in J} p_{v} x_{v, i j c} d v\right)-\rho k_{i j c}-\left(\tau_{i}^{A}-\tau_{i / j}^{A}\right) \Pi_{i / j}^{p}
$$

In terms of after-wedge wages and interest rates, we can use the capital to labor ratio, the intermediate goods to labor ratio, and the implication of Equation 27 that price is a markup over marginal costs to express profits as follows:

$$
\pi_{i j c}=\left(1-\tau_{i}^{A}\right) \tilde{w}_{c} l_{i j c}\left[\frac{\mu}{\gamma}-\frac{1}{\omega_{w}}-\frac{1-\gamma-\delta}{\gamma}-\frac{\left(1-\tau_{i}^{A}\right)}{\omega_{\rho}} \frac{\delta}{\gamma}\right]-\left(\tau_{i}^{A}-\tau_{i / j}^{A}\right) \Pi_{i / j}^{p},
$$

changes on capital structure choices. See Heider and Ljungqvist (2014) for such an analysis.

${ }^{59}$ See Appendix B.2 for the derivation. Note that the price of the intermediate good bundle is 1. 
where $\omega_{w} \equiv\left(\frac{1-\tau_{i}^{e}+\frac{\Pi_{i}^{p}}{W_{i}}\left[\tau_{s}^{c} \theta_{i s}^{w}-\sum_{s^{\prime}} a_{i s^{\prime}}^{w} \tau_{s^{\prime}}^{c} \theta_{i s^{\prime}}^{w}\right]}{1-\tau_{i}^{A}}\right)$ and $\omega_{\rho} \equiv\left(\frac{1+\frac{\Pi_{i}^{p}}{R_{i}}\left[\tau_{s}^{c} \theta_{i s}^{r}-\sum_{s^{\prime}} a_{i s^{\prime}}^{\rho} \tau_{s^{\prime}}^{c} \theta_{i s^{\prime}}^{\rho}\right]}{1-\tau_{i}^{e}}\right)$. Substituting for labor and using the definition of product demand yields:

$$
\pi_{i j c}=\left(1-\tau_{i}^{A}\right) I \mu^{\varepsilon^{P D}} c_{i j c}^{\varepsilon^{P D}+1}\left[\mu-\frac{\gamma}{\omega_{w}}-\frac{1-\gamma-\delta}{1}-\frac{\left(1-\tau_{i}^{A}\right) \delta}{\omega_{\rho}}\right]-\left(\tau_{i}^{A}-\tau_{i / j}^{A}\right) \Pi_{i / j}^{p}
$$

Notice that in the standard case in which there are no apportionment wedges, the term in brackets would be $\mu-1$, indicating that profits are a markup over costs where $\mu \geq 1$. Substituting for $c_{i j c}$, we can express profits as a function of local factor prices, local productivity, and taxes:

$$
\pi_{i j c}=\left(1-\tau_{i}^{A}\right) \tilde{w}_{c}^{\gamma\left(\varepsilon^{P D}+1\right)} \tilde{\rho}_{c}^{\delta\left(\varepsilon^{P D}+1\right)} B_{c}^{-\left(\varepsilon^{P D}+1\right)} \tilde{\mu}_{i c} \kappa-\left(\tau_{i}^{A}-\tau_{i / j}^{A}\right) \Pi_{i / j}^{p},
$$

where $\tilde{\mu}_{i c}$ is an apportionment adjusted markup term and $\kappa$ is a constant term across locations. ${ }^{60}$

Equation 28 shows that apportionment creates an externality between the after-tax profits within multi-state firms. In practice, this tax-shifting term is empirically small relative to the other components of establishment profitability. The intuition for this result is that the potential change in the firm's apportionment tax rates $\left(\tau_{i}^{A}-\tau_{i / j}^{A}\right)$ is small and declines at a rate faster than the impact of increasing establishment on profits. Appendix B.2.2 quantifies this argument explicitly.

\section{B.2.2 Quantifying the Tax Shifting Term}

In this section, we show that log profits can be closely approximated by $\ln \pi_{i j c}=\ln \left(1-\tau_{i}^{A}\right)+$ $\gamma\left(\varepsilon^{P D}+1\right) \ln \tilde{w}+(1-\gamma)\left(\varepsilon^{P D}+1\right) \ln \tilde{\rho}-\left(\varepsilon^{P D}+1\right) \ln B+\tilde{\mu}_{i c}+\ln \kappa$. To illustrate this point, let $\bar{\pi}$ be the average profit of the existing $N$ establishments and assume that the establishments in all states are of the same size. In this case, we can write the change in firm profits from opening the new establishment as:

$$
\pi=\left(1-\tau^{A}\right) \bar{\pi}-\phi N \bar{\pi}\left(\tau^{A}-\tau_{0}^{A}\right),
$$

where $\phi$ is a factor of relative profitability of the old establishments and $\tau_{0}^{A}$ is the pre-existing effective corporate tax rate. It then follows that the share of new establishment profits as a fraction of the total change in profit is given by:

$$
\frac{1-\tau^{A}}{1-\tau^{A}-\phi N\left(\tau^{A}-\tau_{0}^{A}\right)}
$$

From this equation we observe that the fraction is close to 1 when the change in taxes is small, i.e., $\left(\tau^{A}-\tau_{0}^{A}\right) \approx 0$ and is decreasing in the size of the firm $N$. Note that $\left(\tau^{A}-\tau_{0}^{A}\right) \approx\left(\frac{1}{N+1}-\frac{1}{N}\right)$. Related to a point raised by Bradford (1978), one may be concerned that small activity weight changes are associated with large profits, i.e., $N \bar{\pi}$, so the product of activity weight changes and profits may still be large. However, the product is small in this setting. To see this, note that the product of the change in activity weights and profits is roughly:

$$
\underbrace{\left(\frac{1}{N+1}-\frac{1}{N}\right)}_{\text {Activity weight change }} \underbrace{\phi N \bar{\pi}}_{\text {profits }} \text {. }
$$

As $N \rightarrow \infty$, this product goes to zero regardless of the size of $\phi \bar{\pi}$. Since most employment in the U.S. happens at firms that are located in more that ten states, we believe that ignoring the tax shifting

$$
{ }^{60} \kappa \equiv I \mu^{\varepsilon^{P D}}\left(\gamma^{-\gamma} \delta^{-\delta}(1-\gamma-\delta)^{-(1-\gamma-\delta)}\right)^{\varepsilon^{P D}}+1 \text { and } \tilde{\mu}_{i c} \equiv\left[\mu-\frac{\gamma}{\omega_{w}}-\frac{1-\gamma-\delta}{1}-\frac{\left(1-\tau_{i}^{A}\right) \delta}{\omega_{\rho}}\right] .
$$


part of the firm's decision problem does not significantly bias our estimates.

\section{B.3 Local Labor Demand}

$$
L_{c}^{D}\left(w_{c} ; Z_{c}, \tau_{s}^{b}\right)=\mathbb{E}_{\zeta}\left[n^{*}\left(\zeta_{i j c}\right) \mid c=\underset{c^{\prime}}{\operatorname{argmax}}\left\{V_{i j c^{\prime}}\right\}\right] E_{c}
$$

To determine local labor demand, we first solve for the intensive labor demand term.

\section{B.3.1 Intensive Margin}

$$
\begin{aligned}
& l_{i j c}=\frac{y_{i j c}}{B_{i j c}}\left[\tilde{w}_{c}^{\gamma-1}\left(\tilde{\rho}_{c}\right)^{\delta} \gamma^{1-\gamma} \delta^{-\delta}(1-\gamma-\delta)^{-(1-\gamma-\delta)}\right] \\
& l_{i j c}=B_{i j c}^{-\left(\epsilon^{P D}+1\right)} \tilde{w}_{c}^{\left(\gamma \epsilon^{P D}+\gamma-1\right)} \tilde{\rho}_{c}^{\left(1+\epsilon^{P D}\right) \delta} \kappa_{0},
\end{aligned}
$$

where $\kappa_{0}=I \mu^{\epsilon^{P D}} \gamma^{-\gamma\left(\epsilon^{P D}+2\right)+1} \delta^{-\delta\left(\epsilon^{P D}+2\right)}(1-\gamma-\delta)^{-(1-\gamma-\delta)\left(\epsilon^{P D}+2\right)}$. Thus, we can express $\mathbb{E}_{\zeta}\left[l_{i j c}^{*}\left(\zeta_{i j c}\right) \mid c=\right.$ $\left.\underset{c^{\prime}}{\operatorname{argmax}}\left\{V_{i j c^{\prime}}\right\}\right]$ as follows:

$$
\mathbb{E}_{\zeta}\left[n^{*}\left(\zeta_{c}^{j}\right) \mid c\right]=\tilde{w}_{c}^{\left(\gamma \epsilon^{P D}+\gamma-1\right)} \tilde{\rho}_{c}^{\left(1+\epsilon^{P D}\right) \delta} \kappa_{0} \mathbb{E}_{\zeta}\left[B_{i j c}^{-\left(\epsilon^{P D}+1\right)}\right]
$$

where $\mathbb{E}_{\zeta}\left[B_{i j c}^{-\left(\epsilon^{P D}+1\right)}\right]=\exp \left(\left(-\epsilon^{P D}-1\right) \bar{B}_{c}\right) \underbrace{\mathbb{E}_{\zeta}\left[\exp \left(\left(-\epsilon^{P D}-1\right) \zeta_{i j c}\right) \mid c\right]}_{\equiv z_{c}}$.

\section{B.3.2 Growth in Local Labor Demand}

We can now combine this intensive labor demand expression with the expression for aggregate location decisions to determine local labor demand.

$$
L_{c}^{D}=\mathbb{E}_{\zeta}\left[l_{i j c}^{*}\left(\zeta_{i j c}\right) \mid c=\underset{c^{\prime}}{\operatorname{argmax}}\left\{V_{i j c^{\prime}}\right\}\right] E_{c}
$$

Taking logs yields (log) labor demand:

$$
\begin{aligned}
\ln L_{c}^{D} & =\ln \left(\tilde{w}_{c}^{\left(\gamma \epsilon^{P D}+\gamma-1\right)} \tilde{\rho}_{c}^{\left(1+\epsilon^{P D}\right) \delta} \kappa_{0} \exp \left(\bar{B}_{c}\left(-\epsilon^{P D}-1\right)\right) z_{c}\right)+ \\
& +\frac{\bar{B}_{c}}{\sigma^{F}}-\frac{\gamma}{\sigma^{F}} \ln \tilde{w}_{c}-\frac{\delta}{\sigma^{F}} \ln \tilde{\rho}_{c}-\frac{\ln \tilde{\mu}_{i c}}{\left(\varepsilon^{P D}+1\right) \sigma^{F}}-\frac{\ln \left(1-\bar{\tau}_{i s}^{A}\right)}{\left(\varepsilon^{P D}+1\right) \sigma^{F}}-\ln (C)-\ln (\bar{\pi})
\end{aligned}
$$

Simplifying this expression yields the (log) local labor demand curve. ${ }^{61}$

$$
\begin{aligned}
\ln L_{c}^{D} & =\kappa_{2}-\frac{\ln \left(1-\tau_{c}^{b}\right)}{\left(\varepsilon^{P D}+1\right) \sigma^{F}}-\ln \bar{\pi}+\left(\gamma\left(\epsilon^{P D}+1-\frac{1}{\sigma^{F}}\right)-1\right) \ln \tilde{w}_{c}-\frac{\ln \tilde{\mu}_{i c}}{\left(\varepsilon^{P D}+1\right) \sigma^{F}} \\
& +\left(\delta\left(\epsilon^{P D}+1-\frac{1}{\sigma^{F}}\right)\right) \ln \tilde{\rho}_{c}+\left(-\left(\epsilon^{P D}+1\right)+\left(\frac{1}{\sigma^{F}}\right)\right) \bar{B}_{c}+z_{c}
\end{aligned}
$$

\footnotetext{
${ }^{61}$ In the model, we treat all establishments as C-corporations, but some labor is demanded by other types of firms. We assume that C-corporations and non C-corporations are the same in all other dimensions and, for analytical tractability, that corporate status is fixed. As a result, we can replace the apportioned rate with the corporate form weighted average business tax rate that was introduced in Section 4.
} 
where $\kappa_{2}$ is a common term across locations and $\bar{\pi}$ is a sufficient statistic for tax, factor price, and productivity changes in all other cities. ${ }^{62}$

\section{B.4 Equilibrium and Incidence Expressions}

Spatial equilibrium $c$ depends market clearing in factor markets, housing markets, and output markets, and can be expressed in terms of the expressions for log labor supply (Equation 1), the log of housing market clearing condition from Section 1.2, and log labor demand (Equation 29) as follows:

$$
\begin{gathered}
-\frac{\bar{A}_{c}}{\sigma^{W}} \\
-B_{c}^{H} \\
\left.-\left(\ln \kappa_{2}-\frac{\ln \left(1-\tau_{c}^{b}\right)}{\left(\varepsilon^{P D}+1\right) \sigma^{F}}-\ln \bar{\pi}+\left(-\left(\epsilon^{P D}+1\right)+\left(\frac{1}{\sigma^{F}}\right)\right) \bar{B}_{c}-\frac{\ln \tilde{\mu}_{i c}}{\left(\varepsilon^{P D}+1\right) \sigma^{F}}+z_{c}\right)\right] \\
=\left[\begin{array}{ccc}
-1 & \frac{1}{\sigma^{W}} & -\frac{\alpha}{\sigma^{W}} \\
-1 & -1 & 1+\eta_{c} \\
-1 & \varepsilon^{L D} & 0
\end{array}\right] \times\left[\begin{array}{c}
\ln N_{c} \\
\ln w_{c} \\
\ln r_{c}
\end{array}\right]
\end{gathered}
$$

The expressions for log population, wages, and rents can be derived using Cramer's rule yielding the following local corporate tax elasticities:

$$
\begin{aligned}
\frac{\partial \ln N}{\partial \ln \left(1-\tau^{c}\right)} & =\varepsilon^{L S} \frac{\frac{-f_{c}^{C}}{\left(\varepsilon^{P D}+1\right) \sigma^{F}}}{\varepsilon^{L S}-\varepsilon^{L D}} \\
\frac{\partial \ln w_{c}}{\partial \ln \left(1-\tau^{c}\right)} & =\frac{-\frac{f_{c}^{C}}{\left(\varepsilon^{P D}+1\right) \sigma^{F}}}{\left(\frac{1+\eta_{c}-\alpha}{\sigma^{W}\left(1+\eta_{c}\right)+\alpha}\right)-\varepsilon^{L D}} \\
\frac{\partial \ln r_{c}}{\partial \ln \left(1-\tau^{c}\right)} & =\left(\frac{1+\varepsilon^{L S}}{1+\eta_{c}}\right) \frac{-f_{c}^{C}}{\varepsilon^{L S}-\varepsilon^{L D}} \\
\frac{\partial \ln w_{c}}{\partial \ln \left(1-\tau^{c}\right)}-\alpha \frac{\partial \ln r_{c}}{\partial \ln \left(1-\tau^{c}\right)} & =\sigma^{W} \varepsilon^{L S} \frac{-f_{c}^{C}}{\varepsilon^{L S}-\varepsilon^{L D}}
\end{aligned}
$$

where $\left(\frac{1+\eta-\alpha}{\sigma^{W}(1+\eta)+\alpha}\right) \equiv \varepsilon^{L S}$ is the effective labor supply elasticity.

\section{Incidence and Efficiency of Corporate Taxes}

This section discusses the effects of a local corporate tax change on the welfare of agents in other locations and on efficiency. The final section analyzes extreme cases of incidence.

\section{C.1 Global Welfare}

The welfare effects derived in Section 2.2 would provide sufficient information for a state-elected official who is interested in maximizing local welfare. Nonetheless, maximizing local objectives can affect the welfare of agents in other locations. We now characterize the effects on both local "domestic" agents and "foreign" agents using the framework in Kline (2010) and Kline and Moretti (2013) by allowing wages and rental costs in other locations to be affected by tax changes in any given state. We extend

\footnotetext{
${ }^{62}$ Note that $\bar{\pi}$ is a actually a C-corporation and non C-Corporation share weighted average of profits in all other cities. In addition, note that $\kappa_{2} \equiv \ln \kappa_{0} \frac{\ln \kappa}{\left(\varepsilon^{P D}+1\right) \sigma^{F}}$.
} 
their framework to incorporate firm owners and define aggregate social welfare $\mathcal{W}$ as the sum of the expected welfare of workers, firm owners, and landowners: ${ }^{63}$

$$
\mathcal{W}=\mathcal{V}^{W}+\mathcal{V}^{F}+\sum_{c} \mathcal{V}_{c}^{L}
$$

The effect of a corporate tax cut in location $c$ on aggregate worker welfare is now:

$$
\frac{d \mathcal{V}^{W}}{d \ln \left(1-\tau_{c}^{c}\right)}=\underbrace{N_{c}\left(\dot{w}_{c}-\alpha \dot{r}_{c}\right)}_{\text {Domestic Workers }}+\sum_{c^{\prime} \neq c} \underbrace{N_{c^{\prime}}\left(\dot{w}_{c^{\prime}}-\alpha \dot{r}_{c^{\prime}}\right)}_{\text {Foreign Workers }} .
$$

Similar to the logic of Moretti (2010), who analyzes the effects of a labor demand shock in the two city case, a corporate tax cut not only benefits local workers by increasing wages, but it also helps foreign workers via housing cost relief. These gains, however, can be offset to the extent that domestic workers have to pay higher rents and foreign workers earn lower wages.

The effect of a cut in corporate taxes on aggregate firm owner welfare can be written as:

$$
\frac{d \mathcal{V}^{F}}{d \ln \left(1-\tau_{c}^{c}\right)}=E_{c} \dot{\pi}_{c}+\sum_{c^{\prime} \neq c} E_{c^{\prime}} \gamma\left(\varepsilon^{P D}+1\right) \frac{d w_{c^{\prime}}^{c}}{d \ln \left(1-\tau_{c}^{c}\right)},
$$

where $E_{c}$ is the share of establishments in location $c, \dot{\pi}_{c}$ is the percentage change in after-tax profits in location $c, \gamma$ is the output elasticity of labor, and $\varepsilon^{P D}$ is the product demand elasticity. As in Bradford (1978), factor price changes affect all firm owners foreign and domestic. In particular, owners of domestic firms benefit from the mechanical decrease in tax liabilities and capital costs, but have to pay higher wages. Owners of foreign firms do not get the mechanical or capital cost changes, but they do gain from lower wage costs since fewer establishments bid up wages in their local labor markets.

Finally, landowner welfare changes by $\frac{\dot{N}_{c}+\dot{w}_{c}}{1+\eta_{c}}$ in each location. The aggregate of these effects may be positive or negative depending on the net flows of workers and establishments. Empirically estimating global incidence is beyond the scope of this paper (see Fajgelbaum et al. (2015) for such an analysis), yet these calculations illustrate the effects of spatial equilibrium forces on aggregate welfare when policies are set by maximizing local objectives.

\section{C.2 Efficiency}

The previous section detailed the effects of corporate tax changes on the welfare of workers, firm owners, and landlords. In this section, we turn to efficiency considerations by analyzing how state corporate taxes affect a social planner's problem. ${ }^{64}$ The social planner maximizes global welfare $\mathcal{W}=\mathcal{V}^{W}+\mathcal{V}^{F}+\mathcal{V}^{L}$ over $\left\{\tau_{c}^{c}\right\}$ subject to a revenue requirement. The lagrangian takes the following form:

$$
\mathcal{L}=\mathcal{W}-\varphi(\underbrace{\tau_{c}^{c} E_{c} \bar{\pi}_{c}^{p}+\sum_{c^{\prime} \neq c} \tau_{c^{\prime}}^{c} E_{c^{\prime}} \bar{\pi}_{c^{\prime}}^{p}}_{\text {Tax Revenue }}-\mathrm{RR})
$$

\footnotetext{
${ }^{63}$ For simplicity, we assume that there is a continuum of workers, establishments, and landowners of measure one. We use a utilitarian social welfare function that adds up log consumption terms, but one could easily incorporate more general social welfare weights as in Saez and Stantcheva (2013).

${ }^{64}$ This accounting has abstracted away from welfare benefits of government spending which could improve amenities or local productivity. See Suárez Serrato and Wingender (2011) for an analysis of the welfare effects of government spending changes.
} 
where $\bar{\pi}_{c}^{p}$ is the average pretax profit of establishments in location $c$ and RR is the government's revenue requirement. ${ }^{65}$

A consistent message from the previous section is that the effect of a corporate tax change on $\mathcal{W}$ does not depend on behavioral responses. However, behavioral responses have important budgetary consequences that reveal the economic distortions of corporate taxes. ${ }^{66}$ There are two key effects of establishment behavior on the government's budget. The first effect is due to marginal establishments that changed locations as in Busso, Gregory and Kline (2013). These establishments are roughly as profitable as they would have been in their original location without the tax cut, yet tax revenues from these firms decrease. Since the tax revenue required to pay for these cuts depends on how many establishments move, establishment mobility has direct implications for efficiency costs. It follows from Equation 7 that establishment mobility is decreasing in the dispersion of productivity $\sigma^{F}$. As a result, greater productivity dispersion lowers efficiency costs. Intuitively, if establishments are inframarginal due to location-specific productivity advantages, small changes in taxes will not induce establishments to move and will not require excessive payments to new establishments. Measuring this effects empirically requires estimates of the parameters of model.

The second effect on the budget is due to spatial distortions created by local corporate tax changes. Lower taxes induce some establishments to leave the locations where they would be most productive. As a consequence, scale of production, business revenues, tax collections, and aggregate welfare decline. In addition, greater dispersion in (non-sales apportioned) state corporate rates exacerbate these effects. Measuring these effect is more complicated as it requires measures of changes in profitability due to establishment relocation and is an important topic for future research. ${ }^{67}$

Although characterizing global efficiency is beyond the scope of this project, in Section 7 we characterize the impacts of behavioral responses on local budgets from the perspective of state policymakers. Additionally, we derive states' revenue-maximizing tax rates and relate them to the efficiency costs of state corporate taxes.

\section{C.3 Extreme Incidence}

This section explores limiting cases where the formulae in Table 1 display extreme incidence shares. We focus our discussion on the effects of three main parameters that govern worker mobility $\left(\sigma_{W}\right)$, firm mobility $\left(\sigma_{F}\right)$, and the housing market response $(\eta)$. We complement our theoretical discussion with numerical examples presented in Table A1. We consider variations of three cases where one of the agents receives $0 \%$ of incidence and where the remaining incidence may be split or allocated $100 \%$ to one of the other agents. Table A1 provides examples of parameters for each of the following cases:

A: $0 \%$ to Workers. This situation occurs when $\sigma_{W}=0$ implying that workers are perfectly mobile. There are no constraints on how the remaining incidence can be allocated. Sufficiently large values of $\sigma_{F}$ imply that labor demand will not be affected such that workers are fixed and $\beta^{R}=0$. This would imply that $100 \%$ of the gains go to firm owners. Alternatively, it could also be the case that landowners bear $100 \%$ of the benefit while firm owners receive $0 \%$. This

\footnotetext{
${ }^{65}$ We evaluate these costs starting from point of symmetric statutory rates of zero in all locations for simplicity. In general, the initial distribution of tax rates impacts conclusions. For instance, suppose all states except California had a $5 \%$ rate. If California has a $6 \%$ rate, cutting corporate taxes there by one percent would not only increase production but also reduce distortions. However, if California started at $4 \%$ and lowered rates to $3 \%$, then production would increase but the cut would also exacerbate distortions since some establishments that would more productive elsewhere would move to California.

${ }^{66}$ See Hendren (2015) for a discussion of the generality of this calculation.

${ }^{67}$ Cullen and Suárez Serrato (2014) explores how establishment relocation affects productivity as measured by patent activity.
} 
occurs when, holding all other parameters constant, $\eta$ is such that

$$
1+\gamma\left(\varepsilon^{P D}+1\right)\left(\frac{\frac{\mu-1}{\sigma^{F}}}{\frac{1+\eta-\alpha}{\alpha}-\varepsilon^{L D}}-\frac{\delta}{\gamma}\right)=0 .
$$

Note that this does not rely on extreme values of $\sigma^{F}$ and is rather a knife-edge case. Indeed, holding $\eta$ at this level as well as all other parameters and decreasing $\sigma^{F}$, implying relatively more mobile firms, would lower profits below zero.

B: $0 \%$ to land. This situation occurs when $\eta$ is sufficiently large, which implies that the stock of housing is perfectly adaptable to housing demand. There are no constraints on how the remaining incidence can be allocated. For instance, when workers are relatively mobile, and certainly at $\sigma_{W}=0$, firm owners bear all of the benefits. As in the case above, one can also find situations where firm owners earn zero profits, which occurs in knife-edge settings that involve relatively immobile workers and that do not require $\sigma_{F}=0$.

C: $0 \%$ to firm owners. In contrast to workers, firms may earn zero benefits from a tax cut even in cases where $\sigma_{F}>0$. The zero-profit condition given by:

$$
1+\gamma\left(\varepsilon^{P D}+1\right)\left(\frac{\frac{\mu-1}{\sigma^{F}}}{\varepsilon^{L S}-\varepsilon^{L D}}-\frac{\delta}{\gamma}\right)=0
$$

does not have a meaningful economic interpretation beyond the fact that profits are zero. Indeed, this occurs when the profit cost of rising wages is larger than the lower costs due to a cheaper after-tax cost of capital by the exact amount of the decrease in taxes. When this condition holds, the remaining incidence can be allocated to either landowners and workers arbitrarily. One can find examples such that both this condition holds and $\sigma_{W}=0$ so that all incidence is allocated to landowners. Alternatively, one can find cases where this condition holds and $100 \%$ of the incidence is allocated to workers. These situations occur when $\eta$ is large, so that housing supply is very adaptable to changes in the quantity of housing demanded. 
Table A1: Numerical Examples of Extreme Incidence

\begin{tabular}{|c|c|c|c|c|c|c|c|c|c|}
\hline \multirow[b]{2}{*}{ Parameters } & \multicolumn{3}{|c|}{ A: $0 \%$ Workers } & \multicolumn{3}{|c|}{ B: $0 \%$ Land } & \multicolumn{3}{|c|}{ C: $0 \%$ Firms } \\
\hline & Shared & $100 \%$ Land & 100\% Firms & Shared & $100 \%$ Workers & 100\% Firms & Shared & $100 \%$ Workers & 100\% Land \\
\hline$\alpha$ & 0.30 & 0.30 & 0.30 & 0.30 & 0.30 & 0.30 & 0.30 & 0.30 & 0.30 \\
\hline$\gamma$ & 0.15 & 0.15 & 0.15 & 0.15 & 0.15 & 0.15 & 0.15 & 0.15 & 0.15 \\
\hline$\varepsilon^{P D}$ & -5.00 & -5.00 & -5.00 & -5.00 & -5.00 & -5.00 & -5.00 & -5.00 & -5.00 \\
\hline$\eta$ & 3.50 & 29.00 & 3.50 & 100000.00 & 100000.00 & 100000.00 & 3.50 & 100000.00 & 3.50 \\
\hline$\sigma_{W}$ & 0.00 & 0.00 & 0.00 & 0.47 & 0.12 & 1.00 & 0.31 & 0.31 & 0.00 \\
\hline
\end{tabular}

\section{Incidence}

\begin{tabular}{|c|c|c|c|c|c|c|c|c|c|}
\hline Workers & 0.00 & 0.00 & 0.00 & 0.97 & 2.56 & 0.00 & 1.98 & 2.56 & 0.00 \\
\hline Landowners & 1.30 & 8.38 & 0.00 & 0.00 & 0.00 & 0.00 & 1.99 & 0.00 & 8.72 \\
\hline Firmowners & 1.31 & 0.03 & 1.54 & 0.96 & 0.01 & 1.54 & 0.00 & 0.00 & -0.03 \\
\hline \multicolumn{10}{|l|}{ Shares } \\
\hline Workers & $0.00 \%$ & $0.00 \%$ & $0.00 \%$ & $50.00 \%$ & $100.00 \%$ & $0.00 \%$ & $50.00 \%$ & $100.00 \%$ & $0.00 \%$ \\
\hline Landowners & $50.00 \%$ & $100.00 \%$ & $0.00 \%$ & $0.00 \%$ & $0.00 \%$ & $0.00 \%$ & $50.00 \%$ & $0.00 \%$ & $100.00 \%$ \\
\hline Firmowners & $50.00 \%$ & $0.00 \%$ & $100.00 \%$ & $50.00 \%$ & $0.00 \%$ & $100.00 \%$ & $0.00 \%$ & $0.00 \%$ & $0.00 \%$ \\
\hline
\end{tabular}

Notes: This table provides numerical examples where the shares of incidence are allocated in an extreme fashion. The only parameters that vary in this table are $\sigma_{F}, \sigma_{W}$, and $\eta$. For each case, where one of the agents receives $0 \%$ of the incidence, there exists parameters where the incidence can be allcoated in an arbitrary fashion such that the remaining agents can receive from $0 \%$ to $100 \%$ of the incidence. 


\section{Revenue-Maximizing Corporate Tax Rate}

In the next two sections, we briefly derive the revenue-maximizing corporate tax rate under two scenarios about the underlying policymaker's objective. First, we consider the case when the policymaker's objective is to maximize corporate tax revenue while ignoring other tax collections. The second case assumes the policymaker's objective is to maximize all forms of tax revenue. We show that, while the revenue-maximizing tax rate is inversely related to firm mobility, firm mobility on its own does not justify a low maximal tax rate. This conclusion, however, is weakened when the policymaker's objective considers the effects of corporate tax changes on other revenue sources. ${ }^{68}$

\section{D.1 Maximal Tax Rate with No Other State Taxes}

Local (corporate) tax revenue is given by:

$$
\operatorname{TaxRev}_{c}=E_{c} \bar{\pi}_{c} \frac{\tau_{c}^{c}}{1-\tau_{c}^{c}-t_{f e d}} .
$$

Taking logs and differentiating with respect to $\ln \left(1-\tau_{c}^{c}\right)$ we have:

$$
\frac{d \ln \operatorname{TaxRev}_{c}}{d \ln \left(1-\tau_{c}^{c}\right)}=\frac{d \ln E_{c}}{d \ln \left(1-\tau_{c}^{c}\right)}+\dot{\bar{\pi}}_{c}-\frac{1}{\tau_{c}^{c}}-\frac{1}{1-\tau_{c}^{c}-t_{f e d}}
$$

Setting the expression above equal to zero and rearranging we have:

$$
\tau_{c}^{*}=\frac{1}{\dot{\bar{\pi}}_{c}+\dot{E}_{c}}\left(1-t_{f e d}\right)
$$

\section{D.1.1 Maximal Tax Rate with Other State Taxes}

Consider now the maximum tax rate for corporate income when the state also collects personal income. ${ }^{69}$ Local tax revenue is given by:

$$
\operatorname{TotalTaxRev}_{c}=E_{c} \bar{\pi}_{c} \frac{\tau_{c}^{c}}{1-\tau_{c}^{c}-t_{f e d}}+N_{c} w_{c} \tau_{c}^{i}
$$

Following a derivation similar to that in the previous section, we find a revenue-maximizing tax rate given by:

$$
\tau_{c}^{* *}=\frac{1}{\dot{\bar{\pi}}_{c}+\dot{E}_{c}+\left(\text { revshare }_{c}^{\text {pers }} / \text { revshare }_{c}^{C}\right)\left(\dot{w}_{c}+\dot{N}_{c}\right)}\left(1-t_{f e d}\right),
$$

where revshare ${ }_{c}^{\text {pers }} /$ revshare $_{c}^{C}$ is the relative share of personal tax revenues and corporate tax revenues.

\section{D.1.2 Calculating the Tax Elasticity of Establishment Location for States}

This section describes the calculation of the elasticity of establishment location with respect to state corporate tax rates and explores two forms of heterogeneity that may affect this elasticity: size of location (in terms of market share of establishments) and the effects of apportionment across locations in a given state.

\footnotetext{
${ }^{68}$ In addition, these calculations abstract from other potential policy goals (e.g., maximizing welfare) as well as from issues related to assumptions regarding risk aversion of the agents in the model.

${ }^{69}$ In this derivation, we lump sales revenue and personal income tax revenue together. We also ignore the effects of corporate taxes on property tax revenue since local areas rather than states collect the vast majority of property taxes. However, there are interesting fiscal externalities on localities that do collect property taxes.
} 


\section{State Tax Revenue}

In the simple case without apportionment effects, state corporate tax revenue is given by:

$$
\operatorname{TaxRev}_{s}=E_{s} \bar{\pi}_{s} \frac{\tau_{s}^{c}}{1-\tau_{s}^{c}-t_{f e d}}
$$

where $E_{s}$ is the share of national establishments in state $s$ and $\frac{\bar{\pi}_{s}}{1-\tau_{s}^{c}-t_{f e d}}$ is average pre-tax profits. Taking logs and differentiating with respect to $\ln \left(1-\tau_{s}^{c}\right)$ we have:

$$
\frac{d \ln \operatorname{TaxRev}_{s}}{d \ln \left(1-\tau_{s}^{c}\right)}=\frac{d \ln E_{s}}{d \ln \left(1-\tau_{s}^{c}\right)}+\tilde{\pi}_{s}-\frac{1}{\tau_{s}^{c}}-\frac{1}{1-\tau_{s}^{c}-t_{f e d}}
$$

To derive the key component of the expression above - the state level location elasticity $\frac{d \ln E_{s}}{d \ln \left(1-\tau_{s}^{c}\right)}-$ first consider the elasticity with respect to changes at the local PUMA level.

\section{Local Elasticity}

Let $t_{c^{\prime}}$ be effective corporate rate paid in location $c^{\prime}$. Suppose that a policy can be enacted that changes only $t_{c^{\prime}}$ but not other corporate tax rates in the same state. From standard logit formulae (see Train (2009), Chapter 3.6 ), the elasticity of establishment location for a given location $c$ is given by:

$$
\frac{d \log E_{c}}{d \log \left(1-t_{c^{\prime}}\right)}=\left\{\begin{array}{cc}
\frac{1}{-\sigma^{F}\left(\varepsilon^{P D}+1\right)}\left(1-E_{c}\right) & \text { if } c^{\prime}=c \\
-\frac{1}{-\sigma^{F}\left(\varepsilon^{P D}+1\right)} E_{c} & \text { otherwise. }
\end{array}\right.
$$

As we show below, this is not the same exercise as changing the state corporate tax rate. The reason is that the change in the state rate affects the rates of every location within a state and is thus described by a simultaneous change in every state, rather than just a change in $c^{\prime}$. The correct calculation needs to account for both within-states changes in establishment location as well as inter-state changes in establishment location that occur from this joint change.

We now derive the elasticity at the state level under two different cases.

\section{No Apportionment Taxation}

Let $\tau_{S}^{c}$ be the state corporate tax rate in state $S$ and assume that $t_{c}=\tau_{S}^{c}$ for every $c$ in $S$. The experiment of changing $\tau_{S}^{c}$ corresponds to simultaneously changing the rate in every PUMA $c$ in state $S$. The elasticity of the state tax on establishment location for a given location $c$ is then given by:

$$
\begin{aligned}
\frac{d \log E_{c}}{d \log \left(1-t_{S}^{C o r p}\right)} & =\sum_{c^{\prime} \in S} \frac{d \log E_{c}}{d \log \left(1-t_{c^{\prime}}\right)} \frac{d \log \left(1-t_{c^{\prime}}\right)}{d \log \left(1-\tau_{s}^{c}\right)} \\
& =\frac{1}{-\sigma^{F}\left(\varepsilon^{P D}+1\right)}\left(1-\sum_{c^{\prime} \in S} E_{c}^{\prime}\right)
\end{aligned}
$$

where we use the assumption that $\frac{d \log \left(1-t_{c^{\prime}}\right)}{d \log \left(1-\tau_{s}^{c}\right)}=1$. Letting $E_{S} \equiv \sum_{c^{\prime} \in S} E_{c^{\prime}}$ describe the share of establishments in the state, we find that this elasticity is smaller that the own-tax elasticity in a given location by the fraction:

$$
\frac{1-E_{S}}{1-E_{c}}<1 .
$$


This result shows that as taxes are simultaneously reduced in several places, fewer establishments will move into a given location with a tax cut. From this result we can log-linearize to arrive at the elasticity at the state level, which is given by:

$$
\begin{aligned}
\frac{d \log E_{S}}{d \log \left(1-\tau_{s}^{c}\right)} & =\sum_{c \in S}\left(\frac{E_{c}}{E_{S}}\right) \frac{d \log E_{c}}{d \log \left(1-\tau_{s}^{c}\right)} \\
& =\frac{1}{-\sigma^{F}\left(\varepsilon^{P D}+1\right)}\left(1-E_{S}\right) .
\end{aligned}
$$

\section{Apportionment Taxation}

The result in Equation 33 holds when $\frac{d \log \left(1-t_{c}\right)}{d \log \left(1-\tau_{s}^{c}\right)}=1$. However, due to different rules across states and different activity weights across locations in a given state, this derivative is not generally equal to 1 . Following the same logic as above, it can be shown that:

$$
\frac{d \log E_{S}}{d \log \left(1-\tau_{s}^{c}\right)}=\frac{1}{-\sigma^{F}\left(\varepsilon^{P D}+1\right)}\left(1-E_{S}\right)\left(\sum_{c \in S}\left(\frac{E_{c}}{E_{S}}\right) \frac{d \log \left(1-t_{c}\right)}{d \log \left(1-\tau_{s}^{c}\right)}\right),
$$

where the last term measures the size-weighted average effect of a change in the state corporate rate on the effective rate paid by firms in a given state.

This formula accounts for differences across states that are due to size of the state as well as to the formulae used to determine state taxes and the distribution of economic activity within each state. Note that

$$
\frac{d \log \left(1-t_{c}\right)}{d \log \left(1-\tau_{s}^{c}\right)}=\frac{\left(1-\tau_{s}^{c}\right)}{\left(1-t_{c}\right)} \times\left[\left(\theta_{s}^{x} a_{s}^{x}+\theta_{s}^{w} a_{s}^{w}+\theta_{s}^{\rho} a_{c}^{\rho}\right)+\tau_{s}^{c}\left(\theta_{s}^{w} \frac{\partial a_{s}^{w}}{\partial t_{s}^{\text {Corp }}}+\theta_{s}^{\rho} \frac{\partial a_{s}^{\rho}}{\partial t_{s}^{\text {Corp }}}\right)\right],
$$

where $\theta_{S}^{j}$ is the apportionment weight on factor $j$ and $a_{s}^{j}$ is the activity weight is for factor $j$ and where $j=x, w, \rho$ correspond to sales, payroll, and property, respectively.

\section{E Empirical Appendix}

This section has several components. Section E.1 provides a detailed description of estimates underlying Figure 4. Section E.2 provides detailed steps on which parameter is estimated and what data is used. Section E.3 shows evidence on the influence (or lack thereof) of investment incentive changes. In Section E.4, we support the robustness of the reduced-form incidence results using a wide-variety of control variables (the state tax base in subsection E.4.1 and state political and fiscal policy in subsection E.4.2) as well as calibration values in subsection E.4.3. In Section E.5, we provide estimation details on how we estimate the system with four additional moments from Bartik Shocks using classical minimum distance (CMD). Section E.6 presents a complementary approach to our main estimation methodology that estimates the key equations - labor supply, housing supply, and establishment location - equation-by-equation, which facilitates further discussion of our model and provides more flexibility in terms of the estimated structural parameters.

\section{E.1 Annual Effects of Business Tax Cuts on Establishment Growth}

One potential concern is that tax changes may be related to local economic conditions and bias our main result. We measure the effects of local business tax cuts on the growth in the number of local 
establishments using the following specification:

$$
\ln E_{c, t}-\ln E_{c, t-1}=\sum_{h=\underline{h}}^{\bar{h}} \beta_{h}\left[\ln \left(1-\tau_{c, t-h}^{b}\right)-\ln \left(1-\tau_{c, t-1-h}^{b}\right)\right]+\mathbf{D}_{s, t}^{\prime} \boldsymbol{\Psi}_{s, t}+e_{c, t},
$$

where $\ln E_{c, t}-\ln E_{c, t-1}$ is the annual log change in local establishments, $\ln \left(1-\tau_{c, t-h}^{b}\right)-\ln \left(1-\tau_{c, t-1-h}^{b}\right)$ is the annual log change in the net-of-business-tax rate for different time horizons indexed by $h, \mathbf{D}_{s, t}$ is a vector with year dummies as well as state dummies for states in the industrial Midwest in the 1980s. The specification relates changes in establishment growth to leads and lags of annual changes in business taxes, differences out time invariant local characteristics, and adjusts for average national establishment growth and abnormal conditions in rust belt states in the 1980s.

This specification allows for lags that can show the dynamic impacts of tax changes and leads that can detect pre-trends. The baseline specification includes five lags and no leads, i.e., $\bar{h}=5$ and $\underline{h}=0$. In this baseline, we relate business tax changes over the past five years to establishment growth. Summing up the coefficients for each lag provides an estimate of the cumulative effect of a change in business taxes. For example, a state tax change in 2000 has its initial impact $\beta_{0}$ in 2000, its first year impact $\beta_{1}$ in 2001, the second year impact in 2002, etc. The number of local establishments in 2005 reflects the impact of each of these lagged effects, which sum to the cumulative effect $\sum_{h=0}^{5} \beta_{h}$. We also include leads in some specifications. Including leads, i.e., $\underline{h}<0$, enables the detection of abnormal average establishment growth preceding tax changes.

Table A5 shows results for different combinations of leads and lags. Column (1) shows that a one percent cut in business taxes increases establishment growth by roughly $1.5 \%$ over a five-year period. This increase in average growth tends to occur two and three years after the cut. Columns (2) sets $\underline{h}=-2$ and Column (3) sets $\underline{h}=-5$. The estimates of each of the leads in Column (2) indicate that average establishment growth in the two years preceding a business tax cut are not statistically different from zero. The same applies for the specification with 5 leads in Column (3). In addition, the p-value of the joint test that all leads are zero is quite large for both cs. Columns (4) through (7) show similar results with 10 lags and up to 10 leads. Panel A of Figure 4 and Panel B of Figure 4 help visualize the resulting estimates from the ten leads and lags.

Panel A of Figure 4 shows the cumulative effects of the estimates in Column (4). It shows that establishment growth increases following a one percent cut in business taxes, especially two to four years after a tax cut. The cumulative effect after ten years is roughly three percent, which amounts to roughly one fifth of a standard deviation in establishment growth over a ten-year period. Controlling for 10 lags makes the estimates less precise, but the cumulative effect after 10 years is statistically significant at the $90 \%$ level. Panel B of Figure 4 shows the analogous information using the estimates in column (7), which come from a specification with 10 leads and lags. This figure with leads shows a modest dip in average establishment growth in the years before business tax changes occur. However, this decline is statistically indistinguishable from zero. The figure also shows the cumulative effects of the lags if the leads were set to zero. The two cumulative effects with and without leads are quite similar.

Regarding the precision of the event study estimates, it is worth noting three things. First, if we were to narrow the event window around the event, we would reduced the number of estimated effects and increase precision. For example, Column (3) of Table A5 shows statistically significant effects two and three years after the tax cut in a specification that includes leads and lags for five years. Second, having a long event window also reduces the number of data points. Notice that the number of observations in column (7), which corresponds to the event study, is less than half the number of observations in Column (1) and (2). The magnitudes of the two year and three year effects 
are similar across columns, but they become less precise when we increase the number of parameters and decrease the number of observations. Finally, note that we can reject the hypothesis that the cumulative effects are zero in specifications with fewer parameters and more observations.

\section{E.2 Detailed Estimation Steps}

This section enumerates the estimation steps and shows which parameter is being estimated, what data are used, and under what assumptions.

\section{E.2.1 Overview}

There are four main estimation steps:

\section{Estimate Reduced-Form Parameters}

- Estimates $\beta^{W}, \beta^{N}, \beta^{R}, \beta^{E}$.

- Results in Table 4.

2. Estimate Incidence Using Linear Combinations of Reduced-Form Estimates

- Estimates $\beta^{W}-\alpha \beta^{R}, \beta^{R}$, and $1+\left(\frac{\beta^{N}-\beta^{E}}{\beta^{W}}+1\right)\left(\beta^{W}-\frac{\delta}{\gamma}\right)$ from Table 1 .

- Results in Table 5.

\section{Estimate Structural Parameters}

- Estimates $\sigma^{F}, \sigma^{W}, \eta, \varepsilon^{P D}$.

- Results in Table 6.

4. Estimate Incidence using Structural Parameter Estimates

- Estimates $\dot{w}-\alpha \dot{r}, \dot{r}, \dot{\pi}$ from Table 1. Equations 10, 11, and 12 express $\dot{w}, \dot{r}$, and $\dot{\pi}$ in terms of the structural parameters.

- Results in Table 7.

\section{E.2.2 Estimate Reduced-Form Parameters}

1. Parameter: $\beta^{W}$

- Specification: Equation 21 where $Y=W$.

- Data:

- Cells: 490 county groups by decade: 1980-1990, 1990-2000, 2000-2010.

- $\ln w_{c, t}-\ln w_{c, t-10}$ from ACS (see Appendix Section A.2 for wage construction details).

$-\left[\ln \left(1-\tau_{c, t}^{b}\right)-\ln \left(1-\tau^{b}\right)_{c, t-10}\right]$ from sources described in section 4.2.2.

- $\mathbf{D}_{s, t}$ are indicator variables based on geography.

- Identification Assumption: $\mathbb{E}\left(u_{c, t}^{W} \mid\left[\ln \left(1-\tau_{c, t}^{b}\right)-\ln \left(1-\tau_{c, t-10}^{b}\right)\right], \mathbf{D}_{s, t}\right)=0 .{ }^{70}$

\footnotetext{
${ }^{70}$ As we note in the main text in section 5 , this assumption would be violated by potentially confounding elements such as concomitant changes in the tax base, government spending, and productivity shocks. From a dynamic perspective, a violation would also occur if tax changes are the result of adverse local economic conditions that also determine the long-difference in $W$. We support this identifying assumption by showing that the main reduced-form effects of local business taxes on our outcomes are not affected by changes in a number of potential confounders and by showing that the tax changes are not related to prior economic conditions.
} 
- Results in Table A7.

2. Parameter: $\beta^{N}$

- Specification: Equation 21 where $Y=N$.

- Data:

- Cells: 490 county groups by decade: 1980-1990, 1990-2000, 2000-2010.

$-\ln N_{c, t}-\ln N_{c, t-10}$ from BEA Regional Accounts (CA30). ${ }^{71}$

- $\left[\ln \left(1-\tau_{c, t}^{b}\right)-\ln \left(1-\tau^{b}\right)_{c, t-10}\right]$ from sources described in section 4.2.2.

- $\mathbf{D}_{s, t}$ are indicator variables based on geography.

- Identification Assumption: $\mathbb{E}\left(u_{c, t}^{N} \mid\left[\ln \left(1-\tau_{c, t}^{b}\right)-\ln \left(1-\tau_{c, t-10}^{b}\right)\right], \mathbf{D}_{s, t}\right)=0$.

- Results in Table A6. ${ }^{72}$

3. Parameter: $\beta^{R}$

- Specification: Equation 21 where $Y=R$.

- Data:

- Cells: 490 county groups by decade: 1980-1990, 1990-2000, 2000-2010.

- $\ln r_{c, t}-\ln r_{c, t-10}$ from ACS (see Appendix Section A.2 for rental cost details).

- $\left[\ln \left(1-\tau_{c, t}^{b}\right)-\ln \left(1-\tau^{b}\right)_{c, t-10}\right]$ from sources described in section 4.2.2.

- $\mathbf{D}_{s, t}$ are indicator variables based on geography.

- Identification Assumption: $\mathbb{E}\left(u_{c, t}^{R} \mid\left[\ln \left(1-\tau_{c, t}^{b}\right)-\ln \left(1-\tau_{c, t-10}^{b}\right)\right], \mathbf{D}_{s, t}\right)=0$.

- Results in Table A8.

4. Parameter: $\beta^{E}$

- Specification: Equation 21 where $Y=E$.

- Data:

- Cells: 490 county groups by decade: 1980-1990, 1990-2000, 2000-2010.

- $\ln E_{c, t}-\ln E_{c, t-10}$ from County Business Patterns.

- $\left[\ln \left(1-\tau_{c, t}^{b}\right)-\ln \left(1-\tau^{b}\right)_{c, t-10}\right]$ from sources described in section 4.2.2.

- $\mathbf{D}_{s, t}$ are indicator variables based on geography.

- Identification Assumption: $\mathbb{E}\left(u_{c, t}^{E} \mid\left[\ln \left(1-\tau_{c, t}^{b}\right)-\ln \left(1-\tau_{c, t-10}^{b}\right)\right], \mathbf{D}_{s, t}\right)=0$.

- Results in Table 4.

\section{E.2.3 Estimate Incidence Using Linear Combinations of Reduced-Form Estimates}

1. Incidence on Workers

- Expression: $\beta^{W}-\alpha \beta^{R}$

- Data:

- The data for reduced-form estimates of $\beta^{W}$ and $\beta^{R}$ listed in section E.2.2.

\footnotetext{
${ }^{71}$ The comparable estimate in terms of employment rather than population uses employment data from County Business Patterns.

${ }^{72}$ The results for employment rather than population are in Table A9.
} 
$-\alpha$ is calibrated (at different values depending on the Table). ${ }^{73}$

- Identification Assumptions:

$-\mathbb{E}\left(u_{c, t}^{W} \mid\left[\ln \left(1-\tau_{c, t}^{b}\right)-\ln \left(1-\tau_{c, t-10}^{b}\right)\right], \mathbf{D}_{s, t}\right)=0$.

$-\mathbb{E}\left(u_{c, t}^{R} \mid\left[\ln \left(1-\tau_{c, t}^{b}\right)-\ln \left(1-\tau_{c, t-10}^{b}\right)\right], \mathbf{D}_{s, t}\right)=0$.

- Results in Table 5.

2. Incidence on Landowners

- Expression: $\beta^{R}$

- Data:

- The data for reduced-form estimates of $\beta^{R}$ listed in section E.2.2.

- Identification Assumption:

$-\mathbb{E}\left(u_{c, t}^{R} \mid\left[\ln \left(1-\tau_{c, t}^{b}\right)-\ln \left(1-\tau_{c, t-10}^{b}\right)\right], \mathbf{D}_{s, t}\right)=0$.

- Results in Table 5.

3. Incidence on Firm owners

- Expression: $1+\left(\frac{\beta^{N}-\beta^{E}}{\beta^{W}}+1\right)\left(\beta^{W}-\frac{\delta}{\gamma}\right)$

- Data:

- The data for reduced-form estimates of $\beta^{N}, \beta^{E}$, and $\beta^{W}$ listed in section E.2.2.

$-\frac{\delta}{\gamma}$ is calibrated (at different values depending on the Table). ${ }^{74}$

- Identification Assumptions:

$-\mathbb{E}\left(u_{c, t}^{N} \mid\left[\ln \left(1-\tau_{c, t}^{b}\right)-\ln \left(1-\tau_{c, t-10}^{b}\right)\right], \mathbf{D}_{s, t}\right)=0$.

$-\mathbb{E}\left(u_{c, t}^{E} \mid\left[\ln \left(1-\tau_{c, t}^{b}\right)-\ln \left(1-\tau_{c, t-10}^{b}\right)\right], \mathbf{D}_{s, t}\right)=0$.

$-\mathbb{E}\left(u_{c, t}^{W} \mid\left[\ln \left(1-\tau_{c, t}^{b}\right)-\ln \left(1-\tau_{c, t-10}^{b}\right)\right], \mathbf{D}_{s, t}\right)=0$.

- Results in Table 5.

\section{E.2.4 Estimate Structural Parameters}

- Parameters: $\sigma^{F}, \sigma^{W}, \eta, \varepsilon^{P D}$.

- There are four moments in equation 17 :

1. $\beta^{W}-\dot{w}$

2. $\beta^{N}-\dot{w} \varepsilon^{L S}$

3. $\beta^{R}-\frac{1+\varepsilon^{L S}}{1+\eta} \dot{w}$

4. $\beta^{E}-\frac{\mu-1}{\sigma^{F}}-\frac{\gamma}{\sigma^{F}} \dot{w}$

- Definitions:

- Equation 10 defines $\dot{w}$ in terms of the structural parameters.

$-\varepsilon^{L S}=\left(\frac{1+\eta-\alpha}{\sigma^{W}(1+\eta)+\alpha}\right)$ in terms of the structural parameters.

\footnotetext{
${ }^{73}$ See Appendix Tables A24 and A25 for iterations of this table for the following calibrated parameter values: $\alpha \in$ $\{.5, .65\}$, respectively.

${ }^{74}$ See Appendix Tables A26 and A27 for iterations of this table for the following calibrated parameter values: $\frac{\delta}{\gamma} \in$ $\{.75, .5\}$, respectively.
} 
$-\mu=\left[\frac{1}{\varepsilon^{P D}}+1\right]^{-1}$ in terms of the structural parameters.

- Identification Assumptions:

$-\mathbb{E}\left(u_{c, t}^{W} \mid\left[\ln \left(1-\tau_{c, t}^{b}\right)-\ln \left(1-\tau_{c, t-10}^{b}\right)\right], \mathbf{D}_{s, t}\right)=0$.

$-\mathbb{E}\left(u_{c, t}^{N} \mid\left[\ln \left(1-\tau_{c, t}^{b}\right)-\ln \left(1-\tau_{c, t-10}^{b}\right)\right], \mathbf{D}_{s, t}\right)=0$.

$-\mathbb{E}\left(u_{c, t}^{R} \mid\left[\ln \left(1-\tau_{c, t}^{b}\right)-\ln \left(1-\tau_{c, t-10}^{b}\right)\right], \mathbf{D}_{s, t}\right)=0$.

$-\mathbb{E}\left(u_{c, t}^{E} \mid\left[\ln \left(1-\tau_{c, t}^{b}\right)-\ln \left(1-\tau_{c, t-10}^{b}\right)\right], \mathbf{D}_{s, t}\right)=0$.

- Data

- The data for reduced-form estimates of $\beta^{W}, \beta^{N}, \beta^{R}$, and $\beta^{E}$ listed in section E.2.2.

- We calibrate the output elasticity $\gamma$ and $\varepsilon^{P D}$ in some columns (see Table).

- Results in Table 6.

\section{E.2.5 Estimate Incidence using Structural Parameter Estimates}

1. Incidence on Wages

- Expression: $\dot{w}$

- Definitions:

- Equation 10 defines $\dot{w}$ in terms of the structural parameters.

- Data:

- The data are those listed in section E.2.4.

- Identification Assumptions:

- The identification assumptions are those listed in section E.2.4.

- Results in Table 7.

2. Incidence on Landowners

- Expression: $\dot{r}$

- Definitions:

- Equation 11 defines $\dot{r}$ in terms of the structural parameters.

- Data:

- The data are those listed in section E.2.4.

- Identification Assumptions:

- The identification assumptions are those listed in section E.2.4.

- Results in Table 7.

3. Incidence on Workers

- Expression: $\dot{w}-\alpha \dot{r}$

- Definitions:

- Equation 10 defines $\dot{w}$ in terms of the structural parameters.

- Equation 11 defines $\dot{r}$ in terms of the structural parameters.

- Data: 
- The data are those listed in section E.2.4.

$-\alpha$ is calibrated.

- Identification Assumptions:

- The identification assumptions are those listed in section E.2.4.

- Results in Table 7.

4. Incidence on Firm Owners

- Expression: $1+\gamma\left(\varepsilon^{P D}+1\right)\left(\dot{w}-\frac{\delta}{\gamma}\right)$

- Definitions:

- Equation 10 defines $\dot{w}$ in terms of the structural parameters.

- Data:

- The data are those listed in section E.2.4.

$-\gamma$ and $\frac{\delta}{\gamma}$ are calibrated. $\varepsilon^{P D}$ is calibrated in some specifications (see Table).

- Identification Assumptions:

- The identification assumptions are those listed in section E.2.4.

- Results in Table 7.

\section{E.3 Robustness: Investment Tax Credit Changes}

One concern is that concomitant investment incentives might confound the effects of state corporate tax changes in ways that are not detectable in the long difference specification. To address this concern, we use data generously provided by Chirinko and Wilson (2008) and find that there is no relationship between long-run tax changes and investment tax credit changes. Figure A7 shows how the average tax rate change varies for different bins of investment credit changes. The best fit line is fairly flat, the estimated slope is $0.026(\mathrm{se}=.06)$, which is quite modest and not statistically different from zero. For further discussion on concerns regarding the tax base, such as the deductibility of federal corporate taxes and gross receipts taxes, see Appendix Section A.3.4.

\section{E.4 Robustness: Incidence Estimates Using Reduced-Form Effects}

In this section, we establish the robustness of the reduced-form incidence estimates for a few types of controls: (1) state tax base changes in E.4.1 and (2) controls for state political, fiscal policy, and economic condition in subsection E.4.2. We estimate the four main reduced-form effects $-\beta^{N}, \beta^{W}$, $\beta^{R}$, and $\beta^{E}$ - using the specification in Equation 21 plus a given control. We then use those four reduced-form estimates to implement out incidence expressions in Table 1. To construct Appendix Table A19 Columns (1)-(12), we consecutively add the following controls to the baseline specification (i.e., Equation 21). ${ }^{75}$

\section{E.4.1 State Tax Base Controls}

1. Throwback rules. These rules eliminate "nowhere income" that would be untaxed by either the state with the corporation's nexus or the state in which the relevant sales were being made. Data from Bernthal et al. (2012). ${ }^{76}$

\footnotetext{
${ }^{75}$ For Column 13, we control for all of the tax base controls in Columns (1)-(12) other than Column 7 . Column 7 uses a different tax rate that adjusts for federal deductibility (see equation 36), so to avoid using a different tax rate in the all controls specification in Column 13, we use the main tax rate and account for federal deductibility using an indicator for whether or not federal income tax is deductible in a given state-year in Column 13.

${ }^{76}$ See A.3.2 for additional details on data on throwback rules. Specifically, see footnote 47.
} 
2. Combined reporting rules. An indicator of whether a state requires a unitary business to submit combined reporting. Data from Bernthal et al. (2012). ${ }^{77}$

3. Investment tax credit. This variable is the rate of the tax credit. Data from Chirinko and Wilson (2008).

4. Research and development tax credit. This variable is the statutory credit rate adjusted for recapture and type of credit. Data from Wilson (2009).

5. Loss carry-back rules. The number of years that a corporation may carry forward any excess loss following the loss year. Data from CCH (1980-2010).

6. Loss carry-forward rules. The number of years that a corporation may carry forward any excess loss following the loss year. Data from CCH (1980-2010).

7. Franchise Tax. An indicator for whether or not there exists a franchise tax in a given state-year. Data from CCH (1980-2010).

8. Federal Income Tax Deductible. An indicator for whether or not federal income tax is deductible in a given state-year. Data from CCH (1980-2010). To account for federal deductibility, we define the keep rate in for Column 7 of Appendix Table A19 as follows:

$$
\left(1-\tau_{s+f e d, t}\right)= \begin{cases}1-\tau_{s, t}^{c}-\tau_{\text {fed,t }}^{c} & \text { if } I(\text { FedDeductable })_{s, t}=0 \\ \left(1-\tau_{s, t}^{c}\right)\left(1-\tau_{\text {fed,t }}^{c}\right) & \text { if } I(\text { FedDeductable })_{s, t}=1\end{cases}
$$

where $\tau_{f e d, t}^{c}$ is the top U.S. statutory federal corporate tax from the University of Michigan World Tax Database.

9. Federal Income as State Tax Base. An indicator for whether or not federal income is used as the state tax base in a given state-year. Data from CCH (1980-2010).

10. Federal Accelerated Depreciation. An indicator for whether or not federal accelerated depreciation is allowed in a given state-year. Data from CCH (1980-2010).

11. Accelerated Cost Recovery System (ACRS) Depreciation. An indicator for whether or not ACRS is allowed in a given state-year. Data from CCH (1980-2010).

12. Federal Bonus Depreciation. An indicator for whether or not federal bonus depreciation is allowed in a given state-year. Data from CCH (1980-2010).

\section{E.4.2 Controls for State Political, Fiscal Policy, and Economic Conditions}

Similarly, to construct Appendix Table A20 Columns (1)-(10), we consecutively add the following controls to the baseline specification (i.e., Equation 21).

1. Political Controls. This specification includes indicators for political party. In particular, the specification is Equation 21 plus $\mathbb{I}(G o v=D)_{s, t}+\mathbb{I}(G o v=R)_{s, t}+\mathbb{I}(G o v=\text { Indep })_{s, t}$.

2. Sales Tax Rate. This specification includes the state sales tax rate, i.e., Equation 21 plus SalesTax Rate $_{s, t}$.

3. $\Delta$ Sales Tax Rate. This specification includes the percentage change in the state sales tax rate over a 10 year period, i.e., Equation 21 plus $\ln$ SalesTaxRate $_{s, t}-\ln$ SalesTaxRate $_{s, t-10}$.

\footnotetext{
${ }^{77}$ See A.3.2 for additional details on data on combined reporting. Specifically, see footnote 47.
} 
4. Income Tax Rate. This specification includes the state personal income tax rate, i.e., Equation 21 plus IncomeTaxRate I,$t$.

5. $\Delta$ Income Tax Rate. This specification includes the percentage change in the state income tax rate over a 10 year period, i.e., Equation 21 plus $\ln$ IncomeTax Rate $_{s, t}-\ln$ IncomeTax Rate $_{s, t-10}$.

6. $\Delta$ Gov. Expend/capita. This specification includes the percentage change in government expenditures per capita, i.e., Equation 21 plus $\ln$ GovExpendPercapita ${ }_{s, t}-\ln$ GovExpendPercapita $_{s, t-10}$.

7. Corporate Tax Rev. to GDP. This specification includes the corporate tax revenue share of GDP, i.e., Equation 21 plus CorpTaxRevGDPratio,$t$.

8. $\Delta$ Gov. Expend/capita and Corporate Tax Rev. to GDP. This specification is Equation 21 plus $\ln$ GovExpendPercapita $_{s, t}-\ln$ GovExpendPercapita $_{s, t-10}$ and CorpTaxRevGDPratio $o_{s, t}$.

9. Bartik. This equation is the same as specification (4) in the main table. It is included for later iterations of this table, which use state statutory corporate tax rates and state fixed effects.

10. Gross Receipt Tax Control. This specification includes indicators for whether the state has a gross receipts tax. In particular, the specification is Equation 21 plus $\mathbb{I}(G R T)_{s, t}$.

To show that these results are robust to focusing on variation just from statutory state corporate tax rates, we provide estimates from each of the same 10 specifications in Appendix Table A21 for specifications with $\tau_{s, t^{\prime}}^{c}$ in place of $\tau_{c, t^{\prime}}^{b}$ for $t^{\prime} \in\{t, t-10\}$ in the baseline Equation 21. We also provide Appendix Table A22, which uses the same specifications as Appendix Table A21, but also adjusts for federal corporate taxes and deductibility. As in Appendix Table A19, we use the keep rate definition in equation 36 for Appendix Table A22. Finally, we provide results for Equation 21 for each of our 10 controls but with state-fixed effects in Appendix Table A23.

\section{E.4.3 Different Calibrated Parameter Values}

We show how sensitive these tables are to different assumptions about the housing expenditure share $\alpha$ and the output elasticity ratio $\frac{\delta}{\gamma}$. Our baseline calibrated parameter values are $\alpha=.3$ for the housing expenditure share (using data from the Consumer Expenditure Survey) and $\frac{\delta}{\gamma}=.9$ for the output elasticity ratio (using data from the Bureau of Economic Analysis on gross output shares for private industries). Appendix Tables A24, A25, A26, and A27 provide iterations of Table 5 for the following calibrated parameter values: $\alpha \in\{.5, .65\}$ and $\frac{\delta}{\gamma} \in\{.75, .5\}$, respectively.

Finally, to obtain a sense of the range of the estimates for 'extreme' combinations, we run this incidence analysis for all of the combinations of parameter values in the paper, i.e., $\alpha \in\{0.3,0.5$,

$0.65\}$ and $\frac{\delta}{\gamma} \in\{0.5,0.75,0.9\}$, for each of the specifications in the reduced-form incidence tables (i.e., Table A24-A27). Quantitatively, the extremes for each of the shares are: $0.175-0.374,0.403-0.614$, and $0.133-0.335$ for workers, firm owners, and landowners, respectively.

\section{E.5 CMD Estimation of the Simultaneous Equation Model}

This section shows how we introduce Bartik shocks in section E.5.1 and both personal tax and Bartik shocks in section E.5.3 for the all shocks specifications.

\section{E.5.1 CMD Estimation with Moments from Bartik Shocks}

We interpret the Bartik as a proxy for changes in local productivity that may take three forms: a productivity shock to the housing supply, a mean productivity shock to the local area, or a shock to 
the average idiosyncratic productivity of the firms locating in a given area. In order to interpret the variation in this shock in each of the units of these three types of productivity, we estimate auxiliary parameters for the housing supply, labor demand, and establishment location equations as follows:

$$
\begin{gathered}
\Delta B_{c, t}=\varphi \text { Bartik }_{c, t}+v_{c, t} \\
\Delta B_{c, t}^{H}=\varphi^{h} \text { Bartik }_{c, t}+v_{c, t}^{h} \\
\Delta z_{c, t}=\varphi^{z} \text { Bartik }_{c, t}+v_{c, t}^{z} .
\end{gathered}
$$

The auxiliary parameters $\left(\varphi, \varphi^{h}, \varphi^{z}\right)$ project the Bartik shock to each type of productivity shock.

With these productivity measures, we define a new reduced form that relates the matrix of tax and Bartik shocks:

$$
\mathbf{Z}_{c, t}=\left[\Delta \ln \left(1-\tau_{c, t}^{b}\right) \quad B a r t i k_{c, t}\right]
$$

to the same vector of outcomes $\mathbf{Y}_{c, t}$. The matrix $\mathbb{A}$ remains unchanged and the matrix $\mathbb{B}$ in Equation 17 is now given by:

$$
\mathbb{B}=\left[\begin{array}{cc}
\frac{1}{\varepsilon^{L D} \sigma^{F}\left(\varepsilon^{P D}+1\right)} & \frac{\left(\varepsilon^{P D}+1-\frac{1}{\sigma^{F}}\right) \varphi-\varphi^{z}}{\varepsilon^{L D}} \\
0 & 0 \\
0 & \frac{-\eta_{c} \varphi^{h}}{1+\eta_{c}} \\
\frac{1}{-\sigma^{F}\left(\varepsilon^{P D}+1\right)} & \frac{\varphi^{F}}{\sigma^{F}}
\end{array}\right] .
$$

The matrix of reduced form moments $\mathbb{C}$ now includes the effects of taxes and the effects of productivity shocks

$$
\mathbb{C}=\left[\begin{array}{ll}
\boldsymbol{\beta}^{\text {Business Tax }} & \boldsymbol{\beta}^{\text {Bartik }}
\end{array}\right] .
$$

This gives us a total of 8 reduced-form effects. The predicted moments from our model have similar intuitive interpretations as those above and are listed in Appendix E.5.2. 


\section{E.5.2 Equilibrium and Incidence Expressions with Bartik Shocks}

$$
\begin{aligned}
& \Delta \ln w_{c, t}=\phi_{t}^{2}+(\dot{w}) \Delta \ln \left(1-\tau_{c, t}^{b}\right)+\frac{\left(-\left(\varepsilon^{P D}+1\right)+\frac{1}{\sigma^{F}}\right)}{\varepsilon^{L S}-\varepsilon^{L D}} \varphi \operatorname{Bartik}_{c, t} \\
& -\frac{1}{\varepsilon^{L S}-\varepsilon^{L D}} \varphi^{z} \operatorname{Bartik}_{c, t}+\left(\frac{\alpha \eta_{c}}{1+\eta_{c}-\alpha}\right) \frac{\varepsilon^{L S}}{\varepsilon^{L S}-\varepsilon^{L D}} \varphi^{h} \operatorname{Bartik}_{c, t}+u_{c, t}^{2} \\
& \Delta \ln N_{c, t}=\phi_{t}^{1}+\left(\dot{w} \varepsilon^{L S}\right) \Delta \ln \left(1-\tau_{c, t}^{b}\right)+\varepsilon^{L S} \frac{\left(-\left(\varepsilon^{P D}+1\right)+\frac{1}{\sigma^{F}}\right)}{\varepsilon^{L S}-\varepsilon^{L D}} \varphi \text { Bartik }_{c, t} \\
& -\frac{\varepsilon^{L S}}{\varepsilon^{L S}-\varepsilon^{L D}} \varphi^{z} \operatorname{Bartik}_{c, t}+\left(\frac{\alpha \eta_{c}}{1+\eta_{c}-\alpha}\right) \frac{\varepsilon^{L S} \varepsilon^{L D}}{\varepsilon^{L S}-\varepsilon^{L D}} \varphi^{h} \operatorname{Bartik}_{c, t}+u_{c, t}^{1} \\
& \Delta \ln r_{c, t}=\phi_{t}^{3}+\left(\frac{1+\varepsilon^{L S}}{1+\eta_{c}} \dot{w}\right) \Delta \ln \left(1-\tau_{c, t}^{b}\right)+\left(\frac{1+\varepsilon^{L S}}{1+\eta_{c}}\right) \frac{\left(-\left(\varepsilon^{P D}+1\right)+\frac{1}{\sigma^{F}}\right)}{\varepsilon^{L S}-\varepsilon^{L D}} \varphi \text { Bartik }_{c, t} \\
& -\left(\frac{1+\varepsilon^{L S}}{1+\eta_{c}}\right) \frac{1}{\varepsilon^{L S}-\varepsilon^{L D}} \varphi^{z} \operatorname{Bartik}_{c, t}+\left(\frac{\eta_{c}}{1+\eta_{c}-\alpha}\right) \frac{\varepsilon^{L S}\left(1-\varepsilon^{L D} \sigma_{W}\right)}{\varepsilon^{L S}-\varepsilon^{L D}} \varphi^{h} \operatorname{Bartik}_{c, t}+u_{c, t}^{3} \\
& \Delta \ln E_{c, t}=\phi_{t}^{4}+\left(\frac{1}{-\sigma^{F}\left(\varepsilon^{P D}+1\right)}-\frac{\gamma}{\sigma^{F}} \dot{w}\right) \Delta \ln \left(1-\tau_{c, t}^{b}\right) \\
& +\left(\frac{1}{\sigma^{F}}-\frac{\gamma}{\sigma^{F}} \frac{\left(-\left(\varepsilon^{P D}+1\right)+\frac{1}{\sigma^{F}}\right)}{\varepsilon^{L S}-\varepsilon^{L D}}\right) \varphi \operatorname{Bartik}_{c, t}+\frac{\gamma}{\sigma_{F}} \frac{1}{\varepsilon^{L S}-\varepsilon^{L D}} \varphi^{z} \text { Bartik }_{c, t} \\
& -\frac{\gamma}{\sigma_{F}}\left(\frac{\alpha \eta_{c}}{1+\eta_{c}-\alpha}\right) \frac{\varepsilon^{L S}}{\varepsilon^{L S}-\varepsilon^{L D}} \varphi^{h} \operatorname{Bartik}_{c, t}+u_{c, t}^{4}
\end{aligned}
$$

\section{E.5.3 CMD Estimation with Moments from Bartik and Personal Tax Shocks}

We also can add personal tax shocks using similar steps. We incorporate personal taxes into the model in two new places: in the household problem (as mentioned in footnote 9) and in the housing market (as mentioned in footnote 11). In particular, for the household problem, we replace wages with after-tax wages:

$\max _{h, X} \ln A+\alpha \ln h+(1-\alpha) \ln X$ s.t. $r h+\int_{j \in J} p_{j} x_{j} d j=w\left(1-\tau^{i}\right)$, where $X=\left(\int_{j \in J} x_{j}^{\frac{\varepsilon^{P D}+1}{\varepsilon^{P D}}} d j\right)^{\frac{\varepsilon^{P D}}{\varepsilon^{P D}+1}}$,

This addition makes demand for varieties a function of personal tax rate $x_{j}=(1-\alpha) w\left(1-\tau^{i}\right) p_{j}^{\varepsilon^{P D}}$. Similarly, housing demand will have the same expenditure share, but lower total spending. Specifically, housing demand is $H_{c}^{D}=\frac{N_{c} \alpha w_{c}\left(1-\tau_{c}^{i}\right)}{r_{c}}$. Both of these amendments affect indirect utility:

$$
V_{n c}^{W}=a_{0}+\ln w_{c}\left(1-\tau^{i}\right)-\alpha \ln r_{c}+\ln A_{n c},
$$

The second impact is on the supply of housing. As mentioned in footnote 11, housing supply that incorporates personal taxes is $H_{c}^{S}=\left(1-\tau^{i}\right)^{\chi^{H}}\left(B_{c}^{H} r_{c}\right)^{\eta_{c}}$. The housing market clearing condition, $H_{c}^{S}=H_{c}^{D}$, determines the rents $r_{c}$ in location $c$ and is given in log-form by a similar expression to equation 2 :

$$
\ln r_{c}=\frac{1}{1+\eta_{c}} \ln N_{c}+\frac{1}{1+\eta_{c}} \ln w_{c}-\frac{\eta_{c}}{1+\eta_{c}} B_{c}^{H}+\left(\frac{1}{1+\eta_{c}}-\chi^{H}\right) \ln \left(1-\tau_{c}^{i}\right)+a_{1},
$$

where the coefficient on the personal tax keep rate reflects both demand $\frac{1}{1+\eta_{c}}$ and supply forces $-\chi^{H}$. 
With these two additions for personal taxes, we can define a new reduced-form that relates the matrix of tax and Bartik shocks $\mathbf{Z}_{c, t}$ to the same vector of outcomes $\mathbf{Y}_{c, t}$. Specifically, the shocks in our all shocks specification are:

$$
\mathbf{Z}_{c, t}=\left[\Delta \ln \left(1-\tau_{c, t}^{b}\right) \quad \operatorname{Bartik}_{c, t} \quad \Delta \ln \left(1-\tau_{c, t}^{i}\right)\right],
$$

The matrix $\mathbb{A}$ remains unchanged and the matrix $\mathbb{B}$ in Equation 17 is now given by:

$$
\mathbb{B}=\left[\begin{array}{ccc}
\frac{1}{\varepsilon^{L D} \sigma^{F}\left(\varepsilon^{P D}+1\right)} & \frac{\left(\varepsilon^{P D}+1-\frac{1}{\sigma^{F}}\right) \varphi-\varphi^{z}}{\varepsilon^{L D}} & 0 \\
0 & 0 & \frac{1}{\sigma^{W}} \\
0 & \frac{-\eta_{c} \varphi^{h}}{1+\eta_{c}} & \left(\frac{1}{1+\eta_{c}}-\chi^{H}\right) \\
\frac{1}{-\sigma^{F}\left(\varepsilon^{P D}+1\right)} & \frac{\varphi}{\sigma^{F}} & 0
\end{array}\right] .
$$

Pre-multiplying by the inverse of the matrix of structural coefficients $\mathbb{A}$ gives the reduced form:

$$
\mathbf{Y}_{c, t}=\mathbb{A}^{-1} \mathbb{B} \mathbf{Z}_{c, t}+\mathbb{A}^{-1} \mathbf{e}_{c, t}
$$

where

$$
\mathbb{A}^{-1} \mathbb{B}=\left[\begin{array}{lll}
\boldsymbol{\beta}^{\text {Business Tax }} & \boldsymbol{\beta}^{\text {Bartik }} & \boldsymbol{\beta}^{\text {Personal Tax }}
\end{array}\right], \mathbf{Y}_{c, t}=\left[\begin{array}{c}
\Delta \ln w_{c, t} \\
\Delta \ln N_{c, t} \\
\Delta \ln r_{c, t} \\
\Delta \ln E_{c, t}
\end{array}\right], \mathbb{A}=\left[\begin{array}{cccc}
-\frac{1}{\sigma^{W}} & 1 & \frac{\alpha}{\sigma^{W}} & 0 \\
1 & -\frac{1}{\varepsilon^{L D}} & 0 & 0 \\
-\frac{1}{1+\eta} & -\frac{1}{1+\eta} & 1 & 0 \\
\frac{\gamma}{\sigma^{F}} & 0 & 0 & 1
\end{array}\right] .
$$

The three vectors of reduced-form effects of the shocks, which are the three columns of the $4 \times 3$ matrix $\mathbb{A}^{-1} \mathbb{B}$ are the twelve moments that we use in the all shocks specification. Specifically, these three vectors are given by the following expressions.

$$
\boldsymbol{\beta}^{\text {Business Tax }}=\left[\begin{array}{c}
\beta^{W} \\
\beta^{N} \\
\beta^{R} \\
\beta^{E}
\end{array}\right]=\left[\begin{array}{c}
\dot{w} \\
\dot{w} \varepsilon^{L S} \\
\frac{1+\varepsilon^{L S}}{1+\eta} \dot{w} \\
\frac{\mu-1}{\sigma^{F}}-\frac{\gamma}{\sigma^{F}} \dot{w}
\end{array}\right]
$$

$\boldsymbol{\beta}^{\text {Bartik }}$ is a vector of reduced-form effects of Bartik shocks in equations $3738,39,40$, i.e.,

$$
\boldsymbol{\beta}^{\text {Bartik }}=\left[\begin{array}{c}
\beta^{W, B a r t i k} \\
\beta^{N, \text { Bartik }} \\
\beta^{R, \text { Bartik }} \\
\beta^{E, \text { Bartik }}
\end{array}\right]=\left[\begin{array}{c}
\left(\frac{\left(-\left(\varepsilon^{P D}+1\right)+\frac{1}{\sigma^{F}}\right)}{\varepsilon^{L S}-\varepsilon^{L D}} \varphi-\frac{1}{\varepsilon^{L S}-\varepsilon^{L D}} \varphi^{z}+\left(\frac{\alpha \eta_{c}}{1+\eta_{c}-\alpha}\right) \frac{\varepsilon^{L S}}{\varepsilon^{L S}-\varepsilon^{L D}} \varphi^{h}\right) \\
\left(\begin{array}{c}
\left.\varepsilon^{L S} \frac{\left(-\left(\varepsilon^{P D}+1\right)+\frac{1}{\sigma^{F}}\right)}{\varepsilon^{L S}-\varepsilon^{L D}} \varphi-\frac{\varepsilon^{L S}}{\varepsilon^{L S}-\varepsilon^{L D}} \varphi^{z}+\left(\frac{\alpha \eta_{c}}{1+\eta_{c}-\alpha}\right) \frac{\varepsilon^{L S} \varepsilon^{L D}}{\varepsilon^{L S}-\varepsilon^{L D}} \varphi^{h}\right) \\
\left(\left(\frac{1+\varepsilon^{L S}}{1+\eta_{c}}\right) \frac{\left(-\left(\varepsilon^{P D}+1\right)+\frac{1}{\sigma^{F}}\right)}{\varepsilon^{L S}-\varepsilon^{L D}} \varphi-\left(\frac{1+\varepsilon^{L S}}{1+\eta_{c}}\right) \frac{1}{\varepsilon^{L S}-\varepsilon^{L D}} \varphi^{z}+\left(\frac{\eta_{c}}{1+\eta_{c}-\alpha}\right) \frac{\varepsilon^{L S}\left(1-\varepsilon^{L D} \sigma_{W}\right)}{\varepsilon^{L S}-\varepsilon^{L D}} \varphi^{h}\right) \\
\left(\left(\frac{1}{\sigma^{F}}-\frac{\gamma}{\sigma^{F}} \frac{\left(-\left(\varepsilon^{P D}+1\right)+\frac{1}{\sigma^{F}}\right)}{\varepsilon^{L S}-\varepsilon^{L D}}\right) \varphi+\frac{\gamma}{\sigma_{F}} \frac{1}{\varepsilon^{L S}-\varepsilon^{L D}} \varphi^{z}-\frac{\gamma}{\sigma_{F}}\left(\frac{\alpha \eta_{c}}{1+\eta_{c}-\alpha}\right) \frac{\varepsilon^{L S}}{\varepsilon^{L S}-\varepsilon^{L D}} \varphi^{h}\right)
\end{array}\right],
\end{array}\right]
$$

and $\boldsymbol{\beta}^{\text {Personal Tax }}$ is a vector of reduced-form effects of personal tax shocks, i.e., 


$$
\boldsymbol{\beta}^{\text {Personal Tax }}=\left[\begin{array}{l}
\beta^{W, \text { Personal Tax }} \\
\beta^{N, \text { Personal Tax }} \\
\beta^{R, \text { Personal Tax }} \\
\beta^{E, \text { Personal Tax }}
\end{array}\right]=\left[\begin{array}{c}
\left(\frac{-\alpha \chi^{H}(1+\eta)}{\sigma^{F}\left(\varepsilon^{L S}-\varepsilon^{L D}\right)\left[\alpha+\sigma^{W}(1+\eta)\right]}-\frac{\varepsilon^{L S}}{\varepsilon^{L S}-\varepsilon^{L D}}\right) \\
\left(\frac{-\varepsilon^{L D}\left[1+\eta+\alpha\left(-1+\chi^{H}(1+\eta)\right)\right]}{\sigma^{F}\left(\varepsilon^{L S}-\varepsilon^{L D}\left[\alpha+\sigma^{W}(1+\eta)\right]\right.}\right) \\
\left(\frac{\chi^{H}(1+\eta)-\varepsilon^{L D}\left[\sigma^{W}\left(\chi^{H} \eta-\chi^{H}-1\right)-1\right]}{\left(\varepsilon^{L S}-\varepsilon^{L D}\right)\left[\alpha+\sigma^{W}(1+\eta)\right]}\right) \\
\left(\frac{-\gamma\left[1+\eta+\alpha\left(-1+\chi^{H}(1+\eta)\right)\right]}{\sigma^{F}\left(\varepsilon^{L S}-\varepsilon^{L D}\right)\left[\alpha+\sigma^{W}(1+\eta)\right]}\right)
\end{array}\right] .
$$

\section{E.5.4 Model Fit}

We evaluate the fit of our model by comparing the estimated reduced-form effects to the predictions of our model. Table A32 presents the estimated reduced-form effects along with the predicted moments based on the estimated parameters for three cases. Panel (a) shows the model for the case where only taxes are used in estimation and corresponds to Column (1) in Panel (a) of Table 6. In all four cases, the model matches the reduced-form estimates well. However, most of of the effects are not precisely estimated, with the exception of the effect of taxes on establishment growth. This estimation has three parameters and four moments, which allows us to conduct a test of over identifying restrictions. The last line of Panel (a) reports the results of this test and shows that this restriction is not rejected by the data. Panels (b) and (c) report similar results models corresponding to Columns (1) and (5) of Panel (b) of Table 6, respectively. In both cases the models fit the reduced-form estimates well and do not reject the over identification restriction. The benefit of using the additional variation in the Bartik shock is evident in these panels as the corresponding moments are more precisely estimated than those in Panel (a).

\section{E.6 Single-Equation Estimates of Labor Supply, Housing Supply, and Establishment Location}

In this subsection, we present a complementary approach to our main estimation methodology by estimating the labor supply, housing supply, and establishment location equations separately. By isolating each equation, we clarify the potential estimation pitfalls, we show the sources of variation that we use to overcome these pitfalls, and explore how the structural estimates relate to economic features in our model. By contrast, in our main strategy, we estimate a simultaneous equation model that incorporates all of the spatial equilibrium forces of our model. This approach uses classical minimum distance methods to match the reduced-form effects of business tax changes on equilibrium outcomes with the prediction from our model. This strategy improves the precision of our estimates and allows for inference on the incidence to workers, landowners, and firm owners.

\section{E.6.1 Labor Supply}

The $\log$ of Equation 1 relates changes in labor supply $\Delta \ln N_{c, t}$ to changes in wages $\Delta \ln w_{c, t}$, rental costs $\Delta \ln r_{c, t}$, and amenities $\Delta \bar{A}_{c, t}$ in location $c$ and year $t$ :

$$
\Delta \ln N_{c, t}=\frac{\Delta \ln w_{c, t}-\alpha \Delta \ln r_{c, t}}{\sigma^{W}}+\frac{\Delta \bar{A}_{c, t}}{\sigma^{W}}
$$

where $\sigma^{W}$ is the dispersion of idiosyncratic worker location preferences. We define log real wage changes, $\Delta \ln$ Real Wage ${ }_{c, t} \equiv \Delta \ln w_{c, t}-\alpha \Delta \ln r_{c, t}$, where we calibrate $\alpha=0.3$ using data form the Consumer Expenditure Survey. In order to implement this equation, consider estimating the following empirical analogue:

$$
\Delta \ln N_{c, t}=\beta^{L S} \Delta \ln \text { Real Wage }{ }_{c, t}+\mathbf{D}_{s, t}^{\prime} \mathbf{\Psi}_{s, t}^{L S}+\nu_{c, t}^{L S}
$$


where the changes are decadal changes in year $t \in 1990,2000,2010$ are relative to year $t-10, \beta^{L S}$ is total effect of real wage changes, and $\mathbf{D}_{s, t}=\left[\begin{array}{lllll}\mathrm{I}(t=1990) & \ldots & \mathrm{I}(t=2010) & \mathrm{I}(\text { Midwest } 1990)_{s, t}\end{array}\right]^{\prime}$ is a vector with year dummies as well as state dummies for states in the industrial Midwest in the 1980s, and $\nu_{c, t}^{L S}$ is the error term. From Equation 43, it follows that the error term will be composed partly of aggregate amenity shocks to a given area. Since changes in real wages and changes in amenities are likely negatively correlated, an OLS estimate of $\beta^{L S}$ will be biased downwards. Intuitively, rightward shifts in supply due to amenity improvements result in apparently flatter local labor supply curves. Since $\sigma^{W}$ is related to the inverse of $\beta^{L S}$, attenuation in $\beta^{L S}$ results in overestimates of $\sigma^{W}$. In order to deal with this endogeneity concern, we instrument for real wage changes using the Bartik instrument for local labor demand as well as changes in taxes $\Delta \ln \left(1-\tau_{c, t}^{c}\right)$. The exclusion restriction is that workers only value changes in labor demand and corporate taxes only through their effects on the real wage. ${ }^{78}$

Table A33 provides estimates for the preference dispersion parameter $\sigma^{W}$ using both OLS and IV approaches. In both cases, we estimate $\hat{\sigma}^{W}$ as a non-linear function of the estimated $\hat{\beta}^{L S}$ using the delta method. Comparing Columns (1) and (2), we find that OLS indeed overestimates the parameter $\sigma^{W}$ relative to the IV estimate. Our IV estimate yields a point estimate of $\hat{\sigma}^{W}=0.72$ that is significantly different than zero at the $1 \%$ level with a standard error of 0.28 . Figure A16 depicts the relationship of these estimates to worker mobility. Figure A16 plots the mean log change in population for several bins of log change in real wages as well as the fitted values of a first stage regression of changes in log real wages on the Bartik shock and the tax shock. The fitted lines plot the associated estimates from OLS and IV regressions and show that the IV estimates imply that workers are indeed three times more mobile than the OLS estimates would imply. The IV estimate implies that a $\$ 1$ increase in the real wages leads to an increase in population of 1.64 . In Section 3.1 we discuss how this estimate relates to others in the literature.

\section{E.6.2 Housing Market}

The log of housing market clearing condition from Section 1.2 provides the following estimable equation for housing costs:

$$
\Delta \ln r_{c, t}=\beta^{H M}\left(\Delta \ln N_{c, t}+\Delta \ln w_{c, t}\right)+\mathbf{D}_{s, t}^{\prime} \Psi_{s, t}^{H M}+\nu_{c, t}^{H M}
$$

where the changes are decadal changes in year $t \in 1990,2000,2010$ relative to year $t-10, \mathbf{D}_{s, t}$ is a vector with year dummies as well as state dummies for states in the industrial midwest in the 1980s, and $\nu_{c, t}^{H M}$ is the error term. The structural model implies that $\beta^{H M}=\frac{1}{1+\eta}$, the average elasticity of housing supply.

As discussed in the previous section, the error term in this equation is partly composed of productivity shocks to the housing sector. To the extent that these shocks are positively correlated with changes in population, we would expect that OLS estimates of the coefficient $\beta^{H M}$ might be biased. We avoid this potential issue by estimating this equation via IV, where we instrument for changes in population and wages using corporate tax changes and Bartik productivity shocks. As before, we report estimates of the parameter $\eta$ from a delta method calculation.

Table A33 provides estimates for $\eta$. Column (3) provides the OLS estimate and Column (4) provides the IV estimate, which gives a similar, though slightly smaller estimate of the elasticity of housing supply of $0.834(S E=0.432)$. The parameter implies that a $1 \%$ increase in population or wages would raise rental costs by $0.55 \%(S E=0.12)$, which is a statistically significant effect at the $99 \%$ level. While not perfectly comparable to previous estimates, this estimate is within the range

\footnotetext{
${ }^{78}$ In order to ensure that this is the case, we control for changes in state personal income taxes that might drive both the location of establishments and workers.
} 
of parameters from previous studies including those in Notowidigdo (2013) and Suárez Serrato and Wingender (2011). ${ }^{79}$

\section{E.6.3 Establishment Location and Labor Demand}

Log differencing Equation 7 we obtain the following equation:

$$
\Delta \ln E_{c, t}=\underbrace{\left(\frac{\mu-1}{\sigma^{F}}-\frac{\gamma}{\sigma^{F}} \dot{w}\right)}_{\beta^{E S}} \Delta \ln \left(1-\tau_{c, t}^{b}\right)+\mathbf{D}_{s, t}^{\prime} \mathbf{\Psi}_{s, t}^{E S}+\nu_{c, t}^{E S} .
$$

To observe the interpretation of the coefficient $\beta^{E S}$ as a combination of direct and indirect effects, consider first estimating the following alternative equation for establishment share growth:

$$
\Delta \ln E_{c, t}=\beta^{E S} \Delta \ln \left(1-\tau_{c, t}^{b}\right)+\beta_{2}^{E S} \Delta \ln w_{c, t}+\mathbf{D}_{s, t}^{\prime} \mathbf{\Psi}_{s, t}^{E S}+\nu_{c, t}^{E S}
$$

If both changes in wages and changes in taxes are exogenous, Equation 46 shows that $\beta^{E S}$ would be related to $\frac{1}{-\left(\varepsilon^{P D}+1\right) \sigma^{F}}$ and that a coefficient on wages $\beta_{2}^{E S}$ would be related to $-\left(\frac{\gamma}{\sigma^{F}}\right)$. The key issue in estimating this equation is that the structural error term, i.e. the change in common productivity $\Delta \bar{B}_{c, t}$, is likely positively correlated with wages. This omitted variable would likely bias an OLS estimation and produce estimates of the output elasticity of labor $\gamma$ that are negative, contrary to any plausible economic model. Indeed, Column (5) of Table A33 presents the implied estimates from such a regression. As predicted, this estimation yields a non-sensical, negative estimate of the output elasticity of labor $\hat{\gamma}$, which would imply an up-ward sloping labor demand curve.

In order to deal with this endogeneity problem we exclude the endogenous regressor $\Delta \ln w_{c, t}$ (i.e., we impose the constraint that $\beta_{2}^{E S}=0$ ). This exclusion, however, changes the interpretation of the parameter $\beta^{E S}$. This estimate corresponds to the reduced form effects of a business tax cut on establishment growth as reported in Table 4, Column 4. The estimation of the parameter $\sigma^{F}$ from this equation is presented in Section E.6.4.

\section{E.6.4 CMD Estimation of the Establishment Location Equation}

Estimating labor demand functions in models of local labor markets has been limited by the lack of plausibly exogenous labor supply shocks that may trace the slope of the demand function. ${ }^{80}$ Instead, this equation exploits the empirical tradeoff firms make among productivity, corporate taxes, and factor prices to recover the parameters governing labor demand and the incidence on firm profits.

Recall from Section 3.1 that the exact reduced-form of the establishment location equation is given by:

$$
\Delta \ln E_{c, t}=\underbrace{\left(\frac{\mu-1}{\sigma^{F}}-\frac{\gamma}{\sigma^{F}} \dot{w}\right)}_{\beta^{E}} \Delta \ln \left(1-\tau_{c, t}^{b}\right)+\mathbf{D}_{s, t}^{\prime} \mathbf{\Psi}_{s, t}^{4}+u_{c, t}^{4} .
$$

\footnotetext{
${ }^{79}$ Our housing supply elasticity parameter and corresponding estimates are not directly comparable due to our model's assumption of Cobb Douglas housing demand rather than the assumption that each household inelastically demands one unit of housing. This feature makes rent a function of both wages and population rather than just population and slightly alters the functional form. We adopt the Cobb-Douglas assumption to allow households to adjust to shocks over the long run, but this feature is not an essential part of our model or results. In an earlier version of the paper, we used inelastic demand and found similar results to those reported here.

${ }^{80}$ Recent papers have used structural approaches to ensuring a downward-sloping labor demand curve (e.g., Notowidigdo (2013)) or have emphasized the role of local amenities in driving relative demand for skilled and unskilled workers (e.g., Suárez Serrato and Wingender (2011) and Diamond (2012)).
} 
While we derived this equation from the SEM, this equation can also be obtained by log differencing Equation 7. We can decompose the parameter $\beta^{E}$ into two forces: the increased desirability of a location through lower taxes and the countervailing force of higher wages:

$$
m(\boldsymbol{\theta}) \equiv \underbrace{\frac{1}{-\left(\varepsilon^{P D}+1\right) \sigma^{F}}}_{\text {LowerTaxes }} \underbrace{-\left(\frac{\gamma}{\sigma^{F}}\right) \dot{w}(\boldsymbol{\theta})}_{\text {Higher Wages }}
$$

where $\dot{w}(\boldsymbol{\theta})$ is given in Equation 10 and $\boldsymbol{\theta}$ is the vector of parameters of the model. Thus, given the parameters of the model $\eta, \sigma^{W}, \varepsilon^{P D}$, and $\gamma$ and an estimated $\hat{\beta}^{E}$, one can recover an estimate of the productivity dispersion parameter $\sigma^{F}$.

Formally, we recover the estimate of $\sigma^{F}$ via classical minimum distance. We first estimate $\beta^{E}$ via OLS. Using the parameter $\hat{\beta}^{E}$ as an empirical moment of the data along with its respective variance $\hat{\mathbf{V}}$, the classical minimum distance estimator is the solution to Equation 22 where $m(\boldsymbol{\theta})$ is as in Equation 47. This approach takes calibrated values of the parameters $\eta, \sigma^{W}, \varepsilon^{P D}$, and $\gamma$, finds the value $\hat{\sigma}^{F}$ that solves Equation 22 and computes its variance.

Figure A17 shows estimates for $\sigma^{F}$ from the CMD estimation using the values for calibrated parameters discussed above. The graph plots the mean values of log changes in the number of establishments for different bins of log changes in the net of business tax rate. The red line plots the relation between changes in taxes and firm mobility that is implied by the CMD estimation. The parameter estimate in this case is $\hat{\sigma}^{F}=0.1(S E=0.058)$, which is statistically significant. The black line plots the same relationship when we use an implied value of $\sigma^{F}$ from an OLS regression that ignores the indirect effect of tax cuts on firm location through higher wages. The red line is steeper than the black line, which makes firms look more mobile than they would appear in the OLS specification and is consistent with the fact that the CMD estimate is three times smaller than the implied value from the OLS regression. ${ }^{81}$ However, if we consider the conventional wisdom of perfect mobility as given by the vertical green line, we see that even a small value of productivity dispersion $\sigma^{F}$ yields estimates of firm mobility that are far smaller than that implied by the conventional wisdom.

\section{F Accounting for Changes in Government Spending}

We follow Suárez Serrato and Wingender (2011) in modeling the effects of changes in government spending on the local economy. This modeling approach takes into account the effects of changes in labor demand from government, changes in the provision of public goods, and changes in the provision of infrastructure.

Consider first the effects of changes on the welfare of workers. Extending the indirect utility function to account for government services $G S$, we have:

$$
V_{n c}^{W}=a_{0}+\ln w_{c}-\alpha \ln r_{c}+\phi \ln G S_{c}+\ln A_{n c},
$$

where $\phi$ is the worker's valuation of government services. Including a direct effect of government services on utility leads to a naturally extension of Equation 13 for the welfare effects of a change in corporate taxes:

$$
\frac{d \mathcal{V}^{W}}{d \ln \left(1-\tau_{c}^{c}\right)}=N_{c}\left(\dot{w}_{c}-\alpha \dot{r}_{c}+\phi \dot{G} S_{c}\right)
$$

where $\mathcal{V}^{W}=\mathbb{E}_{\varepsilon}\left[\max _{c} V_{n c}^{W}\right]$. Implementing this equation requires two pieces of data: the valuation of

\footnotetext{
${ }^{81}$ The results of these regressions are also presented in table form in Table A33.
} 
government services $\phi$ and the change in services provided. We use the results from Suárez Serrato and Wingender (2011) with an estimate of $\phi=0.45 .{ }^{82}$ Government services are provided by local workers such that $\dot{G} S_{c}$ is determined by changes in expenditure on services as well as changes in the wages of local workers. That is, $\dot{G} S_{c}=\dot{E} x p_{c}^{G S}-\dot{w}_{c}$. We implement this equation empirically with:

$$
\beta^{W}-\alpha \beta^{R}+\phi\left(\dot{E} x p_{c}^{G S}-\beta^{W}\right) .
$$

A key thing to note from this equation is that workers care about the effects of the policy change on their real income $\ln w_{c}-\alpha \ln r_{c}$ and that the equilibrium change in this quantity equals $\beta^{W}-\alpha \beta^{R}$ regardless of whether this change is due to increases in the demand of workers or changes in the supply of workers due to changes in government spending. For the same reason, the incidence on landowners is still given by $\dot{r}_{c}=\beta^{R}$.

Consider now the effects of changing infrastructure spending on the profits of firms. We model infrastructure as a component of productivity by decomposing the productivity shock $B_{c}=\tilde{B}_{c} Z^{\nu}$, where $Z_{c}$ is infrastructure and $\nu$ is the firms' output elasticity of infrastructure. If changes in revenue from a change in the corporate tax rate result in changes in infrastructure spending, then the effect on firm profits can be quantified as a combined change in taxes and an infrastructure-based productivity shock. Following the incidence equations for a productivity shock in Appendix B.4, the combined effects of a tax change on profit is:

$$
\dot{\pi}_{c}+[\underbrace{-\left(\varepsilon^{P D}+1\right)}_{\text {Direct Effect on } \pi}+\underbrace{\gamma\left(\varepsilon^{P D}+1\right) \times\left(\frac{\frac{1}{\sigma^{F}}-\left(\varepsilon^{P D}+1\right)}{\varepsilon^{L S}-\varepsilon^{L D}}\right)}_{\text {Effect of Wage Change on } \pi}] \times \underbrace{\nu \dot{Z}_{c}}_{\text {Size of Productivity Shock }},
$$

where $\dot{\pi}_{c}$ is as given in Equation 14. Implementing this equation requires parameters from our structural estimates as well as two additional pieces of data: the firms' output elasticity of infrastructure $\nu$ and the change in infrastructure spending. We use the results form Suárez Serrato and Wingender (2011) with an average estimate of $\nu=0.27 .^{83}$ Infrastructure $Z_{c}$ is assumed to be imported and does not require the hiring of local workers so that $\dot{Z}_{c}=\dot{E} x p_{c}^{Z}$.

We require an estimate of the effects of a tax cut on revenue in order to implement these equations requires. Since the average share of corporate taxes revenue to income tax revenue is approximately $20 \%$, a static forecast of the change in revenue following a $1 \%$ tax cut would be $-.2 \%$. Given that tax cuts lead to increases in economic activity, the static estimate would be a lower bound on the effects on revenue. We thus assume that the change in revenue following a $1 \%$ tax cut would be $-.1 \%$.

We implement these expanded incidence equations under three alternative scenarios about how the change in revenues affects expenditures on infrastructure and expenditure on government services. The first scenario assumes that, following a tax cut, the decrease in revenue will be used to decrease government services. The second scenario assumes that the associated decrease in revenue will be used to decrease the provision of infrastructure. The third and final scenario assumes that the decrease in revenue will be used to decrease both government services and infrastructure proportionally.

Table A2 presents the results from this exercise. Column (1) presents our baseline results that do not account for changes in government spending. Column (2) assumes that all of the change in

\footnotetext{
${ }^{82}$ Suárez Serrato and Wingender (2011) estimate the value of government services for skilled and unskilled workers. The value we use in our calculations is the average of these two value assuming an average share of skilled workers of $25 \%$.

${ }^{83}$ Suárez Serrato and Wingender (2011) estimate the output elasticity of infrastructure for the labor demand of skilled and unskilled workers. The value we use in our calculations is the average of these two value assuming an average share of skilled workers of $25 \%$.
} 
revenue affects changes in the provision of government services. We use an average share of spending on services to individuals of $90 \%$ following data from the Annual Survey of State Finances from 2013. This implies that a $1 \%$ drop in revenue lowers expenditures on public goods by $1.11 \%$. In this scenario, the decrease in government services lowers worker utility resulting in smaller share of the total benefits of $18 \%$. Column (3) explores the effect of decreasing infrastructure on firm profits. In this case, since only $10 \%$ of spending is assumed to be infrastructure related, a $1 \%$ drop in revenue lowers infrastructure spending by $10 \%$. We observe that the incidence in firm profits falls to 0.71 from 0.81 . However, this decrease in profits only lowers the share of incidence accruing to firm owners to $41 \%$. Finally, consider the case where the decrease in revenue is apportioned proportionally so that a $1 \%$ fall in revenue implies a $1 \%$ decline in spending in each category. Column (4) present the incidence resulting form this scenario. We observe that firm profits are only modestly affected while worker welfare sees a steeper decline. Relative to the baseline case, we observe that the result that firm owners bear a substantial portion of the benefit of a corporate tax cut is only strengthened by accounting for the effects on government spending.

Table A2: Incidence Estimates Accounting for Government Spending

\begin{tabular}{lcccc}
\hline \hline & $(1)$ & $(2)$ & $(3)$ & $(4)$ \\
\hline Assumptions for Analysis & & & & \\
Value of Government Services & $\mathrm{N}$ & $\mathrm{Y}$ & $\mathrm{N}$ & $\mathrm{Y}$ \\
Value for Infrastructure & $\mathrm{N}$ & $\mathrm{N}$ & $\mathrm{Y}$ & $\mathrm{Y}$ \\
Change in Funds & None & Services & Infrastructure & Proportional \\
\hline & & & & \\
Incidence & & & & \\
Landowners & 0.32 & 0.32 & 0.32 & 0.32 \\
Workers & 0.68 & 0.25 & 0.68 & 0.29 \\
Firm Owners & 0.81 & 0.81 & 0.71 & 0.8 \\
\hline & & & & \\
Share of Incidence & & & & $23 \%$ \\
Landowners & $18 \%$ & $23 \%$ & $19 \%$ & $21 \%$ \\
Workers & $38 \%$ & $18 \%$ & $40 \%$ & $57 \%$ \\
Firm Owners & $45 \%$ & $59 \%$ & $41 \%$ & \\
\hline \hline
\end{tabular}

\section{G Accounting for Changes in Local Prices}

This section amends the model and incidence estimates to account for changes in local prices (i.e., the price of non-housing, non-traded goods). We present modified incidence expressions and discuss how the results change. We then provide additional detail on how we amend the demand and supply components of the model to derive the modified incidence expressions.

\section{G.1 Incidence Estimates that Account for Non-traded Goods}

With local goods, the welfare effects of a tax cut in location $c$ on the welfare of workers are similar to the expression in equation 13. The part of the expression that accounts for local increases in rental 
prices, $\left(\alpha \dot{r}_{c}\right)$, is replaced with $\left(\alpha^{H} \dot{r}_{c}+\alpha^{N T} \dot{p}_{c}^{N T}\right)$ :

$$
\begin{aligned}
\frac{d \mathcal{V}^{W}}{d \ln \left(1-\tau_{c}^{c}\right)} & =N_{c}\left(\dot{w}_{c}-\alpha^{H} \dot{r}_{c}+\alpha^{N T} \dot{p}_{c}^{N T}\right) \\
& =N_{c}\left(\beta^{W}-\alpha^{H} \beta^{R}+\alpha^{N T} \beta^{N T}\right),
\end{aligned}
$$

where $\alpha^{H}$ is the expenditure share on housing and $\alpha^{N} T$ is the expenditure share on non-housing, non-traded goods. For firm owners and landowners, the expressions are the same as in 14 and $15 .{ }^{84}$

We implement these modified incidence expressions in four ways. First, we use the local price index from ACCRA instead of $\beta^{R}$ in our baseline approach, i.e., the welfare for workers is measured as follows: $\beta^{W}-.3 \beta^{P, A C C R A}$. Mian and Sufi (2016) show that on an employment basis in their main trade-based classification of industries, non-tradable industries account for $20 \%$ of employment and construction accounts for $11 \%$ of employment. However, other work uses larger shares for expenditure on local goods. In the second implementation, we consider a larger value of $\alpha=.6$ from Beraja, Hurst and Ospina (2016). ${ }^{85}$ In this case, the incidence expression for workers is $\beta^{W}-.6 \beta^{P, A C C R A}$. Third, we split local goods into housing and non-traded, non-housing goods using local expenditure shares from Beraja, Hurst and Ospina (2016), resulting in the following expression for worker welfare: $\beta^{W}-.2 \beta^{P, A C C R A, \text { residual }}-.4 \beta^{P, A C C R A, N T}$ where $\beta^{P, A C C R A \text {, residual }}$ is the reduced-form impact on the portion of the local price index that is not categorized as non-traded. It is calculated using weights in the ACCRA formulas that put .47 on the items in $\beta^{P, A C C R A, N T}$, which implies $\beta^{P, A C C R A \text {,residual }}=$ $\frac{\beta^{P, A C C R A}-.47 \times \beta^{P, A C C R A, N T}}{(1-.47)}$. Finally, for the fourth importation, we use a different measure of local prices from the BLS and measure the welfare effects for workers as $\beta^{W}-.3 \beta^{P, B L S}$.

Table A3 shows the results of accounting for local prices. We find similar estimates to our baseline results when accounting for changes in local prices. Columns (1)-(4) implement the four approaches using the reduced-form effects of local business tax cuts that control for Bartik; Columns (5)-(8) implement the same four approaches using the reduced-form effects that do not control for Bartik (i.e., column (1) of the reduced-form outcome tables). In particular, Column (1) shows the incidence on workers is $.78-.3 \times .16=.73$ where .78 is from the Bartik specification (i.e., Column (4)) in Table A7 and .16 is from the Bartik specification in Table A12. Column (2) uses a higher value of $\alpha$, but the same reduced-form effects as the first column, resulting in a slightly lower impact on workers of, $.78-.6 \times .16=.68$. Column (3) shows that separating local goods into a non-traded group and a residual produces similar results. We use the reduced-form impacts from Tables A12 and A13 to implement the third approach: $\beta^{W}-.2 \beta^{P, A C C R A, \text { residual }}-.4 \beta^{P, A C C R A, N T}=.78-.2 \times .28-.4 \times .02=$ $.66 .{ }^{86}$ Finally, Column (4) uses a different measure of local prices $P^{B L S}$, for which the reduced-form impacts are reported in Table A14. This alternative measure is notably similar to our baseline that uses the change in rental prices. Columns (5)-(8) repeat the same calculations using slightly different inputs from the respective reduced-form tables. Overall, local price increases are modest over a ten year period. Accounting for these impacts results in similar incidence results to our baseline estimates.

\footnotetext{
${ }^{84}$ We also show below (in section G.2.2) that we can use $\dot{\pi}_{c}=1+{\text { Avg } \dot{S} a l e s_{c}}_{\text {to }}$ measure incidence in terms of sales rather than in terms of cost. The resulting estimates are similar (e.g., compare the estimate from Column (1) in Table A15 with the incidence estimates on firm owners that use reduced-form estimates from the same specification such as those in Column (1) of Table 5). We primarily focus on the cost-based estimates for firm owners since they are more precise than those in Table A15, but these results provide further support for the conclusion that firm owners bear a substantial share of the incidence of business tax cuts.

${ }^{85}$ See Tables A24 and A25 for our baseline specification for $\alpha=.5$ and $\alpha=.65$, respectively.

${ }^{86}$ Note that $.28=\beta^{P, A C C R A, \text { residual }}=\frac{\beta^{P, A C C R A}-.47 \times \beta^{P, A C C R A, N T}}{(1-.47)}$.
} 
Table A3: Incidence Estimates Accounting for Changes in Local Prices

\begin{tabular}{|c|c|c|c|c|c|c|c|c|}
\hline & \multicolumn{4}{|c|}{ A. Using Reduced-Form Estimates w/ Bartik Controls } & \multicolumn{4}{|c|}{ B. Using Reduced-Form Estimates w/o Bartik Controls } \\
\hline & $(1)$ & $(2)$ & $(3)$ & $(4)$ & $(5)$ & $(6)$ & $(7)$ & $(8)$ \\
\hline \multicolumn{9}{|l|}{ Incidence } \\
\hline Landowners & 0.32 & 0.32 & 0.32 & 0.32 & 1.17 & 1.17 & 1.17 & 1.17 \\
\hline Workers & 0.73 & 0.68 & 0.66 & 0.52 & 1.34 & 1.22 & 1.18 & 1.08 \\
\hline Firm Owners & 0.81 & 0.81 & 0.81 & 0.81 & 1.63 & 1.63 & 1.63 & 1.63 \\
\hline \multicolumn{9}{|l|}{ Share of Incidence } \\
\hline Landowners & $17.2 \%$ & $17.6 \%$ & $17.9 \%$ & $19.4 \%$ & $28.3 \%$ & $29.1 \%$ & $29.4 \%$ & $30.2 \%$ \\
\hline Workers & $39.3 \%$ & $37.7 \%$ & $37.0 \%$ & $31.6 \%$ & $32.3 \%$ & $30.4 \%$ & $29.7 \%$ & $27.7 \%$ \\
\hline Firm Owners & $43.5 \%$ & $44.7 \%$ & $45.2 \%$ & $49.0 \%$ & $39.4 \%$ & $40.5 \%$ & $41.0 \%$ & $42.1 \%$ \\
\hline Local Price Index & $P^{A C C R A}$ & $P^{A C C R A}$ & $P^{A C C R A, N T}$ & $P^{B L S}$ & $P^{A C C R A}$ & $P^{A C C R A}$ & $P^{A C C R A, N T}$ & $P^{B L S}$ \\
\hline \multicolumn{9}{|l|}{ Parameters } \\
\hline$\alpha$ & 0.3 & 0.6 & & 0.3 & 0.3 & 0.6 & & 0.3 \\
\hline$\alpha^{H}$ & & & 0.2 & & & & 0.2 & \\
\hline$\alpha^{N T}$ & & & 0.4 & & & & 0.4 & \\
\hline
\end{tabular}

Notes: This table shows incidence of local business tax changes over ten years on landowners, firm owners, and workings using different measures of local prices. Local price data are described in Appendix A.4. The first four columns show incidence results based on reduced-form estimates from Column 4 in Table 4-type tables, which controls for Bartik, for all the relevant outcomes in the incidence expressions in equations 48, 14, and 15. The last four columns repeat the same specifications but use the reduced-form estimates from Column 1 in Table 4-type tables, which does not control for Bartik. Specifically, Column (1) and (5) calculate the incidence on workers by taking the difference between the reduced-form impact on wages and $\alpha \hat{\beta}^{P, A C C R A}$ from Tables A7 and A12. For example, the worker estimate in Column (1), which corresponds to the specification controlling for Bartik, is $\hat{\beta}^{W}-\alpha \hat{\beta}^{P, A C C R A}=.78-.3 \times .16=.73$ and for Column (5), which corresponds to the specification not controlling for Bartik, is $\hat{\beta}^{W}-\alpha \hat{\beta}^{P, A C C R A}=1.45-.3 \times .38=1.34$. Column (2) and (6) use an $\alpha$ of .6 instead of .3. Columns (3) and (7) break out traded and non-traded ACCRA price indexes and to present estimates of $\beta^{W}-.2 \beta^{P, A C C R A, \text { residual }}+.4 \beta^{P, A C C R A, N T}$ where $\beta^{P, A C C R A, r e s i d u a l}$ is the ACCRA local price index on items not covered in the NT index. It is calculated using weights in the ACCRA formulas that put .47 on the items in $\beta^{P, A C C R A, N T}$, which implies $\beta^{P, A C C R A, \text { residual }}=\frac{\beta^{P, A C C R A}-.47 \times \beta^{P, A C C R A, N T}}{(1-.47)}$. These estimates are from Tables A12 and A13. The expenditure weight of .6 , which is divided into .2 and .4 , is based on estimates from Beraja, Hurst and Ospina (2016) on the share of total local consumption (.6) and the share of housing consumption (.2), which they assume is entirely local. Finally, Columns (4) and (8) use an alternative local price index from BLS, which isn't available for all locations but covers a large share of the population. In particular, the estimates for workers are $\hat{\beta}^{W}-\alpha \hat{\beta}^{P, B L S}$ and the reduced-form estimates for local prices $\beta^{P, B L S}$ are in Table A14. 


\section{G.2 Deriving Incidence Expressions that Account for Non-traded Goods}

\section{G.2.1 Demand with Non-traded Goods}

In location $c$ with amenities $A$, households maximize Cobb-Douglas utility over housing $h$, a composite $X^{N T}$ of local (non-housing non-traded) goods $x_{j}^{N T}$, a composite $X$ of tradable goods $x_{j}$ while facing a wage $w$, rent $r$, local good prices $p_{j}^{N T}$, and traded good prices $p_{j}$ :

$\max _{h, x^{N T}, X} \ln A+\alpha^{H} \ln h+\alpha^{N T} \ln X^{N T}+\left(1-\alpha^{H}-\alpha^{N T}\right) \ln X$ s.t. $r h+\sum_{j \in J^{N T}} p_{j}^{N T} x_{j}^{N T}+\sum_{j \in J} p_{j} x_{j} d j=w$,

where $X^{N T}=\left(\sum_{j \in J^{N T}}\left(x_{j}^{N T}\right)^{\frac{\epsilon^{P D, N T}}{\epsilon^{P D, N T}}} d j\right)^{\frac{\epsilon^{P D, N T}}{\epsilon^{P D, N T}+1}}, X=\left(\sum_{j \in J} x_{j}^{\frac{\varepsilon^{P D}+1}{\varepsilon^{P D}}} d j\right)^{\frac{\varepsilon^{P D}}{\varepsilon^{P D}+1}}$, and $\epsilon^{P D, N T}<-1$ is the product demand elasticity of local goods.

Demand from each household for local variety $j$ in location $c$ is:

$$
x_{j c}^{N T}=\left(p_{j c}^{N T}\right)^{\epsilon^{P D, N T}} I_{c}^{N T}\left(P_{j c}^{N T}\right)^{1+\epsilon^{P D, N T}}
$$

where $P_{c}^{N T}=\left(\sum_{j \in J_{c}^{N T}} E_{c}^{N T}\left(p_{j c}^{N T}\right)^{1+\varepsilon^{P D}}\right)^{\frac{1}{1+\varepsilon^{P D}}}, E_{c}^{N T}$ is the number of non-traded establishments, and $I_{c}^{N T}=\alpha^{N T} N_{c} w_{c}$ is total expenditures on local goods.

\section{G.2.2 Supply of Non-traded Goods}

Similar to the baseline firm problem, establishments in location $c$ maximize profits over inputs and prices $p_{j c}^{N T}$ while facing a local wage $w_{c}$, national rental rates $\rho$, national prices $p_{v}$ of each variety $v$, and local business taxes $\tau_{c}^{b}$ subject to the production technology in Equation 3:

$$
\pi_{j c}^{N T}=\max _{l_{j c}, k_{j c}, x_{v, j c}, p_{j c}^{N T}}\left(1-\tau_{c}^{b}\right)\left(p_{j c}^{N T} x_{j c}^{N T}-w_{c} l_{j c}-\int_{v \in J} p_{v} x_{v, j c} d v\right)-\rho k_{j c},
$$

Following the same input demand steps in appendix B.2, we can relate sales to unit costs:

$$
\underbrace{p_{j}^{N T} x_{j}^{N T}}_{\equiv \text { Sales } j_{j c}^{N T}}=x_{j}^{N T} \mu^{N T} \underbrace{\frac{1}{B_{j c}}\left[w^{\gamma} \rho^{\delta} \gamma^{-\gamma} \delta^{-\delta}(1-\gamma-\delta)^{-(1-\gamma-\delta)}\right]}_{\equiv c_{j c}}
$$

This expression shows that local prices are a fixed-mark up over unit costs, $p_{j}^{N T}=\mu^{N T} c_{j c}$ where the markup on local goods $\mu^{N T} \equiv\left[\frac{1}{\varepsilon^{P D, N T}}+1\right]^{-1}$ is constant due to CES demand. Since local prices are 
a fixed-mark up over unit costs, we can express after tax profits as follows:

$$
\begin{aligned}
& \pi_{j c}^{N T}=\left(1-\tau_{c}^{b}\right)\left(p_{j c}^{N T}-c_{j c}\right) x_{j c}^{N T} \\
& \pi_{j c}^{N T}=\left(1-\tau_{c}^{b}\right)\left(p_{j c}^{N T}-c_{j c}\right) \frac{\text { Sales }_{j c}^{N T}}{p_{j c}^{N T}} \\
& \pi_{j c}^{N T}=\left(1-\tau_{c}^{b}\right)\left(\mu^{N T} c_{j c}-c_{j c}\right) \frac{\text { Sales }_{j c}^{N T}}{\mu^{N T} c_{j c}} \\
& \pi_{j c}^{N T}=\left(1-\tau_{c}^{b}\right) \frac{\text { Sales }_{j c}^{N T}}{-\varepsilon^{P D, N T}}
\end{aligned}
$$

where the second line comes from the definition of sales, the third line comes from the relationship between prices and costs (from equation 52) and the fourth line comes from the definition of the markup. Similar steps imply that we can express after tax profits for traded-establishments as $\pi_{j c}^{T}=$ $\left(1-\tau_{c}^{b}\right) \frac{\text { Sales }_{j c}}{-\varepsilon^{P D, T}}$.

Therefore total after-tax firm profits is:

$$
\begin{aligned}
E_{c}^{T} \bar{\pi}_{j c}^{T}+E_{c}^{N T} \bar{\pi}_{j c}^{N T} & =\left(1-\tau_{c}^{b}\right)\left(E_{c}^{T} \frac{\text { AvgSales }_{j c}^{T}}{-\varepsilon^{P D, T}}+E_{c}^{N T} \frac{\text { AvgSales }_{j c}^{N T}}{-\varepsilon^{P D, N T}}\right) \\
& =\left(1-\tau_{c}^{b}\right)\left(\frac{\operatorname{TotSales}_{c}^{T}}{-\varepsilon^{P D, T}}+\frac{\operatorname{TotSales}_{c}^{N T}}{-\varepsilon^{P D, N T}}\right) \\
& =\left(1-\tau_{c}^{b}\right) \operatorname{TotSales}_{c}\left(\frac{\operatorname{TotSales}_{c}^{T}}{\text { TotSales }_{c}} \frac{1}{-\varepsilon^{P D, T}}+\frac{\operatorname{TotSales}_{c}^{N T}}{\text { TotSales }_{c}} \frac{1}{-\varepsilon^{P D, N T}}\right)
\end{aligned}
$$

This expression shows that total sales changes reveal information about changes in total profits. In the simple case in which the product demand elasticities are the same, then the term in parenthesis is $\frac{1}{-\varepsilon^{P D}}$ and the average after-tax profit per establishment is: $\bar{\pi}_{c}^{T}=\left(1-\tau_{c}^{b}\right)\left(\frac{\text { AvgSales }_{c}}{-\varepsilon^{P D}}\right)$. In the case in which the product demand elasticities are different, the term in parenthesis will be constant (since the sales shares will be constant due to Cobb Douglas preferences and production technology.) Therefore, in both cases, $\dot{\pi}_{c}=1+$ Avg $\dot{S}$ ales $_{c}$. We can use this expression to quantity $\dot{\pi}_{c}$ when there are both traded and non-traded goods. 
Table A4: Correlation in State Tax Rates

A. Tax Rates

\begin{tabular}{lcccc}
\hline & $\tau_{s}^{c}$ & $\tau_{s}^{\text {sales }}$ & $\tau_{s}^{i}$ & $\tau_{s}^{\text {prop }}$ \\
\hline$\tau_{s}^{c}$ & 1.000 & & & \\
$\tau_{s}^{\text {sales }}$ & 0.008 & 1.000 & & \\
$\tau_{s}^{i}$ & 0.323 & -0.257 & 1.000 & \\
$\tau_{s}^{\text {prop }}$ & 0.113 & -0.030 & 0.012 & 1.000 \\
\hline
\end{tabular}

B. 10 Year Differences in Tax Rates

\begin{tabular}{lcccc}
\hline & $\Delta \tau_{s}^{c}$ & $\Delta \tau_{s}^{\text {sales }}$ & $\Delta \tau_{s}^{i}$ & $\Delta \tau_{s}^{\text {prop }}$ \\
\hline$\Delta \tau_{s}^{c}$ & 1.000 & & & \\
$\Delta \tau_{s}^{\text {sales }}$ & 0.315 & 1.000 & & \\
$\Delta \tau_{s}^{i}$ & 0.078 & -0.007 & 1.000 & \\
$\Delta \tau_{s}^{\text {prop }}$ & -0.046 & -0.191 & -0.176 & 1.000 \\
\hline \hline
\end{tabular}

Notes: This table shows the correlation between tax rates in levels (in Panel A) and changes (in Panel B). See Section 4 for data sources for $\tau_{s}^{c o r p}$ and $\tau_{s}^{i}$. State sales tax rates come from the Book of the States, Table 7.10. The variable is the general sales and gross receipts tax (percent). For property taxes, we use U.S. Censuses as well as the 2009 ACS to obtain an estimate of average property tax liability at the state level. The ratio of these tax liabilities to self reported home values is our estimate of the property tax rate. 
Table A5: Annual Effects of Business Tax Cuts on Establishment Growth

\begin{tabular}{|c|c|c|c|c|c|c|c|}
\hline Establishment Growth & (1) & $(2)$ & $(3)$ & $(4)$ & $(5)$ & $(6)$ & $(7)$ \\
\hline$\Delta$ L Log Net-of-Business-Tax $t$ & $\begin{array}{c}0.11 \\
(0.16)\end{array}$ & $\begin{array}{c}0.16 \\
(0.21)\end{array}$ & $\begin{array}{l}-0.04 \\
(0.24)\end{array}$ & $\begin{array}{c}0.19 \\
(0.18)\end{array}$ & $\begin{array}{c}0.42 \\
(0.26)\end{array}$ & $\begin{array}{c}0.20 \\
(0.30)\end{array}$ & $\begin{array}{c}0.27 \\
(0.38)\end{array}$ \\
\hline$\Delta$ Log Net-of-Business-Tax ${ }_{t-1}$ & $\begin{array}{c}0.14 \\
(0.13)\end{array}$ & $\begin{array}{c}0.36 \\
(0.22)\end{array}$ & $\begin{array}{c}0.36 \\
(0.23)\end{array}$ & $\begin{array}{c}0.14 \\
(0.14)\end{array}$ & $\begin{array}{l}0.47^{*} \\
(0.27)\end{array}$ & $\begin{array}{c}0.54^{* *} \\
(0.27)\end{array}$ & $\begin{array}{c}0.59 \\
(0.39)\end{array}$ \\
\hline$\Delta$ Log Net-of-Business-Tax ${ }_{t-2}$ & $\begin{array}{c}0.48^{* * *} \\
(0.17)\end{array}$ & $\begin{array}{l}0.50^{* *} \\
(0.20)\end{array}$ & $\begin{array}{l}0.51^{* *} \\
(0.24)\end{array}$ & $\begin{array}{l}0.52^{* *} \\
(0.20)\end{array}$ & $\begin{array}{c}0.54^{* *} \\
(0.25)\end{array}$ & $\begin{array}{l}0.61^{* *} \\
(0.29)\end{array}$ & $\begin{array}{c}0.63 \\
(0.38)\end{array}$ \\
\hline$\Delta$ Log Net-of-Business-Tax ${ }_{t-3}$ & $\begin{array}{c}0.57^{* * *} \\
(0.20)\end{array}$ & $\begin{array}{l}0.55^{* *} \\
(0.23)\end{array}$ & $\begin{array}{l}0.58^{* *} \\
(0.25)\end{array}$ & $\begin{array}{l}0.57^{* *} \\
(0.22)\end{array}$ & $\begin{array}{l}0.55^{*} \\
(0.28)\end{array}$ & $\begin{array}{l}0.62^{*} \\
(0.31)\end{array}$ & $\begin{array}{c}0.50 \\
(0.34)\end{array}$ \\
\hline$\Delta$ Log Net-of-Business-Tax ${ }_{t-4}$ & $\begin{array}{c}0.20 \\
(0.13)\end{array}$ & $\begin{array}{c}0.19 \\
(0.13)\end{array}$ & $\begin{array}{c}0.17 \\
(0.16)\end{array}$ & $\begin{array}{c}0.15 \\
(0.25)\end{array}$ & $\begin{array}{c}0.16 \\
(0.30)\end{array}$ & $\begin{array}{c}0.17 \\
(0.34)\end{array}$ & $\begin{array}{c}0.13 \\
(0.37)\end{array}$ \\
\hline$\Delta$ Log Net-of-Business- $\operatorname{Tax}_{t-5}$ & $\begin{array}{c}0.02 \\
(0.25)\end{array}$ & $\begin{array}{c}0.03 \\
(0.26)\end{array}$ & $\begin{array}{l}-0.00 \\
(0.26)\end{array}$ & $\begin{array}{c}0.19 \\
(0.32)\end{array}$ & $\begin{array}{c}0.25 \\
(0.37)\end{array}$ & $\begin{array}{c}0.25 \\
(0.38)\end{array}$ & $\begin{array}{c}0.21 \\
(0.41)\end{array}$ \\
\hline$\Delta$ Log Net-of-Business-Tax ${ }_{t-6}$ & & & & $\begin{array}{c}0.18 \\
(0.25)\end{array}$ & $\begin{array}{c}0.22 \\
(0.31)\end{array}$ & $\begin{array}{c}0.26 \\
(0.31)\end{array}$ & $\begin{array}{c}0.30 \\
(0.36)\end{array}$ \\
\hline$\Delta$ Log Net-of-Business-Tax ${ }_{t-7}$ & & & & $\begin{array}{l}0.34^{* *} \\
(0.16)\end{array}$ & $\begin{array}{l}0.43^{*} \\
(0.23)\end{array}$ & $\begin{array}{c}0.33 \\
(0.23)\end{array}$ & $\begin{array}{l}0.46^{*} \\
(0.26)\end{array}$ \\
\hline$\Delta$ Log Net-of-Business-Tax $t-8$ & & & & $\begin{array}{c}0.21 \\
(0.13)\end{array}$ & $\begin{array}{c}0.21 \\
(0.17)\end{array}$ & $\begin{array}{c}0.15 \\
(0.18)\end{array}$ & $\begin{array}{c}0.26 \\
(0.18)\end{array}$ \\
\hline$\Delta$ Log Net-of-Business-Tax ${ }_{t-9}$ & & & & $\begin{array}{c}0.03 \\
(0.14)\end{array}$ & $\begin{array}{c}0.01 \\
(0.15)\end{array}$ & $\begin{array}{c}0.04 \\
(0.16)\end{array}$ & $\begin{array}{c}0.02 \\
(0.17)\end{array}$ \\
\hline$\Delta$ Log Net-of-Business-Tax ${ }_{t-10}$ & & & & $\begin{array}{c}0.26 \\
(0.16)\end{array}$ & $\begin{array}{c}0.25 \\
(0.16)\end{array}$ & $\begin{array}{l}0.32^{*} \\
(0.16)\end{array}$ & $\begin{array}{l}0.31^{*} \\
(0.18)\end{array}$ \\
\hline$\Delta$ Log Net-of-Business-Tax $\operatorname{Tat}_{t+1}$ & & $\begin{array}{c}0.10 \\
(0.20)\end{array}$ & $\begin{array}{c}0.03 \\
(0.20)\end{array}$ & & $\begin{array}{c}0.13 \\
(0.22)\end{array}$ & $\begin{array}{c}0.20 \\
(0.23)\end{array}$ & $\begin{array}{c}0.02 \\
(0.30)\end{array}$ \\
\hline$\Delta$ Log Net-of-Business-Tax ${ }_{t+2}$ & & $\begin{array}{l}-0.02 \\
(0.16)\end{array}$ & $\begin{array}{c}0.22 \\
(0.20)\end{array}$ & & $\begin{array}{l}-0.06 \\
(0.18)\end{array}$ & $\begin{array}{c}0.30 \\
(0.23)\end{array}$ & $\begin{array}{c}0.08 \\
(0.31)\end{array}$ \\
\hline$\Delta$ Log Net-of-Business-Tax ${ }_{t+3}$ & & & $\begin{array}{l}-0.10 \\
(0.32)\end{array}$ & & & $\begin{array}{c}0.04 \\
(0.33)\end{array}$ & $\begin{array}{l}-0.05 \\
(0.40)\end{array}$ \\
\hline$\Delta$ Log Net-of-Business-Tax ${ }_{t+4}$ & & & $\begin{array}{l}-0.33 \\
(0.22)\end{array}$ & & & $\begin{array}{l}-0.36 \\
(0.25)\end{array}$ & $\begin{array}{l}-0.30 \\
(0.45)\end{array}$ \\
\hline$\Delta$ Log Net-of-Business-Tax ${ }_{t+5}$ & & & $\begin{array}{l}-0.33 \\
(0.23)\end{array}$ & & & $\begin{array}{l}-0.39 \\
(0.27)\end{array}$ & $\begin{array}{l}-0.28 \\
(0.42)\end{array}$ \\
\hline$\Delta$ Log Net-of-Business-Tax $\operatorname{Tax}_{t+6}$ & & & & & & & $\begin{array}{l}-0.15 \\
(0.33)\end{array}$ \\
\hline$\Delta$ Log Net-of-Business-Tax $t+7$ & & & & & & & $\begin{array}{l}-0.30 \\
(0.38)\end{array}$ \\
\hline$\Delta$ Log Net-of-Business-Tax $t+8$ & & & & & & & $\begin{array}{l}-0.30 \\
(0.33)\end{array}$ \\
\hline$\Delta$ Log Net-of-Business-Tax ${ }_{t+9}$ & & & & & & & $\begin{array}{l}-0.05 \\
(0.11)\end{array}$ \\
\hline$\Delta$ Log Net-of-Business-Tax ${ }_{t+10}$ & & & & & & & $\begin{array}{l}-0.11 \\
(0.13)\end{array}$ \\
\hline Observations & 13,230 & 12,250 & 10,780 & 10,780 & 9,800 & 8,330 & 5,880 \\
\hline R-squared & 0.225 & 0.143 & 0.099 & 0.197 & 0.106 & 0.054 & 0.120 \\
\hline Cumulative Effect over 5 Years & $\begin{array}{l}1.51^{* *} \\
(0.75)\end{array}$ & $\begin{array}{l}1.80^{*} \\
(1.02)\end{array}$ & $\begin{array}{c}1.59 \\
(1.14)\end{array}$ & $\begin{array}{c}1.77^{*} \\
(1.03)\end{array}$ & $\begin{array}{c}2.38 \\
(1.58)\end{array}$ & $\begin{array}{c}2.39 \\
(1.72)\end{array}$ & $\begin{array}{c}2.34 \\
(2.10)\end{array}$ \\
\hline Cumulative Effect over 10 Years & & & & $\begin{array}{l}2.79^{*} \\
(1.51)\end{array}$ & $\begin{array}{c}3.49 \\
(2.27)\end{array}$ & $\begin{array}{c}3.49 \\
(2.36)\end{array}$ & $\begin{array}{c}3.70 \\
(2.81)\end{array}$ \\
\hline $\begin{array}{l}\text { P-value of All Lags }=0 \text { : } \\
\text { P-value of All Leads }=0 \text { : }\end{array}$ & 0.003 & $\begin{array}{c}0.012 \\
0.74\end{array}$ & $\begin{array}{c}0.051 \\
0.40\end{array}$ & 0.000 & $\begin{array}{c}0.002 \\
0.66\end{array}$ & $\begin{array}{c}0.037 \\
0.46\end{array}$ & $\begin{array}{c}0.036 \\
0.92\end{array}$ \\
\hline
\end{tabular}

Notes: This table shows the effects of annual local business tax cuts on local establishment growth. Data are for 490 county-groups. See Section 4 for sources. Cumulative effects and F-stats of joint tests that all leads and lags are zero indicate that tax cuts increase local establishment growth and do not exhibit statistically non-zero pre-trends. Regressions use initial population as weights and include year fixed effects and dummies for states in the industrial midwest in the 1980s. Standard errors clustered by state are in parentheses and $* * * \mathrm{p}<0.01,{ }^{* *} \mathrm{p}<0.05,{ }^{*} \mathrm{p}<0.1$. 
Table A6: Effects of Business Tax Cuts on Population Growth over 10 Years

\begin{tabular}{lcccccc}
\hline \hline Population Growth & $(1)$ & $(2)$ & $(3)$ & $(4)$ & $(5)$ & $(6)$ \\
\hline \multirow{3}{*}{$\ln \left(1-\tau^{b}\right)$} & $4.28^{* *}$ & $4.29^{* *}$ & $4.25^{* *}$ & $3.74^{* *}$ & $4.11^{* *}$ & $3.53^{* *}$ \\
& $(1.65)$ & $(1.66)$ & $(1.66)$ & $(1.48)$ & $(1.59)$ & $(1.47)$ \\
$\Delta \mathrm{ITC}$ & & -0.09 & & & & 0.19 \\
& & $(0.25)$ & & & & $(0.25)$ \\
$\Delta \ln$ GOVEXPEND PER CAPITA & & & -0.01 & & & -0.01 \\
& & & $(0.01)$ & & & $(0.01)$ \\
Bartik & & & & $0.44^{* *}$ & & $0.44^{* *}$ \\
& & & & $(0.19)$ & & $(0.17)$ \\
$\Delta \ln \left(1-\tau^{E X T}\right)$ & & & & & $-4.70^{* * *}$ & $-4.74^{* * *}$ \\
& & & & & $(1.70)$ & $(1.63)$ \\
Constant & $0.07^{* * *}$ & $0.07^{* * *}$ & $0.07^{* * *}$ & 0.02 & $0.08^{* * *}$ & 0.03 \\
& $(0.02)$ & $(0.02)$ & $(0.02)$ & $(0.02)$ & $(0.02)$ & $(0.02)$ \\
& & & & & & \\
\hline Observations & 1,470 & 1,470 & 1,470 & 1,470 & 1,470 & 1,470 \\
R-squared & 0.112 & 0.112 & 0.115 & 0.138 & 0.135 & 0.164 \\
\hline \hline
\end{tabular}

Notes: See notes from Table 4. 
Table A7: Effects of Business Tax Cuts on Wage Growth over 10 Years

\begin{tabular}{lcccccc}
\hline \hline Wage Growth & $(1)$ & $(2)$ & $(3)$ & $(4)$ & $(5)$ & $(6)$ \\
\hline \multirow{2}{*}{$\ln \left(1-\tau^{b}\right)$} & 1.45 & 1.50 & 1.45 & 0.78 & 1.42 & 0.82 \\
& $(0.94)$ & $(0.94)$ & $(0.95)$ & $(0.82)$ & $(0.96)$ & $(0.84)$ \\
$\Delta \mathrm{ITC}$ & & $-0.37^{* *}$ & & & & -0.23 \\
& & $(0.15)$ & & & & $(0.16)$ \\
$\Delta \ln$ GOVEXPEND PER CAPITA & & & 0.00 & & & 0.00 \\
& & & $(0.00)$ & & & $(0.00)$ \\
Bartik & & & & $0.56^{* * *}$ & & $0.54^{* * *}$ \\
& & & & $(0.08)$ & & $(0.08)$ \\
$\Delta \ln \left(1-\tau^{E X T}\right)$ & & & & & -0.98 & -0.44 \\
& & & & & $(1.02)$ & $(0.79)$ \\
Constant & $-0.09^{* * *}$ & $-0.09^{* * *}$ & $-0.09^{* * *}$ & $-0.14^{* * *}$ & $-0.09^{* * *}$ & $-0.14^{* * *}$ \\
& $(0.01)$ & $(0.01)$ & $(0.01)$ & $(0.01)$ & $(0.01)$ & $(0.01)$ \\
& & & & & & \\
\hline Observations & 1,470 & 1,470 & 1,470 & 1,470 & 1,470 & 1,470 \\
R-squared & 0.402 & 0.414 & 0.402 & 0.490 & 0.404 & 0.495 \\
\hline \hline
\end{tabular}

Notes: See notes from Table 4. 
Table A8: Effects of Business Tax Cuts on Rental Cost Growth over 10 Years

\begin{tabular}{lcccccc}
\hline \hline Rental Cost Growth & $(1)$ & $(2)$ & $(3)$ & $(4)$ & $(5)$ & $(6)$ \\
\hline \multirow{2}{*}{$\ln \left(1-\tau^{b}\right)$} & 1.17 & 1.33 & 1.17 & 0.32 & 1.02 & 0.43 \\
& $(1.44)$ & $(1.40)$ & $(1.44)$ & $(1.37)$ & $(1.48)$ & $(1.36)$ \\
$\Delta \mathrm{ITC}$ & & $-1.13^{* *}$ & & & & $-0.88^{*}$ \\
& & $(0.55)$ & & & & $(0.50)$ \\
$\Delta \ln$ GOVEXPEND PER CAPITA & & & -0.00 & & & -0.00 \\
& & & $(0.01)$ & & & $(0.01)$ \\
Bartik & & & & $0.70^{* *}$ & & $0.63^{* * *}$ \\
& & & & $(0.27)$ & & $(0.23)$ \\
$\Delta \ln \left(1-\tau^{E X T}\right)$ & & & & & $-4.25^{*}$ & $-2.83^{*}$ \\
& & & & & $(2.39)$ & $(1.58)$ \\
Constant & $0.08^{* * *}$ & $0.08^{* * *}$ & $0.08^{* * *}$ & 0.01 & $0.09^{* * *}$ & 0.03 \\
& $(0.01)$ & $(0.01)$ & $(0.01)$ & $(0.03)$ & $(0.01)$ & $(0.03)$ \\
& & & & & & \\
\hline Observations & 1,470 & 1,470 & 1,470 & 1,470 & 1,470 & 1,470 \\
R-squared & 0.139 & 0.177 & 0.139 & 0.189 & 0.153 & 0.223 \\
\hline \hline
\end{tabular}

Notes: See notes from Table 4. 
Table A9: Effects of Business Tax Cuts on Employment Growth over 10 Years

\begin{tabular}{lcccccc}
\hline \hline Employment Growth & $(1)$ & $(2)$ & $(3)$ & $(4)$ & $(5)$ & $(6)$ \\
\hline & & & & & & \\
$\Delta \ln \left(1-\tau^{b}\right)$ & $4.32^{* *}$ & $4.42^{* *}$ & $4.30^{* *}$ & $3.54^{* *}$ & $4.10^{* *}$ & $3.41^{* *}$ \\
& $(1.79)$ & $(1.73)$ & $(1.80)$ & $(1.51)$ & $(1.69)$ & $(1.41)$ \\
$\Delta \mathrm{ITC}$ & & $-0.67^{* *}$ & & & & -0.32 \\
& & $(0.33)$ & & & & $(0.26)$ \\
$\Delta \ln$ GOVEXPEND PER CAPITA & & & -0.01 & & & -0.01 \\
& & & $(0.01)$ & & & $(0.01)$ \\
Bartik & & & & $0.65^{* * *}$ & & $0.61^{* * *}$ \\
& & & & $(0.17)$ & & $(0.14)$ \\
$\Delta \ln \left(1-\tau^{E X T}\right)$ & & & & & $-6.23^{* * *}$ & $-5.53^{* * *}$ \\
& & & & & $(1.79)$ & $(1.55)$ \\
Constant & $0.13^{* * *}$ & $0.13^{* * *}$ & $0.13^{* * *}$ & $0.06^{* * *}$ & $0.14^{* * *}$ & $0.08^{* * *}$ \\
& $(0.02)$ & $(0.02)$ & $(0.02)$ & $(0.02)$ & $(0.02)$ & $(0.02)$ \\
& & & & & & \\
\hline Observations & 1,470 & 1,470 & 1,470 & 1,470 & 1,470 & 1,470 \\
R-squared & 0.139 & 0.177 & 0.139 & 0.189 & 0.153 & 0.223 \\
\hline \hline
\end{tabular}

Notes: See notes from Table 4. 
Table A10: Effects of Business Tax Cuts on Growth in GOS per Establishment over 10 Years

\begin{tabular}{|c|c|c|c|c|c|c|}
\hline Growth in GOS per establishment & $(1)$ & $(2)$ & $(3)$ & $(4)$ & $(5)$ & $(6)$ \\
\hline$\Delta \ln$ Net-of-Business-Tax Rate & $\begin{array}{l}4.07^{* *} \\
(2.02)\end{array}$ & $\begin{array}{l}3.92^{*} \\
(2.02)\end{array}$ & $\begin{array}{l}4.08^{*} \\
(2.03)\end{array}$ & $\begin{array}{l}3.66^{*} \\
(2.00)\end{array}$ & $\begin{array}{l}4.20^{* *} \\
(1.95)\end{array}$ & $\begin{array}{c}3.50^{*} \\
(1.95)\end{array}$ \\
\hline$\Delta$ State ITC & & $\begin{array}{c}1.05^{* * * *} \\
(0.27)\end{array}$ & & & & $\begin{array}{c}1.06^{* * *} \\
(0.32)\end{array}$ \\
\hline$\Delta \ln$ Gov. Expend./Capita & & & $\begin{array}{c}0.00 \\
(0.00)\end{array}$ & & & $\begin{array}{c}0.00 \\
(0.00)\end{array}$ \\
\hline Bartik & & & & $\begin{array}{c}0.34 \\
(0.22)\end{array}$ & & $\begin{array}{l}0.42^{*} \\
(0.22)\end{array}$ \\
\hline Change in Other States' Taxes & & & & & $\begin{array}{c}3.63 \\
(2.33)\end{array}$ & $\begin{array}{c}2.47 \\
(2.21)\end{array}$ \\
\hline Observations & 1,470 & 1,470 & 1,470 & 1,470 & 1,470 & 1,470 \\
\hline R-squared & 0.138 & 0.172 & 0.138 & 0.150 & 0.149 & 0.196 \\
\hline
\end{tabular}

Notes: This table shows the effects of local business tax changes over ten years on gross operating surplus (GOS) per establishment. The data are decade changes from 1980-1990, 1990-2000, and 2000-2010 for 490 county-groups. GOS data are from BEA regional statistics. See Section 4 for other data sources used in the table. The specifications are exactly the same as in Table 4 . Standard errors clustered by state are in parentheses and $* * * \mathrm{p}<0.01, * * \mathrm{p}<0.05, *$ $\mathrm{p}<0.1$. 
Table A11: Effects of Business Tax Cuts on Growth in Sales Tax Revenue over 10 Years

\begin{tabular}{|c|c|c|c|c|c|c|}
\hline Growth in sales tax revenue per establishment & $(1)$ & $(2)$ & $(3)$ & $(4)$ & $(5)$ & $(6)$ \\
\hline$\Delta \ln$ Net-of-Business-Tax Rate & $\begin{array}{c}2.26 \\
(3.42)\end{array}$ & $\begin{array}{c}2.24 \\
(3.43)\end{array}$ & $\begin{array}{c}2.27 \\
(3.42)\end{array}$ & $\begin{array}{c}2.27 \\
(3.44)\end{array}$ & $\begin{array}{c}2.16 \\
(3.37)\end{array}$ & $\begin{array}{c}2.15 \\
(3.41)\end{array}$ \\
\hline$\Delta$ State ITC & & $\begin{array}{c}0.09 \\
(0.33)\end{array}$ & & & & $\begin{array}{c}0.23 \\
(0.31)\end{array}$ \\
\hline$\Delta \ln$ Gov. Expend./Capita & & & $\begin{array}{c}0.01 \\
(0.01)\end{array}$ & & & $\begin{array}{c}0.01 \\
(0.01)\end{array}$ \\
\hline Bartik & & & & $\begin{array}{c}-0.01 \\
(0.30)\end{array}$ & & $\begin{array}{l}-0.01 \\
(0.30)\end{array}$ \\
\hline Change in Other States' Taxes & & & & & $\begin{array}{l}-3.82 \\
(2.57)\end{array}$ & $\begin{array}{l}-4.12 \\
(2.47)\end{array}$ \\
\hline Observations & 1,422 & 1,422 & 1,422 & 1,422 & 1,422 & 1,422 \\
\hline R-squared & 0.539 & 0.539 & 0.539 & 0.539 & 0.543 & 0.544 \\
\hline
\end{tabular}

Notes: This table shows the effects of local business tax changes over ten years on state sales tax revenue per establishment. The data are decade changes from 1980-1990, 1990-2000, and 2000-2010 for 490 county-groups, but not all states collect sales taxes so the number of observations has 16 fewer county-groups per decade. Sales tax revenue is from the census of governments. See Section 4 for other data sources used in the table. The specifications are exactly the same as in Table 4. Standard errors clustered by state are in parentheses and ${ }^{* * *} \mathrm{p}<0.01,{ }^{* *} \mathrm{p}<0.05,{ }^{*} \mathrm{p}<0.1$. 
Table A12: Effects of Business Tax Cuts on Growth in Local Price Index (ACCRA) over 10 Years

\begin{tabular}{|c|c|c|c|c|c|c|}
\hline Growth in Price Index (ACCRA) & $(1)$ & $(2)$ & $(3)$ & $(4)$ & $(5)$ & $(6)$ \\
\hline$\Delta \ln$ Net-of-Business-Tax Rate & $\begin{array}{c}0.38 \\
(1.39)\end{array}$ & $\begin{array}{c}0.36 \\
(1.38)\end{array}$ & $\begin{array}{c}0.38 \\
(1.39)\end{array}$ & $\begin{array}{c}0.16 \\
(1.51)\end{array}$ & $\begin{array}{c}0.29 \\
(1.43)\end{array}$ & $\begin{array}{c}0.01 \\
(1.55)\end{array}$ \\
\hline$\Delta$ State ITC & & $\begin{array}{c}0.20 \\
(0.19)\end{array}$ & & & & $\begin{array}{c}0.33 \\
(0.21)\end{array}$ \\
\hline$\Delta \ln$ Gov. Expend./Capita & & & $\begin{array}{l}-0.00 \\
(0.00)\end{array}$ & & & $\begin{array}{l}-0.00 \\
(0.00)\end{array}$ \\
\hline Bartik & & & & $\begin{array}{l}0.22^{*} \\
(0.11)\end{array}$ & & $\begin{array}{c}0.23^{* *} \\
(0.11)\end{array}$ \\
\hline Change in Other States' Taxes & & & & & $\begin{array}{l}-2.12 \\
(1.79)\end{array}$ & $\begin{array}{l}-2.34 \\
(1.76)\end{array}$ \\
\hline Observations & 1,201 & 1,201 & 1,201 & 1,201 & 1,201 & 1,201 \\
\hline R-squared & 0.119 & 0.121 & 0.119 & 0.129 & 0.127 & 0.142 \\
\hline
\end{tabular}

Notes: This table shows the effects of local business tax changes over ten years on growth in the ACCRA price index. The data are decade changes from 1980-1990, 1990-2000, and 2000-2010 for 490 county-groups, but some local areas are not covered by ACCRA. See Appendix A.4 for data details on local prices and Section 4 for other data sources. The specifications are exactly the same as in Table 4 . Standard errors clustered by state are in parentheses and $* * * \mathrm{p}<0.01$, ** $\mathrm{p}<0.05, * \mathrm{p}<0.1$. 
Table A13: Effects of Business Tax Cuts on Growth in Local Non-traded Price Index (ACCRA) over 10 Years

\begin{tabular}{|c|c|c|c|c|c|c|}
\hline Growth in Local Non-traded Price Index (ACCRA) & $(1)$ & $(2)$ & $(3)$ & $(4)$ & $(5)$ & $(6)$ \\
\hline$\Delta \ln$ Net-of-Business-Tax Rate & $\begin{array}{c}0.11 \\
(0.88)\end{array}$ & $\begin{array}{c}0.08 \\
(0.86)\end{array}$ & $\begin{array}{c}0.12 \\
(0.88)\end{array}$ & $\begin{array}{c}0.02 \\
(0.91)\end{array}$ & $\begin{array}{c}0.10 \\
(0.89)\end{array}$ & $\begin{array}{c}-0.06 \\
(0.92)\end{array}$ \\
\hline$\Delta$ State ITC & & $\begin{array}{c}0.34^{* *} \\
(0.15)\end{array}$ & & & & $\begin{array}{c}0.39^{* *} \\
(0.15)\end{array}$ \\
\hline$\Delta \ln$ Gov. Expend./Capita & & & $\begin{array}{c}0.00 \\
(0.00)\end{array}$ & & & $\begin{array}{c}0.00 \\
(0.00)\end{array}$ \\
\hline Bartik & & & & $\begin{array}{c}0.09 \\
(0.06)\end{array}$ & & $\begin{array}{c}0.11^{* *} \\
(0.05)\end{array}$ \\
\hline Change in Other States' Taxes & & & & & $\begin{array}{c}-0.33 \\
(1.24)\end{array}$ & $\begin{array}{l}-0.63 \\
(1.07)\end{array}$ \\
\hline Observations & 1,201 & 1,201 & 1,201 & 1,201 & 1,201 & 1,201 \\
\hline R-squared & 0.055 & 0.068 & 0.056 & 0.058 & 0.055 & 0.076 \\
\hline
\end{tabular}

Notes: This table shows the effects of local business tax changes over ten years on growth in the ACCRA non-traded price index. The data are decade changes from 1980-1990, 1990-2000, and 2000-2010 for 490 county-groups, but some local areas are not covered by ACCRA. See Appendix A.4 for data details on local prices and Section 4 for other data sources The specifications are exactly the same as in Table 4. Standard errors clustered by state are in parentheses and $* * * \mathrm{p}<0.01, * * \mathrm{p}<0.05, * \mathrm{p}<0.1$. 
Table A14: Effects of Business Tax Cuts on Growth in Local Price Index (BLS) over 10 Years

\begin{tabular}{|c|c|c|c|c|c|c|}
\hline Growth in Local Price Index (BLS) & $(1)$ & $(2)$ & $(3)$ & $(4)$ & $(5)$ & $(6)$ \\
\hline$\Delta \ln$ Net-of-Business-Tax Rate & $\begin{array}{c}1.25 \\
(0.92)\end{array}$ & $\begin{array}{c}1.35 \\
(0.87)\end{array}$ & $\begin{array}{c}1.27 \\
(0.91)\end{array}$ & $\begin{array}{c}0.86 \\
(0.81)\end{array}$ & $\begin{array}{c}1.19 \\
(0.94)\end{array}$ & $\begin{array}{c}1.06 \\
(0.79)\end{array}$ \\
\hline$\Delta$ State ITC & & $\begin{array}{c}-0.30^{* * *} \\
(0.09)\end{array}$ & & & & $\begin{array}{r}-0.27^{* *} \\
(0.11)\end{array}$ \\
\hline$\Delta \ln$ Gov. Expend./Capita & & & $\begin{array}{c}0.00 * * * \\
(0.00)\end{array}$ & & & $\begin{array}{l}0.00^{* *} \\
(0.00)\end{array}$ \\
\hline Bartik & & & & $\begin{array}{c}0.22^{* * *} \\
(0.07)\end{array}$ & & $\begin{array}{c}0.18^{\text {** }} \\
(0.07)\end{array}$ \\
\hline Change in Other States' Taxes & & & & & $\begin{array}{l}-0.50 \\
(1.31)\end{array}$ & $\begin{array}{c}0.17 \\
(1.13)\end{array}$ \\
\hline Observations & 714 & 714 & 714 & 714 & 714 & 714 \\
\hline R-squared & 0.323 & 0.373 & 0.327 & 0.363 & 0.327 & 0.400 \\
\hline
\end{tabular}

Notes: This table shows the effects of local business tax changes over ten years on growth in the BLS local price index. The data are decade changes from 1980-1990, 1990-2000, and 2000-2010 for 490 county-groups, but not all states are covered by the BLS local price index. See Appendix A.4 for data details on local prices and Section 4 for other data sources. The specifications are exactly the same as in Table 4. Standard errors clustered by state are in parentheses and $* * * \mathrm{p}<0.01,{ }^{* *} \mathrm{p}<0.05, * \mathrm{p}<0.1$. 
Table A15: Effects of Business Tax Cuts on Growth in Single-State Establishments over 10 Years

\begin{tabular}{|c|c|c|c|c|c|c|}
\hline Single-State Establishment Growth & $(1)$ & $(2)$ & $(3)$ & $(4)$ & $(5)$ & $(6)$ \\
\hline$\Delta \ln$ Net-of-Business-Tax Rate & $\begin{array}{l}4.32^{* *} \\
(1.89)\end{array}$ & $\begin{array}{c}3.55^{* *} \\
(1.47)\end{array}$ & $\begin{array}{l}4.30^{* *} \\
(1.90)\end{array}$ & $\begin{array}{l}4.37^{* *} \\
(1.87)\end{array}$ & $\begin{array}{l}4.17^{* *} \\
(1.85)\end{array}$ & $\begin{array}{c}3.42^{* *} \\
(1.47)\end{array}$ \\
\hline Bartik & & $\begin{array}{c}0.63^{* * *} \\
(0.19)\end{array}$ & & & & $\begin{array}{c}0.62^{* * *} \\
(0.18)\end{array}$ \\
\hline$\Delta \ln$ Gov Expend/Capita & & & $\begin{array}{l}-0.01 \\
(0.01)\end{array}$ & & & $\begin{array}{l}-0.01 \\
(0.01)\end{array}$ \\
\hline$\Delta$ State ITC & & & & $\begin{array}{l}-0.35 \\
(0.29)\end{array}$ & & $\begin{array}{l}-0.06 \\
(0.28)\end{array}$ \\
\hline Change in Other States' Taxes & & & & & $\begin{array}{c}-4.20^{* *} \\
(1.70)\end{array}$ & $\begin{array}{c}-3.84^{* *} \\
(1.55)\end{array}$ \\
\hline Observations & 1,470 & 1,470 & 1,470 & 1,470 & 1,470 & 1,470 \\
\hline R-squared & 0.429 & 0.452 & 0.430 & 0.431 & 0.437 & 0.461 \\
\hline
\end{tabular}

Notes: This table shows the effects of local business tax changes over ten years on growth in the number of single-state establishments. The data are decade changes from 1980-1990, 1990-2000, and 2000-2010 for 490 county-groups. See Section 4 for data sources and Section A.5 for details on the construction of our single-state establishment data. The specifications are exactly the same as in Table 4 . Standard errors clustered by state are in parentheses and $* * * \mathrm{p}<0.01$, ** $\mathrm{p}<0.05, * \mathrm{p}<0.1$. 
Table A16: Implied Structural Parameter Estimates Using Reduced-Form Effects

\begin{tabular}{lcccc}
\hline \hline & $(1)$ & $(2)$ & $(3)$ & $(4)$ \\
\hline & & & & \\
Productivity Dispersion $\sigma_{F}$ & $-.09^{*}$ & -.06 & -.23 & -.44 \\
& $(.05)$ & $(.07)$ & $(.21)$ & $(.44)$ \\
Preference Dispersion $\sigma_{W}$ & .26 & .18 & .64 & 1.12 \\
& $(.17)$ & $(.18)$ & $(.98)$ & $(1.71)$ \\
Housing Supply $\eta$ & 3.88 & 13.01 & .64 & 1.09 \\
& $(5.24)$ & $(57.42)$ & $(1.1)$ & $(1.15)$ \\
Product Demand $\varepsilon^{P D}$ & 7.59 & 10.01 & 5.66 & 4.8 \\
& $(6.25)$ & $(13.01)$ & $(4.76)$ & $(3.15)$ \\
& & & & \\
Test of Restriction & & & & \\
\hline P-value of $\beta^{E}=\beta^{N}-\left(\gamma\left(\varepsilon^{P D}+1\right)-1\right) \beta^{W}$ & .12 & .27 & .22 & .2 \\
& & & & \\
Specifications & & & & \\
\hline Net-of-Business Tax & $\mathrm{Y}$ & $\mathrm{Y}$ & $\mathrm{Y}$ & $\mathrm{N}$ \\
Net-of-Corporate Tax & $\mathrm{N}$ & $\mathrm{N}$ & $\mathrm{N}$ & $\mathrm{Y}$ \\
Bartik Control & $\mathrm{N}$ & $\mathrm{Y}$ & $\mathrm{Y}$ & $\mathrm{Y}$ \\
Net-of-Personal Tax Control & $\mathrm{N}$ & $\mathrm{N}$ & $\mathrm{Y}$ & $\mathrm{Y}$ \\
\hline \hline
\end{tabular}

Notes: This table shows the implied structural parameter estimates associated with the reduced-form effects underlying the incidence results in Table 5. Column (1) corresponds to the reduced-form effects from Columns (1)-(3) of Table 5. Recall that these columns use the same reduced-form effects with different calibrated parameter values, which results in the same implied structural parameters (other than for $\hat{\sigma}_{W}=.16(.13)$ in the specification that corresponds to Column (2) of Table 5, i.e., the specification with the same reduced-form effects as Column (1) but with $\alpha=.65)$. Column (2), (3), and (4) in this table correspond to Column (4), (5), and (6) of Table 5, respectively. Standard errors clustered by state are in parentheses and $* * * \mathrm{p}<0.01,{ }^{*} * \mathrm{p}<0.05,{ }^{*} \mathrm{p}<0.1$. 
Table A17: Estimates of Economic Incidence Using Reduced-Form Effects (Only Single-State Establishments)

\begin{tabular}{|c|c|c|c|c|c|c|c|c|c|c|c|c|}
\hline & \multicolumn{6}{|c|}{ A. Incidence } & \multicolumn{6}{|c|}{ B. Share of Incidence } \\
\hline & $(1)$ & $(2)$ & $(3)$ & $(4)$ & $(5)$ & $(6)$ & $(1)$ & $(2)$ & $(3)$ & $(4)$ & $(5)$ & $(6)$ \\
\hline Landowners & $\begin{array}{c}1.17 \\
(1.43)\end{array}$ & $\begin{array}{c}1.17 \\
(1.43)\end{array}$ & $\begin{array}{c}1.17 \\
(1.43)\end{array}$ & $\begin{array}{c}.32 \\
(1.36)\end{array}$ & $\begin{array}{c}1.86 \\
(1.56)\end{array}$ & $\begin{array}{l}.62 \\
(.6)\end{array}$ & $\begin{array}{c}.29 \\
(.18)\end{array}$ & $\begin{array}{c}.33 \\
(.23)\end{array}$ & $\begin{array}{c}.26 \\
(.19)\end{array}$ & $\begin{array}{c}.18 \\
(.47)\end{array}$ & $\begin{array}{l}.42^{* *} \\
(.17)\end{array}$ & $\begin{array}{l}.29 * \\
(.16)\end{array}$ \\
\hline Workers & $\begin{array}{l}1.1^{*} \\
(.59)\end{array}$ & $\begin{array}{c}.69 \\
(.44)\end{array}$ & $\begin{array}{l}1.1^{*} \\
(.59)\end{array}$ & $\begin{array}{c}.68 \\
(.52)\end{array}$ & $\begin{array}{l}.98 \\
(.84)\end{array}$ & $\begin{array}{l}.58^{*} \\
.(33)\end{array}$ & $\begin{array}{c}.28^{* * *} \\
(.09)\end{array}$ & $\begin{array}{l}.19 \\
(.16)\end{array}$ & $\begin{array}{c}.24 * * * \\
(.07)\end{array}$ & $\begin{array}{c}.38 \\
(.48)\end{array}$ & $\begin{array}{l}.22^{*} \\
(.12)\end{array}$ & $\begin{array}{c}.28^{* * *} \\
(.08)\end{array}$ \\
\hline Firmowners & $\begin{array}{l}1.71^{*} \\
(.99)\end{array}$ & $\begin{array}{l}1.71^{*} \\
(.99)\end{array}$ & $\begin{array}{c}2.23^{* *} \\
(.99)\end{array}$ & $\begin{array}{c}.79 \\
(1.58)\end{array}$ & $\begin{array}{l}1.57 \\
(.97)\end{array}$ & $\begin{array}{l}.9^{* *} \\
(.35)\end{array}$ & $\begin{array}{c}.43^{* * *} \\
(.11)\end{array}$ & $\begin{array}{c}.48^{* * *} \\
(.09)\end{array}$ & $\begin{array}{l}.5^{* * *} \\
(.16)\end{array}$ & $\begin{array}{c}.44^{* * *} \\
(.16)\end{array}$ & $\begin{array}{c}.36^{* * *} \\
(.08)\end{array}$ & $\begin{array}{c}.43^{* * *} \\
(.09)\end{array}$ \\
\hline Conventional View Test & & & & & & & & & & & & \\
\hline $\begin{array}{l}\chi^{2} \text { of }\left(S^{W}=100 \% \& S^{F}=0 \%\right) \\
\text { P-value }\end{array}$ & & & & & & & $\begin{array}{c}160.50 \\
0.00\end{array}$ & $\begin{array}{c}110.78 \\
0.00\end{array}$ & $\begin{array}{c}56.94 \\
0.00\end{array}$ & $\begin{array}{l}4.03 \\
0.04\end{array}$ & $\begin{array}{c}81.33 \\
0.00\end{array}$ & $\begin{array}{c}223.27 \\
0.00\end{array}$ \\
\hline
\end{tabular}

\begin{tabular}{|c|c|c|c|c|c|c|c|c|c|c|c|c|}
\hline Net-of-Business Tax & $\mathrm{Y}$ & $\mathrm{Y}$ & $\mathrm{Y}$ & $\mathrm{Y}$ & $\mathrm{Y}$ & $\mathrm{N}$ & $\mathrm{Y}$ & $\mathrm{Y}$ & $\mathrm{Y}$ & $\mathrm{Y}$ & $\mathrm{Y}$ & $\mathrm{N}$ \\
\hline Net-of-Corporate Tax & $\mathrm{N}$ & $\mathrm{N}$ & $\mathrm{N}$ & $\mathrm{N}$ & $\mathrm{N}$ & $\mathrm{Y}$ & $\mathrm{N}$ & $\mathrm{N}$ & $\mathrm{N}$ & $\mathrm{N}$ & $\mathrm{N}$ & $\mathrm{Y}$ \\
\hline Housing share $\alpha$ & .3 & .65 & .3 & .3 & .3 & .3 & .3 & .65 & .3 & .3 & .3 & .3 \\
\hline Output elasticity ratio $\delta / \gamma$ & .9 & .9 & .5 & .9 & .9 & .9 & .9 & .9 & .5 & .9 & .9 & .9 \\
\hline Bartik Control & $\mathrm{N}$ & $\mathrm{N}$ & $\mathrm{N}$ & $\mathrm{Y}$ & $\mathrm{Y}$ & $\mathrm{N}$ & $\mathrm{N}$ & $\mathrm{N}$ & $\mathrm{N}$ & $\mathrm{Y}$ & $\mathrm{Y}$ & $\mathrm{N}$ \\
\hline Net-of-Personal Tax Control & $\mathrm{N}$ & $\mathrm{N}$ & $\mathrm{N}$ & $\mathrm{N}$ & $\mathrm{Y}$ & $\mathrm{N}$ & $\mathrm{N}$ & $\mathrm{N}$ & $\mathrm{N}$ & $\mathrm{N}$ & $\mathrm{Y}$ & $\mathrm{N}$ \\
\hline
\end{tabular}

Notes: This table, which is analogous to Table 5, uses changes in single-state establishments (i.e., using the estimates in Table A15 instead of Panel A of Table 4). See Section A.5 for details on the construction of our single-state establishment data. 
Table A18: Estimates of Economic Incidence Using Reduced-Form Effects (with Employment instead of Population)

\begin{tabular}{|c|c|c|c|c|c|c|c|c|c|c|c|c|}
\hline & \multicolumn{6}{|c|}{ A. Incidence } & \multicolumn{6}{|c|}{ B. Share of Incidence } \\
\hline & $(1)$ & $(2)$ & $(3)$ & $(4)$ & $(5)$ & $(6)$ & $(1)$ & $(2)$ & $(3)$ & $(4)$ & $(5)$ & $(6)$ \\
\hline Landowners & $\begin{array}{c}1.17 \\
(1.43)\end{array}$ & $\begin{array}{c}1.17 \\
(1.43)\end{array}$ & $\begin{array}{c}1.17 \\
(1.43)\end{array}$ & $\begin{array}{c}.32 \\
(1.36)\end{array}$ & $\begin{array}{c}1.86 \\
(1.56)\end{array}$ & $\begin{array}{l}.62 \\
(.6)\end{array}$ & $\begin{array}{l}.3^{*} \\
(.18)\end{array}$ & $\begin{array}{l}.33 \\
(.23)\end{array}$ & $\begin{array}{c}.27 \\
(.19)\end{array}$ & $\begin{array}{l}.17 \\
(.5)\end{array}$ & $\begin{array}{l}.4^{* *} \\
(.16)\end{array}$ & $\begin{array}{l}.3^{* *} \\
(.15)\end{array}$ \\
\hline Workers & $\begin{array}{l}1.1^{*} \\
(.59)\end{array}$ & $\begin{array}{c}.69 \\
(.44)\end{array}$ & $\begin{array}{l}1.1^{*} \\
(.59)\end{array}$ & $\begin{array}{c}.68 \\
(.52)\end{array}$ & $\begin{array}{l}.98 \\
(.84)\end{array}$ & $\begin{array}{l}.58^{*} \\
(.33)\end{array}$ & $\begin{array}{c}.28^{* * *} \\
(.1)\end{array}$ & $\begin{array}{c}.2 \\
(.16)\end{array}$ & $\begin{array}{c}.25^{* * *} \\
(.08)\end{array}$ & $\begin{array}{c}.37 \\
(.36)\end{array}$ & $\begin{array}{l}.21^{*} \\
(.11)\end{array}$ & $\begin{array}{c}.28^{* * *} \\
(.09)\end{array}$ \\
\hline Firmowners & $\begin{array}{c}1.65 \\
(1.04)\end{array}$ & $\begin{array}{l}1.65 \\
(1.04)\end{array}$ & $\begin{array}{l}2.11^{*} \\
(1.13)\end{array}$ & $\begin{array}{c}.85 \\
(1.11)\end{array}$ & $\begin{array}{c}1.77 \\
(1.38)\end{array}$ & $\begin{array}{l}.85^{*} \\
(.5)\end{array}$ & $\begin{array}{c}.42^{* * *} \\
(.11)\end{array}$ & $\begin{array}{c}.47^{* * *} \\
(.09)\end{array}$ & $\begin{array}{c}.48^{* * *} \\
(.16)\end{array}$ & $\begin{array}{c}.46^{* * *} \\
(.15)\end{array}$ & $\begin{array}{c}.38^{* * *} \\
(.07)\end{array}$ & $\begin{array}{c}.42^{* * *} \\
(.07)\end{array}$ \\
\hline Conventional View Test & & & & & & & & & & & & \\
\hline $\begin{array}{l}\chi^{2} \text { of }\left(S^{W}=100 \% \& S^{F}=0 \%\right) \\
\text { P-value }\end{array}$ & & & & & & & $\begin{array}{c}140.55 \\
0.00\end{array}$ & $\begin{array}{c}95.74 \\
0.00\end{array}$ & $\begin{array}{l}62.3 \\
0.00\end{array}$ & $\begin{array}{c}19.15 \\
0.00\end{array}$ & $\begin{array}{c}144.68 \\
0.00\end{array}$ & $\begin{array}{c}1321.58 \\
0.00\end{array}$ \\
\hline
\end{tabular}

Specification

\begin{tabular}{|c|c|c|c|c|c|c|c|c|c|c|c|c|}
\hline Net-of-Business Tax & $\bar{Y}$ & $\bar{Y}$ & $\bar{Y}$ & $\bar{Y}$ & $\bar{Y}$ & $\mathrm{~N}$ & $\bar{Y}$ & $\bar{Y}$ & $\mathrm{Y}$ & $\bar{Y}$ & $\bar{Y}$ & $\mathrm{~N}$ \\
\hline Net-of-Corporate Tax & $\mathrm{N}$ & $\mathrm{N}$ & $\mathrm{N}$ & $\mathrm{N}$ & $\mathrm{N}$ & Y & $\mathrm{N}$ & $\mathrm{N}$ & $\mathrm{N}$ & $\mathrm{N}$ & $\mathrm{N}$ & $\mathrm{Y}$ \\
\hline Housing share $\alpha$ & .3 & .65 & .3 & .3 & .3 & .3 & .3 & .65 & .3 & .3 & .3 & .3 \\
\hline Output elasticity ratio $\delta / \gamma$ & .9 & .9 & .5 & .9 & .9 & .9 & .9 & .9 & .5 & .9 & .9 & .9 \\
\hline Bartik Control & $\mathrm{N}$ & $\mathrm{N}$ & $\mathrm{N}$ & $\mathrm{Y}$ & $\mathrm{Y}$ & $\mathrm{N}$ & $\mathrm{N}$ & $\mathrm{N}$ & $\mathrm{N}$ & Y & $\mathrm{Y}$ & $\mathrm{N}$ \\
\hline Net-of-Personal Tax Control & $\mathrm{N}$ & $\mathrm{N}$ & $\mathrm{N}$ & $\mathrm{N}$ & Y & $\mathrm{N}$ & $\mathrm{N}$ & $\mathrm{N}$ & $\mathrm{N}$ & $\mathrm{N}$ & $\mathrm{Y}$ & $\mathrm{N}$ \\
\hline
\end{tabular}

Notes: This table, which is analogous to Table 5, uses employment changes rather than population changes (i.e., using the estimates in Table A9 instead of A6). 
Table A19: Incidence Estimates Using Reduced-Form Effects, Business Tax Changes (Tax Base Controls)

\begin{tabular}{|c|c|c|c|c|c|c|c|c|c|c|c|c|c|}
\hline \multicolumn{14}{|c|}{ Panel (a) Incidence } \\
\hline & (1) & $(2)$ & $(3)$ & $(4)$ & $(5)$ & $(6)$ & $(7)$ & $(8)$ & (9) & $(10)$ & $(11)$ & $(12)$ & (13) \\
\hline Workers $\dot{w}-\alpha \dot{r}$ & $\begin{array}{l}1.19^{*} \\
(.62)\end{array}$ & $\begin{array}{c}1.12^{*} \\
(.6)\end{array}$ & $\begin{array}{l}1.1^{*} \\
(.59)\end{array}$ & $\begin{array}{c}1.16^{* *} \\
(.59)\end{array}$ & $\begin{array}{l}1.13^{*} \\
(.63)\end{array}$ & $\begin{array}{l}1.05^{*} \\
(.62)\end{array}$ & $\begin{array}{c}1.07^{* *} \\
(.49)\end{array}$ & $\begin{array}{l}.81^{* *} \\
(.34)\end{array}$ & $\begin{array}{c}1.35^{* *} \\
(.58)\end{array}$ & $\begin{array}{c}1.33^{* *} \\
(.58)\end{array}$ & $\begin{array}{l}1.02 \\
(.64)\end{array}$ & $\begin{array}{c}1.21^{* *} \\
(.59)\end{array}$ & $\begin{array}{c}1.32^{* *} \\
(.58)\end{array}$ \\
\hline Landowners $\dot{r}$ & $\begin{array}{c}1.39 \\
(1.44)\end{array}$ & $\begin{array}{c}1.04 \\
(1.45)\end{array}$ & $\begin{array}{c}1.21 \\
(1.47)\end{array}$ & $\begin{array}{c}1.08 \\
(1.46)\end{array}$ & $\begin{array}{c}1.19 \\
(1.49)\end{array}$ & $\begin{array}{c}2.03 \\
(1.32)\end{array}$ & $\begin{array}{c}1.15 \\
(1.32)\end{array}$ & $\begin{array}{l}.38 \\
(.82)\end{array}$ & $\begin{array}{c}1.68 \\
(1.35)\end{array}$ & $\begin{array}{c}1.67 \\
(1.43)\end{array}$ & $\begin{array}{c}.29 \\
(1.89)\end{array}$ & $\begin{array}{c}1.21 \\
(1.46)\end{array}$ & $\begin{array}{l}2.21^{*} \\
(1.25)\end{array}$ \\
\hline Firmowners $\dot{\pi}$ & $\begin{array}{l}1.94^{*} \\
(1.05)\end{array}$ & $\begin{array}{l}1.61^{*} \\
(.92)\end{array}$ & $\begin{array}{l}1.63^{*} \\
(.89)\end{array}$ & $\begin{array}{l}1.76^{*} \\
(.95)\end{array}$ & $\begin{array}{l}1.51^{*} \\
(.79)\end{array}$ & $\begin{array}{c}1.65^{* *} \\
(.84)\end{array}$ & $\begin{array}{l}1.59^{*} \\
(.84)\end{array}$ & $\begin{array}{c}1.02^{* *} \\
(.41)\end{array}$ & $\begin{array}{l}1.68^{*} \\
(.86)\end{array}$ & $\begin{array}{c}1.95^{* *} \\
(.91)\end{array}$ & $\begin{array}{l}1.17 \\
(.8)\end{array}$ & $\begin{array}{l}1.65^{*} \\
(.88)\end{array}$ & $\begin{array}{c}1.82^{* * *} \\
(.69)\end{array}$ \\
\hline
\end{tabular}

\begin{tabular}{|c|c|c|c|c|c|c|c|c|c|c|c|c|c|}
\hline \multicolumn{14}{|c|}{ Panel (b) Shares of Incidence } \\
\hline & $(1)$ & $(2)$ & $(3)$ & $(4)$ & $(5)$ & $(6)$ & $(7)$ & $(8)$ & $(9)$ & $(10)$ & $(11)$ & $(12)$ & $(13)$ \\
\hline Worker Share & $\begin{array}{c}.26^{* * *} \\
(.08)\end{array}$ & $\begin{array}{l}.3^{* * *} \\
(.11)\end{array}$ & $\begin{array}{c}.28^{* * *} \\
(.09)\end{array}$ & $\begin{array}{c}.29 * * * \\
(.1)\end{array}$ & $\begin{array}{c}.29 * * * \\
(.11)\end{array}$ & $\begin{array}{c}.22^{* * *} \\
(.07)\end{array}$ & $\begin{array}{c}.28^{* * *} * \\
(.1)\end{array}$ & $\begin{array}{l}.37^{* *} \\
(.15)\end{array}$ & $\begin{array}{c}.29 * * * \\
(.08)\end{array}$ & $\begin{array}{c}.27^{* * *} \\
(.08)\end{array}$ & $\begin{array}{l}.41 \\
(.35)\end{array}$ & $\begin{array}{c}.3^{* * *} \\
(.1)\end{array}$ & $\begin{array}{c}.25^{* * *} \\
(.08)\end{array}$ \\
\hline Landowner Share & $\begin{array}{l}.31^{*} \\
(.16)\end{array}$ & $\begin{array}{c}.28 \\
(.21)\end{array}$ & $\begin{array}{c}.31 \\
(.19)\end{array}$ & $\begin{array}{l}.27 \\
(.2)\end{array}$ & $\begin{array}{c}.31 \\
(.21)\end{array}$ & $\begin{array}{c}.43^{* * *} \\
(.11)\end{array}$ & $\begin{array}{l}.3 \\
(.2)\end{array}$ & $\begin{array}{l}.17 \\
(.27)\end{array}$ & $\begin{array}{l}.36^{* *} \\
(.15)\end{array}$ & $\begin{array}{l}.34^{* *} \\
(.16)\end{array}$ & $\begin{array}{l}.12 \\
(.63)\end{array}$ & $\begin{array}{l}.3 \\
(.2)\end{array}$ & $\begin{array}{c}.41^{* * *} \\
(.11)\end{array}$ \\
\hline Firmowner Share & $\begin{array}{c}.43^{* * *} \\
(.1)\end{array}$ & $\begin{array}{c}.43^{* * *} \\
(.12)\end{array}$ & $\begin{array}{c}.41^{* * *} \\
(.12)\end{array}$ & $\begin{array}{c}.44^{* * *} \\
(.12)\end{array}$ & $\begin{array}{l}.4^{* * *} \\
(.13)\end{array}$ & $\begin{array}{c}.35^{* * *} \\
(.08)\end{array}$ & $\begin{array}{c}.42^{* * *} \\
(.12)\end{array}$ & $\begin{array}{l}.46^{* * *} \\
(.12)\end{array}$ & $\begin{array}{c}.36^{* * *} \\
(.1)\end{array}$ & $\begin{array}{c}.39 * * * \\
(.11)\end{array}$ & $\begin{array}{l}.47 \\
(.29)\end{array}$ & $\begin{array}{c}.41^{* * *} \\
(.12)\end{array}$ & $\begin{array}{c}.34^{* * *} \\
(.06)\end{array}$ \\
\hline
\end{tabular}

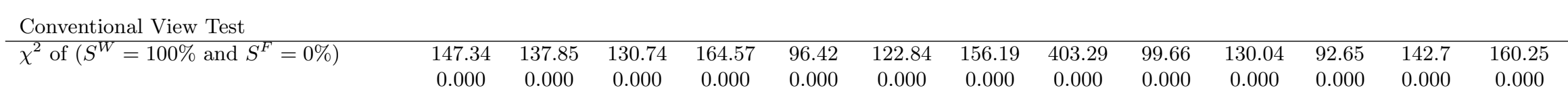

Specifications

\begin{tabular}{|c|c|c|c|c|c|c|c|c|c|c|c|c|c|}
\hline Throwback Tax Rule & $\mathrm{Y}$ & $\mathrm{N}$ & $\mathrm{N}$ & $\mathrm{N}$ & $\mathrm{N}$ & $\mathrm{N}$ & $\mathrm{N}$ & $\mathrm{N}$ & $\mathrm{N}$ & $\mathrm{N}$ & $\mathrm{N}$ & $\mathrm{N}$ & $\mathrm{Y}$ \\
\hline Combined Reporting & $\mathrm{N}$ & $\mathrm{Y}$ & $\mathrm{N}$ & $\mathrm{N}$ & $\mathrm{N}$ & $\mathrm{N}$ & $\mathrm{N}$ & $\mathrm{N}$ & $\mathrm{N}$ & $\mathrm{N}$ & $\mathrm{N}$ & $\mathrm{N}$ & $\mathrm{Y}$ \\
\hline INvestment Tax Credit & $\mathrm{N}$ & $\mathrm{N}$ & $\mathrm{Y}$ & $\mathrm{N}$ & $\mathrm{N}$ & $\mathrm{N}$ & $\mathrm{N}$ & $\mathrm{N}$ & $\mathrm{N}$ & $\mathrm{N}$ & $\mathrm{N}$ & $\mathrm{N}$ & $\mathrm{Y}$ \\
\hline R\&D Tax Credit Rate & $\mathrm{N}$ & $\mathrm{N}$ & $\mathrm{N}$ & Y & $\mathrm{N}$ & $\mathrm{N}$ & $\mathrm{N}$ & $\mathrm{N}$ & $\mathrm{N}$ & $\mathrm{N}$ & $\mathrm{N}$ & $\mathrm{N}$ & $\mathrm{Y}$ \\
\hline Loss carry-back rules & $\mathrm{N}$ & $\mathrm{N}$ & $\mathrm{N}$ & $\mathrm{N}$ & $\mathrm{Y}$ & $\mathrm{N}$ & $\mathrm{N}$ & $\mathrm{N}$ & $\mathrm{N}$ & $\mathrm{N}$ & $\mathrm{N}$ & $\mathrm{N}$ & $\mathrm{Y}$ \\
\hline Loss carry-forward rules & $\mathrm{N}$ & $\mathrm{N}$ & $\mathrm{N}$ & $\mathrm{N}$ & $\mathrm{N}$ & $\mathrm{Y}$ & $\mathrm{N}$ & $\mathrm{N}$ & $\mathrm{N}$ & $\mathrm{N}$ & $\mathrm{N}$ & $\mathrm{N}$ & $\mathrm{Y}$ \\
\hline Franchise Tax & $\mathrm{N}$ & $\mathrm{N}$ & $\mathrm{N}$ & $\mathrm{N}$ & $\mathrm{N}$ & $\mathrm{N}$ & $\mathrm{Y}$ & $\mathrm{N}$ & $\mathrm{N}$ & $\mathrm{N}$ & $\mathrm{N}$ & $\mathrm{N}$ & $\mathrm{Y}$ \\
\hline Federal Income Tax Deductible Controls & $\mathrm{N}$ & $\mathrm{N}$ & $\mathrm{N}$ & $\mathrm{N}$ & $\mathrm{N}$ & $\mathrm{N}$ & $\mathrm{N}$ & $\mathrm{Y}$ & $\mathrm{N}$ & $\mathrm{N}$ & $\mathrm{N}$ & $\mathrm{N}$ & $\mathrm{Y}$ \\
\hline Federal Income as State Tax Base & $\mathrm{N}$ & $\mathrm{N}$ & $\mathrm{N}$ & $\mathrm{N}$ & $\mathrm{N}$ & $\mathrm{N}$ & $\mathrm{N}$ & $\mathrm{N}$ & $\mathrm{Y}$ & $\mathrm{N}$ & $\mathrm{N}$ & $\mathrm{N}$ & $\mathrm{Y}$ \\
\hline Federal Accelerate Depreciation & $\mathrm{N}$ & $\mathrm{N}$ & $\mathrm{N}$ & $\mathrm{N}$ & $\mathrm{N}$ & $\mathrm{N}$ & $\mathrm{N}$ & $\mathrm{N}$ & $\mathrm{N}$ & $\mathrm{Y}$ & $\mathrm{N}$ & $\mathrm{N}$ & $\mathrm{Y}$ \\
\hline ACRS Depreciation & $\mathrm{N}$ & $\mathrm{N}$ & $\mathrm{N}$ & $\mathrm{N}$ & $\mathrm{N}$ & $\mathrm{N}$ & $\mathrm{N}$ & $\mathrm{N}$ & $\mathrm{N}$ & $\mathrm{N}$ & $\mathrm{Y}$ & $\mathrm{N}$ & $\mathrm{Y}$ \\
\hline Federal Bonus Depreciation & $\mathrm{N}$ & $\mathrm{N}$ & $\mathrm{N}$ & $\mathrm{N}$ & $\mathrm{N}$ & $\mathrm{N}$ & $\mathrm{N}$ & $\mathrm{N}$ & $\mathrm{N}$ & $\mathrm{N}$ & $\mathrm{N}$ & $\mathrm{Y}$ & $\mathrm{Y}$ \\
\hline
\end{tabular}

Notes: See notes of Table 5; See Section A.3.2 for supplemental tax data sources and Section E.4 for estimating equations and subsection E.4.1 for variable definitions. 
Table A20: Incidence Estimates Using Reduced-Form Effects, Business Tax Changes (Political, Fiscal Policy, Economic Conditions)

\begin{tabular}{|c|c|c|c|c|c|c|c|c|c|c|}
\hline \multicolumn{11}{|c|}{ Panel (a) Incidence } \\
\hline & $(1)$ & $(2)$ & $(3)$ & $(4)$ & $(5)$ & $(6)$ & $(7)$ & $(8)$ & $(9)$ & $(10)$ \\
\hline Workers $\dot{w}-\alpha \dot{r}$ & $\begin{array}{l}1.15^{*} \\
(.59)\end{array}$ & $\begin{array}{l}1.1^{*} \\
(.61)\end{array}$ & $\begin{array}{c}1.54^{* *} \\
(.64)\end{array}$ & $\begin{array}{l}1.34^{*} \\
(.72)\end{array}$ & $\begin{array}{l}1.36^{*} \\
(.71)\end{array}$ & $\begin{array}{l}1.1^{*} \\
(.59)\end{array}$ & $\begin{array}{c}1.39^{* * *} \\
(.52)\end{array}$ & $\begin{array}{c}1.39^{* * *} \\
(.52)\end{array}$ & $\begin{array}{l}.68 \\
(.52)\end{array}$ & $\begin{array}{c}1.08^{* *} \\
(.49)\end{array}$ \\
\hline Landowners $\dot{r}$ & $\begin{array}{c}.93 \\
(1.52)\end{array}$ & $\begin{array}{c}1.07 \\
(1.48)\end{array}$ & $\begin{array}{c}1.17 \\
(1.61)\end{array}$ & $\begin{array}{c}1.63 \\
(1.54)\end{array}$ & $\begin{array}{c}1.72 \\
(1.56)\end{array}$ & $\begin{array}{c}1.17 \\
(1.43)\end{array}$ & $\begin{array}{c}1.79 \\
(1.22)\end{array}$ & $\begin{array}{c}1.79 \\
(1.22)\end{array}$ & $\begin{array}{c}.32 \\
(1.36)\end{array}$ & $\begin{array}{c}1.12 \\
(1.21)\end{array}$ \\
\hline Firmowners $\dot{\pi}$ & $\begin{array}{l}1.6^{*} \\
(.89)\end{array}$ & $\begin{array}{c}1.56^{*} \\
(.91)\end{array}$ & $\begin{array}{c}2.05^{* *} \\
(.9)\end{array}$ & $\begin{array}{c}1.69^{*} \\
(.99)\end{array}$ & $\begin{array}{c}2.03^{* *} \\
(1.02)\end{array}$ & $\begin{array}{c}1.63^{*} \\
(.9)\end{array}$ & $\begin{array}{c}1.98^{* *} \\
(.88)\end{array}$ & $\begin{array}{c}1.98^{* *} \\
(.88)\end{array}$ & $\begin{array}{c}.81 \\
(1.4)\end{array}$ & $\begin{array}{l}1.6^{*} \\
(.83)\end{array}$ \\
\hline
\end{tabular}

\begin{tabular}{|c|c|c|c|c|c|c|c|c|c|c|}
\hline \multicolumn{11}{|c|}{ Panel (b) Shares of Incidence } \\
\hline & $(1)$ & $(2)$ & $(3)$ & $(4)$ & $(5)$ & $(6)$ & $(7)$ & $(8)$ & $(9)$ & $(10)$ \\
\hline Worker Share & $\begin{array}{l}.31^{* *} \\
(.13)\end{array}$ & $\begin{array}{c}.29 * * * \\
(.11)\end{array}$ & $\begin{array}{l}.32^{* *} \\
(.14)\end{array}$ & $\begin{array}{c}.29^{* * *} \\
(.1)\end{array}$ & $\begin{array}{l}.27^{* *} \\
(.11)\end{array}$ & $\begin{array}{c}.28^{* * *} \\
(.09)\end{array}$ & $\begin{array}{c}.27^{* * *} \\
(.07)\end{array}$ & $\begin{array}{c}.27 * * * \\
(.07)\end{array}$ & $\begin{array}{c}.37 \\
(.43)\end{array}$ & $\begin{array}{c}.28^{* * *} \\
(.1)\end{array}$ \\
\hline Landowner Share & $\begin{array}{c}.25 \\
(.26)\end{array}$ & $\begin{array}{l}.29 \\
(.21)\end{array}$ & $\begin{array}{c}.25 \\
(.23)\end{array}$ & $\begin{array}{l}.35^{* *} \\
(.14)\end{array}$ & $\begin{array}{l}.34^{* *} \\
(.17)\end{array}$ & $\begin{array}{c}.3 \\
(.19)\end{array}$ & $\begin{array}{c}.35^{* * *} \\
(.13)\end{array}$ & $\begin{array}{c}.35^{* * *} \\
(.13)\end{array}$ & $\begin{array}{l}.18 \\
(.48)\end{array}$ & $\begin{array}{c}.3^{*} \\
(.18)\end{array}$ \\
\hline Firmowner Share & $\begin{array}{c}.44^{* * *} \\
(.14)\end{array}$ & $\begin{array}{c}.42^{* * *} \\
(.13)\end{array}$ & $\begin{array}{c}.43^{* * *} \\
(.12)\end{array}$ & $\begin{array}{c}.36^{* * *} \\
(.09)\end{array}$ & $\begin{array}{c}.4^{* * *} \\
(.1)\end{array}$ & $\begin{array}{c}.42^{* * *} \\
(.12)\end{array}$ & $\begin{array}{c}.38^{* * *} \\
(.09)\end{array}$ & $\begin{array}{c}.38^{* * *} \\
(.09)\end{array}$ & $\begin{array}{c}.45^{* * *} \\
(.13)\end{array}$ & $\begin{array}{c}.42^{* * * *} \\
(.1)\end{array}$ \\
\hline
\end{tabular}

\begin{tabular}{|c|c|c|c|c|c|c|c|c|c|c|}
\hline \multicolumn{11}{|l|}{ Conventional View Test } \\
\hline$\chi^{2}$ of $\left(S^{W}=100 \%\right.$ and $\left.S^{F}=0 \%\right)$ & 145.34 & 130.84 & 73.08 & 85.61 & 94.50 & 130.47 & 116.5 & 115.71 & 6.96 & 153.98 \\
\hline & 0.000 & 0.000 & 0.000 & 0.000 & 0.000 & 0.000 & 0.000 & 0.000 & 0.010 & 0.000 \\
\hline
\end{tabular}

\begin{tabular}{|c|c|c|c|c|c|c|c|c|c|c|}
\hline Political Controls & $\mathrm{Y}$ & $\mathrm{N}$ & $\mathrm{N}$ & $\mathrm{N}$ & $\mathrm{N}$ & $\mathrm{N}$ & $\mathrm{N}$ & $\mathrm{N}$ & $\mathrm{N}$ & $\mathrm{N}$ \\
\hline Sales Tax Rate & $\mathrm{N}$ & $\mathrm{Y}$ & $\mathrm{N}$ & $\mathrm{N}$ & $\mathrm{N}$ & $\mathrm{N}$ & $\mathrm{N}$ & $\mathrm{N}$ & $\mathrm{N}$ & $\mathrm{N}$ \\
\hline$\Delta$ Sales Tax Rate & $\mathrm{N}$ & $\mathrm{N}$ & $\mathrm{Y}$ & $\mathrm{N}$ & $\mathrm{N}$ & $\mathrm{N}$ & $\mathrm{N}$ & $\mathrm{N}$ & $\mathrm{N}$ & $\mathrm{N}$ \\
\hline Income Tax Rate & $\mathrm{N}$ & $\mathrm{N}$ & $\mathrm{N}$ & $\mathrm{Y}$ & $\mathrm{N}$ & $\mathrm{N}$ & $\mathrm{N}$ & $\mathrm{N}$ & $\mathrm{N}$ & $\mathrm{N}$ \\
\hline$\Delta$ Income Tax Rate & $\mathrm{N}$ & $\mathrm{N}$ & $\mathrm{N}$ & $\mathrm{N}$ & $\mathrm{Y}$ & $\mathrm{N}$ & $\mathrm{N}$ & $\mathrm{N}$ & $\mathrm{N}$ & $\mathrm{N}$ \\
\hline$\Delta$ Gov. Expend/capita & $\mathrm{N}$ & $\mathrm{N}$ & $\mathrm{N}$ & $\mathrm{N}$ & $\mathrm{N}$ & $\mathrm{Y}$ & $\mathrm{N}$ & $\mathrm{Y}$ & $\mathrm{N}$ & $\mathrm{N}$ \\
\hline Corporate Tax Rev. to GDP & $\mathrm{N}$ & $\mathrm{N}$ & $\mathrm{N}$ & $\mathrm{N}$ & $\mathrm{N}$ & $\mathrm{N}$ & $\mathrm{Y}$ & $\mathrm{Y}$ & $\mathrm{N}$ & $\mathrm{N}$ \\
\hline Bartik & $\mathrm{N}$ & $\mathrm{N}$ & $\mathrm{N}$ & $\mathrm{N}$ & $\mathrm{N}$ & $\mathrm{N}$ & $\mathrm{N}$ & $\mathrm{N}$ & $\mathrm{Y}$ & $\mathrm{N}$ \\
\hline Gross Receipt Tax Control & $\mathrm{N}$ & $\mathrm{N}$ & $\mathrm{N}$ & $\mathrm{N}$ & $\mathrm{N}$ & $\mathrm{N}$ & $\mathrm{N}$ & $\mathrm{N}$ & $\mathrm{N}$ & $\mathrm{Y}$ \\
\hline
\end{tabular}

Notes: See notes of Table 5; See Section A.5 for supplemental data sources and Section E.4 for variable definitions and estimating equations. 
Table A21: Incidence Estimates Using Estimated Reduced-Form Effects, Corporate Rate Changes

\begin{tabular}{|c|c|c|c|c|c|c|c|c|c|c|}
\hline \multicolumn{11}{|c|}{ Panel (a) Incidence } \\
\hline & $(1)$ & $(2)$ & $(3)$ & $(4)$ & (5) & (6) & (7) & $(8)$ & (9) & $(10)$ \\
\hline Workers $\dot{w}-\alpha \dot{r}$ & $\begin{array}{l}.58^{*} \\
(.34)\end{array}$ & $\begin{array}{l}.59^{*} \\
(.33)\end{array}$ & $\begin{array}{c}.75^{* *} \\
(.3)\end{array}$ & $\begin{array}{l}.58^{*} \\
(.34)\end{array}$ & $\begin{array}{l}.7^{* *} \\
(.32)\end{array}$ & $\begin{array}{l}.59^{*} \\
(.33)\end{array}$ & $\begin{array}{l}.57^{*} \\
(.33)\end{array}$ & $\begin{array}{l}.58^{*} \\
(.33)\end{array}$ & $\begin{array}{c}.41 \\
(.28)\end{array}$ & $\begin{array}{l}.52^{*} \\
(.29)\end{array}$ \\
\hline Landowners $\dot{r}$ & $\begin{array}{c}.65 \\
(.58)\end{array}$ & $\begin{array}{l}.65 \\
(.6)\end{array}$ & $\begin{array}{c}.38 \\
(.78)\end{array}$ & $\begin{array}{l}.63 \\
(.6)\end{array}$ & $\begin{array}{c}.52 \\
(.73)\end{array}$ & $\begin{array}{l}.62 \\
(.6)\end{array}$ & $\begin{array}{c}.59 \\
(.61)\end{array}$ & $\begin{array}{c}.59 \\
(.61)\end{array}$ & $\begin{array}{l}.27 \\
(.51)\end{array}$ & $\begin{array}{c}.43 \\
(.59)\end{array}$ \\
\hline Firmowners $\dot{\pi}$ & $\begin{array}{c}.91^{* * *} \\
(.32)\end{array}$ & $\begin{array}{c}.92^{* * *} \\
(.35)\end{array}$ & $\begin{array}{l}.97^{* *} \\
(.38)\end{array}$ & $\begin{array}{c}.92^{* * *} \\
(.29)\end{array}$ & $\begin{array}{c}.96^{* *} \\
(.4)\end{array}$ & $\begin{array}{c}.91^{* * *} \\
(.33)\end{array}$ & $\begin{array}{c}.89 * * * \\
(.34)\end{array}$ & $\begin{array}{l}.9 * * * \\
(.33)\end{array}$ & $\begin{array}{l}.71^{*} \\
(.42)\end{array}$ & $\begin{array}{l}.8^{* *} \\
(.34)\end{array}$ \\
\hline
\end{tabular}

Panel (b) Shares of Incidence

\begin{tabular}{|c|c|c|c|c|c|c|c|c|c|c|}
\hline & $(1)$ & $(2)$ & (3) & $(4)$ & $(5)$ & $(6)$ & $(7)$ & $(8)$ & $(9)$ & $(10)$ \\
\hline Worker Share & $\begin{array}{c}.27 * * * \\
(.09)\end{array}$ & $\begin{array}{c}.27^{* * *} \\
(.08)\end{array}$ & $\begin{array}{l}.36^{* *} \\
(.16)\end{array}$ & $\begin{array}{c}.27^{* * *} \\
(.09)\end{array}$ & $\begin{array}{c}.32^{* * *} \\
(.12)\end{array}$ & $\begin{array}{c}.28^{* * *} \\
(.08)\end{array}$ & $\begin{array}{c}.28^{* * *} \\
(.09)\end{array}$ & $\begin{array}{c}.28^{* * *} \\
(.09)\end{array}$ & $\begin{array}{l}.29 * * \\
(.13)\end{array}$ & $\begin{array}{l}.3^{* * *} \\
(.11)\end{array}$ \\
\hline Landowner Share & $\begin{array}{l}.3^{* *} \\
(.15)\end{array}$ & $\begin{array}{l}.3^{* *} \\
(.15)\end{array}$ & $\begin{array}{l}.18 \\
(.27)\end{array}$ & $\begin{array}{c}.3^{*} \\
(.16)\end{array}$ & $\begin{array}{c}.24 \\
(.21)\end{array}$ & $\begin{array}{l}.29^{*} \\
(.16)\end{array}$ & $\begin{array}{l}.29^{*} \\
(.17)\end{array}$ & $\begin{array}{l}.29^{*} \\
(.17)\end{array}$ & $\begin{array}{c}.19 \\
(.28)\end{array}$ & $\begin{array}{l}.25 \\
(.22)\end{array}$ \\
\hline Firmowner Share & $\begin{array}{c}.43^{* * *} \\
(.09)\end{array}$ & $\begin{array}{c}.42^{* * *} \\
(.08)\end{array}$ & $\begin{array}{l}.46^{* * * *} \\
(.12)\end{array}$ & $\begin{array}{c}.43^{* * *} \\
(.11)\end{array}$ & $\begin{array}{c}.44^{* * *} \\
(.1)\end{array}$ & $\begin{array}{c}.43^{* * *} \\
(.1)\end{array}$ & $\begin{array}{c}.43^{* * *} \\
(.1)\end{array}$ & $\begin{array}{c}.43^{* * *} \\
(.1)\end{array}$ & $\begin{array}{c}.51^{* *} \\
(.2)\end{array}$ & $\begin{array}{c}.46^{* * *} \\
(.13)\end{array}$ \\
\hline
\end{tabular}

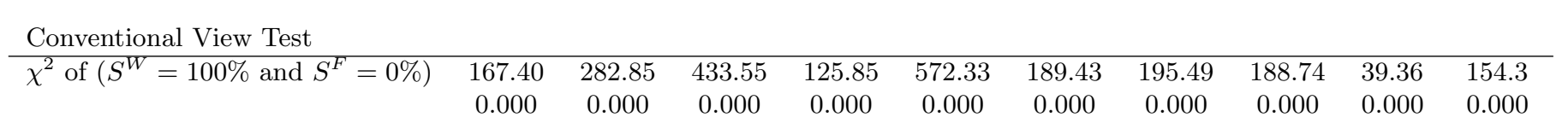

Specifications

\begin{tabular}{|c|c|c|c|c|c|c|c|c|c|c|}
\hline Political Controls & $\mathrm{Y}$ & $\mathrm{N}$ & $\mathrm{N}$ & $\mathrm{N}$ & $\mathrm{N}$ & $\mathrm{N}$ & $\mathrm{N}$ & $\mathrm{N}$ & $\mathrm{N}$ & $\mathrm{N}$ \\
\hline Sales Tax Rate & $\mathrm{N}$ & $\mathrm{Y}$ & $\mathrm{N}$ & $\mathrm{N}$ & $\mathrm{N}$ & $\mathrm{N}$ & $\mathrm{N}$ & $\mathrm{N}$ & $\mathrm{N}$ & $\mathrm{N}$ \\
\hline$\Delta$ Sales Tax Rate & $\mathrm{N}$ & $\mathrm{N}$ & $\mathrm{Y}$ & $\mathrm{N}$ & $\mathrm{N}$ & $\mathrm{N}$ & $\mathrm{N}$ & $\mathrm{N}$ & $\mathrm{N}$ & $\mathrm{N}$ \\
\hline Income Tax Rate & $\mathrm{N}$ & $\mathrm{N}$ & $\mathrm{N}$ & $\mathrm{Y}$ & $\mathrm{N}$ & $\mathrm{N}$ & $\mathrm{N}$ & $\mathrm{N}$ & $\mathrm{N}$ & $\mathrm{N}$ \\
\hline$\Delta$ Income Tax Rate & $\mathrm{N}$ & $\mathrm{N}$ & $\mathrm{N}$ & $\mathrm{N}$ & $\mathrm{Y}$ & $\mathrm{N}$ & $\mathrm{N}$ & $\mathrm{N}$ & $\mathrm{N}$ & $\mathrm{N}$ \\
\hline$\Delta$ Gov. Expend/capita & $\mathrm{N}$ & $\mathrm{N}$ & $\mathrm{N}$ & $\mathrm{N}$ & $\mathrm{N}$ & $\mathrm{Y}$ & $\mathrm{N}$ & $\mathrm{Y}$ & $\mathrm{N}$ & $\mathrm{N}$ \\
\hline Corporate Tax Rev. to GDP & $\mathrm{N}$ & $\mathrm{N}$ & $\mathrm{N}$ & $\mathrm{N}$ & $\mathrm{N}$ & $\mathrm{N}$ & $\mathrm{Y}$ & $\mathrm{Y}$ & $\mathrm{N}$ & $\mathrm{N}$ \\
\hline Bartik & $\mathrm{N}$ & $\mathrm{N}$ & $\mathrm{N}$ & $\mathrm{N}$ & $\mathrm{N}$ & $\mathrm{N}$ & $\mathrm{N}$ & $\mathrm{N}$ & $\mathrm{Y}$ & $\mathrm{N}$ \\
\hline Gross Receipt Tax Control & $\mathrm{N}$ & $\mathrm{N}$ & $\mathrm{N}$ & $\mathrm{N}$ & $\mathrm{N}$ & $\mathrm{N}$ & $\mathrm{N}$ & $\mathrm{N}$ & $\mathrm{N}$ & $\mathrm{Y}$ \\
\hline
\end{tabular}

Notes: See notes of Table 5; See Section A.5 for supplemental data sources and Section E.4 for variable definitions and estimating equations. 
Table A22: Incidence Estimates Using Estimated Reduced-Form Effects, Corporate Rate Changes (Including Federal Corp. Tax)

\begin{tabular}{|c|c|c|c|c|c|c|c|c|c|c|}
\hline \multicolumn{11}{|c|}{ Panel (a) Incidence } \\
\hline & $(1)$ & $(2)$ & $(3)$ & $(4)$ & $(5)$ & (6) & (7) & $(8)$ & (9) & $(10)$ \\
\hline Workers $\dot{w}-\alpha \dot{r}$ & $\begin{array}{l}.82^{* *} \\
(.36)\end{array}$ & $\begin{array}{l}.79^{* *} \\
(.35)\end{array}$ & $\begin{array}{l}.82^{* *} \\
(.33)\end{array}$ & $\begin{array}{l}.79^{* *} \\
(.34)\end{array}$ & $\begin{array}{l}.76^{* *} \\
(.35)\end{array}$ & $\begin{array}{l}.82^{* *} \\
(.34)\end{array}$ & $\begin{array}{l}.8^{* *} \\
(.34)\end{array}$ & $\begin{array}{l}.82^{* *} \\
(.34)\end{array}$ & $\begin{array}{c}.59^{* *} \\
(.3)\end{array}$ & $\begin{array}{c}.72^{* * * *} \\
(.24)\end{array}$ \\
\hline Landowners $\dot{r}$ & $\begin{array}{c}.34 \\
(.87)\end{array}$ & $\begin{array}{c}.43 \\
(.82)\end{array}$ & $\begin{array}{c}.47 \\
(.84)\end{array}$ & $\begin{array}{c}.35 \\
(.83)\end{array}$ & $\begin{array}{c}.61 \\
(.79)\end{array}$ & $\begin{array}{c}.41 \\
(.83)\end{array}$ & $\begin{array}{c}.42 \\
(.84)\end{array}$ & $\begin{array}{c}.44 \\
(.83)\end{array}$ & $\begin{array}{c}.27 \\
(.87)\end{array}$ & $\begin{array}{c}.1 \\
(.87)\end{array}$ \\
\hline Firmowners $\dot{\pi}$ & $\begin{array}{c}1.02^{* * *} \\
(.41)\end{array}$ & $\begin{array}{c}1.02^{* *} \\
(.43)\end{array}$ & $\begin{array}{c}1.05^{* * *} \\
(.4)\end{array}$ & $\begin{array}{l}1^{* *} \\
(.39)\end{array}$ & $\begin{array}{c}1.04^{* *} \\
(.43)\end{array}$ & $\begin{array}{c}1.03^{* *} \\
(.41)\end{array}$ & $\begin{array}{c}1.02^{* *} \\
(.43)\end{array}$ & $\begin{array}{c}1.04^{* *} \\
(.42)\end{array}$ & $\begin{array}{l}.78 \\
(.48)\end{array}$ & $\begin{array}{l}.85^{* *} \\
(.39)\end{array}$ \\
\hline
\end{tabular}

\begin{tabular}{|c|c|c|c|c|c|c|c|c|c|c|}
\hline \multicolumn{11}{|c|}{ Panel (b) Shares of Incidence } \\
\hline & $(1)$ & $(2)$ & $(3)$ & $(4)$ & $(5)$ & $(6)$ & $(7)$ & $(8)$ & $(9)$ & $(10)$ \\
\hline Worker Share & $\begin{array}{c}.38^{* *} \\
(.18)\end{array}$ & $\begin{array}{c}.35^{* *} \\
(.15)\end{array}$ & $\begin{array}{c}.35^{* *} \\
(.15)\end{array}$ & $\begin{array}{l}.37^{* *} \\
(.16)\end{array}$ & $\begin{array}{c}.32^{* * *} \\
(.11)\end{array}$ & $\begin{array}{l}.36^{* *} \\
(.15)\end{array}$ & $\begin{array}{l}.36^{* *} \\
(.15)\end{array}$ & $\begin{array}{l}.36^{* *} \\
(.14)\end{array}$ & $\begin{array}{c}.36 \\
(.24)\end{array}$ & $\begin{array}{c}.43 \\
(.29)\end{array}$ \\
\hline Landowner Share & $\begin{array}{l}.16 \\
(.31)\end{array}$ & $\begin{array}{c}.19 \\
(.26)\end{array}$ & $\begin{array}{c}.2 \\
(.26)\end{array}$ & $\begin{array}{c}.16 \\
(.29)\end{array}$ & $\begin{array}{l}.25 \\
(.2)\end{array}$ & $\begin{array}{c}.18 \\
(.27)\end{array}$ & $\begin{array}{c}.19 \\
(.26)\end{array}$ & $\begin{array}{l}.19 \\
(.26)\end{array}$ & $\begin{array}{l}.16 \\
(.4)\end{array}$ & $\begin{array}{l}.06 \\
(.48)\end{array}$ \\
\hline Firmowner Share & $\begin{array}{c}.47^{* * *} \\
(.14)\end{array}$ & $\begin{array}{c}.45^{* * *} \\
(.11)\end{array}$ & $\begin{array}{c}.45^{* * *} \\
(.11)\end{array}$ & $\begin{array}{c}.47^{* * *} \\
(.14)\end{array}$ & $\begin{array}{c}.43^{* * *} \\
(.09)\end{array}$ & $\begin{array}{c}46^{* * *} \\
(.12)\end{array}$ & $\begin{array}{c}.46^{* * *} \\
(.12)\end{array}$ & $\begin{array}{c}.45^{* * *} \\
(.12)\end{array}$ & $\begin{array}{c}.48^{* * *} \\
(.17)\end{array}$ & $\begin{array}{c}.51^{* * *} \\
(.19)\end{array}$ \\
\hline
\end{tabular}

\begin{tabular}{|c|c|c|c|c|c|c|c|c|c|c|}
\hline \multicolumn{11}{|l|}{ Conventional View Test } \\
\hline$\chi^{2}$ of $\left(S^{W}=100 \%\right.$ and $\left.S^{F}=0 \%\right)$ & 271.06 & 445.18 & 394.07 & 340.56 & 525.79 & 402.05 & 471.04 & 468.11 & 128.11 & 95.18 \\
\hline & 0.000 & 0.000 & 0.000 & 0.000 & 0.000 & 0.000 & 0.000 & 0.000 & 0.000 & 0.000 \\
\hline
\end{tabular}

\begin{tabular}{|c|c|c|c|c|c|c|c|c|c|c|}
\hline Political Controls & $\mathrm{Y}$ & $\mathrm{N}$ & $\mathrm{N}$ & $\mathrm{N}$ & $\mathrm{N}$ & $\mathrm{N}$ & $\mathrm{N}$ & $\mathrm{N}$ & $\mathrm{N}$ & $\mathrm{N}$ \\
\hline Sales Tax Rate & $\mathrm{N}$ & $\mathrm{Y}$ & $\mathrm{N}$ & $\mathrm{N}$ & $\mathrm{N}$ & $\mathrm{N}$ & $\mathrm{N}$ & $\mathrm{N}$ & $\mathrm{N}$ & $\mathrm{N}$ \\
\hline$\Delta$ Sales Tax Rate & $\mathrm{N}$ & $\mathrm{N}$ & $\mathrm{Y}$ & $\mathrm{N}$ & $\mathrm{N}$ & $\mathrm{N}$ & $\mathrm{N}$ & $\mathrm{N}$ & $\mathrm{N}$ & $\mathrm{N}$ \\
\hline Income Tax Rate & $\mathrm{N}$ & $\mathrm{N}$ & $\mathrm{N}$ & $\mathrm{Y}$ & $\mathrm{N}$ & $\mathrm{N}$ & $\mathrm{N}$ & $\mathrm{N}$ & $\mathrm{N}$ & $\mathrm{N}$ \\
\hline$\Delta$ Income Tax Rate & $\mathrm{N}$ & $\mathrm{N}$ & $\mathrm{N}$ & $\mathrm{N}$ & $\mathrm{Y}$ & $\mathrm{N}$ & $\mathrm{N}$ & $\mathrm{N}$ & $\mathrm{N}$ & $\mathrm{N}$ \\
\hline$\Delta$ Gov. Expend/capita & $\mathrm{N}$ & $\mathrm{N}$ & $\mathrm{N}$ & $\mathrm{N}$ & $\mathrm{N}$ & $\mathrm{Y}$ & $\mathrm{N}$ & $\mathrm{Y}$ & $\mathrm{N}$ & $\mathrm{N}$ \\
\hline Corporate Tax Rev. to GDP & $\mathrm{N}$ & $\mathrm{N}$ & $\mathrm{N}$ & $\mathrm{N}$ & $\mathrm{N}$ & $\mathrm{N}$ & $\mathrm{Y}$ & $\mathrm{Y}$ & $\mathrm{N}$ & $\mathrm{N}$ \\
\hline Bartik & $\mathrm{N}$ & $\mathrm{N}$ & $\mathrm{N}$ & $\mathrm{N}$ & $\mathrm{N}$ & $\mathrm{N}$ & $\mathrm{N}$ & $\mathrm{N}$ & $\mathrm{Y}$ & $\mathrm{N}$ \\
\hline Gross Receipt Tax Control & $\mathrm{N}$ & $\mathrm{N}$ & $\mathrm{N}$ & $\mathrm{N}$ & $\mathrm{N}$ & $\mathrm{N}$ & $\mathrm{N}$ & $\mathrm{N}$ & $\mathrm{N}$ & $\mathrm{Y}$ \\
\hline
\end{tabular}

Notes: See notes of Table 5; See Section A.5 for supplemental data sources and Section E.4 for variable definitions and estimating equations. 
Table A23: Incidence Estimates Using Reduced-Form Effects, State Fixed Effects

\begin{tabular}{|c|c|c|c|c|c|c|c|c|c|c|}
\hline \multicolumn{11}{|c|}{ Panel (a) Incidence } \\
\hline & (1) & $(2)$ & $(3)$ & $(4)$ & $(5)$ & $(6)$ & (7) & $(8)$ & (9) & $(10)$ \\
\hline Workers $\dot{w}-\alpha \dot{r}$ & $\begin{array}{l}1.25 \\
(.79)\end{array}$ & $\begin{array}{c}1.39^{* *} \\
(.7)\end{array}$ & $\begin{array}{c}2.31^{* * *} \\
(.69)\end{array}$ & $\begin{array}{c}1.72^{* *} \\
(.7)\end{array}$ & $\begin{array}{c}2.05^{* *} \\
(.94)\end{array}$ & $\begin{array}{c}1.37^{* *} \\
(.69)\end{array}$ & $\begin{array}{l}1.01^{*} \\
(.57)\end{array}$ & $\begin{array}{l}1.01^{*} \\
(.57)\end{array}$ & $\begin{array}{l}1.2^{* *} \\
(.54)\end{array}$ & $\begin{array}{c}1.32^{* *} \\
(.65)\end{array}$ \\
\hline Landowners $\dot{r}$ & $\begin{array}{c}2.44 \\
(1.81)\end{array}$ & $\begin{array}{c}1.77 \\
(1.73)\end{array}$ & $\begin{array}{c}.51 \\
(3.35)\end{array}$ & $\begin{array}{l}3.66^{* *} \\
(1.79)\end{array}$ & $\begin{array}{c}.12 \\
(2.88)\end{array}$ & $\begin{array}{c}1.72 \\
(1.72)\end{array}$ & $\begin{array}{c}.41 \\
(1.92)\end{array}$ & $\begin{array}{c}.4 \\
(1.93)\end{array}$ & $\begin{array}{c}1.16 \\
(1.61)\end{array}$ & $\begin{array}{c}1.4 \\
(1.75)\end{array}$ \\
\hline Firmowners $\dot{\pi}$ & $\begin{array}{c}1.74^{*} \\
(1)\end{array}$ & $\begin{array}{l}1.76^{*} \\
(.99)\end{array}$ & $\begin{array}{c}1.96 \\
(1.32)\end{array}$ & $\begin{array}{l}2.57^{* *} \\
(1.05)\end{array}$ & $\begin{array}{c}1.76 \\
(1.23)\end{array}$ & $\begin{array}{l}1.76^{*} \\
(.99)\end{array}$ & $\begin{array}{c}1.26 \\
(1.06)\end{array}$ & $\begin{array}{c}1.25 \\
(1.05)\end{array}$ & $\begin{array}{c}1.51^{* *} \\
(.76)\end{array}$ & $\begin{array}{l}1.66^{*} \\
(.99)\end{array}$ \\
\hline
\end{tabular}

Panel (b) Shares of Incidence

\begin{tabular}{|c|c|c|c|c|c|c|c|c|c|c|}
\hline & (1) & (2) & (3) & (4) & (5) & (6) & (7) & (8) & (9) & (10) \\
\hline Worker Share & $\begin{array}{c}.23^{* *} \\
(.1)\end{array}$ & $\begin{array}{c}.28^{* * *} \\
(.1)\end{array}$ & $\begin{array}{c}.48 \\
(.46)\end{array}$ & $\begin{array}{c}.22 * * * \\
(.06)\end{array}$ & $\begin{array}{c}.52 \\
(.47)\end{array}$ & $\begin{array}{c}.28 * * * \\
(.1)\end{array}$ & $\begin{array}{c}.38 \\
(.33)\end{array}$ & $\begin{array}{c}.38 \\
(.34)\end{array}$ & $\begin{array}{l}.31^{* *} \\
(.15)\end{array}$ & $\begin{array}{l}.3^{* *} \\
(.13)\end{array}$ \\
\hline Landowner Share & $\begin{array}{c}.45 * * * \\
(.15)\end{array}$ & $\begin{array}{l}.36^{* *} \\
(.16)\end{array}$ & $\begin{array}{l}.11 \\
(.61)\end{array}$ & $\begin{array}{c}.46^{* * *} \\
(.09)\end{array}$ & $\begin{array}{l}.03 \\
(.7)\end{array}$ & $\begin{array}{l}.35^{* *} \\
(.17)\end{array}$ & $\begin{array}{l}.15 \\
(.54)\end{array}$ & $\begin{array}{l}.15 \\
(.55)\end{array}$ & $\begin{array}{c}.3 \\
(.25)\end{array}$ & $\begin{array}{c}.32 \\
(.21)\end{array}$ \\
\hline Firmowner Share & $\begin{array}{c}.32^{* * *} \\
(.09)\end{array}$ & $\begin{array}{c}.36^{* * *} \\
(.1)\end{array}$ & $\begin{array}{l}.41^{* *} \\
(.2)\end{array}$ & $\begin{array}{c}.32^{* * *} \\
(.06)\end{array}$ & $\begin{array}{l}.45 \\
(.28)\end{array}$ & $\begin{array}{c}.36^{* * *} \\
(.1)\end{array}$ & $\begin{array}{l}.47^{* *} \\
(.22)\end{array}$ & $\begin{array}{l}.47^{* *} \\
(.22)\end{array}$ & $\begin{array}{c}.39 * * * \\
(.13)\end{array}$ & $\begin{array}{c}.38^{* * *} \\
(.1)\end{array}$ \\
\hline
\end{tabular}

\begin{tabular}{|c|c|c|c|c|c|c|c|c|c|c|}
\hline \multicolumn{11}{|l|}{ Conventional View Test } \\
\hline \multirow{2}{*}{$\chi^{2}$ of $\left(S^{W}=100 \%\right.$ and $\left.S^{F}=0 \%\right)$} & 89.41 & 90.87 & 6.90 & 158.91 & 8.33 & 88.47 & 66.76 & 65.18 & 83.12 & 89.86 \\
\hline & 0.000 & 0.000 & 0.010 & 0.000 & 0.000 & 0.000 & 0.000 & 0.000 & 0.000 & 0.000 \\
\hline \multicolumn{11}{|l|}{ Specifications } \\
\hline Political Controls & $\mathrm{Y}$ & $\mathrm{N}$ & $\mathrm{N}$ & $\mathrm{N}$ & $\mathrm{N}$ & $\mathrm{N}$ & $\mathrm{N}$ & $\mathrm{N}$ & $\mathrm{N}$ & $\mathrm{N}$ \\
\hline Sales Tax Rate & $\mathrm{N}$ & $\mathrm{Y}$ & $\mathrm{N}$ & $\mathrm{N}$ & $\mathrm{N}$ & $\mathrm{N}$ & $\mathrm{N}$ & $\mathrm{N}$ & $\mathrm{N}$ & $\mathrm{N}$ \\
\hline$\Delta$ Sales Tax Rate & $\mathrm{N}$ & $\mathrm{N}$ & $\mathrm{Y}$ & $\mathrm{N}$ & $\mathrm{N}$ & $\mathrm{N}$ & $\mathrm{N}$ & $\mathrm{N}$ & $\mathrm{N}$ & $\mathrm{N}$ \\
\hline Income Tax Rate & $\mathrm{N}$ & $\mathrm{N}$ & $\mathrm{N}$ & $\mathrm{Y}$ & $\mathrm{N}$ & $\mathrm{N}$ & $\mathrm{N}$ & $\mathrm{N}$ & $\mathrm{N}$ & $\mathrm{N}$ \\
\hline$\Delta$ Income Tax Rate & $\mathrm{N}$ & $\mathrm{N}$ & $\mathrm{N}$ & $\mathrm{N}$ & $\mathrm{Y}$ & $\mathrm{N}$ & $\mathrm{N}$ & $\mathrm{N}$ & $\mathrm{N}$ & $\mathrm{N}$ \\
\hline$\Delta$ Gov. Expend/capita & $\mathrm{N}$ & $\mathrm{N}$ & $\mathrm{N}$ & $\mathrm{N}$ & $\mathrm{N}$ & $\mathrm{Y}$ & $\mathrm{N}$ & $\mathrm{Y}$ & $\mathrm{N}$ & $\mathrm{N}$ \\
\hline Corporate Tax Rev. to GDP & $\mathrm{N}$ & $\mathrm{N}$ & $\mathrm{N}$ & $\mathrm{N}$ & $\mathrm{N}$ & $\mathrm{N}$ & Y & $\mathrm{Y}$ & $\mathrm{N}$ & $\mathrm{N}$ \\
\hline Bartik & $\mathrm{N}$ & $\mathrm{N}$ & $\mathrm{N}$ & $\mathrm{N}$ & $\mathrm{N}$ & $\mathrm{N}$ & $\mathrm{N}$ & $\mathrm{N}$ & $\mathrm{Y}$ & $\mathrm{N}$ \\
\hline Gross Receipt Tax Control & $\mathrm{N}$ & $\mathrm{N}$ & $\mathrm{N}$ & $\mathrm{N}$ & $\mathrm{N}$ & $\mathrm{N}$ & $\mathrm{N}$ & $\mathrm{N}$ & $\mathrm{N}$ & $\mathrm{Y}$ \\
\hline
\end{tabular}

Notes: See notes of Table 5; See Section A.5 for supplemental data sources and Section E.4 for variable definitions and estimating equations. 
Table A24: Estimates of Economic Incidence Using Reduced-Form Effects $(\alpha=.5)$

\begin{tabular}{|c|c|c|c|c|c|c|c|c|}
\hline & \multicolumn{4}{|c|}{ A. Incidence } & \multicolumn{4}{|c|}{ B. Share of Incidence } \\
\hline & $(1)$ & $(2)$ & $(3)$ & $(4)$ & $(1)$ & $(2)$ & $(3)$ & $(4)$ \\
\hline Workers & $\begin{array}{l}0.86^{*} \\
(0.45)\end{array}$ & $\begin{array}{l}1.13^{* *} \\
(0.49)\end{array}$ & $\begin{array}{l}0.87^{*} \\
(0.45)\end{array}$ & $\begin{array}{c}0.62 \\
(0.42)\end{array}$ & $\begin{array}{l}0.24^{*} \\
(0.11)\end{array}$ & $\begin{array}{l}0.27^{* *} \\
(0.10)\end{array}$ & $\begin{array}{l}0.24^{*} \\
(0.11)\end{array}$ & $\begin{array}{c}0.35 \\
(0.51)\end{array}$ \\
\hline Landowners & $\begin{array}{c}1.17 \\
(1.43)\end{array}$ & $\begin{array}{c}1.27 \\
(1.42)\end{array}$ & $\begin{array}{c}1.17 \\
(1.43)\end{array}$ & $\begin{array}{c}0.32 \\
(1.36)\end{array}$ & $\begin{array}{c}0.32 \\
(0.22)\end{array}$ & $\begin{array}{c}0.30 \\
(0.21)\end{array}$ & $\begin{array}{c}0.32 \\
(0.22)\end{array}$ & $\begin{array}{c}0.18 \\
(0.52)\end{array}$ \\
\hline Firm Owners & $\begin{array}{l}1.63^{*} \\
(0.90)\end{array}$ & $\begin{array}{l}1.79^{* *} \\
(0.80)\end{array}$ & $\begin{array}{l}1.63^{*} \\
(0.90)\end{array}$ & $\begin{array}{c}0.81 \\
(1.40)\end{array}$ & $\begin{array}{c}0.44^{* * *} \\
(0.11)\end{array}$ & $\begin{array}{c}0.43^{* * *} \\
(0.10)\end{array}$ & $\begin{array}{c}0.44^{* * *} \\
(0.11)\end{array}$ & $\begin{array}{c}0.46^{* * * *} \\
(0.11)\end{array}$ \\
\hline Conventional View Test & & & & & & & & \\
\hline $\begin{array}{l}\chi^{2} \text { of }\left(S^{W}=100 \% \text { and } S^{F}=0 \%\right) \\
\text { P-value }\end{array}$ & & & & & $\begin{array}{l}141.1 \\
0.000\end{array}$ & $\begin{array}{c}94.2 \\
0.000\end{array}$ & $\begin{array}{l}139.4 \\
0.000\end{array}$ & $\begin{array}{c}4.6 \\
0.032\end{array}$ \\
\hline Controls & & & & & & & & \\
\hline State Fixed Effects & $\mathrm{N}$ & $\mathrm{Y}$ & $\mathrm{N}$ & $\mathrm{N}$ & $\mathrm{N}$ & $\mathrm{Y}$ & $\mathrm{N}$ & $\mathrm{N}$ \\
\hline$\Delta \ln$ Gov./Capita & $\mathrm{N}$ & $\mathrm{N}$ & $\mathrm{Y}$ & $\mathrm{N}$ & $\mathrm{N}$ & $\mathrm{N}$ & $\mathrm{Y}$ & $\mathrm{N}$ \\
\hline Bartik & $\mathrm{N}$ & $\mathrm{N}$ & $\mathrm{N}$ & $\mathrm{Y}$ & $\mathrm{N}$ & $\mathrm{N}$ & $\mathrm{N}$ & $\mathrm{Y}$ \\
\hline
\end{tabular}

Notes: See notes of Table 5, which is our baseline that uses calibration values $\alpha=.3$ and $\frac{\delta}{\gamma}=.9$. This table shows results for $\alpha=.5$ and $\frac{\delta}{\gamma}=.9$. Recall that $\alpha$ is the housing expenditure share and can also reflect the influence of local prices, which may be sensitive to increases in the price of housing services (Moretti, 2013). 
Table A25: Estimates of Economic Incidence Using Reduced-Form Effects $(\alpha=.65)$

\begin{tabular}{|c|c|c|c|c|c|c|c|c|}
\hline & \multicolumn{4}{|c|}{ A. Incidence } & \multicolumn{4}{|c|}{ B. Share of Incidence } \\
\hline & $(1)$ & $(2)$ & $(3)$ & $(4)$ & $(1)$ & $(2)$ & $(3)$ & $(4)$ \\
\hline Workers & $\begin{array}{c}0.69 \\
(0.44)\end{array}$ & $\begin{array}{l}0.94^{*} \\
(0.51)\end{array}$ & $\begin{array}{c}0.69 \\
(0.44)\end{array}$ & $\begin{array}{c}0.57 \\
(0.47)\end{array}$ & $\begin{array}{c}0.20 \\
(0.16)\end{array}$ & $\begin{array}{c}0.23 \\
(0.17)\end{array}$ & $\begin{array}{c}0.20 \\
(0.16)\end{array}$ & $\begin{array}{c}0.33 \\
(0.57)\end{array}$ \\
\hline Landowners & $\begin{array}{c}1.17 \\
(1.43)\end{array}$ & $\begin{array}{c}1.27 \\
(1.42)\end{array}$ & $\begin{array}{c}1.17 \\
(1.43)\end{array}$ & $\begin{array}{c}0.32 \\
(1.36)\end{array}$ & $\begin{array}{c}0.34 \\
(0.24)\end{array}$ & $\begin{array}{c}0.32 \\
(0.23)\end{array}$ & $\begin{array}{c}0.34 \\
(0.24)\end{array}$ & $\begin{array}{c}0.19 \\
(0.55)\end{array}$ \\
\hline Firm Owners & $\begin{array}{l}1.63^{*} \\
(0.90)\end{array}$ & $\begin{array}{c}1.79^{* *} \\
(0.80)\end{array}$ & $\begin{array}{l}1.63^{*} \\
(0.90)\end{array}$ & $\begin{array}{c}0.81 \\
(1.40)\end{array}$ & $\begin{array}{c}0.47^{* * *} \\
(0.10)\end{array}$ & $\begin{array}{c}0.45^{* * *} \\
(0.09)\end{array}$ & $\begin{array}{c}0.47^{* * *} \\
(0.10)\end{array}$ & $\begin{array}{c}0.48^{* * * *} \\
(0.12)\end{array}$ \\
\hline Conventional View Test & & & & & & & & \\
\hline $\begin{array}{l}\chi^{2} \text { of }\left(S^{W}=100 \% \text { and } S^{F}=0 \%\right) \\
\text { P-value }\end{array}$ & & & & & $\begin{array}{l}108.1 \\
0.000\end{array}$ & $\begin{array}{l}71.0 \\
0.000\end{array}$ & $\begin{array}{l}107.3 \\
0.000\end{array}$ & $\begin{array}{c}3.4 \\
0.065\end{array}$ \\
\hline Controls & & & & & & & & \\
\hline State Fixed Effects & $\mathrm{N}$ & $\mathrm{Y}$ & $\mathrm{N}$ & $\mathrm{N}$ & $\mathrm{N}$ & $\mathrm{Y}$ & $\mathrm{N}$ & $\mathrm{N}$ \\
\hline$\Delta \ln$ Gov./Capita & $\mathrm{N}$ & $\mathrm{N}$ & $\mathrm{Y}$ & $\mathrm{N}$ & $\mathrm{N}$ & $\mathrm{N}$ & $\mathrm{Y}$ & $\mathrm{N}$ \\
\hline Bartik & $\mathrm{N}$ & $\mathrm{N}$ & $\mathrm{N}$ & Y & $\mathrm{N}$ & $\mathrm{N}$ & $\mathrm{N}$ & $\mathrm{Y}$ \\
\hline
\end{tabular}

Notes: See notes of Table 5 , which is our baseline that uses calibration values $\alpha=.3$ and $\frac{\delta}{\gamma}=.9$. This table shows results for $\alpha=.65$ and $\frac{\delta}{\gamma}=.9$. Recall that $\alpha$ is the housing expenditure share. We provide this robustness table for $\alpha=.65$ to be consistent with estimates from Diamond (2012) in terms of wage-to-rent sensitivity. 
Table A26: Estimates of Economic Incidence Using Reduced-Form Effects $\left(\frac{\delta}{\gamma}=.75\right)$

\begin{tabular}{|c|c|c|c|c|c|c|c|c|}
\hline & \multicolumn{4}{|c|}{ A. Incidence } & \multicolumn{4}{|c|}{ B. Share of Incidence } \\
\hline & $(1)$ & $(2)$ & $(3)$ & $(4)$ & $(1)$ & $(2)$ & $(3)$ & $(4)$ \\
\hline Workers & $\begin{array}{l}1.10^{*} \\
(0.59)\end{array}$ & $\begin{array}{l}1.38^{* *} \\
(0.59)\end{array}$ & $\begin{array}{l}1.10^{*} \\
(0.59)\end{array}$ & $\begin{array}{c}0.68 \\
(0.52)\end{array}$ & $\begin{array}{c}0.27^{* * *} \\
(0.08)\end{array}$ & $\begin{array}{c}0.30^{* * *} \\
(0.10)\end{array}$ & $\begin{array}{c}0.27^{* * *} \\
(0.08)\end{array}$ & $\begin{array}{c}0.33 \\
(0.29)\end{array}$ \\
\hline Landowners & $\begin{array}{c}1.17 \\
(1.43)\end{array}$ & $\begin{array}{c}1.27 \\
(1.42)\end{array}$ & $\begin{array}{c}1.17 \\
(1.43)\end{array}$ & $\begin{array}{c}0.32 \\
(1.36)\end{array}$ & $\begin{array}{c}0.29 \\
(0.20)\end{array}$ & $\begin{array}{c}0.28 \\
(0.18)\end{array}$ & $\begin{array}{c}0.29 \\
(0.20)\end{array}$ & $\begin{array}{c}0.16 \\
(0.47)\end{array}$ \\
\hline Firm Owners & $\begin{array}{c}1.80^{* *} \\
(0.90)\end{array}$ & $\begin{array}{l}1.93^{* *} \\
(0.83)\end{array}$ & $\begin{array}{l}1.80^{* *} \\
(0.90)\end{array}$ & $\begin{array}{c}1.04 \\
(1.19)\end{array}$ & $\begin{array}{c}0.44^{* * *} \\
(0.14)\end{array}$ & $\begin{array}{c}0.42^{* * *} \\
(0.12)\end{array}$ & $\begin{array}{c}0.44^{* * *} \\
(0.14)\end{array}$ & $\begin{array}{c}0.51^{* *} \\
(0.17)\end{array}$ \\
\hline Conventional View Test & & & & & & & & \\
\hline $\begin{array}{l}\chi^{2} \text { of }\left(S^{W}=100 \% \text { and } S^{F}=0 \%\right) \\
\text { P-value }\end{array}$ & & & & & $\begin{array}{c}83.0 \\
0.000\end{array}$ & $\begin{array}{c}89.9 \\
0.000\end{array}$ & $\begin{array}{c}81.9 \\
0.000\end{array}$ & $\begin{array}{c}87.4 \\
0.000\end{array}$ \\
\hline Controls & & & & & & & & \\
\hline State Fixed Effects & $\mathrm{N}$ & $\mathrm{Y}$ & $\mathrm{N}$ & $\mathrm{N}$ & $\mathrm{N}$ & $\mathrm{Y}$ & $\mathrm{N}$ & $\mathrm{N}$ \\
\hline$\Delta \ln$ Gov./Capita & $\mathrm{N}$ & $\mathrm{N}$ & $\mathrm{Y}$ & $\mathrm{N}$ & $\mathrm{N}$ & $\mathrm{N}$ & $\mathrm{Y}$ & $\mathrm{N}$ \\
\hline Bartik & $\mathrm{N}$ & $\mathrm{N}$ & $\mathrm{N}$ & $\mathrm{Y}$ & $\mathrm{N}$ & $\mathrm{N}$ & $\mathrm{N}$ & $\mathrm{Y}$ \\
\hline
\end{tabular}

Notes: See notes of Table 5, which is our baseline that uses calibration values $\alpha=.3$ and $\frac{\delta}{\gamma}=.9$. This table shows results for $\alpha=.3$ and $\frac{\delta}{\gamma}=.75$. 
Table A27: Estimates of Economic Incidence Using Reduced-Form Effects $\left(\frac{\delta}{\gamma}=.5\right)$

\begin{tabular}{|c|c|c|c|c|c|c|c|c|}
\hline & \multicolumn{4}{|c|}{ A. Incidence } & \multicolumn{4}{|c|}{ B. Share of Incidence } \\
\hline & $(1)$ & $(2)$ & $(3)$ & $(4)$ & $(1)$ & $(2)$ & $(3)$ & $(4)$ \\
\hline Workers & $\begin{array}{l}1.10^{*} \\
(0.59)\end{array}$ & $\begin{array}{l}1.38^{* *} \\
(0.59)\end{array}$ & $\begin{array}{l}1.10^{*} \\
(0.59)\end{array}$ & $\begin{array}{c}0.68 \\
(0.52)\end{array}$ & $\begin{array}{c}0.25^{* * * *} \\
(0.07)\end{array}$ & $\begin{array}{c}0.29^{* * *} \\
(0.09)\end{array}$ & $\begin{array}{c}0.25 * * * \\
(0.07)\end{array}$ & $\begin{array}{c}0.28 \\
(0.17)\end{array}$ \\
\hline Landowners & $\begin{array}{c}1.17 \\
(1.43)\end{array}$ & $\begin{array}{c}1.27 \\
(1.42)\end{array}$ & $\begin{array}{c}1.17 \\
(1.43)\end{array}$ & $\begin{array}{c}0.32 \\
(1.36)\end{array}$ & $\begin{array}{c}0.27 \\
(0.20)\end{array}$ & $\begin{array}{c}0.26 \\
(0.18)\end{array}$ & $\begin{array}{c}0.27 \\
(0.20)\end{array}$ & $\begin{array}{c}0.13 \\
(0.44)\end{array}$ \\
\hline Firm Owners & $\begin{array}{r}2.08^{* *} \\
(0.95)\end{array}$ & $\begin{array}{l}2.16^{* *} \\
(0.89)\end{array}$ & $\begin{array}{l}2.08^{* *} \\
(0.95)\end{array}$ & $\begin{array}{c}1.42 \\
(0.96)\end{array}$ & $\begin{array}{c}0.48^{* * *} \\
(0.17)\end{array}$ & $\begin{array}{c}0.45^{* * *} \\
(0.13)\end{array}$ & $\begin{array}{c}0.48^{* * *} \\
(0.17)\end{array}$ & $\begin{array}{r}0.59^{* *} \\
(0.29)\end{array}$ \\
\hline Conventional View Test & & & & & & & & \\
\hline $\begin{array}{l}\chi^{2} \text { of }\left(S^{W}=100 \% \text { and } S^{F}=0 \%\right) \\
\text { P-value }\end{array}$ & & & & & $\begin{array}{c}48.8 \\
0.000\end{array}$ & $\begin{array}{c}68.5 \\
0.000\end{array}$ & $\begin{array}{c}48.3 \\
0.000\end{array}$ & $\begin{array}{c}48.4 \\
0.000\end{array}$ \\
\hline Controls & & & & & & & & \\
\hline State Fixed Effects & $\mathrm{N}$ & $\mathrm{Y}$ & $\mathrm{N}$ & $\mathrm{N}$ & $\mathrm{N}$ & $\mathrm{Y}$ & $\mathrm{N}$ & $\mathrm{N}$ \\
\hline$\Delta \ln$ Gov./Capita & $\mathrm{N}$ & $\mathrm{N}$ & $\mathrm{Y}$ & $\mathrm{N}$ & $\mathrm{N}$ & $\mathrm{N}$ & $\mathrm{Y}$ & $\mathrm{N}$ \\
\hline Bartik & $\mathrm{N}$ & $\mathrm{N}$ & $\mathrm{N}$ & $\mathrm{Y}$ & $\mathrm{N}$ & $\mathrm{N}$ & $\mathrm{N}$ & $\mathrm{Y}$ \\
\hline
\end{tabular}

Notes: See notes of Table 5 , which is our baseline that uses calibration values $\alpha=.3$ and $\frac{\delta}{\gamma}=.9$. This table shows results for $\alpha=.3$ and $\frac{\delta}{\gamma}=.5$. 
Table A28: Estimates of Economic Incidence Using Reduced-Form Effects (Controlling for Lagged GDP growth)

\begin{tabular}{|c|c|c|c|c|c|c|c|c|}
\hline & \multicolumn{4}{|c|}{ A. Incidence } & \multicolumn{4}{|c|}{ B. Share of Incidence } \\
\hline & $(1)$ & $(2)$ & $(3)$ & $(4)$ & $(1)$ & $(2)$ & $(3)$ & $(4)$ \\
\hline Workers & $\begin{array}{l}1.2^{* *} \\
(.55)\end{array}$ & $\begin{array}{c}1.6^{* * *} \\
(.56)\end{array}$ & $\begin{array}{c}1.21^{* *} \\
(.55)\end{array}$ & $\begin{array}{l}.78^{*} \\
(.47)\end{array}$ & $\begin{array}{c}.26^{* * *} \\
(.07)\end{array}$ & $\begin{array}{c}.29^{* * *} \\
(.09)\end{array}$ & $\begin{array}{c}.26^{* * *} \\
(.07)\end{array}$ & $\begin{array}{l}.28^{* *} \\
(.12)\end{array}$ \\
\hline Landowners & $\begin{array}{c}1.74 \\
(1.11)\end{array}$ & $\begin{array}{c}2.1 \\
(1.44)\end{array}$ & $\begin{array}{c}1.74 \\
(1.11)\end{array}$ & $\begin{array}{l}.84 \\
(.94)\end{array}$ & $\begin{array}{c}.37^{* * *} \\
(.12)\end{array}$ & $\begin{array}{c}.38^{* * *} \\
(.13)\end{array}$ & $\begin{array}{c}.37^{* * *} \\
(.12)\end{array}$ & $\begin{array}{l}.31 \\
(.2)\end{array}$ \\
\hline Firmowners & $\begin{array}{c}1.71^{* *} \\
(.85)\end{array}$ & $\begin{array}{c}1.79^{* *} \\
(.77)\end{array}$ & $\begin{array}{c}1.71^{* *} \\
(.85)\end{array}$ & $\begin{array}{l}1.12^{*} \\
(.63)\end{array}$ & $\begin{array}{c}.37 * * * \\
(.09)\end{array}$ & $\begin{array}{c}.33^{* * *} \\
(.08)\end{array}$ & $\begin{array}{c}.37^{* * *} \\
(.09)\end{array}$ & $\begin{array}{r}.41^{* * *} \\
(.08)\end{array}$ \\
\hline Conventional View Test & & & & & & & & \\
\hline $\begin{array}{l}\chi^{2} \text { of }\left(S^{W}=100 \% \text { and } S^{F}=0 \%\right) \\
\text { P-value }\end{array}$ & & & & & $\begin{array}{l}98.57 \\
0.000\end{array}$ & $\begin{array}{l}96.65 \\
0.000\end{array}$ & $\begin{array}{l}97.65 \\
0.000\end{array}$ & $\begin{array}{c}262.52 \\
0.000\end{array}$ \\
\hline Controls & & & & & & & & \\
\hline State Fixed Effects & $\mathrm{N}$ & $\mathrm{Y}$ & $\mathrm{N}$ & $\mathrm{N}$ & $\mathrm{N}$ & $\mathrm{Y}$ & $\mathrm{N}$ & $\mathrm{N}$ \\
\hline$\Delta \ln$ Gov./Capita & $\mathrm{N}$ & $\mathrm{N}$ & $\mathrm{Y}$ & $\mathrm{N}$ & $\mathrm{N}$ & $\mathrm{N}$ & $\mathrm{Y}$ & $\mathrm{N}$ \\
\hline Bartik & $\mathrm{N}$ & $\mathrm{N}$ & $\mathrm{N}$ & $\mathrm{Y}$ & $\mathrm{N}$ & $\mathrm{N}$ & $\mathrm{N}$ & $\mathrm{Y}$ \\
\hline Lagged State GDP Growth & $\mathrm{Y}$ & $\mathrm{Y}$ & $\mathrm{Y}$ & $\mathrm{Y}$ & $\mathrm{Y}$ & $\mathrm{Y}$ & $\mathrm{Y}$ & $\mathrm{Y}$ \\
\hline
\end{tabular}

Notes: See notes of Table 5 , which is our baseline that uses calibration values $\alpha=.3$ and $\frac{\delta}{\gamma}=.9$. This table shows results from the same specifications as the baseline table, but with controls for two lags of state GDP growth. 
Table A29: Estimates of Economic Incidence Using Reduced-Form Effects (Dropping 1980-1990)

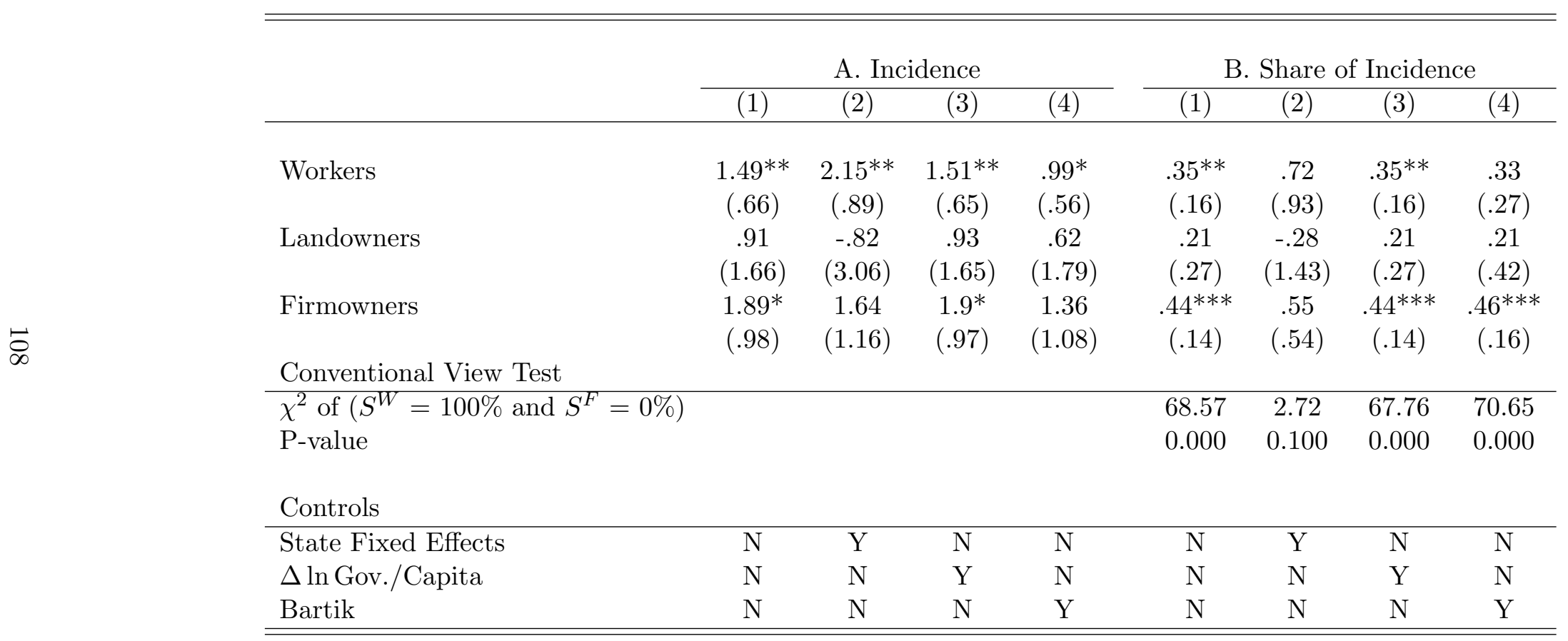

Notes: See notes of Table 5, which is our baseline that uses calibration values $\alpha=.3$ and $\frac{\delta}{\gamma}=.9$. This table shows results from the same specifications as the baseline table, but without the 490 observations for the change from 1980-1990. There are 980 observations in each specification. We provide this table to address potential concerns regarding the sensitivity of the results to the Tax Reform Act of 1986. 
Table A30: Incidence Estimates Using Reduced-Form Effects with Tax Rate Controls

\begin{tabular}{|c|c|c|c|c|}
\hline \multicolumn{5}{|c|}{ Panel (a) Incidence } \\
\hline & $(1)$ & $(2)$ & $(3)$ & $(4)$ \\
\hline Workers $\dot{w}-\alpha \dot{r}$ & $\begin{array}{l}1.1^{*} \\
(.61)\end{array}$ & $\begin{array}{c}1.49^{* *} \\
(.59)\end{array}$ & $\begin{array}{l}1.1^{*} \\
(.61)\end{array}$ & $\begin{array}{c}1.59^{* *} \\
(.66)\end{array}$ \\
\hline \multirow[t]{2}{*}{ Landowners $\dot{r}$} & 1.07 & 1.15 & 1.21 & 1.2 \\
\hline & $(1.48)$ & $(1.52)$ & $(1.25)$ & $(1.6)$ \\
\hline \multirow[t]{2}{*}{ Firmowners $\dot{\pi}$} & $1.56^{*}$ & $1.69^{* *}$ & $1.64^{*}$ & $1.75^{*}$ \\
\hline & $(.91)$ & $(.76)$ & $(.88)$ & $(.9)$ \\
\hline \multicolumn{5}{|c|}{ Panel (b) Shares of Incidence } \\
\hline & $(1)$ & $(2)$ & $(3)$ & $(4)$ \\
\hline \multirow{2}{*}{ Worker Share } & $.29^{* * *}$ & $.34^{* * *}$ & $.28^{* * *}$ & $.35^{* * *}$ \\
\hline & $(.11)$ & $(.13)$ & $(.09)$ & $(.12)$ \\
\hline \multirow[t]{2}{*}{ Landowner Share } & .29 & .27 & $.31^{*}$ & .26 \\
\hline & $(.21)$ & $(.22)$ & $(.16)$ & $(.23)$ \\
\hline \multirow[t]{2}{*}{ Firmowner Share } & $42^{* * *}$ & $.39 * * *$ & $42^{* * *}$ & $.39^{* * *}$ \\
\hline & $(.13)$ & $(.12)$ & $(.11)$ & $(.14)$ \\
\hline \multicolumn{5}{|l|}{ Conventional View Test } \\
\hline \multirow[t]{2}{*}{$\chi^{2}$ of $\left(S^{W}=100 \%\right.$ and $\left.S^{F}=0 \%\right)$} & 130.8 & 83.3 & 104 & 69.7 \\
\hline & 0.000 & 0.000 & 0.000 & 0.000 \\
\hline \multicolumn{5}{|l|}{ Specifications } \\
\hline \multirow{3}{*}{$\begin{array}{l}\text { State Sales Tax Rate } \\
\text { State Individual Income Tax Rate } \\
\text { State Property Tax Rate }\end{array}$} & $\mathrm{Y}$ & $\mathrm{N}$ & $\mathrm{N}$ & $\mathrm{Y}$ \\
\hline & $\mathrm{N}$ & $\mathrm{Y}$ & $\mathrm{N}$ & $\mathrm{Y}$ \\
\hline & $\mathrm{N}$ & $\mathrm{N}$ & $\mathrm{Y}$ & $\mathrm{Y}$ \\
\hline
\end{tabular}

Notes: See notes of Table 5, which is our baseline that uses calibration values $\alpha=.3$ and $\frac{\delta}{\gamma}=.9$. This table shows results from the same specifications as the baseline table, but with controls for different state tax rates. See Table A4 for notes on data sources. 
Table A31: Incidence Estimates Using Reduced-Form Effects with Tax Rate Change Controls

\begin{tabular}{|c|c|c|c|c|}
\hline \multicolumn{5}{|c|}{ Panel (a) Incidence } \\
\hline & $(1)$ & $(2)$ & $(3)$ & $(4)$ \\
\hline Workers $\dot{w}-\alpha \dot{r}$ & $\begin{array}{l}1.1^{*} \\
(.59)\end{array}$ & $\begin{array}{l}1.08^{*} \\
(.59)\end{array}$ & $\begin{array}{c}1.13^{* * *} \\
(.37)\end{array}$ & $\begin{array}{c}1.12^{* * *} \\
(.37)\end{array}$ \\
\hline Landowners $\dot{r}$ & $\begin{array}{l}1.15 \\
(1.43)\end{array}$ & $\begin{array}{l}1.21 \\
(1.4)\end{array}$ & $\begin{array}{c}1.24 \\
(1.15)\end{array}$ & $\begin{array}{c}1.3 \\
(1.1)\end{array}$ \\
\hline Firmowners $\dot{\pi}$ & $\begin{array}{c}1.63^{*} \\
(.9)\end{array}$ & $\begin{array}{l}1.65^{*} \\
(.93)\end{array}$ & $\begin{array}{c}1.67^{* *} \\
(.69)\end{array}$ & $\begin{array}{c}1.72^{* *} \\
(.73)\end{array}$ \\
\hline \multicolumn{5}{|c|}{ Panel (b) Shares of Incidence } \\
\hline & $(1)$ & $(2)$ & $(3)$ & $(4)$ \\
\hline Worker Share & $\begin{array}{l}.28^{* * *} \\
(.09)\end{array}$ & $\begin{array}{c}.27^{* * *} \\
(.09)\end{array}$ & $\begin{array}{c}.28 * * * \\
(.09)\end{array}$ & $\begin{array}{c}.27^{* * *} \\
(.08)\end{array}$ \\
\hline Landowner Share & $\begin{array}{c}.3 \\
(.19)\end{array}$ & $\begin{array}{l}.31^{*} \\
(.17)\end{array}$ & $\begin{array}{l}.31^{*} \\
(.17)\end{array}$ & $\begin{array}{l}.31^{* *} \\
(.15)\end{array}$ \\
\hline Firmowner Share & $\begin{array}{l}.42^{* * * *} \\
(.12) \\
\end{array}$ & $\begin{array}{l}.42^{* * *} \\
(.11) \\
\end{array}$ & $\begin{array}{c}.41^{* * *} \\
(.11) \\
\end{array}$ & $\begin{array}{l}.41^{* * *} \\
(.09) \\
\end{array}$ \\
\hline \multicolumn{5}{|l|}{ Conventional View Test } \\
\hline$\chi^{2}$ of $\left(S^{W}=100 \%\right.$ and $\left.S^{F}=0 \%\right)$ & $\begin{array}{l}137.7 \\
0.000\end{array}$ & $\begin{array}{l}141.6 \\
0.000\end{array}$ & $\begin{array}{l}139.8 \\
0.000\end{array}$ & $\begin{array}{l}154.7 \\
0.000\end{array}$ \\
\hline \multicolumn{5}{|l|}{ Specifications } \\
\hline $\begin{array}{l}\Delta \text { State Sales Tax Rate } \\
\Delta \text { State Income Tax Rate } \\
\Delta \text { State Property Tax Rate }\end{array}$ & $\begin{array}{l}\mathrm{Y} \\
\mathrm{N} \\
\mathrm{N}\end{array}$ & $\begin{array}{l}\mathrm{N} \\
\mathrm{Y} \\
\mathrm{N}\end{array}$ & $\begin{array}{l}\mathrm{N} \\
\mathrm{N} \\
\mathrm{Y}\end{array}$ & $\begin{array}{l}\mathrm{Y} \\
\mathrm{Y} \\
\mathrm{Y}\end{array}$ \\
\hline
\end{tabular}

Notes: See notes of Table 5, which is our baseline that uses calibration values $\alpha=.3$ and $\frac{\delta}{\gamma}=.9$. This table shows results from the same specifications as the baseline table, but with controls for different state tax rates. See Table A4 for notes on data sources. 
Table A32: Empirical and Predicted Moments from Structural Model

\begin{tabular}{|c|c|c|c|c|}
\hline \multicolumn{5}{|c|}{ Panel (a) Business Tax Shock } \\
\hline & Population & Wage & Rent & Establishments \\
\hline \multicolumn{5}{|c|}{ Empirical Moments } \\
\hline Business Tax & $\begin{array}{c}4.275^{* * *} \\
(1.642)\end{array}$ & $\begin{array}{c}1.451 \\
(0.938)\end{array}$ & $\begin{array}{c}1.172 \\
(1.428)\end{array}$ & $\begin{array}{l}4.074^{* *} \\
(1.815)\end{array}$ \\
\hline \multicolumn{5}{|c|}{ A. Predicted Moments $\left(\gamma=.15, \varepsilon^{P D}=-2.5\right)$} \\
\hline Business Tax & 3.514 & 0.839 & 0.591 & 4.542 \\
\hline \multicolumn{2}{|c|}{ Over-id Test } & & \multicolumn{2}{|c|}{ Test: $\beta^{E}=\beta^{N}-\left(\gamma\left(\varepsilon^{P D}+1\right)-1\right) \beta^{W}$} \\
\hline$\chi^{2}$-Stat & 2.453 & & T-stat & -1.566 \\
\hline$\chi^{2}$-P-Value & 0.117 & & $\mathrm{P}$-value & 0.117 \\
\hline \multicolumn{5}{|c|}{ Panel (b) All Shocks } \\
\hline & Population & Wage & Rent & Establishments \\
\hline \multicolumn{5}{|c|}{ Empirical Moments } \\
\hline Business Tax & $\begin{array}{c}1.516 \\
(1.915)\end{array}$ & $\begin{array}{c}1.534 \\
(1.117)\end{array}$ & $\begin{array}{c}1.857 \\
(1.562)\end{array}$ & $\begin{array}{c}1.749 \\
(1.540)\end{array}$ \\
\hline Bartik & $\begin{array}{c}0.446^{* *} \\
(0.183)\end{array}$ & $\begin{array}{c}0.554^{* * *} \\
(0.079)\end{array}$ & $\begin{array}{c}0.697 * * * \\
(0.257)\end{array}$ & $\begin{array}{c}0.600 * * * \\
(0.189)\end{array}$ \\
\hline Personal Tax & $\begin{array}{c}1.731 \\
(1.247) \\
\end{array}$ & $\begin{array}{c}-0.588 \\
(0.728)\end{array}$ & $\begin{array}{l}-1.192 \\
(1.173) \\
\end{array}$ & $\begin{array}{c}1.247 \\
(1.420)\end{array}$ \\
\hline \multicolumn{5}{|c|}{ B. Predicted Moments $\left(\gamma=.15, \varepsilon^{P D}=-2.5\right)$} \\
\hline Business Tax & 0.736 & 0.944 & 1.111 & 1.893 \\
\hline Bartik & 0.424 & 0.571 & 0.730 & 0.479 \\
\hline Personal Tax & 1.052 & -0.596 & -1.559 & 0.322 \\
\hline Over-id Test & & & \multicolumn{2}{|c|}{ Test: $\beta^{E}=\beta^{N}-\left(\gamma\left(\varepsilon^{P D}+1\right)-1\right) \beta^{W}$} \\
\hline$\chi^{2}$-Stat & 4.665 & & T-stat & -1.217 \\
\hline$\chi^{2}$-P-Value & 0.458 & & P-value & 0.224 \\
\hline \multicolumn{5}{|c|}{ C. Predicted Moments $(\gamma=.15, \alpha=.30)$ and estimated $\varepsilon^{P D}$} \\
\hline Business Tax & 0.583 & 0.646 & 0.420 & 1.589 \\
\hline Bartik & 0.397 & 0.572 & 0.725 & 0.447 \\
\hline Personal Tax & 1.053 & -0.359 & -0.996 & 0.495 \\
\hline Over-id Test & & & \multicolumn{2}{|c|}{ Test: $\beta^{E}=\beta^{N}-\left(\gamma\left(\varepsilon^{P D}+1\right)-1\right) \beta^{W}$} \\
\hline$\chi^{2}$-Stat & 5.378 & & T-stat & -1.334 \\
\hline$\chi^{2}$-P-Value & 0.251 & & $\mathrm{P}$-value & 0.182 \\
\hline
\end{tabular}

Notes: This table shows the estimated reduced forms used in our minimum distance estimation as well as the models predicted by our model. The reduced forms are estimated via a system OLS. The data are decade changes from 1980-1990, 1990-2000, and 2000-2010 for 490 county-groups. See Section 4 for data sources. All parameters assume $\delta=0.9 \times \gamma$ and $\alpha=0.3$. In addition, Panel (a) presents estimates of the model using only the tax shock for parameters $\left(\gamma=.15, \varepsilon^{P D}=-2.5\right)$; panel (b) uses the business tax shock, the Bartik shock and the personal income tax shock for parameters $\left(\gamma=.15, \varepsilon^{P D}=-2.5\right)$; and Panel (c) usqs 1 ll shocks, calibrates $\gamma=.15$ and estimates $\varepsilon^{P D}$. Results of the $\chi^{2}$ test of over identifying restrictions are below each model along with the result of the test of the restriction $\beta^{E}=\beta^{N}-\left(\gamma\left(\varepsilon^{P D}+1\right)-1\right) \beta^{W}$ that is implied by calibrating $\varepsilon^{P D}$. See Section 6 for more details on the estimation. Regressions use initial population as weights and include year fixed effects and dummies for states in the industrial midwest in the 1980s. Standard errors clustered by state are in parentheses and $* * * \mathrm{p}<0.01,{ }^{* *} \mathrm{p}<0.05,{ }^{*} \mathrm{p}<0.1$. 
Table A33: Estimates of Structural Parameters

\begin{tabular}{|c|c|c|c|c|c|c|}
\hline & $(1)$ & $(2)$ & $(3)$ & $(4)$ & $(5)$ & $(6)$ \\
\hline & \multicolumn{2}{|c|}{ Worker Location } & \multicolumn{2}{|c|}{ Housing Supply } & \multicolumn{2}{|c|}{ Firm Location } \\
\hline & OLS & IV & OLS & IV & OLS & CMD \\
\hline Idiosyncratic Location & $2.312^{* * *}$ & $0.717^{* * *}$ & & & & \\
\hline Preference Dispersion $\sigma^{W}$ & $(0.767)$ & $(0.277)$ & & & & \\
\hline Elasticity of Housing & & & $0.963^{* * *}$ & $0.834^{*}$ & & \\
\hline Supply $\eta$ & & & $(0.208)$ & $(0.432)$ & & \\
\hline Idiosyncratic Location & & & & & $0.331^{*}$ & $0.097^{*}$ \\
\hline Productivity Dispersion $\sigma^{F}$ & & & & & $(0.174)$ & $(0.058)$ \\
\hline Output Elasticity & & & & & -0.316 & \\
\hline of Labor $\gamma$ & & & & & $(0.225)$ & \\
\hline $\mathrm{N}$ & 1470 & 1470 & 1470 & 1470 & 1470 & 1470 \\
\hline Instrument & & Bartik \& Tax & & Bartik \& Tax & & \\
\hline First Stage F-stat & & 46.718 & & 15.32 & & \\
\hline Calibrated Parameters: & & & & & & \\
\hline$\varepsilon^{P D}$ & & & & & -2.5 & -2.5 \\
\hline$\gamma$ & & & & & & 0.15 \\
\hline$\sigma^{W}$ & & & & & & 0.7 \\
\hline$\eta$ & & & & & & 1.75 \\
\hline
\end{tabular}

Notes: This table shows the estimated coefficients of the parameters in our structural model. The data are decade changes from 1980-1990, 1990-2000, and 2000-2010 for 490 county-groups. See Section 4 for data sources. Col (1)-(2) estimate the parameter of worker preference dispersion $\sigma^{W}$, Col (3)-(4) the parameter of the housing supply equation $\eta$, and Col (5)-(6) the parameters of the firm location equation $\gamma$ and $\sigma^{F}$. Col (1)-(5) are estimated via OLS or IV as noted and the parameters are recovered via delta-method calculations. Col (6) is recovered using a classical minimum distance approach. See Section 6 for more details on the specific equations and calibration choices. $\varepsilon^{P D}$ denotes the elasticity of product demand. Regressions use initial population as weights and include year fixed effects and dummies for states in the industrial midwest in the 1980s. Standard errors clustered by state are in parentheses and $* * * \mathrm{p}<0.01$, $* * \mathrm{p}<0.05, * \mathrm{p}<0.1$. 
Table A34: Policy Probit of Payroll Apportionment Weight Changes

\begin{tabular}{lcc}
\hline \hline Independent Variables & Coefficient & Standard Error \\
\hline Mean Payroll Weight of Other States & $-.3608^{* * *}$ & $(.114)$ \\
Mean Payroll Weight of Other States $(t-1)$ & .2737 & $(.1947)$ \\
Mean Payroll Weight of Other States $(t-2)$ & .0491 & $(.1368)$ \\
Corporate Tax Rate & -.1225 & $(.2548)$ \\
Corporate Tax Rate $(t-1)$ & .2714 & $(.2813)$ \\
Corporate Tax Rate $(t-2)$ & -.128 & $(.1115)$ \\
Individual Income Tax Rate & .2006 & $(.2853)$ \\
Individual Income Tax Rate $(t-1)$ & -.4287 & $(.3978)$ \\
Individual Income Tax Rate $(t-2)$ & .2957 & $(.2492)$ \\
State Income Growth $(t-1)$ & -1.4585 & $(1.5766)$ \\
State Income Growth $(t-2)$ & -1.194 & $(1.5084)$ \\
National Unemployment Rate $(t-1)$ & -.0792 & $(.0776)$ \\
National Unemployment Rate $(t-2)$ & .0716 & $(.0938)$ \\
\hline
\end{tabular}

Notes: This table shows how observable economic and tax policy conditions relate to apportionment formula changes. The specification is the same as the policy probit in Goolsbee and Maydew (2000). The dependent variable is an indicator that equals one if payroll apportionment weights are changed. The analysis is at the state-year level for years from 1978 through 2010. There are 1500 observations due to the lags. State income growth is the log difference in per capita GDP from BEA and the national unemployment rate is from BLS. Robust standard errors are in parentheses and $* * * \mathrm{p}<0.01, * * \mathrm{p}<0.05, * \mathrm{p}<0.1$.

Table A35: Policy Probit of Statutory State Corporate Tax Changes

\begin{tabular}{lcc}
\hline \hline Independent Variables & Coefficient & Standard Error \\
\hline Mean Corporate Tax Rate of Other States & $2.7234^{* * *}$ & $(.9537)$ \\
Mean Corporate Tax Rate of Other States $(t-1)$ & $-3.9527^{* * *}$ & $(.9882)$ \\
Mean Corporate Tax Rate of Other States $(t-2)$ & .7191 & $(1.0997)$ \\
Payroll Weight & -.0227 & $(.0185)$ \\
Payroll Weight $(t-1)$ & .0056 & $(.0271)$ \\
Payroll Weight $(t-2)$ & .0312 & $(.0209)$ \\
Individual Income Tax Rate & -.2777 & $(.3036)$ \\
Individual Income Tax Rate $(t-1)$ & .1707 & $(.3773)$ \\
Individual Income Tax Rate $(t-2)$ & .0875 & $(.223)$ \\
State Income Growth $(t-1)$ & -.6771 & $(1.2064)$ \\
State Income Growth $(t-2)$ & .1552 & $(1.5484)$ \\
National Unemployment Rate $(t-1)$ & -.0539 & $(.089)$ \\
National Unemployment Rate $(t-2)$ & .0783 & $(.0779)$ \\
\hline
\end{tabular}

Notes: This table shows how observable economic and tax policy conditions relate to statutory state corporate tax rate changes. The specification is the same as the policy probit in Goolsbee and Maydew (2000), but with a different dependent variable. The dependent variable is an indicator that equals one if the statutory state corporate tax rate change exceeds 0.5 percentage points. The analysis is at the state-year level for years from 1978 through 2010 . There are 1500 observations due to the lags. State income growth is the log difference in per capita GDP from BEA and the national unemployment rate is from BLS. Robust standard errors are in parentheses and $* * * \mathrm{p}<0.01, * * \mathrm{p}<0.05, *$ $\mathrm{p}<0.1$. 
Table A36: Revenue-Maximizing Corporate Tax Rates By State

\begin{tabular}{|c|c|c|c|c|c|c|c|}
\hline \multirow[b]{2}{*}{ State } & \multirow{2}{*}{$\begin{array}{l}\text { Establishment } \\
\text { Share } E_{s}\end{array}$} & \multirow{2}{*}{$\begin{array}{l}\text { Revenue Ratio } \\
\operatorname{rev}_{s}^{\text {pers }} / \operatorname{rev}_{s}^{C}\end{array}$} & \multirow{2}{*}{$\begin{array}{l}\text { Sales Apport. } \\
\text { Weight } \theta_{s}^{x}\end{array}$} & \multirow{2}{*}{$\begin{array}{c}\text { Corporate } \\
\text { Tax Rate } \tau_{s}\end{array}$} & \multicolumn{3}{|c|}{ Revenue Max. Corp. Rate } \\
\hline & & & & & $\tau_{s}^{*}$ & $\tau_{s}^{* *}$ & $\tau_{s}^{* *} /\left(1-\theta_{s}^{x}\right)$ \\
\hline Alabama & 1.4 & 16.4 & 33 & 6.5 & 30.6 & 2.2 & 3.3 \\
\hline Alaska & 0.3 & 0.4 & 33 & 9.4 & 32.3 & 24.1 & 36.1 \\
\hline Arizona & 1.8 & 22.1 & 80 & 7.0 & 30.0 & 1.7 & 8.3 \\
\hline Arkansas & 0.9 & 15.0 & 50 & 6.5 & 30.7 & 2.4 & 4.7 \\
\hline California & 11.7 & 9.2 & 50 & 8.8 & 32.0 & 3.7 & 7.4 \\
\hline Colorado & 2.1 & 21.1 & 100 & 4.6 & 31.0 & 1.7 & \\
\hline Connecticut & 1.2 & 21.9 & 50 & 7.5 & 31.0 & 1.7 & 3.3 \\
\hline Delaware & 0.3 & 9.2 & 33 & 8.7 & 29.6 & 3.7 & 5.5 \\
\hline Florida & 6.7 & 14.6 & 50 & 5.5 & 31.2 & 2.4 & 4.9 \\
\hline Georgia & 3.0 & 19.8 & 100 & 6.0 & 29.6 & 1.8 & \\
\hline Hawaii & 0.4 & 57.3 & 33 & 6.4 & 28.6 & 0.7 & 1.0 \\
\hline Idaho & 0.6 & 26.2 & 50 & 7.6 & 33.8 & 1.4 & 2.8 \\
\hline Illinois & 4.3 & 9.0 & 100 & 7.3 & 31.6 & 3.8 & \\
\hline Indiana & 2.0 & 20.7 & 90 & 8.5 & 32.9 & 1.8 & 17.7 \\
\hline Iowa & 1.1 & 30.4 & 100 & 12.0 & 32.0 & 1.2 & \\
\hline Kansas & 1.0 & 16.0 & 33 & 7.1 & 30.6 & 2.2 & 3.4 \\
\hline Kentucky & 1.2 & 20.4 & 50 & 6.0 & 31.3 & 1.8 & 3.6 \\
\hline Louisiana & 1.4 & 18.1 & 100 & 8.0 & 32.2 & 2.0 & \\
\hline Maine & 0.6 & 16.9 & 100 & 8.9 & 34.0 & 2.1 & \\
\hline Maryland & 1.8 & 14.0 & 50 & 8.3 & 31.6 & 2.5 & 5.1 \\
\hline Massachusetts & 2.3 & 9.2 & 50 & 8.8 & 31.9 & 3.7 & 7.4 \\
\hline Michigan & 3.0 & 26.4 & 100 & 4.9 & 31.5 & 1.4 & \\
\hline Minnesota & 2.0 & 19.9 & 87 & 9.8 & 33.2 & 1.8 & 14.1 \\
\hline Mississippi & 0.8 & 17.2 & 33 & 5.0 & 30.5 & 2.1 & 3.1 \\
\hline Missouri & 2.1 & 42.8 & 33 & 6.3 & 31.2 & 0.9 & 1.3 \\
\hline Montana & 0.5 & 13.4 & 33 & 6.8 & 36.8 & 2.7 & 4.0 \\
\hline Nebraska & 0.7 & 22.1 & 100 & 7.8 & 31.6 & 1.7 & \\
\hline Nevada & 0.8 & & 100 & 0.0 & 29.2 & & \\
\hline New Hampshire & 0.5 & 2.0 & 50 & 8.5 & 31.2 & 12.1 & 24.1 \\
\hline New Jersey & 3.1 & 10.6 & 50 & 9.0 & 31.0 & 3.3 & 6.5 \\
\hline New Mexico & 0.6 & 26.1 & 33 & 7.6 & 32.0 & 1.4 & 2.1 \\
\hline New York & 7.1 & 14.3 & 100 & 7.1 & 34.6 & 2.5 & \\
\hline North Carolina & 3.0 & 14.3 & 50 & 6.9 & 31.3 & 2.5 & 5.0 \\
\hline North Dakota & 0.3 & 14.2 & 33 & 6.4 & 35.3 & 2.5 & 3.8 \\
\hline Ohio & 3.5 & 141.5 & 60 & 8.5 & 31.4 & 0.3 & 0.7 \\
\hline Oklahoma & 1.2 & 24.0 & 33 & 6.0 & 31.7 & 1.5 & 2.3 \\
\hline Oregon & 1.5 & 16.8 & 100 & 7.9 & 32.8 & 2.1 & \\
\hline Pennsylvania & 4.1 & 15.1 & 90 & 10.0 & 33.2 & 2.4 & 23.9 \\
\hline Rhode Island & 0.4 & 19.0 & 33 & 9.0 & 34.5 & 1.9 & 2.9 \\
\hline South Carolina & 1.4 & 45.1 & 100 & 5.0 & 30.6 & 0.8 & \\
\hline South Dakota & 0.4 & 34.7 & 100 & 0.0 & 36.5 & 1.1 & \\
\hline Tennessee & 1.8 & 9.1 & 50 & 6.5 & 29.4 & 3.7 & 7.4 \\
\hline Texas & 7.2 & & 100 & 0.0 & 30.3 & & \\
\hline Utah & 0.9 & 18.3 & 50 & 5.0 & 31.4 & 2.0 & 4.0 \\
\hline Vermont & 0.3 & 15.7 & 50 & 8.5 & 34.7 & 2.3 & 4.6 \\
\hline Virginia & 1.5 & 18.4 & 50 & 6.0 & 30.1 & 2.0 & 3.9 \\
\hline Washington & 2.4 & & 100 & 0.0 & 31.9 & & \\
\hline West Virginia & 0.5 & 16.3 & 50 & 8.5 & 30.8 & 2.2 & 4.4 \\
\hline Wisconsin & 1.9 & 14.7 & 100 & 7.9 & 32.8 & 2.4 & \\
\hline
\end{tabular}

Notes: This table shows the corporate tax revenue-maximizing corporate tax rate $\tau_{s}^{*}$ and the total tax revenuemaximizing corporate tax rate $\tau_{s}^{* *}$, which accounts for some fiscal externalities. These calculations are based on 2010 data and average national parameter estimates and do not incorporate heterogeneous housing markets. See Section 7 and Section D in the appendix for details. Sources: U.S. Census ASG and those in Section 4. 
Figure A1: Time Series of State Corporate Tax Rates by State

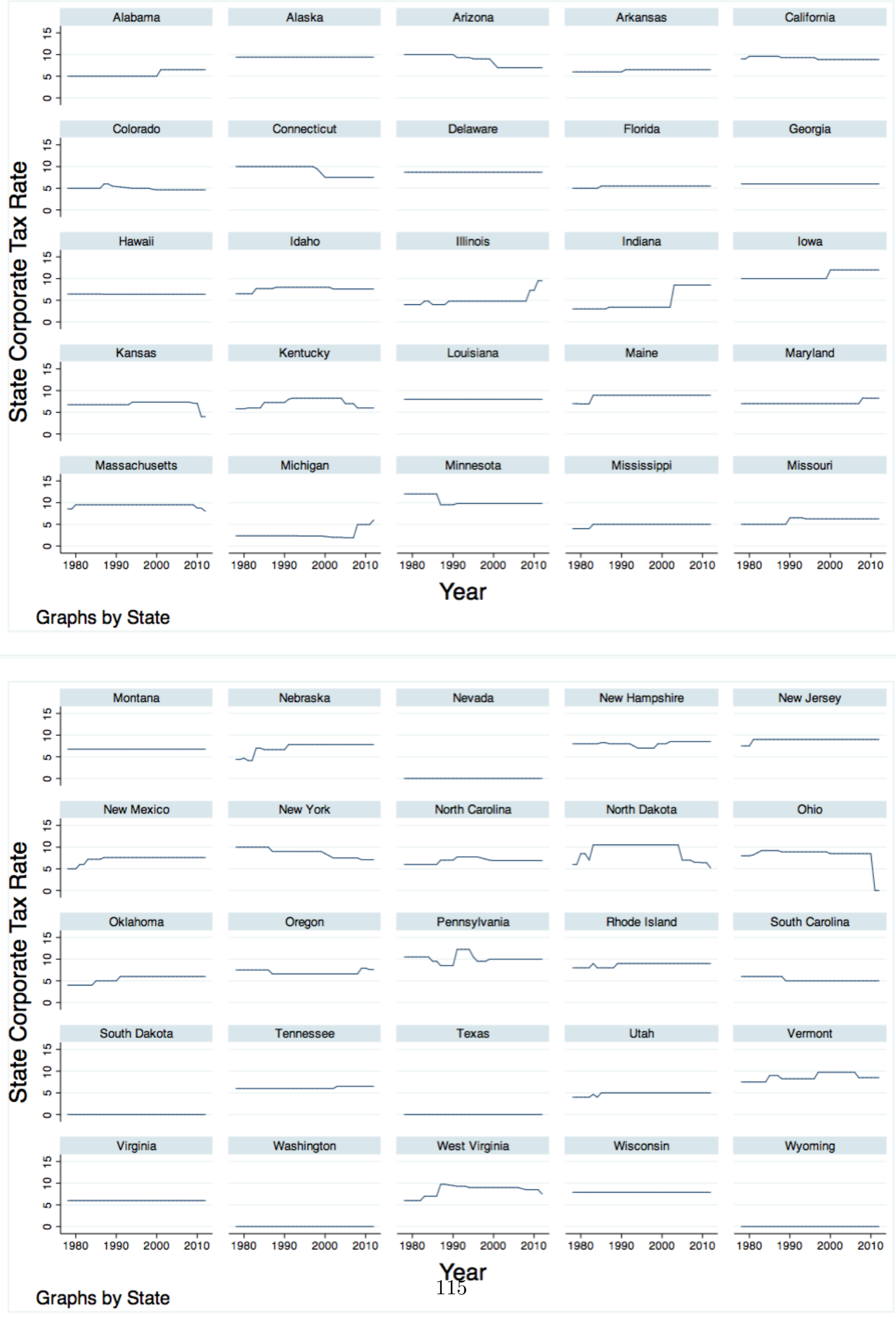


Figure A2: State Corporate Tax Apportionment Rules in 2012

A. Payroll Apportionment Rate by State

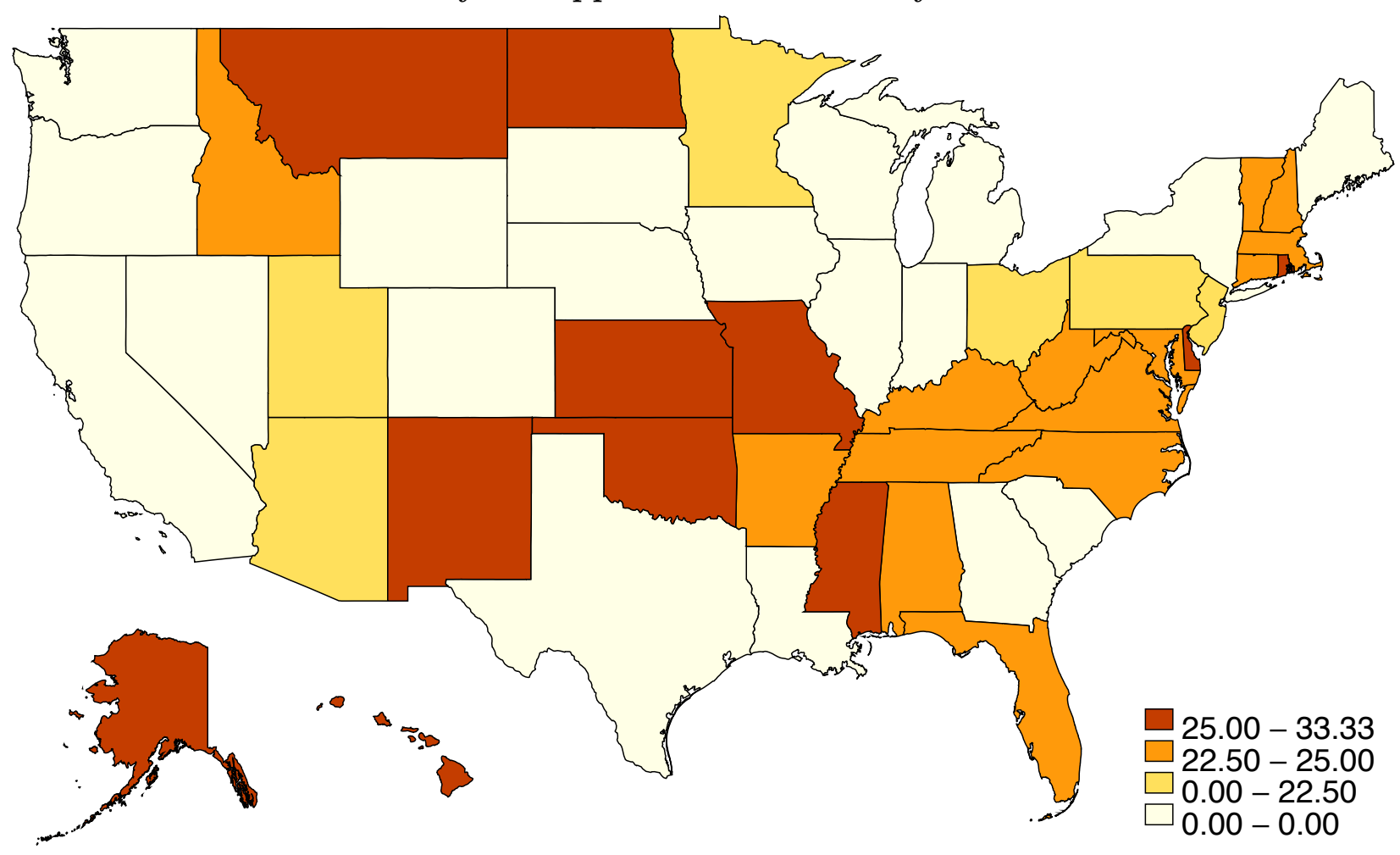

B. Sales Apportionment Rate by State

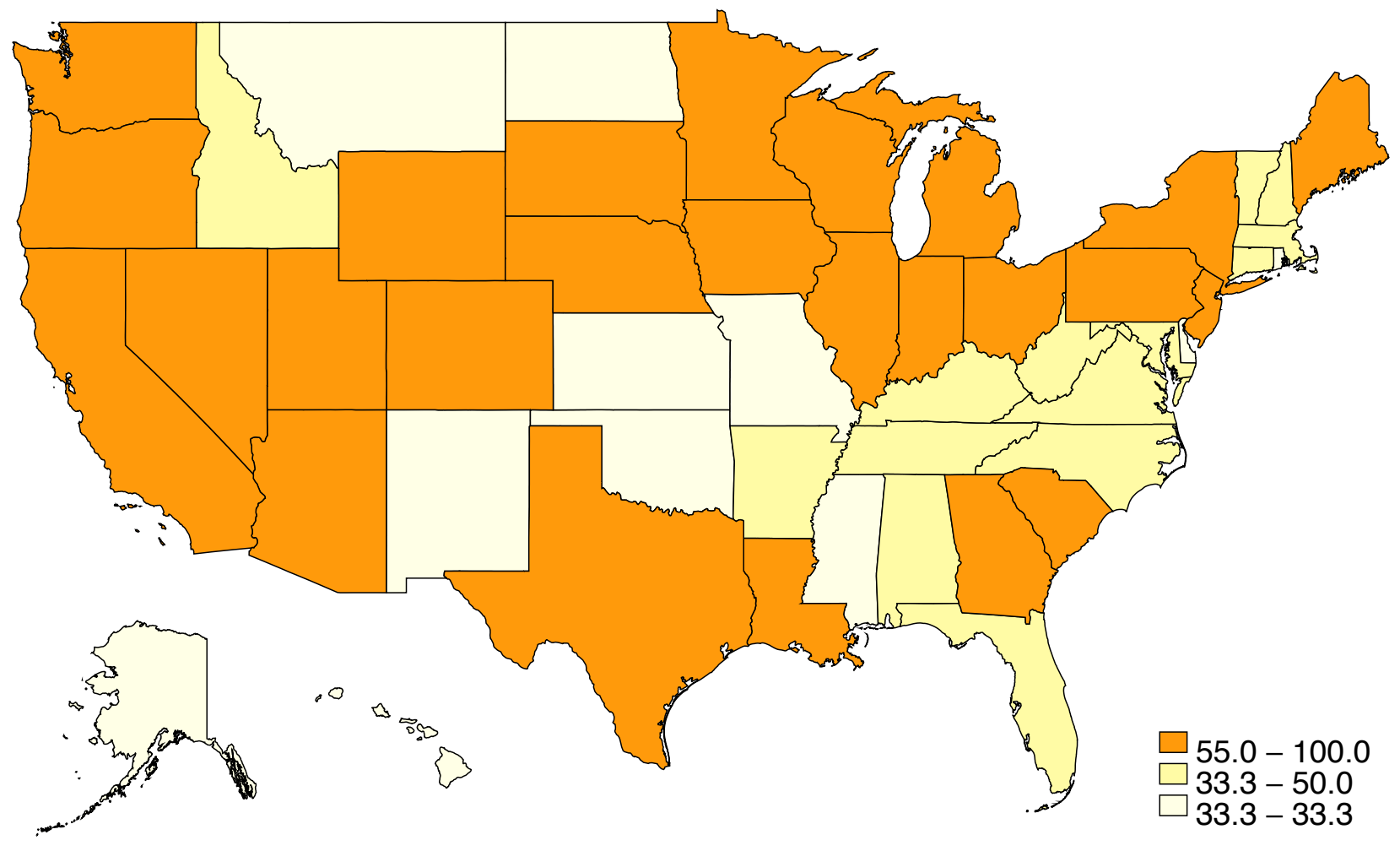


Figure A3: 30 Year Change State Corporate Tax Rates and Rules: 1980-2010

\section{A. Corporate Tax Rate Changes by State}

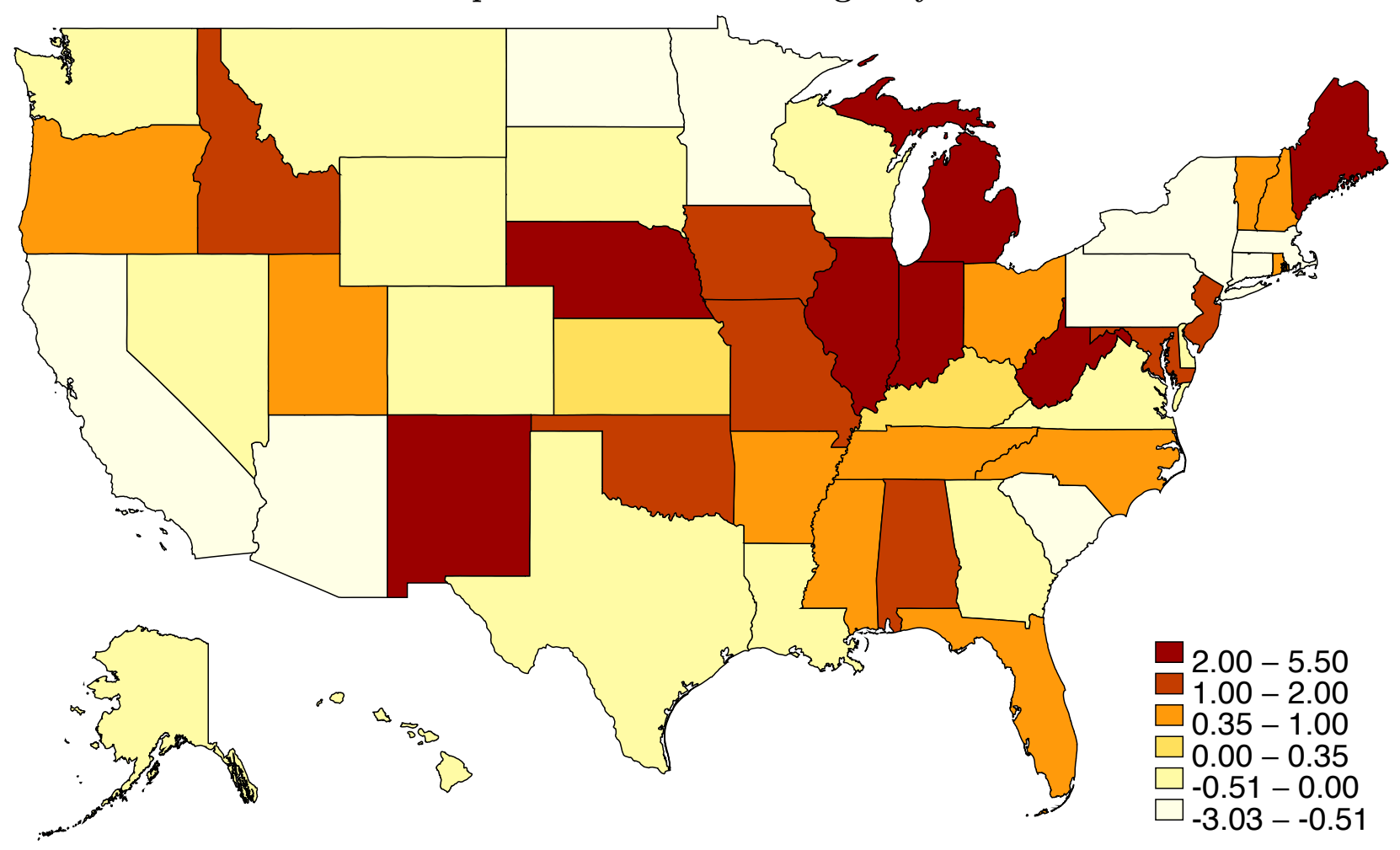

B. Sales Apportionment Rate Changes by State

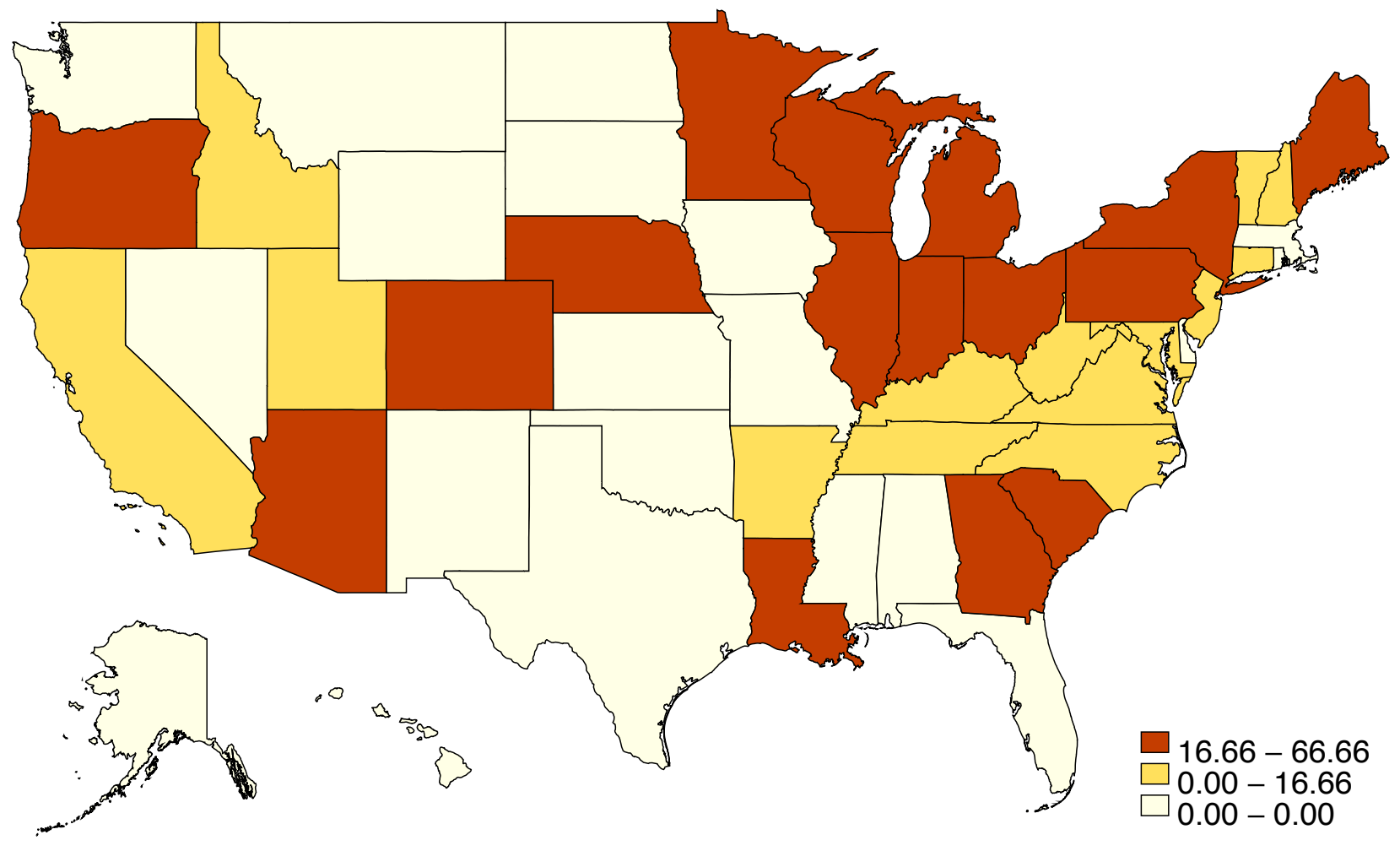


Figure A4: Shares of Total U.S. Establishments and Population in 2010

\section{A. Establishment Share by State}

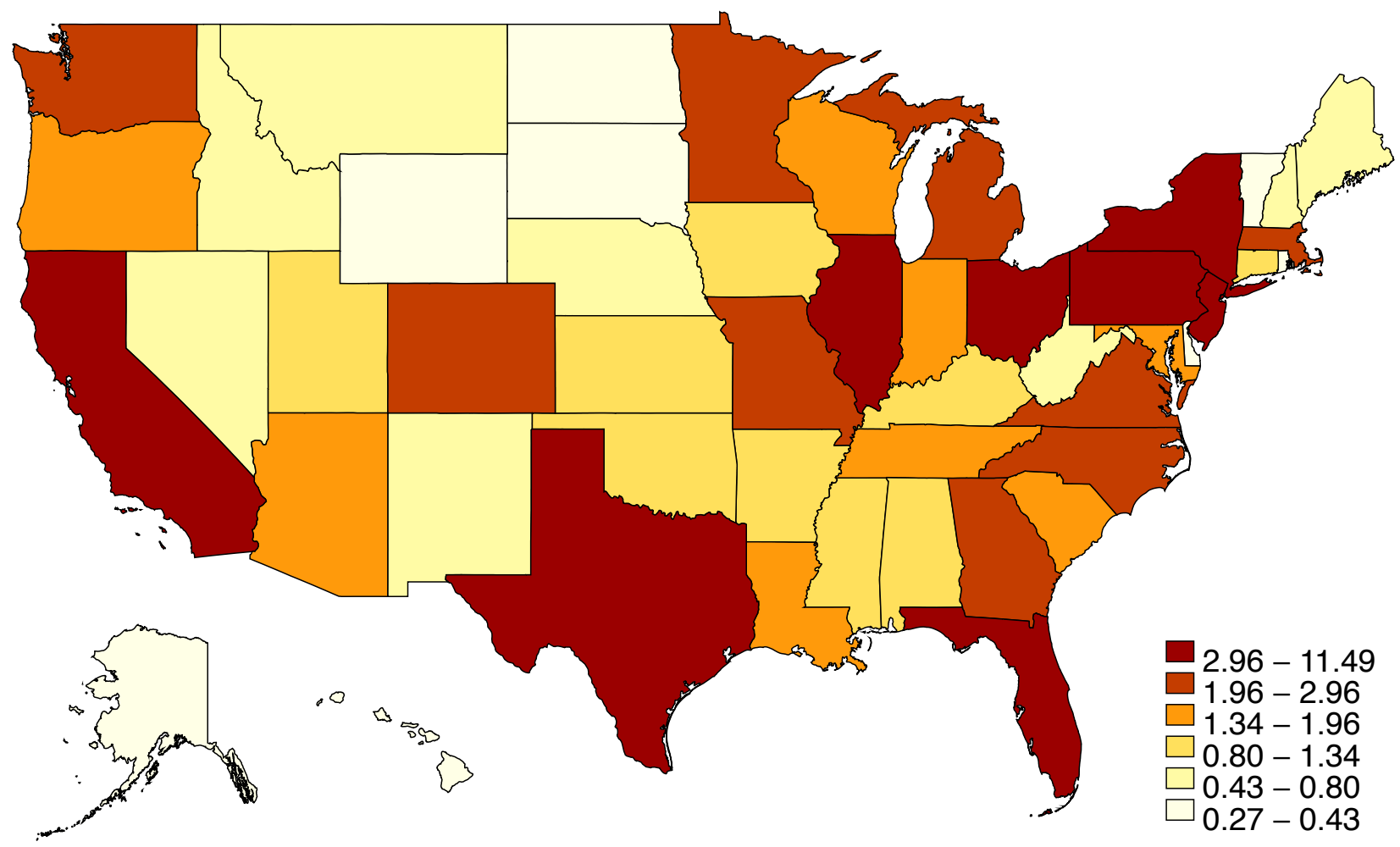

B. Population Share by State

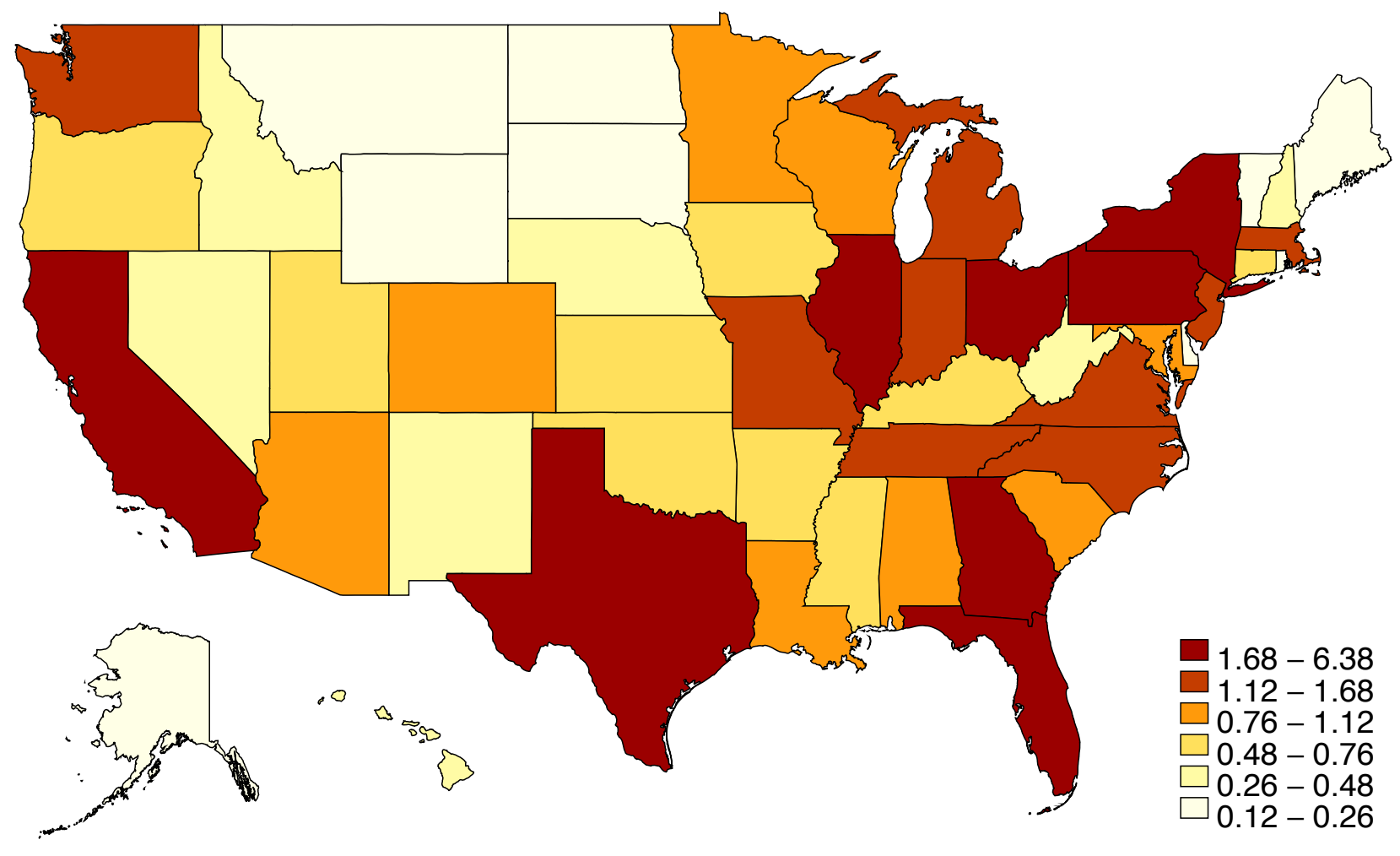


Figure A5: 30 Year Change in Share of Establishments and Population: 1980-2010

A. Change in Establishment Share by State

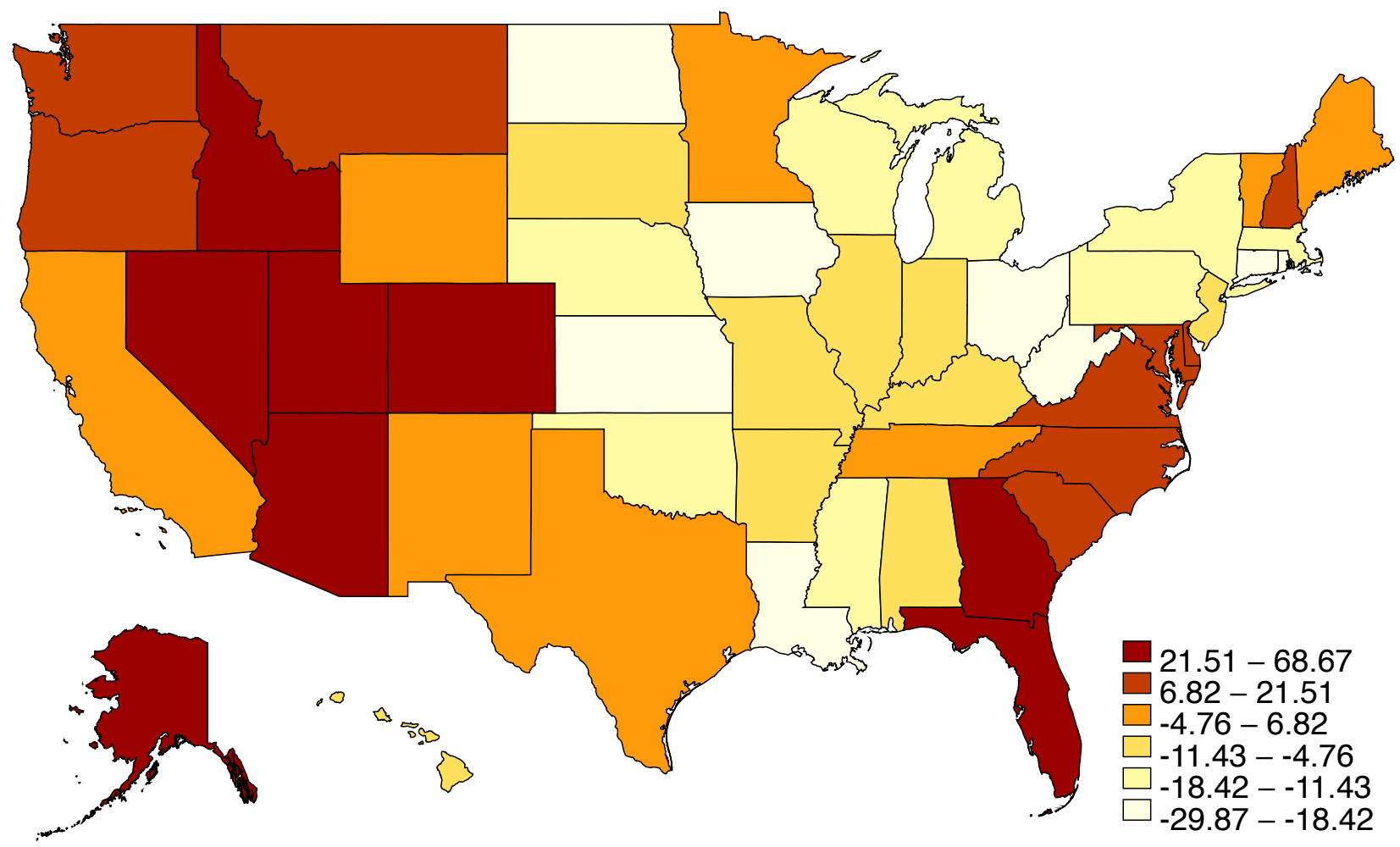

B. Change in Population Share by State

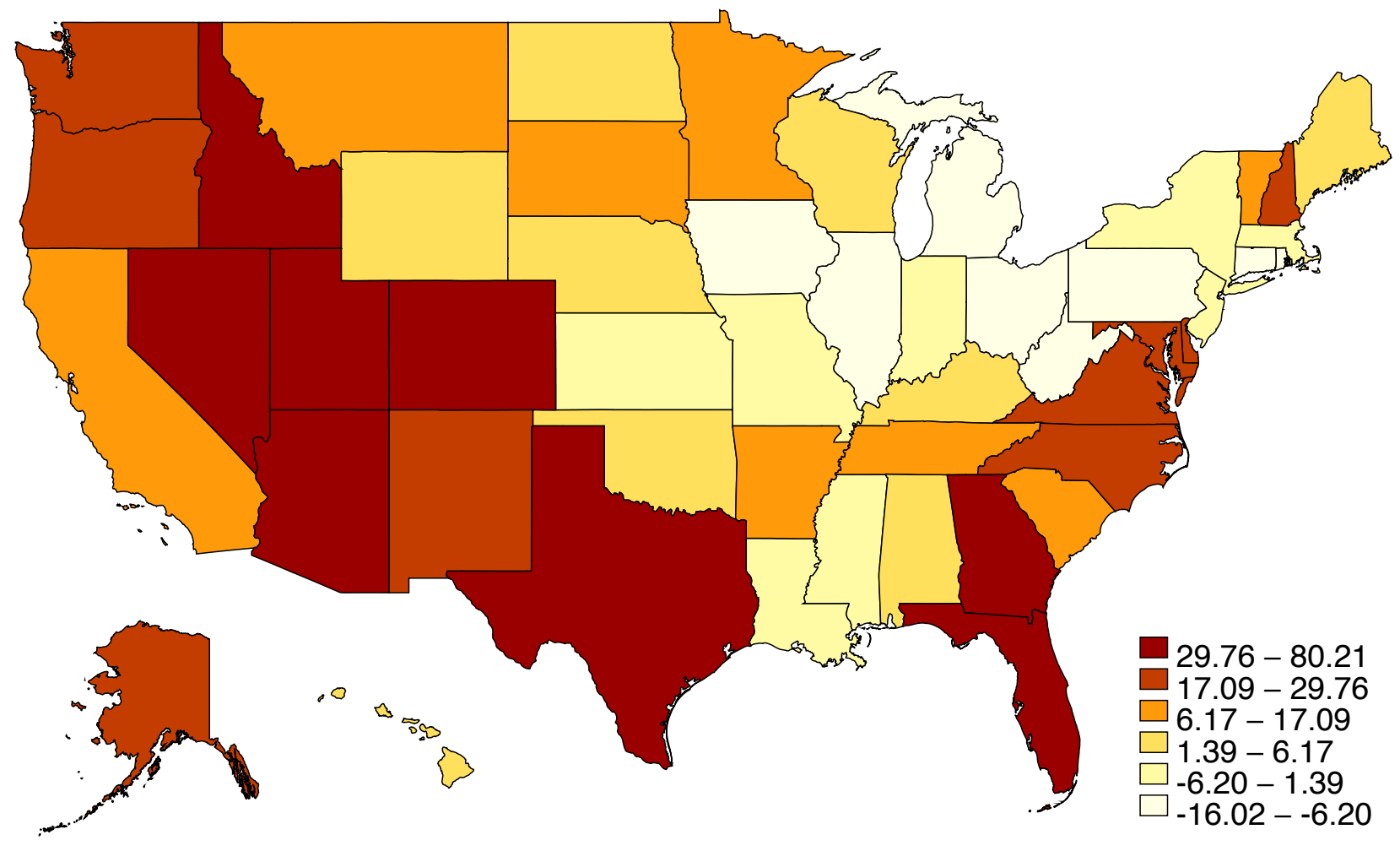


Figure A6: Decadal Changes in State Corporate Tax Policy

Panel (a) Corporate Tax Rate Changes

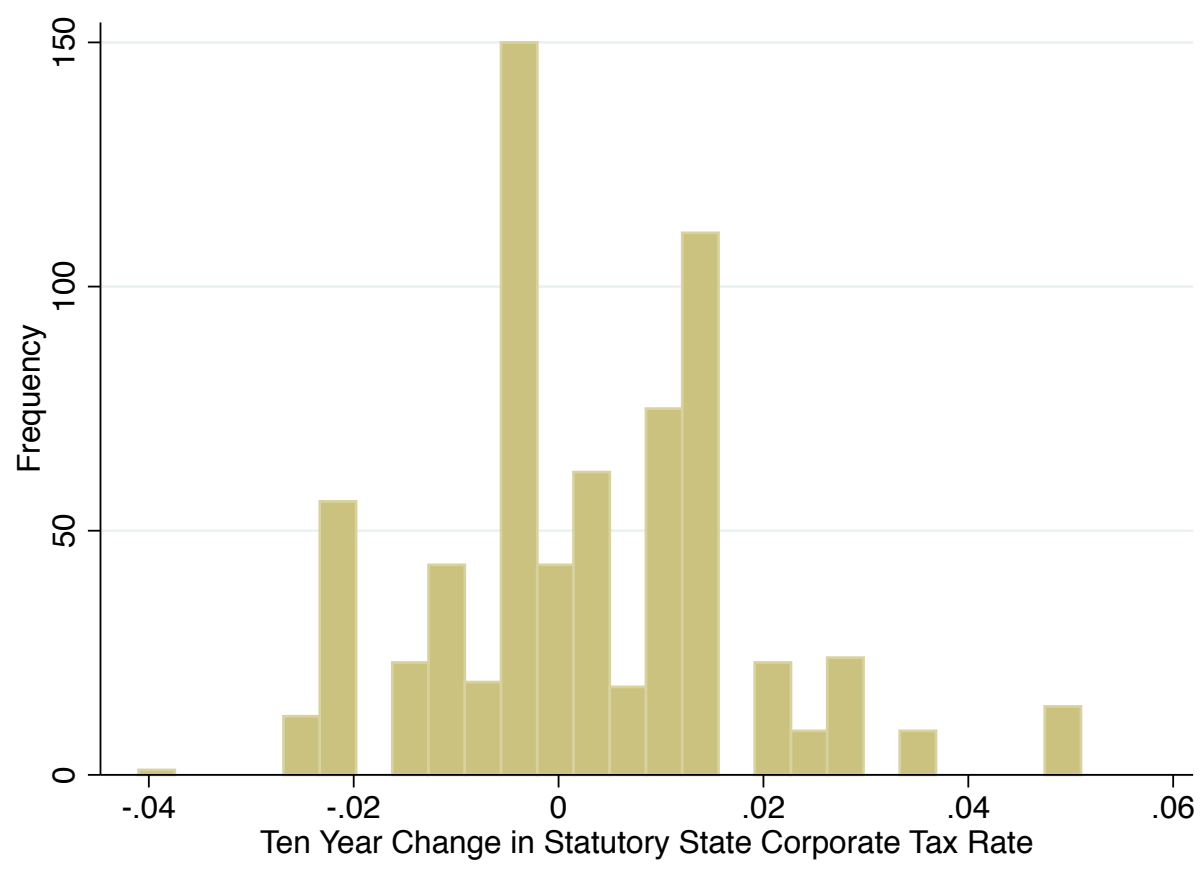

Panel (b) Payroll Apportionment Weight Changes

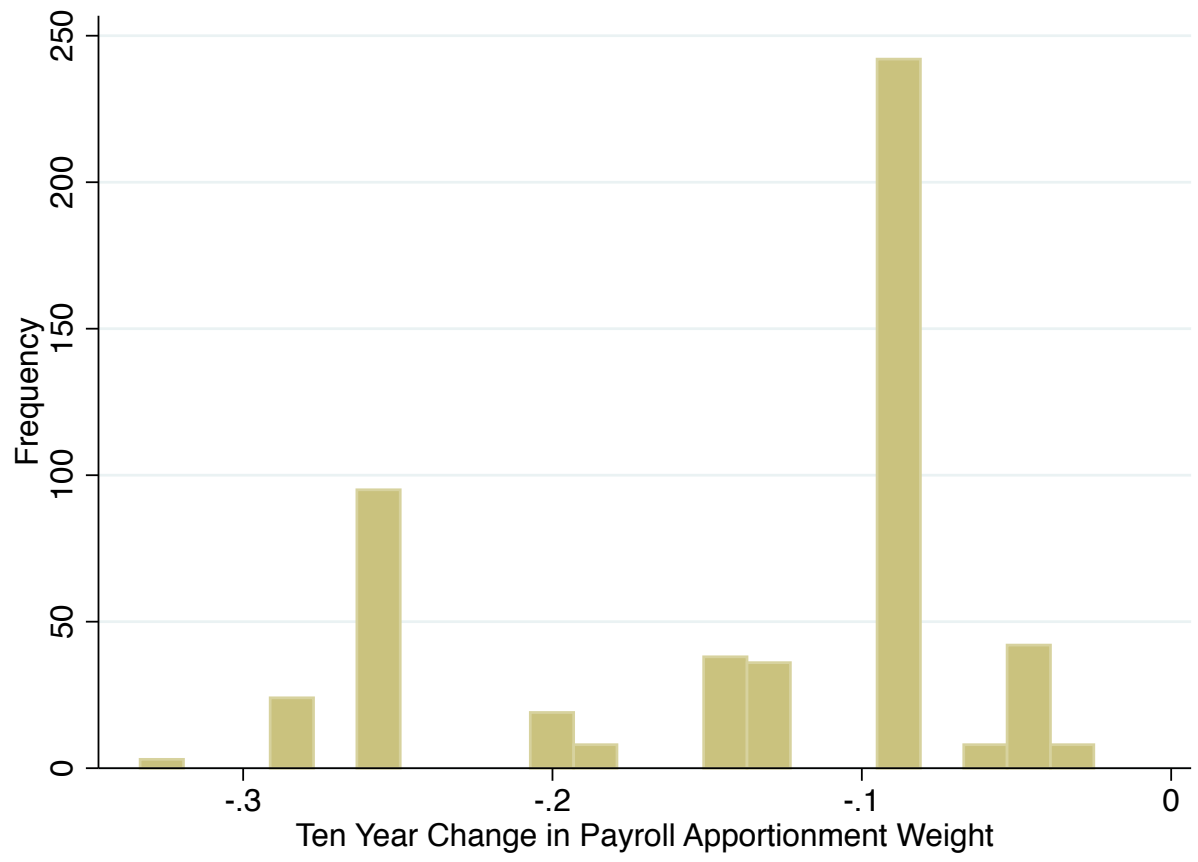

Notes: These figures show changes in corporate tax policy in the baseline PUMA-decade sample of 490 PUMAs over 1980-1990, 1990-2000, and 2000-2010. Panel (a) is a histogram showing the distribution of non-zero changes in corporate tax rates in the pooled sample. Panel (b) is a similar figure for payroll apportionment weights. 
Figure A7: Testing for Concomitant Tax Base Changes

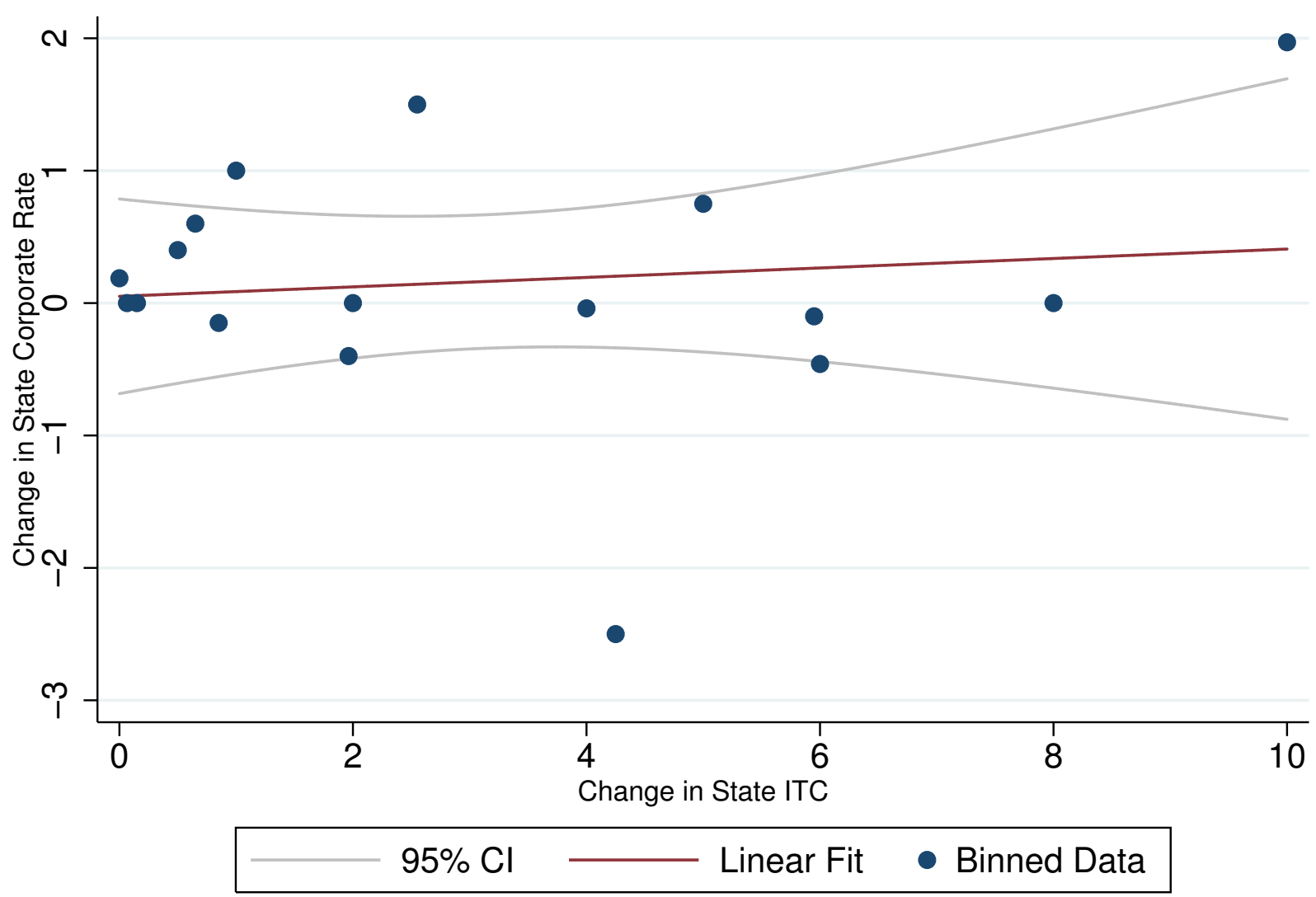

Data from Wilson and Chirinko (2008). 10 Yr Changes. D.Corp $=0.2+0.026$ (D.ITC), with se $=.06$

Notes: This figure, which uses data generously provided by Chirinko and Wilson (2008), illustrates that there is no detectable relationship between corporate tax rate changes and investment tax credit changes. It shows the average state corporate tax rate change for different bins of state investment credit changes. The estimated relationship is $\Delta \tau_{s, t}^{c}=0.2+0.026 \Delta I T C_{s, t}$, with se $=0.06$ and $R^{2}=.001$. Changes are measured over ten-year periods. 
Figure A8: Cumulative Effects of Business Tax Cuts on Population Growth

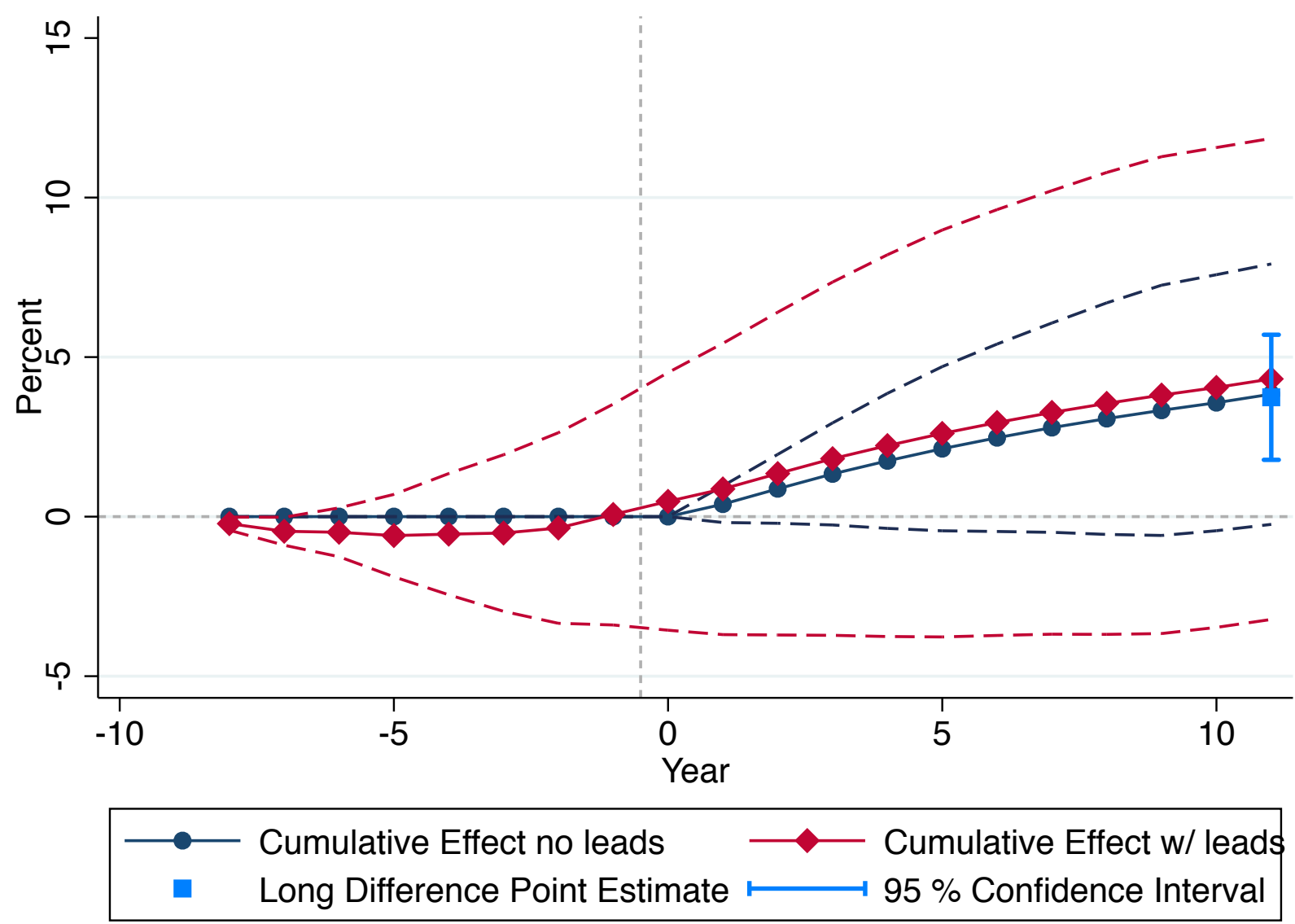

Notes: This figure shows the cumulative annual effects of local business tax cuts on local population growth over different time horizons with pre-trends. It plots the analogous estimates as Figure 4. See Section 4 for data sources and Section E for estimation details. 
Figure A9: Cumulative Effects of Business Tax Cuts on Growth in Gross Operating Surplus

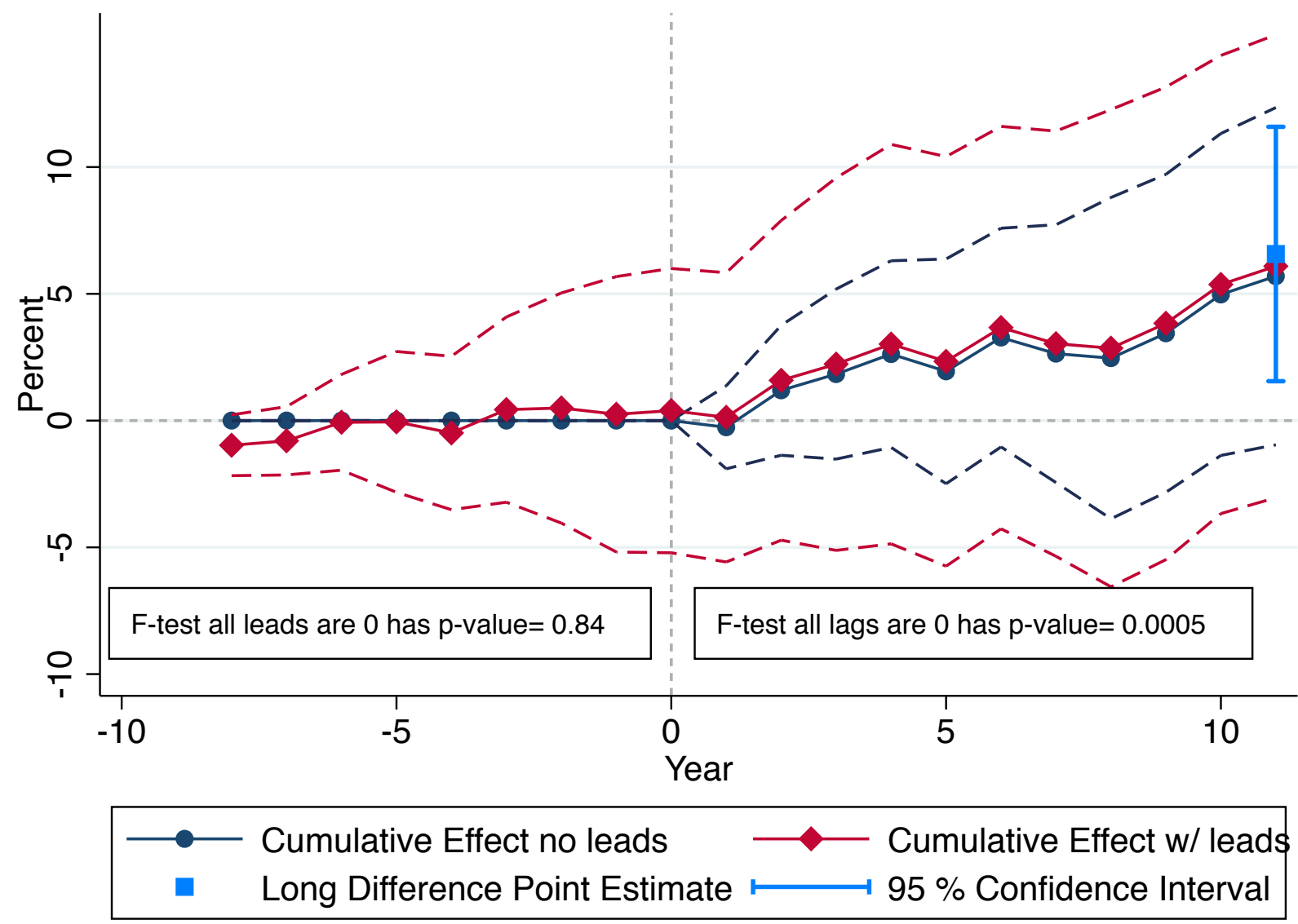

Notes: This figure shows the cumulative annual effects of local business tax cuts on state gross operating surplus over different time horizons with pre-trends. It plots the analogous estimates as Figure 4. See Section 4 for data sources and Section E for estimation details. 
Figure A10: Effect of Business Tax Cut on Establishment Growth over 10 Years

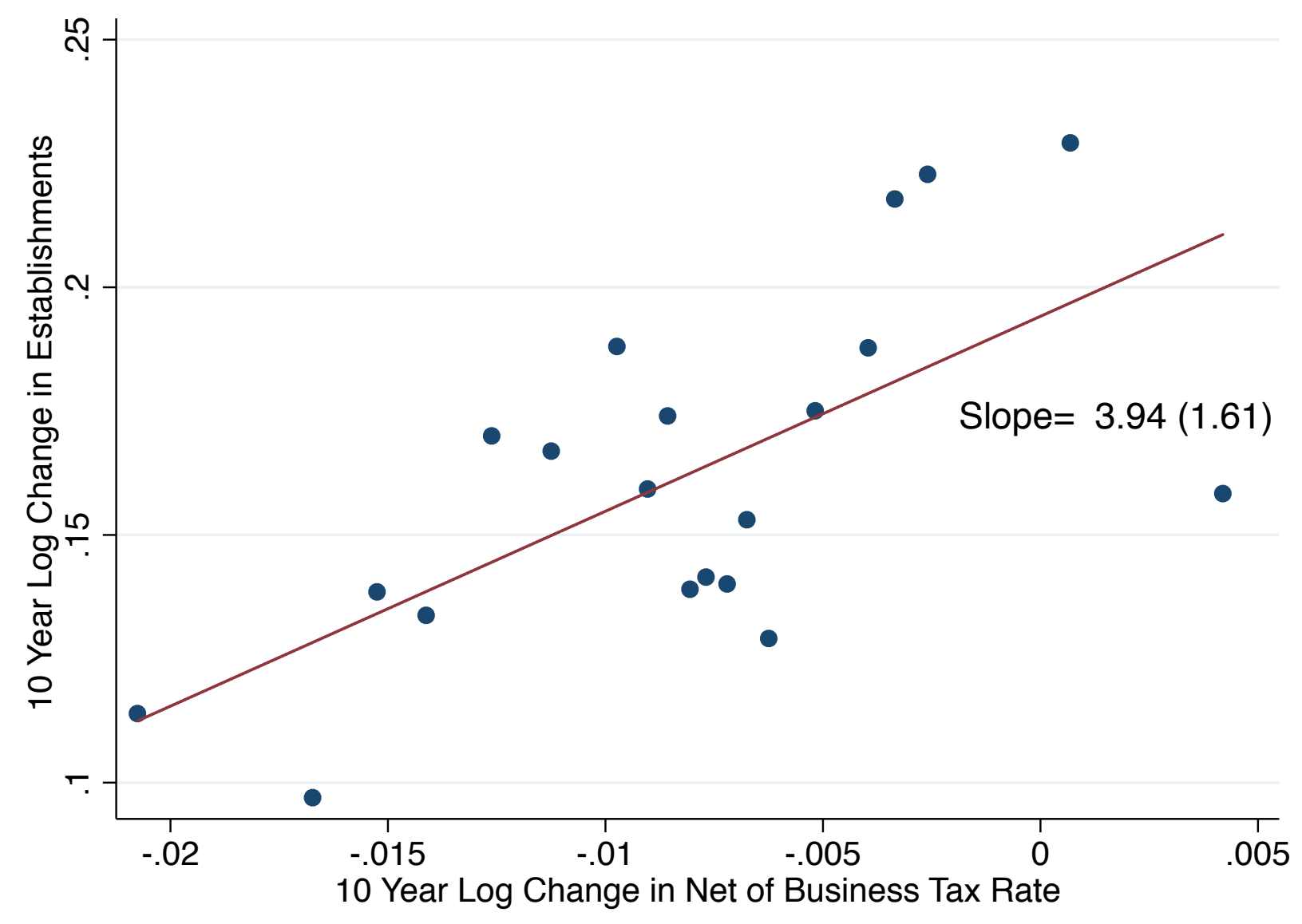

Notes: This figure shows the mean log change in the number of establishments over 10 years by bin of log change in the net-of-business-tax rate $\tau^{b}$ over 10 years. The data are unweighted, at the county-group level, and are only adjusted for year fixed effects. Standard errors clustered by state are in parentheses and ${ }^{* * *} \mathrm{p}<0.01,{ }^{* *} \mathrm{p}<0.05,{ }^{*} \mathrm{p}<0.1$. 
Figure A11: Effect of Business Tax Cut on Population Growth over 10 Years

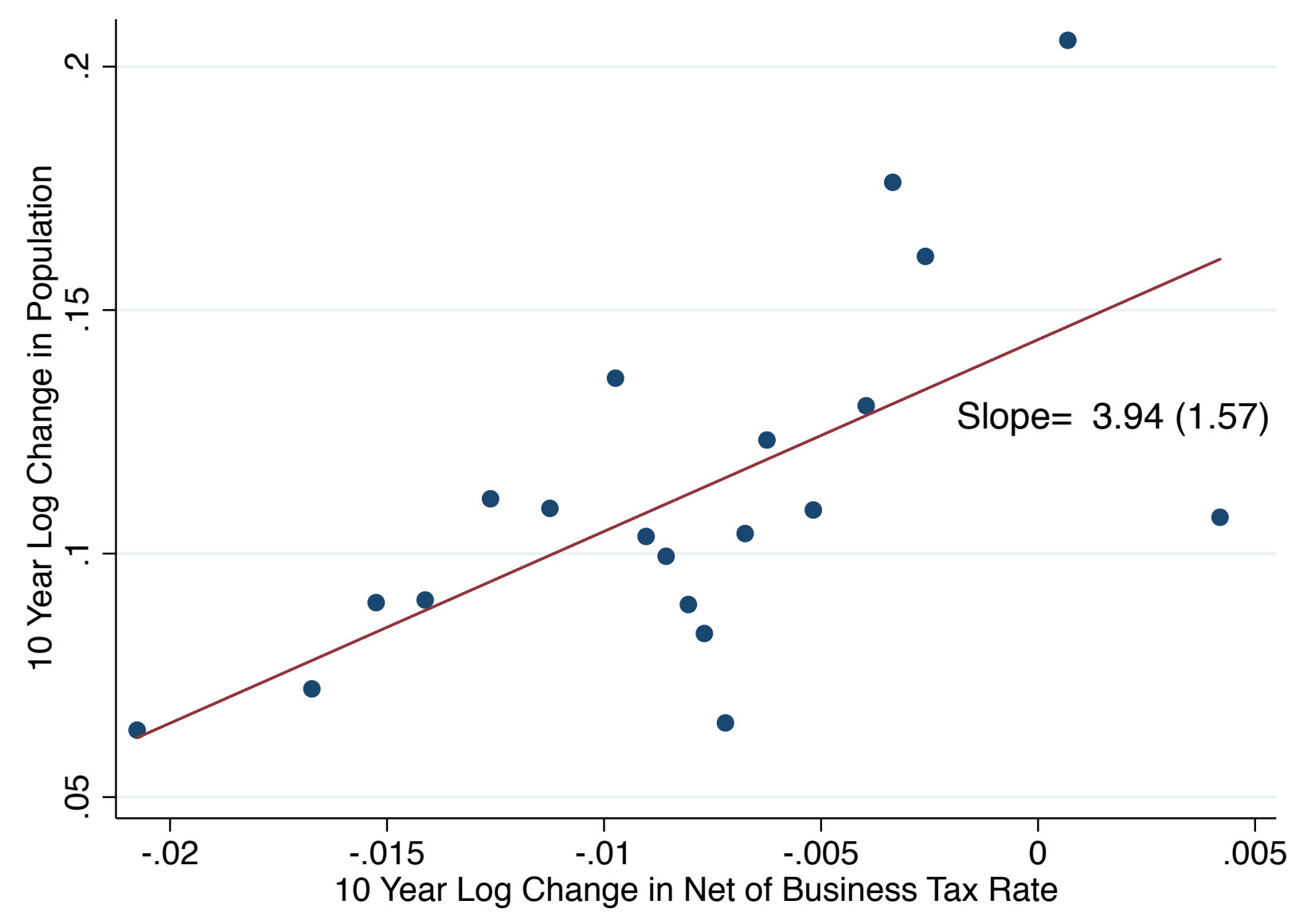

Notes: This figure shows the mean log change in the population over 10 years by bin of log change in the net-ofbusiness-tax rate $\tau^{b}$ over 10 years. The data are unweighted, at the county-group level, and are only adjusted for year fixed effects. Standard errors clustered by state are in parentheses and ${ }^{* * *} \mathrm{p}<0.01,{ }^{* *} \mathrm{p}<0.05,{ }^{*} \mathrm{p}<0.1$. 
Figure A12: Effect of Business Tax Cut on Wage Growth over 10 Years

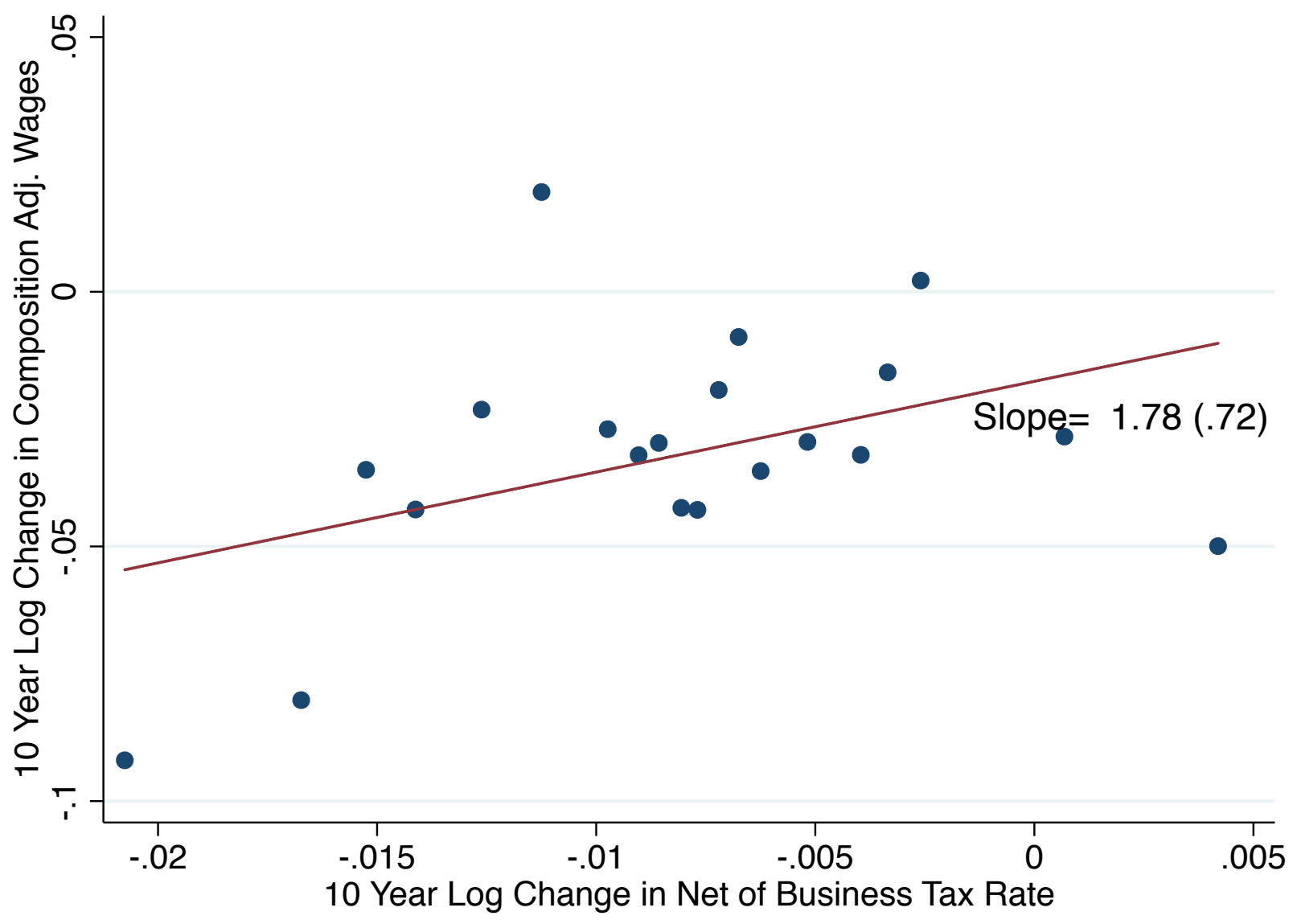

Notes: This figure shows the mean log change in wages over 10 years by bin of log change in the net-of-business-tax rate $\tau^{b}$ over 10 years. The data are unweighted, at the county-group level, and are only adjusted for year fixed effects. As in the main text, wages are a composition constant index. Standard errors clustered by state are in parentheses and $* * * \mathrm{p}<0.01, * * \mathrm{p}<0.05, * \mathrm{p}<0.1$. 
Figure A13: Effect of Business Tax Cut on Rental Cost Growth over 10 Years

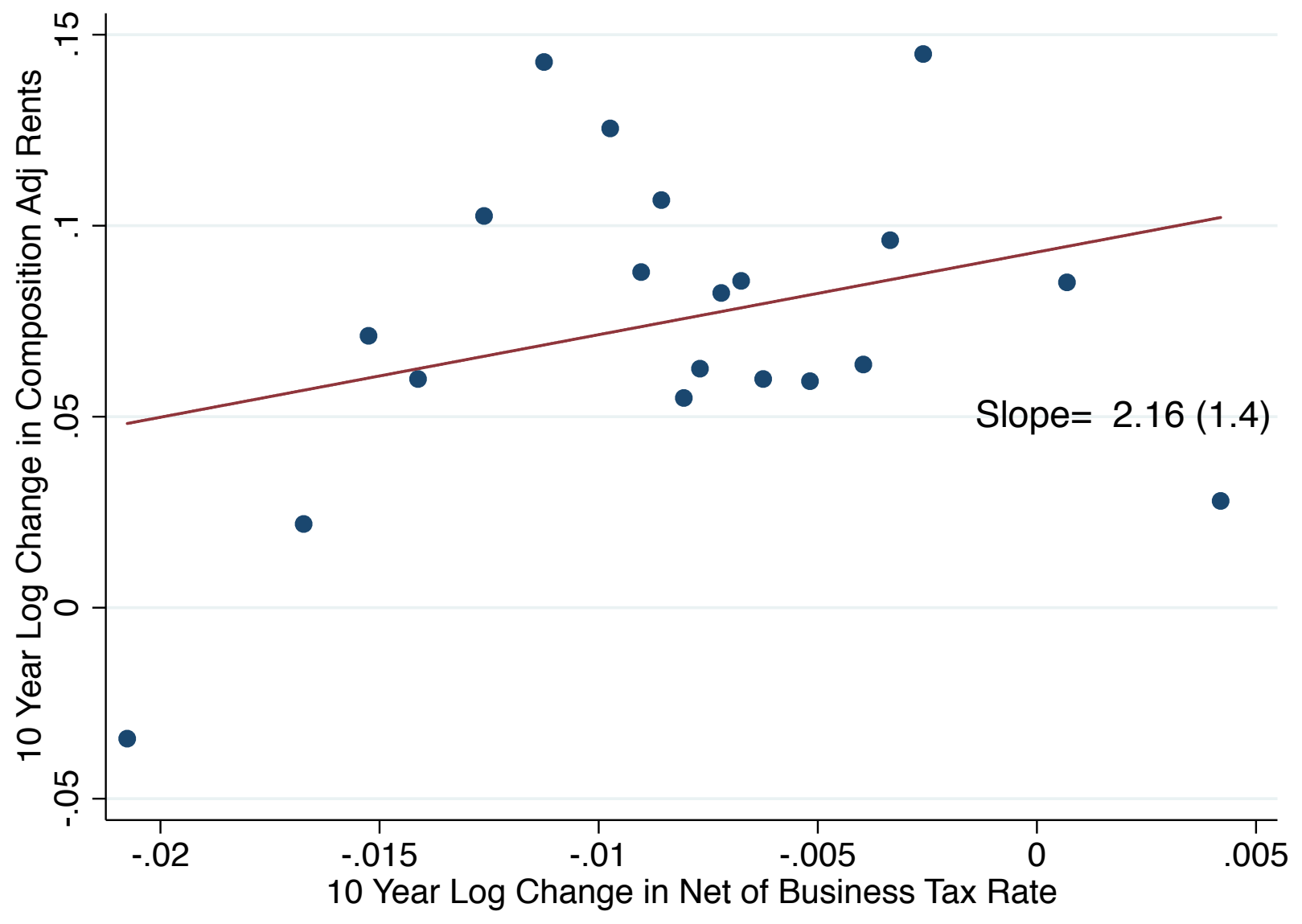

Notes: This figure shows the mean log change in rents over 10 years by bin of log change in the net-of-business-tax rate $\tau^{b}$ over 10 years. The data are unweighted, at the county-group level, and are only adjusted for year fixed effects. As in the main text, rental costs are a composition constant index. Standard errors clustered by state are in parentheses and $* * * \mathrm{p}<0.01, * * \mathrm{p}<0.05, * \mathrm{p}<0.1$. 
Figure A14: Effect of Business Tax Cut on Growth in GOS per Establishment over 10 Years

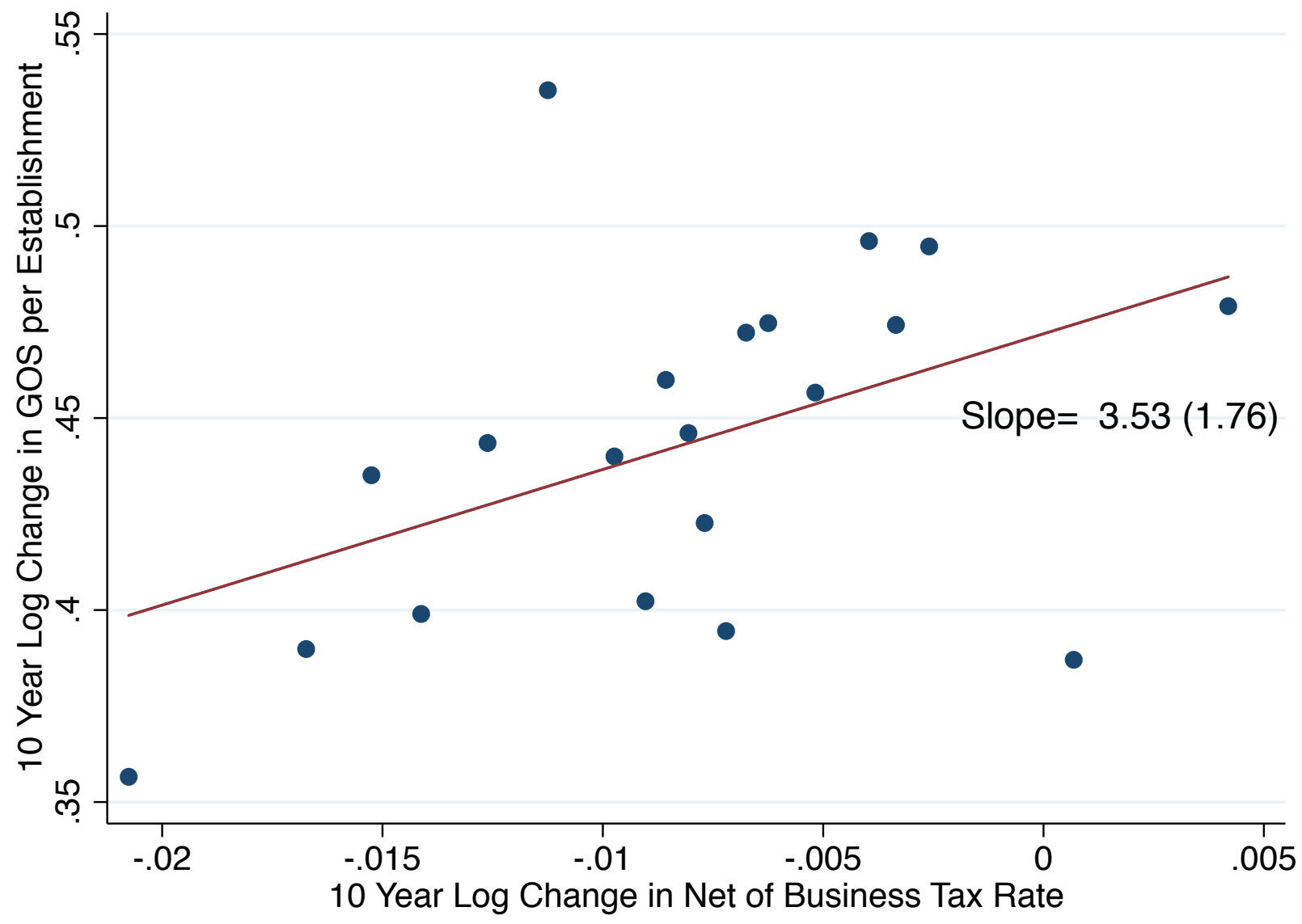

Notes: This figure shows the mean log change in state gross operating surplus per establishment over 10 years by bin of $\log$ change in the net-of-business-tax rate $\tau^{b}$ over 10 years. The data are unweighted, at the county-group level, and are only adjust for year fixed effects. To account for the consumption of fixed capital, which is $44 \%$ of GOS on average during the sample period of 1980 to 2010 (NIPA Table 1.14), one needs to multiply this point estimate by (1-.44). In particular, the point estimate implies an estimated effect of $(1-.44) \times 3.53=1.98$ on net operating surplus per establishment. Standard errors clustered by state are in parentheses and ${ }^{* * *} \mathrm{p}<0.01,{ }^{* *} \mathrm{p}<0.05,{ }^{*} \mathrm{p}<0.1$. 
Figure A15: Effect of Business Tax Cut on Growth in Sales Tax Revenue per Establishment

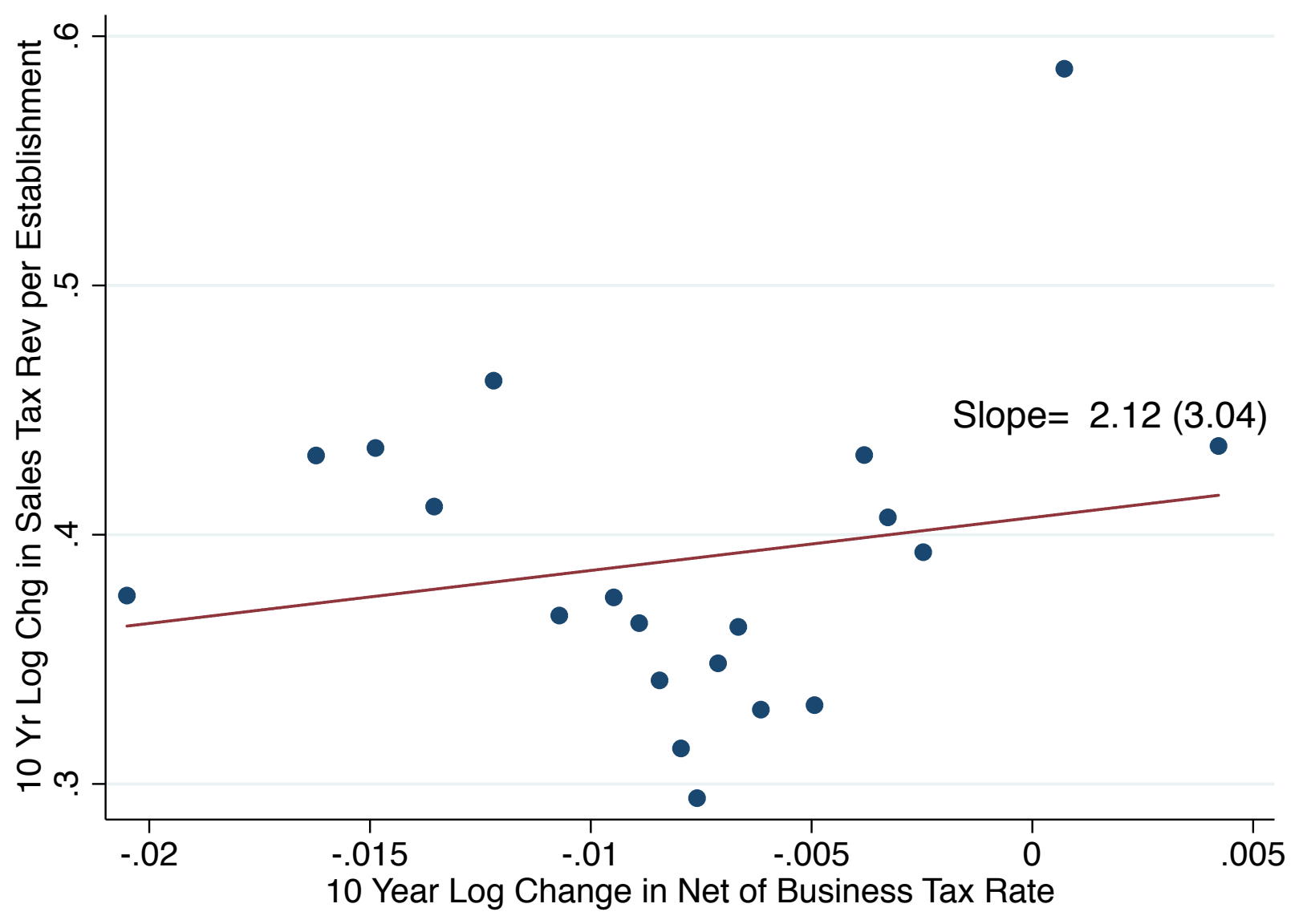

Notes: This figure shows the mean log change in state sales tax revenue per establishment over 10 years by bin of log change in the net-of-business-tax rate $\tau^{b}$ over 10 years. The data are unweighted, at the county-group level, and are only adjust for year fixed effects. Standard errors clustered by state are in parentheses and $* * * \mathrm{p}<0.01, * * \mathrm{p}<0.05, *$ $\mathrm{p}<0.1$. 
Figure A16: Estimates of Worker Location Equation

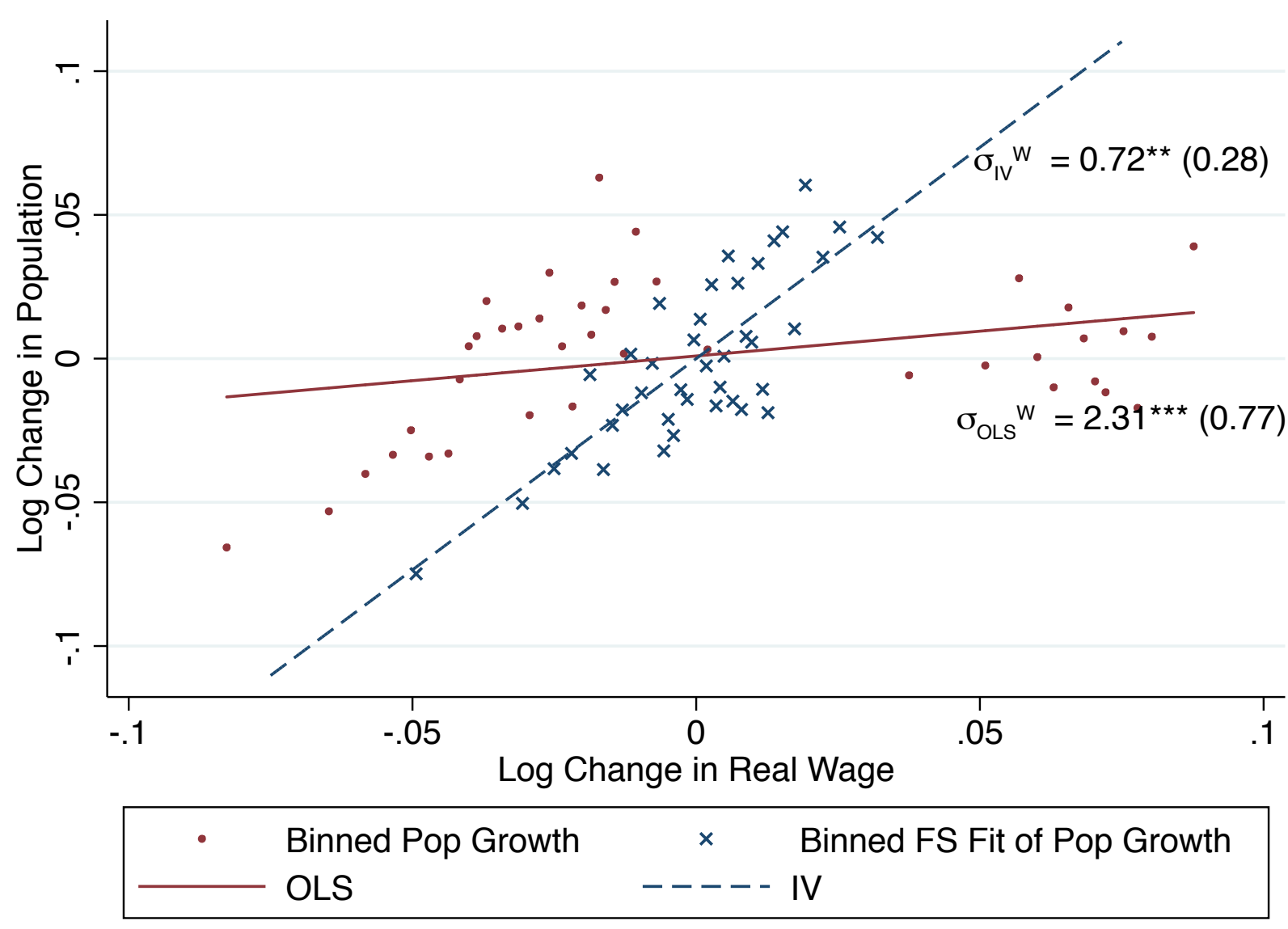

Notes: This figure illustrates the importance of accounting for regional amenities when estimating the parameters that govern worker mobility. Ignoring amenity changes attenuates the effects of wage changes on population changes. In particular, the figure shows the mean log change in population by bin of log change in real wage as well as the fitted values of a first stage regression of real wage on the Bartik shock and the tax shock. Using these fitted values illustrates how real wage changes (that are orthogonal to amenity changes) relate to population changes. The fitted lines in the figure plot the associated estimates via OLS and IV from Table A33. Standard errors clustered by state are in parentheses and $* * * \mathrm{p}<0.01, * * \mathrm{p}<0.05,{ }^{*} \mathrm{p}<0.1$. 
Figure A17: Estimates of Establishment Location Equation

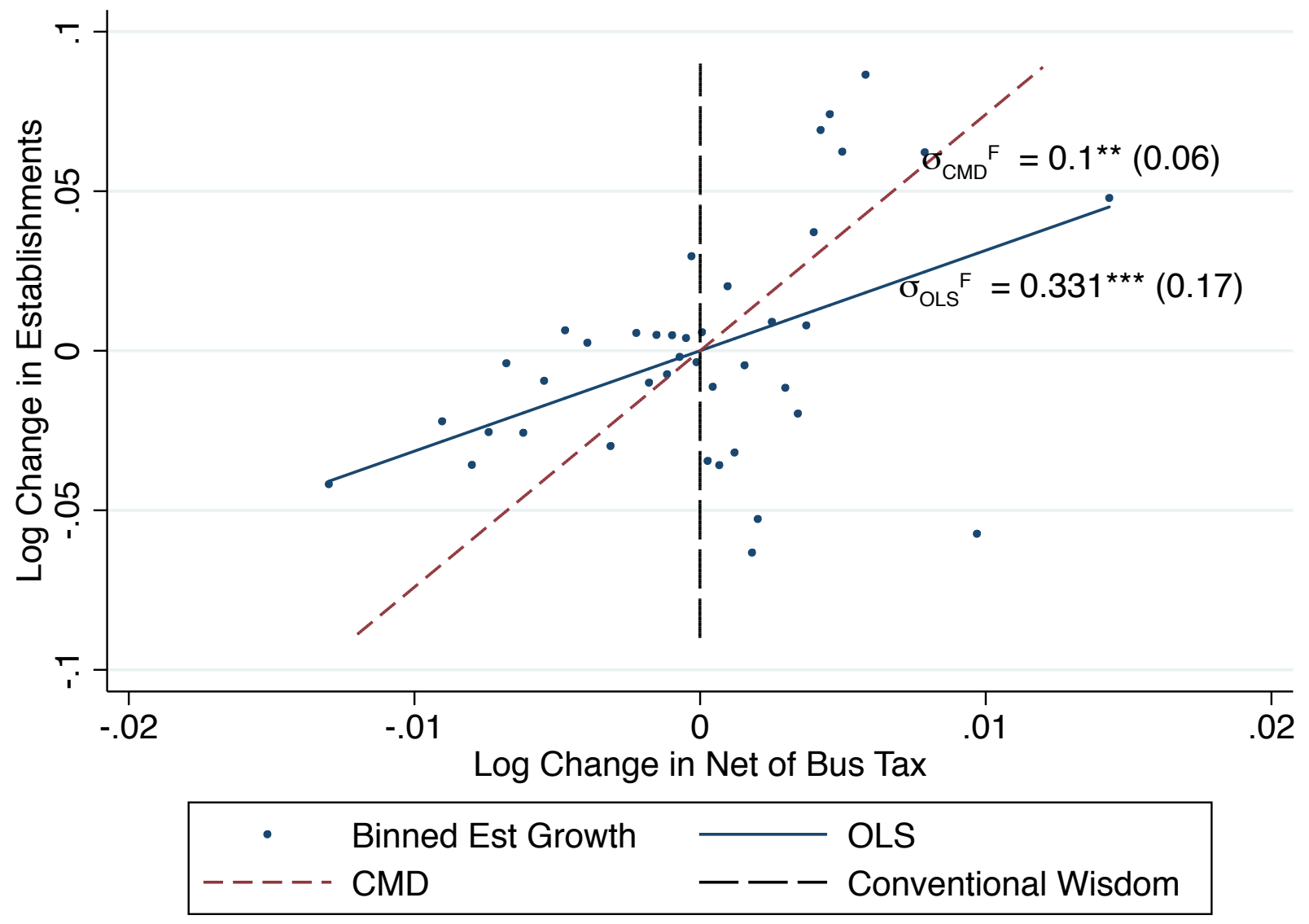

Notes: This figure illustrates how establishment location choices relate to business taxes. The conventional view on corporate taxation in an open economy, which is based on models that neither incorporate the location decisions of business nor the possibility that a business's productivity can differ across locations, effectively implies that business location will be very responsive to tax differentials over the long-run (Gordon and Hines, 2002). This figure shows how this conventional wisdom on responsiveness compares to the empirical responsiveness of location decisions to business tax changes over a ten-year period. In particular, it shows the mean log change in establishments by bin of log change in the net-of-business-tax rate. The fitted lines plot the associated estimates via OLS and classical minimum distance (CMD) from Table A33 Col. 5 and 6, respectively (see Section E.6.4 for more detail). The OLS line shows the relationship between log changes in net-of-business-taxes and establishment growth. The positive slope indicates that tax cuts increase the number of local establishments over a ten-year period. However, ignoring equilibrium effects of tax changes on wages attenuates the effects of business tax changes on establishment growth. The CMD line shows that accounting for these impacts increases estimated responsiveness. Nonetheless, accounting for equilibrium impacts still yields substantially lower responsiveness to tax changes than the conventional wisdom implies. Section 2 quantifies how lower responsiveness affects the incidence and efficiency of corporate taxation. Standard errors clustered by state are in parentheses and ${ }^{* * *} \mathrm{p}<0.01,{ }^{* *} \mathrm{p}<0.05,{ }^{*} \mathrm{p}<0.1$. See Appendix Figure A16 for the analogous figure for worker location. 
Figure A18: Robustness of Economic Incidence

Panel (a)

Landowner's Share of Incidence for $\alpha=0.3$ and Calibrated Values of $\gamma$ and $\varepsilon^{P D}$

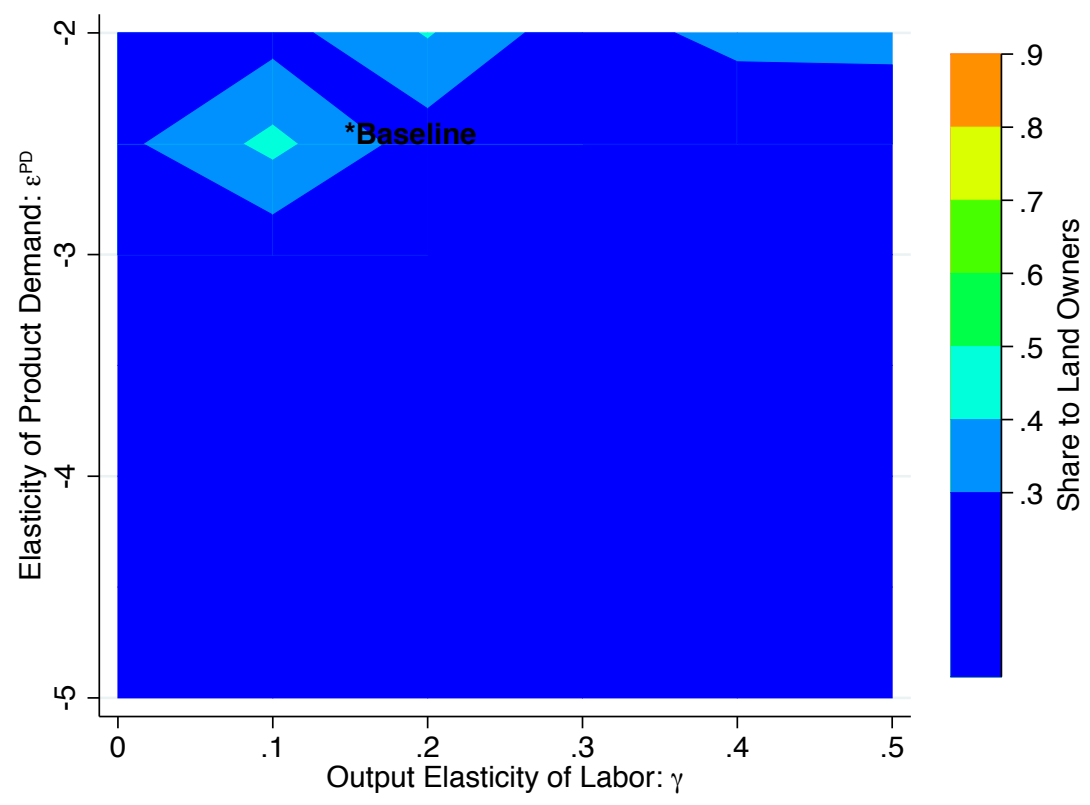

Panel (b)

Landowner's Share of Incidence for $\gamma=.15$ and Calibrated Values of $\alpha$ and $\varepsilon^{P D}$

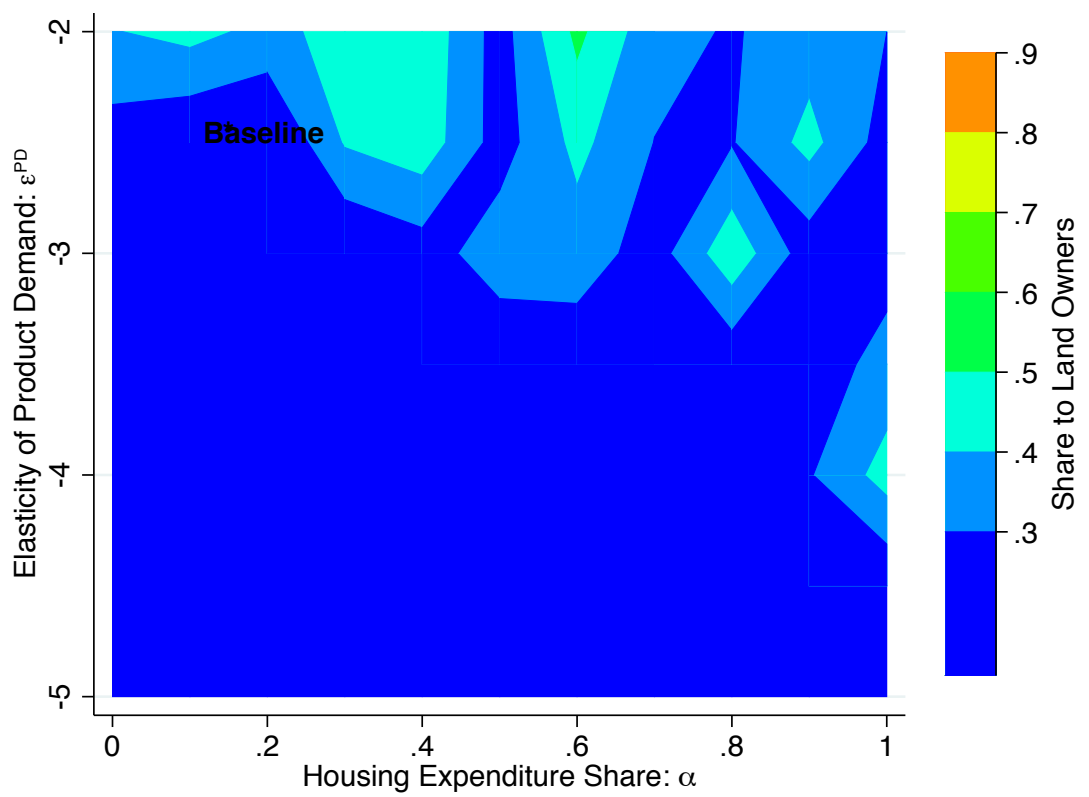

Notes: This figure, which is analogous to Figure 5 for landowners instead of firm owners, shows how our estimates of landowner incidence vary across the parameter space. Specifically, the figures plot landowner incidence shares for a variety of parameter values relative to our baseline parameters values of $\gamma=0.15, \varepsilon^{P D}=-2.5$, and $\alpha=.3$. See Section 6 for more detail. 
Figure A19: Robustness of Economic Incidence

\section{Panel (a)}

Workers' Share of Incidence for $\alpha=0.3$ and Calibrated Values of $\gamma$ and $\varepsilon^{P D}$

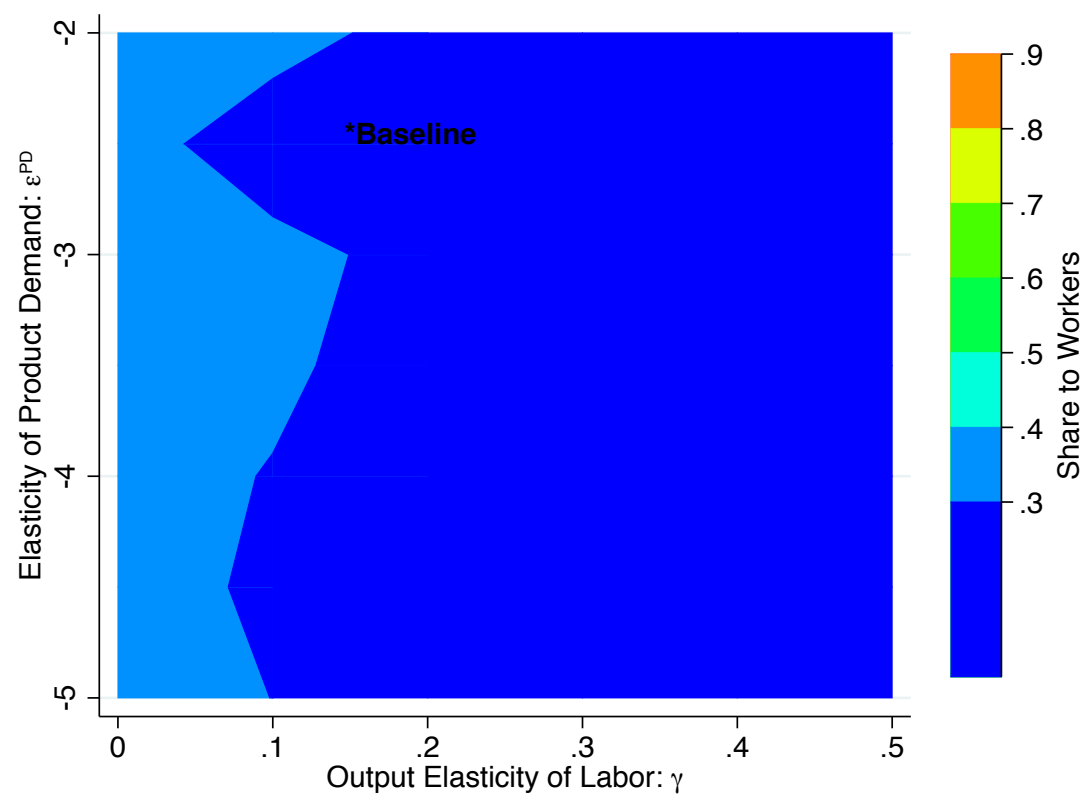

$$
\text { Panel (b) }
$$

Workers' Share of Incidence for $\gamma=.15$ and Calibrated Values of $\alpha$ and $\varepsilon^{P D}$

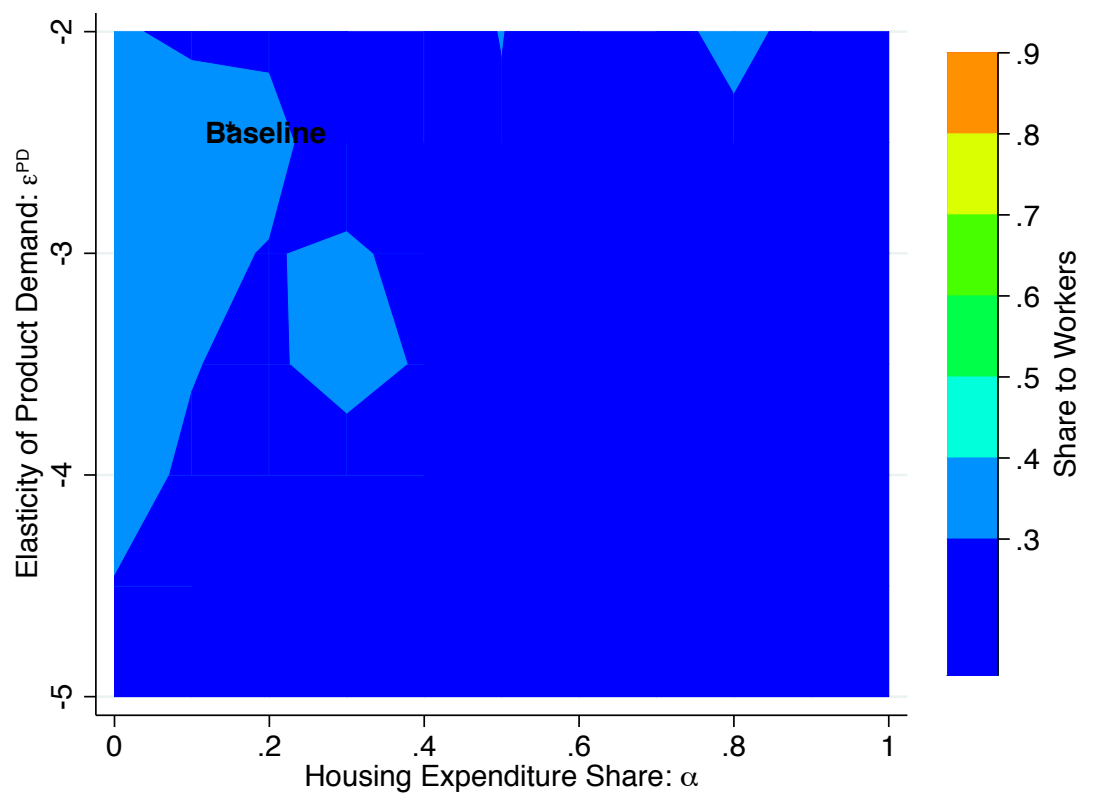

Notes: This figure, which is analogous to Figure 5 for workers instead of firm owners, shows how our estimates of worker incidence vary across the parameter space. Specifically, the figures plot worker incidence shares for a variety of parameter values relative to our baseline parameters values of $\gamma=0.15, \varepsilon^{P D}=-2.5$, and $\alpha=.3$. See Section 6 for more detail. 
Figure A20: Robustness of Economic Incidence (Using Employment Effects)

$$
\text { Panel (a) }
$$

Firm Owner's Share of Incidence for $\alpha=0.3$ and Calibrated Values of $\gamma$ and $\varepsilon^{P D}$

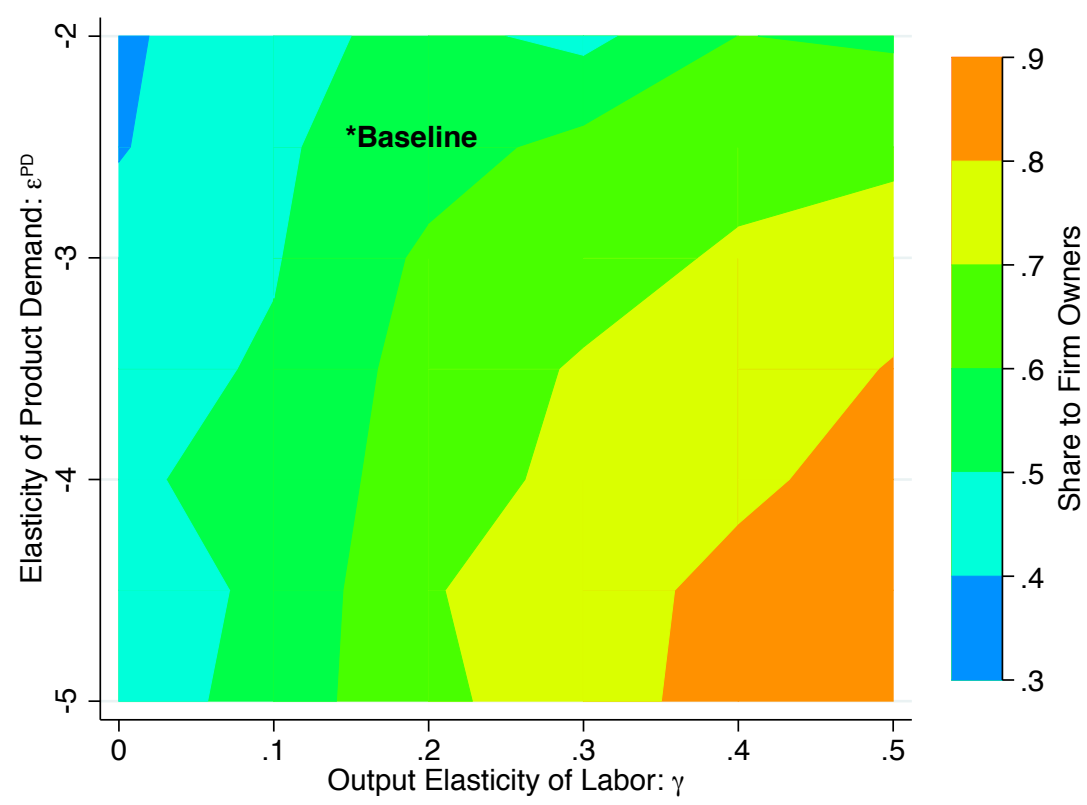

Panel (b)

Firm Owner's Share of Incidence for $\gamma=.15$ and Calibrated Values of $\alpha$ and $\varepsilon^{P D}$

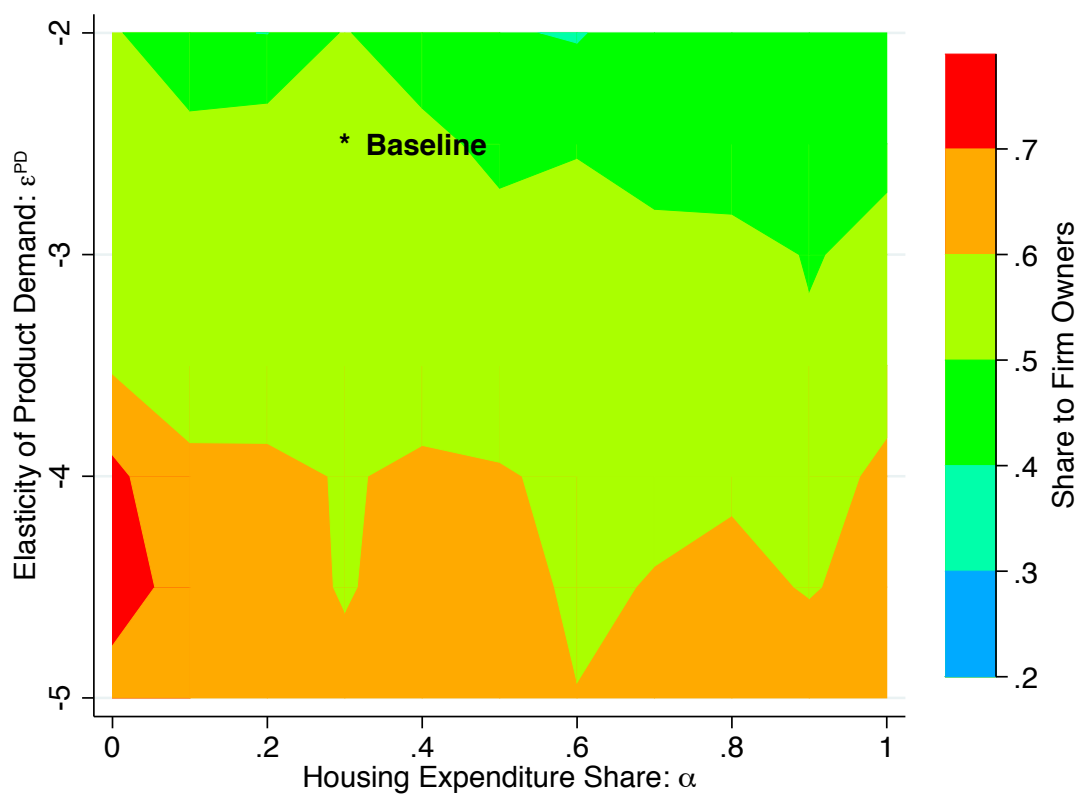

Notes: This figure, which is analogous to Figure 5 for firm owners based on employment changes rather than based on population changes (i.e., using the estimates in Table A9 instead of A6), shows how our estimates of firm owner incidence vary across the parameter space. Specifically, the figures plot firm owner incidence shares for a variety of parameter values relative to our baseline parameters values of $\gamma=0.15, \varepsilon^{P D}=-2.5$, and $\alpha=.3$. See Section 6 for more detail. 
Figure A21: Robustness of Economic Incidence
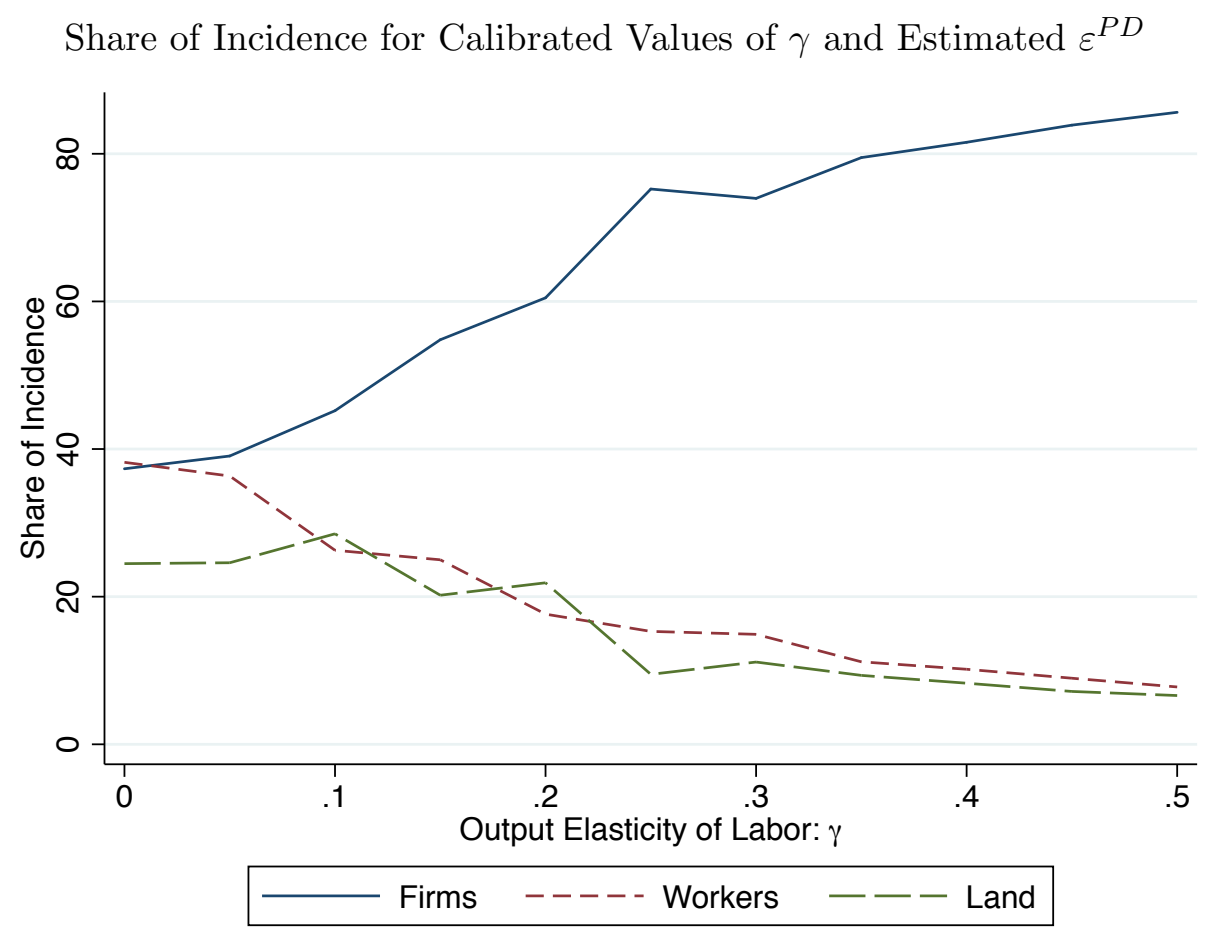

Notes: This figure shows that the shares of incidence to firm owners, workers, and landowners are independent of the calibrated values for the output elasticity of labor $\gamma$. Similar to Part A of Figure 5, it indicates that our baseline empirical result - that firm owners bear a substantial share of incidence - is robust to using a variety of calibrated parameter values. Appendix Figure A22 shows the relationship between calibration values and estimates as well as their implications for markups. See Section 3 for more detail. 
Figure A22: Estimates of $\varepsilon^{P D}$ and Associated Markups for Values of $\gamma$

$$
\text { Panel (a) Estimates of } \varepsilon^{P D}
$$

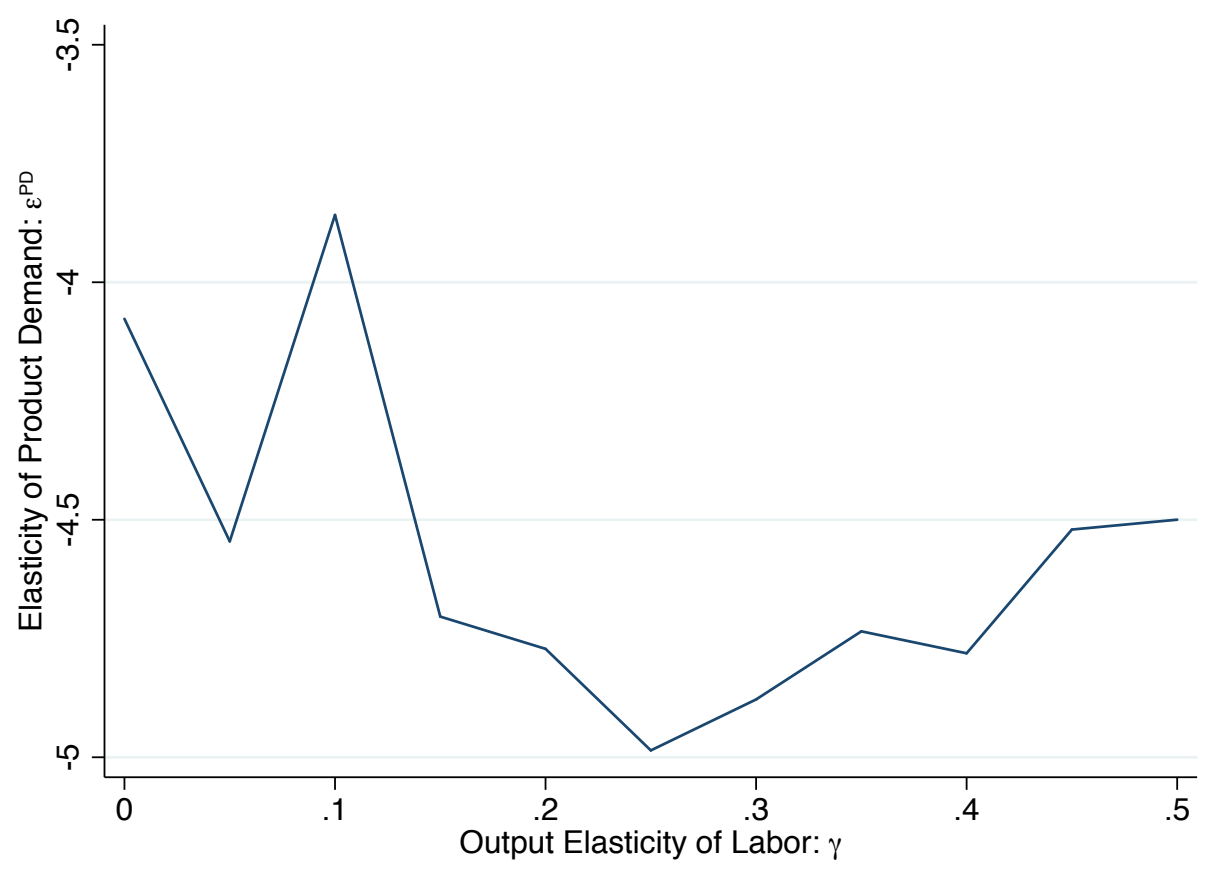

Panel (b) Estimates of Product Markups

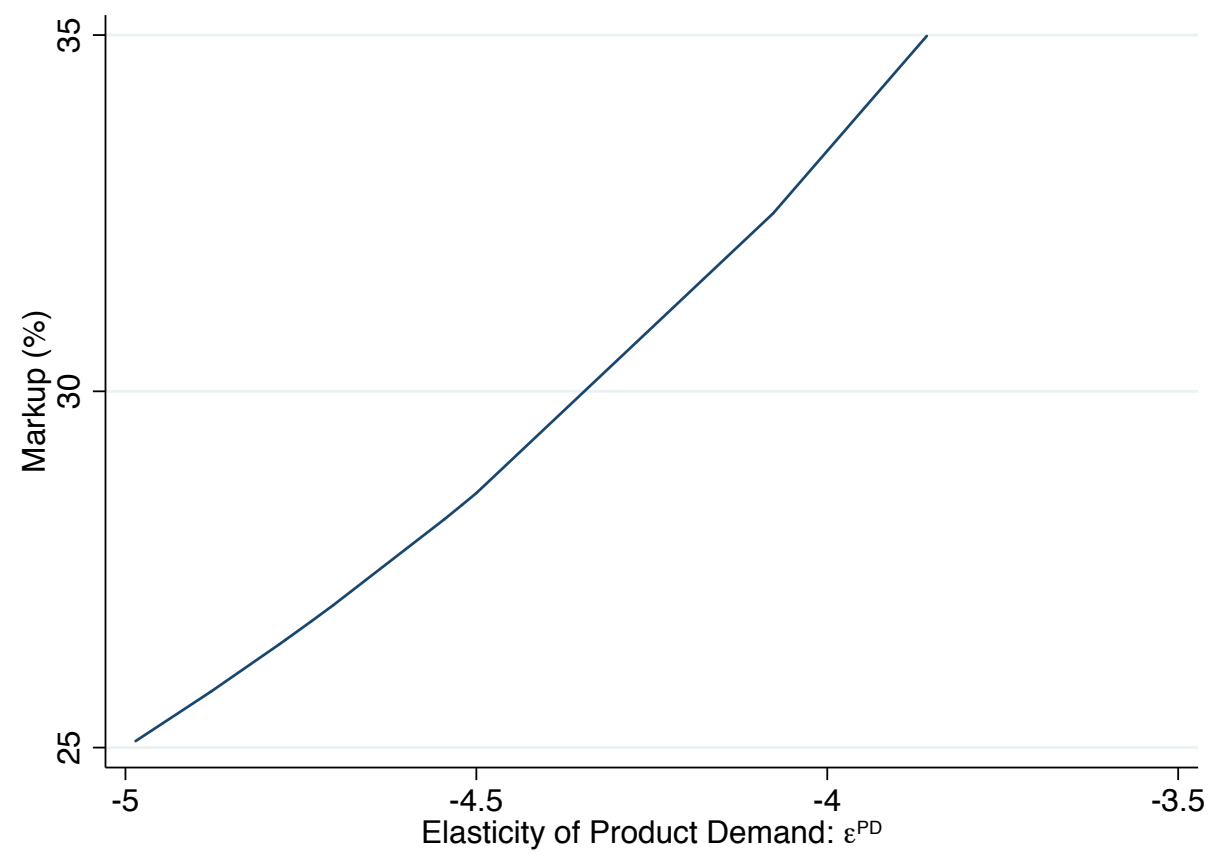

Notes: These figures show the estimated value of $\varepsilon^{P D}$ for different values of $\gamma$ in Panel (a). These estimates correspond to different version of the CMD model with two shocks as in Panel (b) of Table 6. Panel (b) plots the associated markup for a given value of $\varepsilon^{P D}$. 